\title{
Heterogeneity among displaced workers
}

Citation for published version (APA):

Kriechel, B. (2003). Heterogeneity among displaced workers. [Doctoral Thesis, Maastricht University]. ROA. https://doi.org/10.26481/dis.20031127bk

Document status and date:

Published: 01/01/2003

DOI:

10.26481/dis.20031127bk

Document Version:

Publisher's PDF, also known as Version of record

\section{Please check the document version of this publication:}

- A submitted manuscript is the version of the article upon submission and before peer-review. There can be important differences between the submitted version and the official published version of record.

People interested in the research are advised to contact the author for the final version of the publication, or visit the DOI to the publisher's website.

- The final author version and the galley proof are versions of the publication after peer review.

- The final published version features the final layout of the paper including the volume, issue and page numbers.

Link to publication

\footnotetext{
General rights rights.

- You may freely distribute the URL identifying the publication in the public portal. please follow below link for the End User Agreement:

www.umlib.nl/taverne-license

Take down policy

If you believe that this document breaches copyright please contact us at:

repository@maastrichtuniversity.nl

providing details and we will investigate your claim.
}

Copyright and moral rights for the publications made accessible in the public portal are retained by the authors and/or other copyright owners and it is a condition of accessing publications that users recognise and abide by the legal requirements associated with these

- Users may download and print one copy of any publication from the public portal for the purpose of private study or research.

- You may not further distribute the material or use it for any profit-making activity or commercial gain

If the publication is distributed under the terms of Article $25 \mathrm{fa}$ of the Dutch Copyright Act, indicated by the "Taverne" license above, 
Heterogeneity among Displaced Workers 
(c)2003 Ben Kriechel, Maastricht

All rights reserved. No part of this publication may be reproduced, stored in a retrieval system, or transmitted, in any form, or by any means, electronic, mechanical, photocopying, recording or otherwise, without the prior permission in writing, from the author.

Published by ROA

Postbus 616

6200 MD Maastricht

ISBN 90-5321-378-3

Printed in the Netherlands by Unigraphic 


\title{
Heterogeneity among Displaced Workers
}

\author{
Proefschrift
}

ter verkrijging van de graad van doctor aan de Universiteit Maastricht, op gezag van de Rector Magnificus,

Prof. dr. A. Nieuwenhuijzen Kruseman volgens het besluit van het College van Decanen, in het openbaar te verdedigen op donderdag 27 november 2003 om 16.00 uur

door

Ben Kriechel 


\title{
Promotor
}

\author{
Prof. dr. G. A. Pfann
}

\section{Beoordelingscommissie}

Prof. dr. J.A.M. Heijke (voorzitter)

Prof. dr. J.J. Hartog

Prof. dr. F.C. Palm

Dit onderzoek is gefinancierd door de Nederlandse Organisatie voor Wetenschappelijk Onderzoek (NWO), project 400-44-001.

This research has been financed by the Netherlands Organization for Scientific Research (NWO), grant 400-44-001. 


\section{Acknowledgements}

Sometime in 1997 I got a phone-call from Carina Furnée who apparently knew that I was looking for a Ph.D. position in economics. She gave me the hint to call Gerard Pfann who was said to have a project that might be of interest to me. The talk with Gerard turned out to be quite promising. I do not remember whether it was mentioned in our first meeting or in one of the subsequent meetings that the personnel data of Fokker might become available and that it would be an excellent project to look into the causes and consequences of worker displacement at the firm.

Fokker! That company had been the focus of my attention ever since I got interested in airplanes ... and that was long before I got interested into economics. Thanks to my uncle Peter, who had worked there all his working life as an engineer, I had posters of Fokker, I had visited on one of their open days, and when the Fokker 50 and 100 were developed I got plots of their design.

The decision to take the offer was easy: An interesting and exciting topic, possibly unique data, and Gerard as my supervisor. It sounded just great. I must say that I do not regret this decision. Gerard was an excellent supervisor. He introduced me into his network of colleagues and fellow researchers. At the right times he helped me to get on the tracks again, while at other times he gave me the freedom to learn from my own mistakes. I have learned a lot from him in terms of research, the scientific community, and life. He created a wonderful research environment at the Business Investment Research Center (BIRC).

Thanks to the scientific council of BIRC I came into contact with Norman Bradburn. Norman invited me to the National Opinion Research Center at the University of Chicago to learn about survey research. There was a lot to learn about surveys, and getting 
hands-on experience on several running projects at the NORC proved to be an effective way to learn about the art and the science of survey research. Thanks are also due to Julie Antelman who allowed me to stay at her house for the three months that I visited. It has always been a pleasure to stay with her.

Two other persons of the scientific council where especially important for my research: My gratitude goes out to Dan Hamermesh for his help and guidance in the literature and research on displacement. On the other spectrum of the council I am indebted to Hans van der Zouwen who shared with me his extensive knowledge on surveys and was patient enough to comment on my efforts in the survey world.

Developing my own survey nevertheless proved difficult. I received help from Lex Borghans, Bob Lalonde, and Chris Flinn, who provided me with their surveys. Some of their good ideas were incorporated into the 'Fokker Survey'.

This research would have been impossible without the help of the bankruptcy trustees. Especially, Mr. Ben Knüppe, responsible for the personnel, was key to the success of this thesis as he made the personnel data available, and he was the one that was especially interested in the consequences of the bankruptcy for the personnel. But also the workers that helped in the pilot of the study, those that commented in a focus group meeting in Maastricht as well as those that were willing to fill in the questionnaire in a focus group meeting in Amsterdam were crucial to the development of the survey and contributed to its success. Again, I would like to thank them for their effort. My thanks go to also all the workers that completed the survey. I understand that to some it was quite difficult and emotional to receive a survey about the death of a company in which they wanted to spend the rest of their working life.

Sending out a survey is a tremendous task. I thought that I could send out those surveys by myself, but when the boxes of printed surveys, envelopes and letters arrived, it became clear that packing would mean a huge logistic effort. This was supported by the 'packing' team who did some evening shifts to help me send out my survey: Allard Bruinshood, Sara Villanueva-Alcantara, Jaap Bos, Andie Tatkon-Coker, Mindel van de Laar thanks for your help in that respect.

Ellen Nelissen also helped packing, answering phones and getting all the bills paid. She was a tremendous help. Later on Ingrid van Weers took her position and helped to book our trips, organizing the Scientific Council in Chicago, and get those administrative stuff done. In the last stages of this thesis Adela Buttolo helped me to prepare the right letters that precede any Ph.D. defense. Thanks for all that support. 
My time at BIRC would have been much less exciting and probably much less productive without my colleagues Wilko Letterie and Boris Blumberg, Mindel van de Laar and - later on - Michael Polder and Jasper Kok. We had many good discussions, meetings, trips and meals. It has been a good time.

The q-seminars were an integral part of the BIRC experience, providing the opportunity to present finished or unfinished research. Besides those that were mentioned above, René Belderbosch and Martin Carree joined us to listen yet again to some story about Fokker. Thanks for your patience and your comments.

Beyond those people that were mentioned already, Thomas Bauer, Michael Burda, Janet Currie, Tor Eriksson, Mike Gibbs, Rosemar Hyson, Peter Kuhn, Ed Lazear, Derek Neal, Ken Troske, Jan van Ours, and Niels Westergård-Nielsen commented on papers that resulted in chapters of this thesis. Seminar and conference participants of the following conferences also contributed in various ways to this thesis: the NAKE Research Day as well as the NAKE Workshops at Tilburg, Amsterdam, Groningen and Maastricht, the METEOR Conference 1999 at Maastricht University, four Meetings of BIRC's Scientific Council (Maastricht, St. Gerlach, and Chicago), the 2nd IZA European Summer School, several IZA Workshops, the METEOR conference 'The Production of Human Capital' as well as the ROA/Skopje Conference on 'Skills Obsolescence' at Maastricht, the annual EEA Meeting at Lausanne, the CAED 2001 Conference at Aarhus, the Annual Society of Labor Economics Meeting at Baltimore, the CEPR/SITE Conference 'Incentives and Beyond' at Stockholm, and the EALE conference at Sevilla.

Steve Tuson deserves some credit for improving the language of my manuscript. He could not convince me to rewrite the thesis in proper (British) English, nevertheless he found numerous errors, typos and sentences that barely resembled English.

I would like to thank the members of my assessment commission, Hans Heijke, Franz Palm and Joop Hartog for their comments on the manuscript. I tried to incorporate as much as possible in the short time that remained. But your comments and thoughts as well as the speed of your work was greatly appreciated. Hans Heijke also gave me the opportunity to publish my thesis as part of 'his' Ph.D. series. I could not resist that offer, especially when I realized that I would be number three of the series. I am indebted to the two persons of my 'shadow commission'. Jaap Bos and Peter Somers, thank you (again) for critically reading the thesis at its final stage in order to eliminate 
as many errors as possible.

Thomas Dohmen has been a long time friend. We seem to follow each other - and I must say I do not mind that. Having you as a colleague and co-author was great. I have benefitted a great deal from your expertise, and was glad to return some of my knowledge. Doing research together has been fun and your friendship was invaluable.

My uncle Peter Somers deserves my special appreciation. As one of the 'displaced' Fokker workers he encouraged me to do the research and was always open for my questions. He helped me with insights about the company, the search process and with comments on various parts of the research. Your your critical comments were to the point and your help was invaluable.

My parents deserve my thanks as well. They have always allowed me to take my own decisions and supported me whenever I needed it.

The most important person is my wife Rianne. Getting to know you was the best thing that could have happened to me. You always supported me in writing this thesis, and are always interested in my research. Unfortunately, my work does not sound as well and as spectacular as your work. 


\section{Contents}

1 Introduction $\quad \mathbf{1}$

1.1 Informed Observer Approach . . . . . . . . . . . . . . . . . 5

1.2 History of Fokker . . . . . . . . . . . . . . . . . 6

1.3 Problem Statement . . . . . . . . . . . . . . . . . . . . . . . 9

1.4 Outline of the Study . . . . . . . . . . . . . . . . . . . . . 11

2 Literature $\quad 13$

2.1 Empirical Studies of Displacement . . . . . . . . . . . . . . . . . 16

2.1.1 Case Studies . . . . . . . . . . . . . . . . . . . . . 16

2.1.2 Socio-Economic Panels . . . . . . . . . . . . . . . . . . . 20

2.1.3 Administrative Data . . . . . . . . . . . . . . . . 26

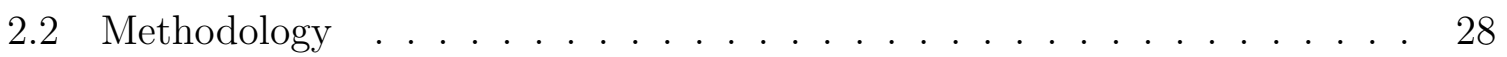

2.2.1 Estimation Strategy _ . . . . . . . . . . . . . . . . . . 29

2.3 Search Time and Wage Losses . . . . . . . . . . . . . . . . . . . 31

2.3 .1 U.S. Studies . . . . . . . . . . . . . . . . . . . . 32

2.3 .2 European Studies . . . . . . . . . . . . . . . . . . . . . 35

2.3.3 Open Questions . . . . . . . . . . . . . . . . 38

3 Internal Labor Markets $\quad 41$

3.1 Introduction . . . . . . . . . . . . . . . . . . . . . 42

3.2 The Firm and its Personnel Data . . . . . . . . . . . . . . . . . . 44

3.2.1 The Firm . . . . . . . . . . . . . . . . . . . . . . . . 44

3.2 .2 The Data . . . . . . . . . . . . . . . . . . . . . . 44

3.2.3 Development of the Workforce . . . . . . . . . . . . . . . . 45

3.3 The Corporate Hierarchy . . . . . . . . . . . . . . . . . . . . . . 46

3.3.1 Identification of Levels . . . . . . . . . . . . . . . . 46

3.3.2 Structural Stability and the Size of Levels . . . . . . . . . . . . . . . . 48

3.4 Mobility . . . . . . . . . . . . . . . . . . . . . . 48

3.4 .1 Entry and Exit . . . . . . . . . . . . . . . . . . 48

3.4 .2 Vertical Job Mobility . . . . . . . . . . . . . . . . . 51

3.4.3 Lateral Job Mobility . . . . . . . . . . . . . . . . 56 
3.5 Wages and the Hierarchy . . . . . . . . . . . . . . . . . 58

3.5.1 Administrative Rules in Wage Setting . . . . . . . . . . . . . . 59

3.5.2 Job Levels and Wages . . . . . . . . . . . . . . . . . . . . 60

3.6 Wage Growth and Job Transitions . . . . . . . . . . . . . . . . . . 65

3.6.1 How are Promotions and Demotions Defined? . . . . . . . . . . 65

3.6.2 Wages and Promotions . . . . . . . . . . . . . . . 66

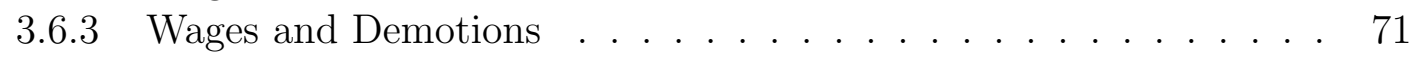

3.7 Careers . . . . . . . . . . . . . . . . . . . . 71

3.7 .1 New Hires versus Incumbents . . . . . . . . . . . . . . . . 72

3.7 .2 Job Ladders Across Hierarchical Levels . . . . . . . . . . . . . . . 73

3.7.3 Monkey Bars Within Hierarchical Levels . . . . . . . . . . . . . . 76

3.8 Conclusion . . . . . . . . . . . . . . . . . . . . . . 77

4 Ranks and Organizational Change $\quad 79$

4.1 Introduction . . . . . . . . . . . . . . . . . . 80

4.2 A theoretical model of hierarchical workforce reorganization . . . . . . . 81

4.3 Econometric specification of the hierarchical decision model . . . . . . . . 83

4.4 Personnel data . . . . . . . . . . . . . . . . . 86

4.5 Estimating the hierarchical model and testing hypotheses . . . . . . . . . 91

4.6 Restructuring and wage inequality within the firm . . . . . . . . . . 97

4.7 Conclusions . . . . . . . . . . . . . . . . . . . 100

5 Development and Conduct $\quad 103$

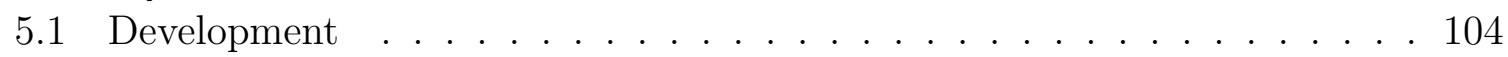

5.1 .1 Population . . . . . . . . . . . . . . . . . . 104

5.1 .2 Instrument Development . . . . . . . . . . . . . . . . . 108

5.1 .3 Testing . . . . . . . . . . . . . . . . . . . 109

5.1 .4 The 'Fokker Survey' Questionnaire . . . . . . . . . . . . . . . 110

5.2 Conduct . . . . . . . . . . . . . . . . . . . . . . . . . . 114

5.2 .1 Response . . . . . . . . . . . . . . . . . 114

5.2.2 Non-Response in the Fokker Survey . . . . . . . . . . . . . . . . . 117

5.3 Conclusion . . . . . . . . . . . . . . . . . . . . . . . . . 123

6 Some Results of the Fokker Survey 127

6.1 Labor Market Status . . . . . . . . . . . . . . . . . . . . . . 128

6.2 Wages after the Bankruptcy . . . . . . . . . . . . . . . . . . 158

7 Heterogeneity among Displaced Workers 173

7.1 Introduction . . . . . . . . . . . . . . . . . . . . . . . 174

7.2 The Displaced Worker Survey and Personnel Data . . . . . . . . . . . . 175

7.2.1 The Personnel Data . . . . . . . . . . . . . . . 177

7.2 .2 The 'Fokker Survey' . . . . . . . . . . . . . . . . . . . . . 179

7.3 Post Displacement Search Time . . . . . . . . . . . . . . . . . . . . . 180

7.4 Displacement Losses . . . . . . . . . . . . . . . . . . . . 183 
7.4.1 Displacement Losses: The First Job . . . . . . . . . . . . . . . . . 184

7.4.2 Three Years Later: Testing the Ranking Model . . . . . . . . . . 188

7.5 Updating the Reservation Wage over Time . . . . . . . . . . . . . . . . 189

7.6 Conclusion . . . . . . . . . . . . . . . . . . 195

8 Reservation Wages 199

8.1 Introduction . . . . . . . . . . . . . . . . . . . 200

8.2 Regional Job Offers . . . . . . . . . . . . . . . . . . . . . . 201

8.3 Role of Information . . . . . . . . . . . . . . . . . . . . . 203

8.3 .1 Job Referral . . . . . . . . . . . . . . . . . . 203

8.3 .2 Neighborhood Networks . . . . . . . . . . . . . . . . . 206

8.4 Search Model . . . . . . . . . . . . . . . . . . 207

8.5 Data . . . . . . . . . . . . . . . . . . . . 209

8.5.1 The Personnel Data . . . . . . . . . . . . . . . . . . 210

8.5.2 The 'Fokker Survey' . . . . . . . . . . . . . . . . . . . . . . 210

8.6 Empirical Model . . . . . . . . . . . . . . . . . . . . . . . . . 211

8.7 Empirical Results . . . . . . . . . . . . . . . . . . . . . . . 213

8.7 .1 Regional Differences . . . . . . . . . . . . . 220

8.8 Conclusion . . . . . . . . . . . . . . . . . . . . . . . . . . . 221

9 Conclusion 223

9.1 Future Research . . . . . . . . . . . . . . . . . . . . . . . 228

$\begin{array}{ll}\text { Summary in Dutch } & 243\end{array}$

$\begin{array}{ll}\text { Biography } & 249\end{array}$

$\begin{array}{ll}\text { The Questionnaire } & 251\end{array}$ 



\section{List of Figures}

3.1 Development and Composition of the Workforce by Activities . . . . . 46

3.2 Inflow- Outflow and Employment Growth Rates . . . . . . . . . . . 50

3.3 Monthly Mobility . . . . . . . . . . . . . . . . . . . . 56

3.4 Mean Wage . . . . . . . . . . . . . . . . . . . 63

3.5 Job Level Wage Distributions in $1991 \ldots$. . . . . . . . . . . . . . . 64

4.1 Tree Structure of the Firm's Restructuring Problem . . . . . . . . . . . . 84

4.2 Effects of a Profit Growth Shock on the Hierarchical Structure . . . . . . 93

4.3 Effects of a Volatility Shock on the Hierarchical Structure . . . . . . . . . 95

4.4 Effects of a Shock in Rent Shares on the Hierarchical Structure . . . . . . 96

4.5 Effects of a Shock in Firing Costs on the Hierarchical Structure . . . . . 98

4.6 Workforce Restructuring and Wage Inequality . . . . . . . . . . . . . . 99

6.1 Educational Levels over Employed in 1997, 1998, 1999 . . . . . . . . . . . 133

6.2 Educational Levels over Unemployed in 1997, 1998, 1999 . . . . . . . . . 134

6.3 Age Categories - Employed versus Survey Respondents . . . . . . . . . . 142

6.4 Wage Index - Fokker N.V. Versus All Industry . . . . . . . . . . . . . . . 161

6.5 Index of Respondents' Income Versus Industry wages . . . . . . . . . . . 162

7.1 Job Expectations, Predicted Wages and Wage Expectations . . . . . . . 194

8.1 Two digit Postcode Regions . . . . . . . . . . . . . . . . . . . . . . . . 204

8.2 Development of Reservation versus First Accepted Wage . . . . . . . . . 216

8.3 Reservation Wages for Selected Regions . . . . . . . . . . . . . . . . . 217

8.4 Accepted Wages for Selected Regions . . . . . . . . . . . . . . . . . . . 218 



\section{List of Tables}

2.1 Durham Workers: In and Out of Sample . . . . . . . . . . . . . . 17

2.2 New Jobs Two Years After Closing of the Durham Mills . . . . . . . . . 18

2.3 U.S. Data-sets . . . . . . . . . . . . . . . . . . . . . . . . . 21

2.4 European Data-sets . . . . . . . . . . . . . . . . . . . . . 23

2.5 Displacement Definition in European Data-sets . . . . . . . . . . . . 25

2.6 Survey of Studies of Displacement . . . . . . . . . . . . . . . . . . 34

2.7 Earnings Losses in Europe . . . . . . . . . . . . . . . . . . . . . . 37

3.1 Hierarchical Composition, 1987-1996 . . . . . . . . . . . . . . . . 48

3.2 Entry into Hierarchical Levels, 1987-1996 . . . . . . . . . . . . . . . . 49

3.3 Exit from Hierarchical Levels, 1987-1996 . . . . . . . . . . . . . . . . . 51

3.4 Transition Matrix $1987-1991 \ldots \ldots \ldots$. . . . . . . . . . . 53

3.5 Transition Matrix $1991-1996 \ldots \ldots \ldots \ldots$

3.6 Lateral Job Transitions to a Different Field of Activity . . . . . . . . . . 57

3.7 Distribution of Pay for New Hires in Wage Deciles . . . . . . . . . . . . . 61

3.8 Distribution of Pay for Separating Workers in Wage Deciles . . . . . . . . 62

3.9 Salary Premium of Promotion . . . . . . . . . . . . . . . . . 67

3.10 Distribution of Pay for Promotees in Salary Deciles . . . . . . . . . . . 68

3.11 Serial Correlation in Wage Growth . . . . . . . . . . . . . . . 69

3.12 Promotion and Wage Growth . . . . . . . . . . . . . . . . 70

3.13 Age and Tenure: New Hires versus Promoted Incumbents . . . . . . . . . 72

3.14 Education Level: New Hires versus Promoted Incumbents . . . . . . . . . 74

4.1 The Structure of Labor Input Before and After Restructuring . . . . . . 86

4.2 Organizational Change . . . . . . . . . . . . . . . . . 87

4.3 Variables Describing Rank Specific Profits . . . . . . . . . . . . . . . 89

4.4 Variables Explaining Multivariate Binomial Layoff Decisions . . . . . . . 90

4.5 Parameter Estimates . . . . . . . . . . . . . . . . . . . . 92

5.1 Composition Fokker Workforce . . . . . . . . . . . . . . . 107

5.2 Probit Non-Response . . . . . . . . . . . . . . . . . . . . . . . . . . . . 119

5.3 Employment Status in 1999 - Response vs. Non-Response . . . . . . . . 123 
5.4 Weights and response rate - Non-Response Study . . . . . . . . . . . . . 124

5.5 Percentages by Strata - Non-Response Study . . . . . . . . . . . . . . . . . 124

5.6 Percentages by Strata - Respondents 'Fokker Survey' . . . . . . . . . . . 125

5.7 Outcomes - Non-response Study . . . . . . . . . . . . . . 126

6.1 Education Levels - Fokker Survey vs. 'matched' SEP . . . . . . . . . . . 129

6.2 Age Categories - Fokker Survey vs. 'matched' SEP . . . . . . . . . . . . 130

6.3 Labor Market Status - Aggregated . . . . . . . . . . . . . . . . . . 131

6.4 Labor Market Status by Educational Levels - Employed . . . . . . . . . 136

6.5 Labor Market Status by Education Levels - Unemployed . . . . . . . . 137

6.6 Number of Employers by Education Level . . . . . . . . . . . . . . . . . 138

6.7 Age Categories - Employed Workers . . . . . . . . . . . . . . . . . 140

6.8 Age Categories - Unemployed Workers . . . . . . . . . . . . . . . . 141

6.9 Searching Time per Week — Employed in 1999 . . . . . . . . . . . . . 143

6.10 Searching Time per Week — Unemployed in 1999 . . . . . . . . . . . . 144

6.11 Number of Letters per Four Weeks — Employed in 1999 . . . . . . . . . 145

6.12 Number of Letters per Four Weeks - Unemployed in 1999 . . . . . . . . 146

6.13 Evaluation of Training for Job-applications . . . . . . . . . . . . . . . 148

6.14 Evaluation of Help in Contacting Potential Employers . . . . . . . . . . . 148

6.15 Participation in (Re-)Training by Education Levels - Employed . . . . . 149

6.16 Participation in (Re-)Training by Education Levels - Unemployed . . . . 150

6.17 Participation in (Re-)Training by Age Levels - All Employed . . . . . . 151

6.18 Participation in (Re-)Training by Age Levels - All Unemployed . . . . . 152

6.19 Channels of Successful Job Search . . . . . . . . . . . . . . . . . 153

6.20 Search Cost by Education Level . . . . . . . . . . . . . . . . . . . . . 154

6.21 Search Cost by Age Level . . . . . . . . . . . . . . . . . . . . . . . 155

6.22 Size of the New Employer - Displaced Workers in Fokker Survey . . . . 155

6.23 Type of Employment Contract - Fokker Survey . . . . . . . . . . . . . . 156

6.24 Schooling Requirements for Acquiring a Job . . . . . . . . . . . . . 157

6.25 The Importance of Work Experience in Getting the New Job . . . . . . . 157

6.26 Current Responsibility Compared to Responsibilities at Fokker N.V. . . . 159

6.27 Aggregate Income Post-Displacement . . . . . . . . . . . . . . . . . 161

6.28 Aggregate Income Post-Displacement incl. Benefits . . . . . . . . . . . . 163

6.29 Income by Education Levels . . . . . . . . . . . . . . . . . . . . . 165

6.30 Income by Education Levels incl. Benefits . . . . . . . . . . . . . . . 166

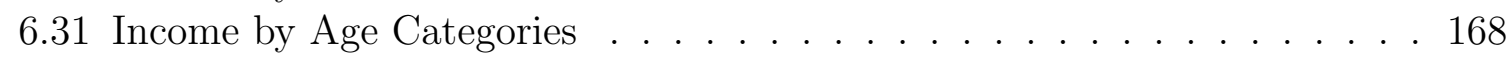

6.32 Income by Age Categories incl. Benefits . . . . . . . . . . . . . . . . 169

6.33 Average Monthly Income by Plants . . . . . . . . . . . . . . . . . . . . 170

6.34 Average Monthly Income by Plants incl. Benefits . . . . . . . . . . . . . 171

7.1 Composition of Fokker Workforce and Survey Population . . . . . . . . . 176

7.2 Survival Analysis: Timing of First Employment after Displacement . . . 181

7.3 Estimates of Wage Differences . . . . . . . . . . . . . . . . . . . . . 185

7.4 Wage Losses Three Years after Displacement . . . . . . . . . . . . . 188 
7.5 Average Salary and Number of Matches per 3 Month Period . . . . . . . 190

7.6 Piece-wise Constant Hazard Model . . . . . . . . . . . . . . . . . . . . 193

8.1 Number of Offers: Fokker Survey . . . . . . . . . . . . . . . . . . 202

8.2 Unconditional Mean Arrival Rate . . . . . . . . . . . . . . . . . . . . . . 212

8.3 Regression Results . . . . . . . . . . . . . . . . . . . . . . . . . 214

8.4 Regression Results - Local Variables . . . . . . . . . . . . . . . . . 215

8.5 Interquartile range . . . . . . . . . . . . . . . . . . . . . . 221 



\section{Introduction}

There is also another sacred bird, whose name is the Phoenix. I for my part did not see him except only in picture; for indeed he in fact resorts to them quite rarely, at intervals of five hundred years, as the inhabitants of the City of the Sun say. He resorts then, they assert, when his father dies. He is, if closely resembling his picture, of this size and of this kind: some of his feathers are of golden plumage and some red. In the highest degree he is most similar in shape and his size to an eagle. He then, they say, contrives the following, although they make statements not credible to me: starting out from Arabia, he conveys his father, after plastering him in myrrh, to the shrine of the Sun and buries him in the Suns shrine and he conveys him thus: first he moulds as large an egg of myrrh as he is able to carry and afterward makes trial of carrying it; next, when he is done with making trial, just then after hollowing the egg, he puts his father into it and with other myrrh he plasters in that space at whichever point in the egg he made the hollow and puts in his father; finally, his father placed within, the object becomes the same weight and, after finishing the plastering in, he conveys him toward Egypt to the Suns shrine. That, they say, that bird does.

(Herodotus, Inquieries) 


\section{Introduction}

As in the legends of the firebird 'Phoenix', death is often seen as a new beginning. Rising from the ashes of the old bird comes a new bird, the new generation. This image can be found in many religions, but also in everyday life - even in economics: From an economics perspective, life and death of firms is normal. New firms enter the market just as old firms decline. New products appear just as old products are no longer produced. However, the death of a firm - like the death of a close person - has its consequences on the surroundings, and in this case even on the bits and pieces a firm is made of: the employees of the firm, the knowledge they embody as a person but also as an organization, and the machinery. The workers of the firms have to be reallocated, they have to find new employers that can make use of their skills, or learn new skills altogether. In this thesis, life after the firm closure is examined. In other words, an examination of what rises out of the ashes of the dying company.

Already in the early writings of economics one can find references to the learning, usage and the reward for skills. Adam Smith refers to the value of skills in a society as wealth. In his description, he already appears to see skills and knowledge embodied in the workforce as human capital.

"When any expensive machine is erected, the extraordinary work to be performed by it before it is worn out, it must be expected, will replace the capital laid out upon it, with at least the ordinary profits. A man educated at the expence of much labour and time to any of those employments which require extraordinary dexterity and skill, may be compared to one of those expensive machines. The work which he learns to perform, it must be expected, over and above the usual wages of common labour, will replace to him the whole expence of his education, with at least the ordinary profits of an equally valuable capital. It must do this too in a reasonable time, regard being had to the very uncertain duration of human life, in the same manner as to the more certain duration of the machine." — Smith (1776, Book I.x.b)

Smith describes the investment in the skills of the workers in analogy to a machine. Thus, he argues, human capital can be seen as an asset, which on its own will lead to some reward when it is put into use. Such skills and knowledge will yield higher rewards, or higher wages. However, the skills and knowledge have to be acquired, and often their application or use is linked to some form of production, machine, or even company. The value of the skills should - according to Adam Smith — be accounted into the 'wealth of a nation': 
"[...] of the acquired and useful abilities of all the inhabitants or members of the society. The acquisition of such talents, by the maintenance of the acquirer during his education, study, or apprenticeship, always costs a real expence, which is a capital fixed and realized, as it were, in his person. Those talents, as they make a part of his fortune, so do they likewise of that of the society to which he belongs. The improved dexterity of a workman may be considered in the same light as a machine or instrument of trade which facilitates and abridges labour, and which, though it costs a certain expence, repays that expence with a profit." — Smith (1776, II.i.17)

The wealth embodied in skills and abilities of workers depends on its usefulness in the economy, as the skill and the abilities have to be linked to a production process, an industry or even a specific firm. After the closure of a firm, the question remains as to how far the skills acquired can still be used, and what happens when these skills become superfluous altogether. In the beginning of the 19th century, Say warns us that as a result of specialization in the economy we do now enjoy higher productivity, but at the cost of lower flexibility of the worker:

"A man, whose whole life is devoted to the execution of a single operation, will most assuredly acquire the faculty of executing it better and quicker than others; but he will, at the same time, be rendered less fit for every other occupation, corporeal or intellectual; his other faculties will be gradually blunted or extinguished; and the man, as an individual, will degenerate in consequence. To have never done any thing but make the eighteenth part of a pin, is a sorry account for a human being to give of his existence. Nor is it to be imagined that this degeneracy from the dignity of human nature is confined to the labourer, that plies all his life at the file or the hammer; men, whose professional duties call into play the finest faculties of the mind, are subject to similar degradation. This division of occupations has given rise to the profession of attorneys, whose sole business it is to appear in the courts of justice instead of the principals, and to follow up the different steps of the process on their behalf. These legal practitioners are, confessedly, seldom deficient in technical skill and ability; yet it is not uncommon to meet with men, even of eminence in this profession, wholly ignorant of the most simple processes of the manufactures they every day make use of; who, if they were set to work to mend the simplest article of their furniture, would 


\section{Introduction}

scarcely know how to begin, and could probably not drive a nail, without exciting the risibility of every carpenter's awkward apprentice; and if placed in a situation of a greater emergency, called upon, for instance, to save a drowning friend, or to rescue a fellow-townsman from a hostile attack, would be in a truly distressing perplexity; whereas a rough peasant, inhabiting a semi-barbarous district, would probably extricate himself from a similar situation with honour." — Say (1802, Book I, Chapter VIII, I.VIII.24)

The insight that specialization leads to inflexibility, and that workers loose skills they do not employ are used in the literature that concerns itself with the investment in education, or the human capital literature. In this literature, the returns to investment in general and specific education is estimated. As we could see in the above quotes, these were concepts that were already seen at or before early industrialization took place, and subsequently became more and more important. Using the examples of Say, the 'rough peasant' becomes less and less important in the more industrialized settings, whereas the specialized workmen can be found almost everywhere. This has implications for those workmen that specialized in skills specific to technologies or firms that became less important, superfluous or died out altogether.

Can they make use of some of their insights, knowledge or skills at different firms, in different industries or working with different production technologies? This question was tackled in studies on innovation and the 'displacement' of men. Early and lucid accounts are given by two studies of Elizabeth Baker on changes in the printing industry (see also Chapter 2).

The formalization of the human capital literature by Mincer, Schulz and Becker has led to a renewed interest in the returns of education, but also in skills or informal education. In the displacement literature, examining the (wage) losses of firm closures, the distinction between general and industry specific knowledge was introduced by Neal (1995). This was a result of his finding that experience with one industry is rewarded more if a worker stays within his own industry after displacement than those workers that switch industry. This gives an indication that skills learned within a firm of one industry can be used at other firms of the same industry.

However, even accounting for age, tenure, education levels and industry specific skills, the variation of the post-displacement outcomes varied significantly (cf. Kletzer, 1998). Following the plant level studies of displacement and incorporating the knowledge of the career within the firm allowed us to lift the curtain a little further in this dissertation. The method used to develop the survey among the displaced workers follows the 
'Informed Observer Approach' which will be described in the next section.

\subsection{Informed Observer Approach}

The 'Informed Observer Approach' is a central concept linking different branches of research within the NWO Pionier project that also financed this study. Rather than relying solely on ones own intuition, a researcher should enhance his understanding of the processes at hand by talking to those persons that take the decisions of interest, that are involved in the process at hand. Based on these talks with experts and the existing economic theory, new models can be derived. In the proposal the methodology is described "[...] to combine the interview/survey approach, frequently applied in management sciences, and the analytical modelling and estimation techniques from economics to investigate investment decisions of firms."

The use of using interviews to understand an economic agent's decision is not new per se. In his discussion of the revealed preference theory, Sen (1973) suggests that Economists should not only look at the behavior of economic agents - as was done in the revealed preference theory: "The idea that behavior is the one real source of information is extremely limiting for empirical work and is not easy to justify in terms of the methodological requirement of our discipline." It limits the economist to speculations which might result in causal relationships modelled that seem to fit the data, but have nothing to do with the decision process of the agent involved.

A second pillar of the 'Informed Observer Approach' is therefore to collect data on the insights gained by the expert talks. These data allow us then to test or develop new models. The 'Informed Observer Approach' grounds its theories on practical experiences of the actors involved, and hence insures a reality check of theories. The data collection and model building insures that theories are firmly grounded in economic theory and empirically tested. By using a combination of interviews and (empirical) observation, based on economic models we can go beyond simple observation but also beyond simple theorizing. While we as researchers try to understand the real world, hence, we should put much effort into the gathering of new data. All too often, however, economists still rely on government statistics and on personal intuition for the verification of theories. Their intuition can be faulty, for they have little direct experience with economic life. Government data often do not address the questions that are central to the researcher's questions. Interpretation or the use of proxies are used to fit the data with models, while a self-collected data-set might have been better equipped to address the problem, 


\section{Introduction}

and answer the researcher's questions. Before we can move on to more aggregate and more elaborate questions, the inner workings of the firm, its investment decisions and the internal employment relationships have to be studied. Using the informed-observer approach enables us to achieve a better understanding of the working of firms' decisions.

The 'Informed Observer Approach' was also central to this study. Based on the existing models and estimation of workers' displacement losses, we invited a group of former employees to focus group meetings and in-depth interviews. These meetings gave us a basis to understand both the firm level data that we obtained as well as to develop a questionnaire that was geared to our target population. We benefited from several talks to the bankruptcy trustee as well as several workers who answered our questions and clarified problems encountered.

\subsection{History of Fokker}

This study is based on the bankruptcy of the Dutch aircraft manufacturer Fokker. In order to gain some understanding of the circumstances of the company, its development and roots, its historical development will be shortly summarized in this section. This section draws from several sources: the beginning years and information on the founder of the company, Anthony Fokker, can be found in book length in Franquinet (1946). A general history of the company is written by van Huijstee (1997), while an insightful book on the last years of Fokker is written by Martijn (1996).

\section{Anthony Fokker and the beginning of aviation}

The first decades of the company were molded by the aviation pioneer Anthony Fokker. In his young years, Anthony Fokker - after having studied for four years at Polytechnic college - dropped out of college to construct his own aircraft. However, his father disagreed with his son's decision and sent him to the engineering school of Bingen (Germany) to specialize in the construction of automobiles. Arriving in Germany he found an engineering school close to the one in Bingen that besides teaching a course in automobile technology also taught an aviation course. Even though the course turned out to be a disappointment — the teacher had no ideas on how to build aircraft — Anthony Fokker convinced his father and a German officer von Daum to finance his endeavor of building an aircraft. Lieutenant von Daum also arranged the usage of an assembly hall in the Zeppelin hangars of Baden-Baden for the construction. While the first model was 
a total mishap, Anthony Fokker eagerly went on to build a second improved model. This second model, finished around Christmas of 1910, actually took off - one meter off the ground to be precise - but was crashed by his companion von Daum. In the spring of 1911, Anthony finished his third model. This model could fly for 20 minutes and reach a speed of $90 \mathrm{~km} / \mathrm{h}$. When von Daum crashed with this model again, he was bought out by Anthony Fokker using his father's money. He repaired the damage on the aircraft and called it "the Spider" - the first 'Fokker aircraft'. With this aircraft he obtained his pilot licence on May 16th 1911. He continued to give public demonstrations and invested the money he earned to improve and build new aircraft.

In February 1912 he opened a plant near Berlin. Up until 1913 some twenty aircraft — variations of the original spider design — were manufactured. Subsequently different designs were developed and sold mainly to the German military. When the war broke out the demand for his military aircraft rose substantially. At the end of the war more than 3000 aircraft had been produced by 'Fokker Flugzeugwerke GmbH'. Anticipating the disarmament and the destruction of any aircraft remaining in Germany, Anthony Fokker shipped as much equipment and as many parts as possible to the Netherlands.

\section{The golden interwar years}

In 1919, the 'NV Nederlandsche Vliegtuigenfabriek' was founded, settling its plant in Amsterdam-North. Due to the connection of Anthony Fokker with the German military, the company did not use his family name, initially. As the military aircraft found little interest, the company developed passenger aircraft. Fokker also expanded to the United States in the 1920s under the name Atlantic Aircraft. At the end of the 1920s Fokker was the biggest aircraft manufacturer of that time, employing some 1500 workers in the Netherlands and the United States. More than 65 percent of all aircraft built at that time came from Fokker.

In 1929, the American part of Fokker became a subsidiary of General Motors as General Aviation Corp (GAC). A crash in 1931, killing a famous football coach and seven other passengers, ended the golden era of Fokker in the United States. The death of Anthony Fokker in 1939 ended the era of the aircraft pioneer leading his company.

\section{Post WWII, rebuilding}

Just prior to the occupation, KLM had ordered the first full-metal passenger aircraft, the Fokker F24. As the order could never be fulfilled due to the occupation, the aircraft 


\section{Introduction}

was never built. However, its design was the precursor to the Fokker F27 which reestablished Fokker's fame after the war. The firm never reached similar levels to those of the 1920s, however in niche markets and with some technologies it remained market leader. For example adhesive technology, which was developed by engineer Schliekelmann set the groundwork for innovative construction from Fokker. Just after the war, he experimented with possibilities of gluing metal. This would allow construction of lighter and cheaper aircraft. The methodology that evolved from this process, is used by many other producers such as Boeing, British Aerospace, Airbus. The company remained one of the leaders in using innovative concepts of gluing in aircraft design.

The post war era left a battered plant behind. Most of the useful material was plundered, and production was at a standstill. The first aeroplane to be built, the F25 'Promotor', was a four seater. The prototype had its maiden flight on 20 October 1946, and Fokker was back into aircraft production again. Only 21 of these aeroplanes were built, as market demand was insufficient to support a bigger line. In these early postwar years trainers, small aircraft, and building licensed (military) aircraft designs kept the company going.

In April 1949 a merger from 1947 between Fokker, Aviolanda en 'Mij De Schelde (vliegtuigbouw)' was reversed. As this coincided with the 30th anniversary of the company, they were allowed to use the predicate 'Koninklijke' ('royal') in their name, from which henceforth the company was called 'NV Koninklijke Nederlandse Vliegtuigenfabriek Fokker'.

The first announced crisis and reorganization, in which concerns were raised that Fokker would not be able to independently construct aircraft, hence should reorganize or close the departments for aircraft development altogether, was in the fall of 1949. This uncertainty about the future of aircraft development allowed several American companies to offer contracts to Fokker personnel. It lead to a significant exodus of talented people to the United States.

In 1950s the development of the F27 commenced, giving room to 28 passengers and using two turboprop engines. The maiden flight of F27 was on 24 November 1955. It was the beginning of a new era for Fokker. The interest in the aircraft was, at first, quite small. However, from the 1960s onwards orders for this most successful aircraft of the company came in. By 1968 more than 400 of the aircraft had been sold. In 1964 Fokker started to develop the F28 'Fellowship', a 65 seater with jet engines. However, the aircraft never came close to the success of the F27 Friendship.

In 1971, the firm had to pass through more turbulences. As the sales of the F27 were 
decreasing, a reorganization had to take place. In 1971, 1750 employees were sacked. In that time it constituted about 20 percent of its entire personnel. In the 1980s, history repeated itself. In the aftermath of the second oil crisis, sales of the F27 and F28 dropped yet again. The plans for a cooperation with McDonnell Douglas to build a successor of the F28 were cancelled nine months after they were started, resulting in a reorganization that cost 1400 workers their job.

\section{F50 and F100 period}

In 1983 the decision was taken to simultaneously construct a successor to the F27 and the F28. This simultaneous development of two new aircraft brought high development costs. In December 1985, the Fokker 50, made its maiden flight, followed a year later by the Fokker 100. The market seemed right for these aircraft, yet in 1987 Fokker walked the thin line of bankruptcy as the development costs had been enormous. However, by 1989, several huge orders for the Fokker 100 were coming in. Fokker had to hire additional personnel to increase its size to about 14.000 employees. This was a period of hope for a bright future. However, the Gulf war in 1990/91 disturbed this picture. It lead to a crisis among the airline companies, which translated itself into fewer orders for aircraft or even the cancellation of existing orders. In addition, the dollar exchange rate kept falling, leaving Fokker with relatively high production costs relative to the prices it could obtain in dollars. The maiden flight of the Fokker 70 in April 1993 was preceded by an announcement of massive reorganization within the company: the lay-off of more than 1800 employees. In this year, DASA took a majority stake of 51 percent in the company, following talks and negotiations since the early 1990s. Ever since 1993, Fokker made losses. More reorganizations followed in 1994, 1995. When in January 1996 the negotiations between DASA and the Dutch government to save the company failed, it sounded the death toll for Fokker. The company went bankrupt on March 15, 1996.

\subsection{Problem Statement}

Displaced workers are not fired for personal reasons but for structural causes. This study aims to analyze the carryings-on of workers who used to be employed by the one and only large aeroplane manufacturing firm in the Netherlands, Fokker Aircraft Company. Fokker went officially bankrupt in 1996, but began systematically reducing its workforce in 1992, a period of major stagnation in the Dutch economy and in most other Western 


\section{Introduction}

European countries (Deterink, Knüppe, Leuftink and Schimmelpenninck 1997).

The main problem statement of displacement research and also of this thesis can be summarized in the following two questions:

- Does displacement diminish the values of workers' skills, prior education, or experience?

- If so, what groups suffer the most severe losses and how can we measure these losses?

Since 1980 studies have used large household data sets, with either retrospective information on pre- and post-displacement history, or histories based on longitudinal data (with the latter type of data sets containing usually very few displaced workers). The outcomes of these studies stressed that displaced workers have been concentrated in occupations (i) with below-average levels of education; (ii) related to high-tenured positions or of workers with a high age profile with substantial variation by occupation and industry (Kletzer 1989); (iii) with high pre-displacement earnings (Fallick 1991). Moreover, displaced workers with vocational training were often found to be less mobile than those with more general training, managerial experience, or higher education.

Evidence from the United States suggests that the average displaced worker loses perhaps 10 to 15 percent of prior wage upon reemployment. Losses are greatest for more senior workers. Many authors attribute the loss to destroyed firm-specific human capital.

The policy interest, on which much has been written, is twofold: In Europe the interest is in protection of declining plants, to identify vulnerable groups of displaced workers and if possible cushion their losses. In the U.S., less so than in Europe because there is less need for a specific focus, the emphasis has been on giving advance notice to workers prior to displacement and to providing longer-term payments for subsistence and job search to those displaced.

Novel in this study is the concentration on the individual plant level, re-establishing the old-style mass shutdown study but analyzing the data using what we now know about modelling investment in human capital. All the research on displacement in the last 15 years has used massive amounts of micro (often household) data that were typically not well designed to answer the questions of interest. All the old case studies had great data, but no framework of theory from which to form questions.

Before investigating the displacement component of the study, a study of the workings of the firm before the displacement was performed. Here, we investigated careers, 
position changes, and reorganizations to answer research questions such as:

- What is the pattern of job mobility within the firm?

- What is the relation between careers and wages within the firm?

At the date of the bankruptcy, the viable parts of the firm were preserved, and slimmed components of the firm were spun-off by the bankruptcy trustees. This allowed us to investigate the downsizing problem:

- Who should be selected to stay given a firm's structure and the information on the workers available?

One of the problems of displacement research using household data-sets is the heterogeneity of workers that is not reflected in the data, but influences the post displacement outcomes. Our case allowed us to investigate the workers for ten years before the displacement, observing all internal career data of the firm. Further, job descriptions and hierarchical levels are comparable within our firm, whilst this is not necessarily the case across firms. This leads us to some sub-questions that can be addressed using firm level data of the type that were available for this thesis:

- What is the influence of the position a worker has within a firm on the post displacement outcome?

- How do careers within a firm influence the post displacement experience?

- How do workers learn about their labor market opportunities and the value of their skills after displacement?

We may be able to distinguish between good and unsuccessful strategies for the displaced worker. Given that the workers were from one single firm and used the network of former employees extensively to meet even after the bankruptcy, we could also investigate the influence of the group's reaction to wages paid to similar workers.

\subsection{Outline of the Study}

In the subsequent chapter the literature on displacement will be surveyed. We will start with the early historical studies from the 1920s and the related case studies from the 1950s, to then go on discussing the 'modern' displacement studies and the data-sets 
used. In Chapter 3, the internal labor market of the company from 1987-1996 will be analyzed. The hierarchical structure, careers, and their dynamics will be discussed. In Chapter 4, the challenging question of the selection of workers in reorganization will be examined. Building on an option model under uncertainty, we estimate an hierarchical elimination model. In Chapter 5, we discuss the development and set-up of the survey among displaced workers. Here we also examine the problem of non-response. Chapter 6 gives an overview of the aggregate results of the survey. Chapter 7 examines the question of displacement losses in more depth. Making use of the information of previous careers within the company, and including specific variables on pre-displacement jobs, we investigate the heterogenous outcome of wage losses and search time. We also propose a model of worker learning, which is then extended in Chapter 8 where we focus on the local labor market and the integration of search time and reservation wages. 


\section{Displacement Literature and Data Used}

"The last group of questions, which still remain to be discussed, is concerned with the relation of capital in general to wages in general. It is obvious that though capital in general is constantly competing with labour for the field of employment in particular trades; yet since capital itself is the embodiment of labour as well as of waiting, the competition is really between some kinds of labour aided by a good deal of waiting, and other kinds of labour aided by less waiting. When for instance it is said that "capitalistic machinery has displaced much labour that was employed in making boots," what is meant is, that formerly there were many who made boots by hand, and a very few who made awls and other simple implements, aided by a little waiting; while now there are rather fewer persons occupied in boot making; and they make a much larger number of boots than before by aid of powerful machines, made by engineers aided by a good deal of waiting. There is a real and effective competition between labour in general and waiting in general. But it covers a small part of the whole field, and is of small importance relatively to the benefits which labour derives from obtaining cheaply the aid of capital, and therefore of efficient methods in the production of things that it needs."

(Marshall, 1920, Book VI, Chapter II.36) 


\section{Literature}

The interest in displaced workers is an old one in the history of labor economics. From as far back as a century ago, studies into the displacement of workers can be found. While the perceived causes of plant closings and subsequent worker displacement changed over time, the interest remained. In the early 20th century, economists were most concerned with the mechanization of work, leading to the dismissal of many workers, and for nonmechanized plants to plant closings. This fear of mechanization remained the main factor of worker displacement until the increase in trade flows started a discussion of plant closings as a result of free trade from the 1970s onwards. This fear of the result of the free trade on the employment of (American) workers led to programs to aid displaced workers. In the 1980s the availability of socio-economic panel data eased investigation into the causes and consequences of displacement. The research was also spurred by the discussion around 'advanced notice' regulation, ${ }^{1}$ requiring employers to announce a plant closing to the work-force well in advance, which was implemented in 1988.

One aspect that has been extensively researched in the 1970's and 1980's is losses from displacement, where losses have to be seen as private losses if one considers the income loss through the loss of specific investment, and the loss of rents. A survey of the displacement literature of that time can be found in Hamermesh (1989b). Finally, in the 1990s the availability of administrative data allowed for investigations that were not dependent on survey data. The survey by Fallick (1996) covers the more recent literature on displacement. And unlike Hamermesh (1989b), he includes some of the case- and industry-studies.

Displacement studies were mainly interested in the magnitude of lost earnings for those workers who become displaced relative to the income gained in their previous employment. Second, in addition to the impact of displacement on unemployment, the search for new jobs is often investigated. This was also a result of the understanding that the earnings losses of re-employed (displaced) workers alone understates the magnitude of wage losses. On the aggregate and policy level the question of who bears the costs of structural adjustment is the key issue in the displacement literature. They were probably also the reason to commence with the Displaced Worker Supplement to the Current Populations Survey (CPS), one of the 'work horses' that empirical investigators use in displacement research in the United States.

While the initial interest in displacement through technological change in the early 20th century could also be found in Europe (see e.g. Käler (1933)), the displacement literature and its empirical investigation did not take place until recently. The availabil-

\footnotetext{
${ }^{1}$ See for a detailed discussion Ehrenberg and Jakubson (1988).
} 
ity of administrative data and the methodological approach of Jacobson, LaLonde and Sullivan (1993) spurred some further research into displacement losses in Europe.

There are considerable differences in the definition of 'displaced workers' over the studies in this literature. The definitions vary from general lay-offs (including 'firing for cause') to large scale lay-offs due to plant closure or reorganization only. All survey papers touch upon this issue, as it is crucial to the understanding and interpretation of the results generated. Fallick (1996, p. 5) notes that: "[t]here is considerable disagreement in the literature about how to formally define 'displaced workers.' The question of definition is not merely academic. Government programs are often justified on the grounds that society should compensate the losers for structural changes that benefit us on aggregate, especially if those changes are due to a change in government policy."

Based on a definition of the Ministry of Labor, in the time before the Displaced Worker Supplement to the CPS, displaced workers were often identified as those workers being fired or unemployed in declining industries, local labor markets, or occupations. This is, however quite a broad category. With the introduction of the Displaced Worker Supplement, the questioning used to identify displaced workers in the survey became a focal point of a definition. According to the Displaced Worker Supplement a worker is considered displaced if he filled in that he lost his job due to "a plant closing, an employer going out of business, a layoff without recall, or some similar reason." ${ }^{2}$ This is close to the general definition which Kletzer (1998, p. 116) suggests: "The definition of a displaced (or dislocated) worker in the survey attempts to implement the common understanding of this term. Displaced workers are understood to be individuals with established work histories, involuntarily separated from their jobs by mass layoff or plant closure (rather than because of individual job performance), who have little chance of being recalled to jobs with their old employer." However, slight differences in other surveys exist and can result in differences in estimation outcomes.

The definition of a displaced worker is easier in case studies, as they are usually based on plant closures, hence all workers are displaced. Similarly, administrative data, observing workers attachment to plants can identify displacement as plant closure ${ }^{3}$ or based on a large-scale downsizing. ${ }^{4}$

\footnotetext{
${ }^{2}$ DWS, as it was quoted in Seitchik (1991, p. 51).

${ }^{3}$ However, the administrative data sometimes indicates 'false plant deaths', see Kuhn (2002, pp. 1314).

${ }^{4} \mathrm{~A}$ large-scale downsizing is often identified by a reduction in workforce of 30 percent or more. This 'rule' is introduced by Jacobson, LaLonde and Sullivan (1990) who pioneered the research of displacement using administrative data. The definition per se is ad hoc, but they show some sensitivity results using different definitions. Over time, the 30 percent rule was adopted by other researchers
} 
The strict definition of displaced workers will be used in the context of this thesis. We will only use those workers that were laid off as the result of the bankruptcy and subsequent plant closure.

In this chapter we will review the findings of earlier studies of displaced workers. In the following section we will investigate the data (sets) used in empirical studies of displacement. The second section will discuss the methodology used to investigate displaced workers, while the third and final section discusses the results of earlier studies and open questions.

\subsection{Empirical Studies of Displacement}

The influence of displacement research and labor market data collection has always been a reciprocal one. While in the early 20th century, researchers collected data on case and industry studies as an indication of the importance of the displacement issues, the discussion of economists already focusses on the possibility of collecting representative, nationwide data in order to investigate the issue further. ${ }^{5}$ After World War II, due to increased trade, a renewed policy interest in the 'displaced' workers losing from free trade emerged.

\subsubsection{Case Studies}

The first displacement studies were all based on case or industry studies. At those times no representative (labor) panels existed. ${ }^{6}$ Economists who wanted to study the result of worker displacement had to resort to primary data collection. There are many case studies on plant closures and displacement, however most of them were only published in policy reports or books and are therefore not easily available. I will review some pre-World War II case studies, and touch upon the case studies around the closure of the meat-packing plants in the 1950s and 1960s.

\section{Durham hosiery workers}

De Vyver (1940) examines the job search of the 381 displaced workers when the Durham Hosiery mill was closed in December 1935. As this is the one of the earliest, detailed

working with administrative data.

${ }^{5}$ See for example Jerome (1932) for an early call to collect nationwide, plant level data for this purpose.

${ }^{6}$ However, Jerome (1932) suggest collecting data both on workers and on investments and mechanizations of firms to study the technology induced worker displacement. 
Table 2.1: Durham Workers: In and Out of Sample

\begin{tabular}{lrrr}
\hline & number & male & female \\
\hline Displaced workers (traced) & 381 & 147 & 234 \\
Transferred before closing & 71 &. & . \\
Temporary or colored workers & 22 & . & . \\
\hline Total workers in September 1935 & 474 & &
\end{tabular}

Notes: Based on De Vyver (1940, p. 106).

case study of a plant shut-down that is published in an economic journal, I will describe it in more detail. The case at hand is also similar to the plant closure that is central to this dissertation in that we use administrative data of the firm to find workers, but also as information in evaluating the survey results.

The company had decided to permanently discontinue the manufacturing of 'ladies seamless cotton hosiery'7, affecting a chain of hosiery mills located in and around Durham, North Carolina. De Vyver (1940, footnote 1 on page 105) notes with respect to the general applicability of the results that "[t]he Durham hosiery workers, therefore, became unemployed during a period when Durham's other industries were experiencing a general increase both in employment and in total wages paid. It is probable, therefore, that the picture here presented is less drastic than a composite study of many shutdowns would be." However, he notes that the " results of the investigation might well be added to data gathered elsewhere in order to ascertain how long a time is likely to elapse between technological unemployment and absorption into a new position." His interest was especially with respect to the newly introduced unemployment insurance laws, which were supposed to support workers through such a transitory period. From the pay-roll records of "one week in September, 1935, before the number of employees had been reduced in anticipation of the shutdown", names and addresses as well as other useful information concerning the then 474 employees were copied. Two years after the shutdown the 381 workers were traced and interviewed about their new job, how long they had been employed, and how long they had been unemployed. The group of workers was - compared to the average American workforce - somewhat younger and had a higher percentage of female workers. Most workers found employment in the same or similar occupations, however, not all in permanent positions. Some female workers left the labor force whereas some men returned to work on their farm (cf. Table 2.2).

The incomes earned, two years later, were higher for the majority of workers. 50.75

\footnotetext{
${ }^{7}$ Hosiery are socks and stockings.
} 
Table 2.2: New Jobs Two Years After Closing of the Durham Mills

\begin{tabular}{|c|c|c|c|}
\hline & Number & Category perc. & Total perc. \\
\hline \multicolumn{4}{|c|}{ Regular Jobs } \\
\hline Textile operations or related trade & 191 & $67.25 \%$ & $50.13 \%$ \\
\hline Other & 35 & $12.32 \%$ & $9.19 \%$ \\
\hline Farmers & 15 & $5.28 \%$ & $3.94 \%$ \\
\hline Housekeepers & 43 & $15.14 \%$ & $11.29 \%$ \\
\hline Subtotal & 284 & $100.00 \%$ & $74.54 \%$ \\
\hline \multicolumn{4}{|c|}{ Temporary Jobs } \\
\hline Textile operations or related trade & 22 & $52.38 \%$ & $5.77 \%$ \\
\hline Other & 10 & $23.81 \%$ & $2.62 \%$ \\
\hline Odd Jobs & 10 & $23.81 \%$ & $2.62 \%$ \\
\hline Subtotal & 42 & $100.00 \%$ & $11.02 \%$ \\
\hline Unknown & 55 & $100.00 \%$ & $14.44 \%$ \\
\hline Total & 381 & & $100.00 \%$ \\
\hline
\end{tabular}

Notes: Based on De Vyver (1940, pp. 109-111).

percent claimed to have a higher income in the new job, 13.93 percent reported no change, whereas 35.52 percent reported a decrease in earnings. This is based on a total of 201 workers reporting their wages. Most of the new jobs were found in Durham County, only 11 former workers had moved permanently out of the municipality. Male workers searched for an average of five months while being unemployed, whereas woman searched on average eight months. Older workers did not have more difficulties in finding a job, with the exception of those older than 55 years.

\section{Technological change in the printing industry}

Baker (1930) describes in detail the process of increased mechanization in the printing industry in the United States in the early years of the 20th century, to examine how realistic the fear of technology induced displacement, or so called "technological unemployment" is [p. 442]. She investigates the adoption of new machines and the constellation of employment in 36 plants representative of the New York printing market. This is done over a five year period spanning from 1924 to 1929. While she finds that increased mechanization does not lead to a total decrease in employment in the firms, the workers most affected by the technological advancement, printing assistants, experienced lower employment. In a follow-up study she compares the New York and Chicago 
situation of printing in the period from 1924-1930. Chicago was less unionized and had bigger printing plants than New York, but was overall smaller in market-size. Baker (1933) finds that the unionized plants in New York indeed retard mechanization slightly, while the plants with low union-coverage in Chicago adopt the new technology faster, hence displacing more printing assistants. However, the results of plant profitability are ambiguous and it is not certain which approach yields higher overall returns.

\section{Shutdown of meatpacking plants}

In the post World War II period, several meat-packing companies rationalized their operations. Shultz and Weber (1966) and Bradburn (1964) examine the result of these structural adjustments in the meat-packing industries. In Bradburn (1964) no attempt was made to pin down specific wage losses, but rather a general discussion of the incidence and the reactions to the job loss is given. Workers are followed in their decision to relocate, or to stay within the same municipality. On an industry wide level Shultz and Weber (1966) summarize the effects of the meat-plant closings. They give an overview of various instruments used to cushion workers from the effects of displacement. They advocate the use of local aid to worker placement within the municipalities and are critical of any 'preferred' treatment of presumably disadvantaged groups.

\section{Job search assistance}

Steinberg and Montfort (1987) use data that were generated from experiments of job search assistance and training at several plants of Michigan car suppliers. Of the closing plants, two are randomly selected into an experiment of retraining and placement, while two other plants serve as a control group. Two years after the plant closure a survey is conducted to extract the labor market history of a sample of workers from all plants. They examine outcomes in search time for the four plants.

They find that tenure rather than age has a large impact on the duration of search. They attribute this finding to the firm-specific knowledge embodied in workers with longer tenure. Then, higher tenure increases the pre-displacement wages to a level above outside offers - due to the firm specific knowledge - and if reservation wages are pegged to this wage, unemployment durations are likely to be longer (Steinberg and Montfort 1987, p. 201). They find that overall the program substantially reduced unemployment durations. 


\section{Mine closures}

The mine closures in the Province of Limburg in the Netherlands from 1967-1974 also resulted in an investigation into the social consequences of the closure on the mining district (see (Mesing 1988)) This was based on aggregated data and expert interviews. The initial downsizing of the workforce and the closure of several mines around 1967 went relatively smoothly through early retirement and placement into alternative jobs. However, further restructuring that led to the final closure of the last mines in December of 1974 have had a significant impact on the labor market in Southern Limburg. While the government attempted to 'reconstruct' the industrial base in the area, the outcomes were mixed and the unemployment in the region remained high for a prolonged period.

\section{Fokker}

While the mine closures encompassed probably the largest overall workforce reduction in the Netherlands, this was done over almost a decade. The bankruptcy of Fokker N.V. lead to what is probably the single largest displacement in the economic history of the Netherlands. On the day of the bankruptcy, 5664 workers were employed in those parts that were closing down. A study of the consequences of this displacement will be presented in this thesis. It is based on 10 years of pre-displacement data, as well as three years of post-displacement labor market information.

\subsubsection{Socio-Economic Panels}

All U.S. based displacement papers — with the exception of case or industry studies either use the Displaced Worker Study (DWS), the Current Population Survey (CPS), the Panel Study of Income Dynamics (PSID), or the National Longitudinal Study of Income (NLS). One notable exception is the paper by Jacobson et al. (1993), ${ }^{8}$ which uses unemployment insurance records. This paper has had its influence on the European literature, as it offered an alternative route towards studying the displacement question, especially if no suitable panel of income and displacement (as the DWS) is available. It commenced the use of administrative data in this literature. We will first summarize the socio-economic panels used to study displacement and then investigate the administrative data that have been used..$^{9}$

\footnotetext{
${ }^{8}$ This study is described in more detail in Jacobson et al. (1990).

${ }^{9}$ Tables 2.3 and 2.4 summarize the US and European data, respectively.
} 
Table 2.3: U.S. Data-sets

\begin{tabular}{lll}
\hline Data-set & Observation & Time period \\
\hline CPS & 250,000 persons & $1940-$ \\
Displaced Worker Supplement & 250,000 persons & $1984-$ \\
PSID & 40,000 persons & $1968-$ \\
NLS & 5,000 persons per cohort & $1966-$ \\
\hline
\end{tabular}

\section{CPS and Displaced Worker Supplement}

The Current Population Survey (CPS) collects since the 1940s monthly labor data of a representative sample of 48,000 households. The main purpose of the survey is to collect information on the employment situation, information on demographic characteristics such as age, sex, race, marital status, educational attainment, family relationship, as well as job related information such as occupation, and industry. The survey rotates and refreshes the sample every other year, making it difficult to use in longitudinal research. In the supplement of displaced workers gathered in 1984, 1986, 1988, 1990, 1992, workers are asked about displacement experience in the previous five years, whereas from 1994 onwards, this recall period is shortened to a 3 year period.

One problem of the CPS supplement is that it only records one job-loss. If multiple job losses occur, the respondent is asked about the job loss on the longest job held (Farber 1999b, p. 61). Besides the change of recall period in the 1994 redesign, the - for displacement research important - answer categories of reasons of job loss were also altered. In the 1984-1992 DWS six responses were allowed (1) plant closing, (2) slack work, (3) position / shift abolished, (4) seasonal job ended, (5) self-employment ended, and (6) other. All workers that suffered a job loss were asked to fill in the supplement. From 1996 onwards, only those answering (1), (2) or (3), were asked the supplement questions. Farber (1999b, p. 67) is especially concerned about the increase in the "other" category (6), not being interviewed. A significant amount of respondents choose this answer and were not interviewed. Further, Topel (1990) showed, using both the PSID and the CPS $(1982,1984)$ data that the Current Population Survey tends to overestimate the wage losses. He attributes this to the recall bias of the (then five year long) recall period: shorter and less severe displacements might already have been forgotten when the CPS collects data. Therefore, only severe displacement experiences enter the data. This is confirmed by an extensive study of Evans and Leighton (1995), who use the overlapping nature of the CPS supplement to investigate recall bias of displacement at several points in time. They show that there is an underestimation of 
the displacement incidence by 30 to 40 percent, and that this is not randomly distributed over population groups. Particularly those groups most affected tend to underreport displacement.

\section{PSID}

While the PSID was initiated in 1968 as a short term longitudinal poverty study (five years), it was decided to use a nationwide probabilistic sample of the American population. ${ }^{10}$ The focus of the survey was on income dynamics, initially including sociopsychological measures as well as economic and demographic variables. Due to its success, in 1972 it was decided to prolong the study. The study is household based, and started out with a representative sample of 5000 households, which increased over the duration of the study, as it tried to follow all members of the household investigated. The study collects data annually. There was a split sample to investigate poverty, sampling 2500 of the households to be at or below 150 percent of the poverty line, while the other 2500 households were representative of the U.S. society as a whole. ${ }^{11}$ Currently, nearly 8000 households are followed, yielding a total of 40000 persons followed, from initially 18000 in 1968. From the mid-80s continuous employment and income histories were compiled within the PSID, which increased its value for many economist interested specifically in income and income dynamics. It has a long time series of income, ${ }^{12}$ work and demographic information.

The length of the observation period and the specific question whether a job was lost due to plant closures made the PSID an interesting data set for displacement research. However, the major drawback of this data-set for displacement research is the small number of displaced workers. Hamermesh (1987) and (1989a), Ruhm (1991), Berry, Gottschalk and Wissoker (1998) and Magnani (2001) have all used the PSID in displacement research.

\section{NLS}

The National longitudinal study is collected by the Census Bureau and the Center for Human Resource Research (CHRR) at Ohio State University. The first set of surveys, initiated in 1966, consisted of four cohorts. They are referred to as the 'older men',

\footnotetext{
${ }^{10}$ The information on the PSID is based on a Brown, Duncan and Stafford (1996) and information on the PSID web-site. See <http://www.isr.umich.edu/src/psid/overview.html> .

${ }^{11}$ Sampling weights are available to adjust for the over-representation of low income households.

${ }^{12}$ The income is a monthly time series sine the $1980 \mathrm{~s}$.
} 
Table 2.4: European Data-sets

\begin{tabular}{llll}
\hline Country & Data-set & Observation & Time period \\
\hline \multirow{2}{*}{$\begin{array}{l}\text { Belgium } \\
\text { Britain }\end{array}$} & Social Security Administrative Data & $3800-6471$ & \\
& British Household Panel Survey & 8000 & $1985-$ \\
Denmark & JHPS) & & $1991-$ \\
France & Annut Governmental Database & all residents & $1980-$ \\
Germany & IAB & $1 / 25$ th of French population & $1976-1996$ \\
& GSOEP & 200,000 & $1975-1990$ \\
Netherlands & UI longitudinal data (UI) & 3600 households & $1984-$ \\
& Labour Force Survey (LFS) & 209,478 & $1992-1993$ \\
& Firm Employment Data (FE) & 4020 & $1985-1990$ \\
& 26,000 & $1992-1996$ \\
\hline
\end{tabular}

'mature women', 'young men', and 'young women' cohorts of the NLS. Each of these cohorts encompass about 5,000 persons. In 1979, a longitudinal study of a cohort of young men and women aged 14 to 22 was initiated, the so called National Longitudinal Survey of Youth 1979 (NLSY79). In 1997, the NLS program was again expanded with a new cohort of young people aged 12 to 16 as of December 31, 1996. This new cohort is the National Longitudinal Survey of Youth 1997 (NLSY97).

Data about schooling, career, marriage and fertility, training investments, child-care usage, as well as drug and alcohol use are gathered. The depth and breadth of each survey allow for analysis of an extensive variety of topics such as the transition from school to work, job mobility, youth unemployment, educational attainment and the returns to education, welfare recipiency, the impact of training, and retirement decisions.

The effect of displacement on older men is done by Shapiro and Sandell (1985) using the fact that the NLS has a cohort of older workers. Maxwell and D'Amico (1986) use the NLS to estimated displacement wage losses for men and women. Using the separate data-sets for men and woman from the same cohort, they show that males have higher chances of becoming displaced. However, once displaced, they also recover more quickly towards their initial labor market situation. Krashinsky (2002) uses the NLSY data-set to confirm the adverse selection model of Gibbons and Katz (1991).

\section{GSOEP}

Since 1984, the German socio-economic panel (GSOEP) has been collected. It is similar in content to the American PSID as it is a representative longitudinal study of private households. It provides information on all household members, consisting of Germans 
living in the West- and since the reunification together with an added sample for the East-German states. Foreigners and recent immigrants to Germany are also included. In 1998, there were more than 6,600 households, and more than 12,700 persons sampled. Besides the administrative data of the German 'Bundesanstalt für Arbeit', this is the only data-set used for German displacement research. Couch (2001) uses this data-set to investigate wage losses in Germany. Burda and Mertens (1998) combine both the GSOEP and an early version of the IAB (Administrative) data to investigate displacement wage losses in Germany. The GSOEP is used in their study to identify displacement in the IAB data. Displacement is identified by a question on the reasons for a job change or loss that was included in the GSOEP from 1992 onwards. A respondent is assumed to be displaced if he indicated that he lost his job because "the company closed down, was laid off" (Couch 2001, p. 562). ${ }^{13}$

\section{BHPS}

The British Household Panel Survey (BHPS) is the U.K. socio-economic panel. It is collected by the Institute for Social and Economic Research at the University of Essex. Since 1991, a representative sample of 5,000 households is surveyed about demographic and household characteristics, household organization, labor market, health, education, housing and consumption, income, social and political values. Borland, Gregg, Knight and Wadsworth (2002) use these data to estimate wage losses and incidence of displacement for the United Kingdom.

\section{CSB Belgium}

The Belgian socio-economic panel is worked out by the Centre for Social Policy, University of Antwerp (UFSIA). Since 1985, a sample representative of Belgian households and individuals is available. There were 6471 individuals in 1985, and 3800 in 1992 (including a refreshed sample of 900 households). It collects demographic characteristics, activity status, employment situation, monthly (net) income of all household members, household wealth, housing situation, life-style indicators, subjective income evaluation. Albæk, van Audenrode and Browning (2002) use this data-set to investigate displacement effects in Belgium.

${ }^{13}$ It is unclear, however, whether this means 'laid off because of plant closure', or 'plant closure and/or laid off'. 
Table 2.5: Displacement Definition in European Data-sets

\begin{tabular}{|c|c|c|c|}
\hline Country & Data-set & Displacement Definition & Income Definition \\
\hline Belgium & CSB & $\begin{array}{l}\text { All the workers who separate from } \\
\text { a firm where employment has been } \\
\text { reduced by } 30 \% \text { or more during the } \\
\text { reference year and which had more } \\
\text { than } 5 \text { employees before the layoffs } \\
\text { started. }\end{array}$ & $\begin{array}{l}\text { Annual earnings con- } \\
\text { ditional on employ- } \\
\text { ment }\end{array}$ \\
\hline Britain & BHPS & $\begin{array}{l}\text { Workers who lost a job in declining } \\
\text { industries }\end{array}$ & $\begin{array}{l}\text { Annual conditional } \\
\text { on employment }\end{array}$ \\
\hline Denmark & Adm. Data & $\begin{array}{l}\text { All the workers who separate from } \\
\text { a plant where employment has been } \\
\text { reduced by } 30 \% \text { or more during the } \\
\text { reference year and which had more } \\
\text { than } 5 \text { employees before the layoffs } \\
\text { started. }\end{array}$ & $\begin{array}{l}\text { Annual conditional } \\
\text { on employment }\end{array}$ \\
\hline France & Ann. Soc. Data & $\begin{array}{l}\text { All workers leaving within one (two) } \\
\text { years of 'death' of a firm are consid- } \\
\text { ered displaced }\end{array}$ & $\begin{array}{l}\text { Total average real } \\
\text { daily earnings } \\
\text { weighted by the } \\
\text { number of days } \\
\text { worked in the par- } \\
\text { ticular job }\end{array}$ \\
\hline \multirow[t]{2}{*}{ Germany } & $\mathrm{IAB}$ & $\begin{array}{l}\text { Identify plant closure: number of } \\
\text { employees drops to zero; } \\
\text { displaced workers are those leaving } \\
\text { a plant that closed down within one } \\
\text { (two) years }\end{array}$ & $\begin{array}{l}\text { Earnings of dis- } \\
\text { placed workers who } \\
\text { have been unem- } \\
\text { ployed for at least } \\
\text { one week }\end{array}$ \\
\hline & GSOEP $+\mathrm{IAB}$ & $\begin{array}{l}\text { Involuntary separation is identified } \\
\text { directly in GSOEP (self reported), } \\
\text { and is interpreted as displacement; } \\
\text { In IAB identification is through Pro- } \\
\text { bit prediction from GSOEP data }\end{array}$ & $\begin{array}{l}\text { annual income of all } \\
\text { displaced who had } \\
\text { positive unemploy- } \\
\text { ment spell }\end{array}$ \\
\hline \multirow[t]{3}{*}{ Netherlands } & OSA FE & $\begin{array}{l}\text { Separations labelled as layoffs and } \\
\text { separations from shrinking firms }\end{array}$ & n.a. \\
\hline & OSA LFS & $\begin{array}{l}\text { Layoffs for business and economic } \\
\text { reasons }\end{array}$ & hourly wage data \\
\hline & UI Data & $\begin{array}{l}\text { Unemployment insurance inflow } \\
\text { (minus sanctions responsibility job } \\
\text { loss) }\end{array}$ & n.a. \\
\hline
\end{tabular}




\section{Dutch OSA data}

The OSA labor force panel (LFS), was first conducted in 1985. It is a interviewerconducted, biannual panel survey among a representative sample of around 2000 households, yielding somewhat more than 4000 workers. Layoffs can only be identified for business and economic reasons. In the data set hourly wage data is available. The biannual OSA firm employment (FE) panel studies labor demand. It was first conducted in 1989, among approximately 2500 firms and institutions. The time period 1992-1996 encompasses some 26000 workers. Separations labelled as layoffs and separations from shrinking firms. Abbring, van den Berg, Gautier, Gijsbert, van Lomwel, van Ours and Ruhm (2002) use both panels and some administrative data from unemployment insurance institutions to estimate wage losses, incidence and search duration of displacement.

\subsubsection{Administrative Data}

The use of administrative data was initiated in the realm of displacement research by a seminal paper of Jacobson et al. (1993). They combined unemployment insurance (UI) data with information from a survey to investigate the dynamics of wage changes before and after displacement. This spurred research on similar data-sets both in the United States and in Europe. It pushed government agencies to consider how to publish the administrative data in such a way that they can be used for research while insuring the protection of the individuals privacy.

\section{Pennsylvania and California unemployment insurance data}

Jacobson et al. (1993) combine information from the unemployment insurance data with information from quarterly firm reports. These data give a complete and unbiased picture of the earnings and employment situation of workers, and by identifying workers of the same plant, they are able to reconstruct the evolution of employment and wages by plant. They are able to observe up to six pre-separation years and up to seven postseparation years. The use of unemployment insurance data allows the construction of data-sets with huge sample sizes and includes workers that are not displaced as a control group. The identification of displacement is done through the definition of 'mass layoff' separators, for which they choose a downsizing of the workforce by 30 percent or more. This has to be done as no information on the reason for worker separation is given in the data-set. There are, of course, also several shortcomings of the data. First of all, the information on the worker and the firm is not detailed. Only crude demographic variables 
for the workers are known. Further, workers that leave the state of Pennsylvania can also not be observed. Finally, the lack of information on the separation forces Jacobson et al. (1993) to define displacement with a 'mass-layoff' indicator. There are several reasons why this could not be a displacement in the strict sense. Some laid-off workers could be part of the 'displacement sample', biasing the results somewhat.

Schoeni, Dalia, McCarthy and Vernez (1996) construct a similar data-set for California. They used wage files and unemployment income files provided by Californias Employment Development Department covering six years during which the state suffered the brunt of the defence downturn. These statistics allowed the tracking of wage, employment, and demographic characteristics of each individual aerospace worker who was employed in California in 1989. In total 517,000 aerospace workers were followed! In a similar fashion a comparison group of 315,000 people who were employed in similar durable goods manufacturing jobs in non-aerospace industries in California was constructed.

For each quarter they have information on each workers quarterly wages, industry of employment, participation in unemployment insurance, and the number of weeks he received unemployment insurance. Furthermore, only age, sex, and ethnicity are available for workers who have ever received unemployment insurance.

\section{European administrative data}

Following the lead of Jacobson et al. (1993), several administrative data-sets were also made available and used in European countries. In France there is a data-set of $1 / 25^{\text {th }}$ of the entire employed working population, which can be combined on the plant level. Germany has the 'IAB-Stichprobe', which is based on the unemployment insurance information and some information on the plants that employ workers. The public use file has, however, only few (demographic) variables of a worker. Abbring et al. (2002) also combined unemployment insurance information on a plant level for two years to investigate displacement effects. However, these data also suffer from limited information on the worker. The most extensive administrative data-set is probably the administrative data from Denmark. It follows the entire population. While the individual information was limited at first, information is subsequently added and information from several surveys are linked to the administrative data. 


\subsection{Methodology}

There are three approaches to the question of worker displacement. The 'old' studies of plant closures are of a case study character analyzing only a single plant closure, but following the worker's decisions in depth. They have the advantage of more detailed data, clear identification of the displaced workers, and the possibility to follow comparable workers of a single plant. On the other hand, these studies are not representative for the entire economy, but rather analyze the decline of a specific firm. To our knowledge there is no comparable case-study approach comparable to the U.S. studies done in the Netherlands nor in any other European country.

To get a broad, economy-wide picture there are two alternative data sources: employment panels and administrative data. For the U.S., the employment panels consist of the well-known panels of the Panel Study of Income Dynamics (PSID), the Displaced Worker Study (DWS). For Europe well-known panels are the German Socio-Economic Panel (GSOEP), the Dutch OSA-Panel and the British BHPS. The administrative data usually consist of unemployment insurance or unemployment agency data. For the American case a well known study is Jacobson et al. (1993) using unemployment insurance data from the State of Pennsylvania. In the European case, the German IAB data-set of the German national labor office, in France the five percent sample of the fiscal administrative data, in Belgium and in Holland the unemployment insurance data, and in Denmark the 'national' database of all inhabitants were used.

Both the panel and the administrative data have advantages over the case-study approach in that they are representative of the economy as a whole, and they often consist of both displaced and non-displaced workers, which facilitates the choice of a comparison group. However, this representativeness usually comes at a cost. With the exception of the displaced worker study, which was specifically geared to the question of displacement, it is not easy to identify displaced workers. Either a self-assessed evaluation of the reasons for discharge is asked to the respondent, or the category 'displaced' does not exist and has to be estimated through other means. Secondly, and this is mostly a problem with the administrative data, the information about the workers is often sketchy, and crucial variables are not available. The shortcomings of data have always lead to ingenious detours in order to overcome these defects. Hence there have been many solutions to the shortcomings especially in the European research which lacks the equivalent of the "Displaced Worker Study". Burda and Mertens (1998) for example use the German Socio-Economic Panel, which can categorize fired workers into displaced 
and not displaced, to predict the occurrence of displacement in the IAB data given the variables available in both data-sets. Abbring et al. (2002) use three data-sets for the analysis of displacement: an administrative longitudinal unemployment insurance data set to examine the unemployment spells and re-employment duration, a panel, Labor Force Survey (OSA Panel) for the demographic information and wage drop estimation of displaced workers, and the Firm Employment Data Set (again administrative records), to estimate the incidence of displacement in the Netherlands. Administrative data for Belgium and Denmark (Albæk et al. 2002) and France (Bender, Dustmann, Margolis and Meghir 2002) have been used to reconstruct mass layoffs on the firm or plant level by considering a worker to be displaced if the plant lays off $30 \%$ or more of its workforce.

\subsubsection{Estimation Strategy}

\section{Early 'case studies'}

The early case studies mostly tabulated the unemployment experience of workers, charting the number of unemployed and the duration of unemployment. Some, e.g. De Vyver (1940), even indicate the direction of wage losses. However, none of them use regression methods. Many of the studies are more interested in the experience of unemployment and the relocation or re-orientation of workers.

\section{Wage loss regressions}

Early displacement studies estimated wage loss regressions using basic Mincerian wage equations (Mincer 1974):

$$
\ln W_{i}=\beta_{0}+\beta_{1} \text { Education }+\beta_{2} f(\text { Tenure })+\beta_{3} f(\text { Experience })+\beta_{4} X+v_{i}
$$

where wages are the returns to investment in human capital, both through schooling and through learning on the job (captured by some function of tenure, usually quadratic) and experience, and where other demographic and job related variables are collected in $X$. Finally, $v_{i}$ is the individual error. Comparing wage equations before and after displacement allowed to examine wage losses. This was extended to allow for selection of workers that do not find employment (Heckman 1979), correcting for workers that were still unemployed at the date of the survey (Kletzer 1989). However, this approach was criticized for neglecting the general wage development of workers had they not been displaced. Hence, more recent studies included reference groups of employed workers, 
comparing the displacement experience to that of not-displaced workers with similar characteristics. For example, the estimation strategy includes both displaced and the 'control group' of all other workers in an annual wage equation as in e.g. Ruhm (1991) and Couch (2001) :

$$
\ln W_{i t}=\alpha_{i}+\gamma_{t} M_{t}+X_{i t} \beta+\sum_{k=b}^{K} D_{i t}^{k} \delta_{k}+v_{i t}
$$

where $\ln W_{i t}$ is the $\log$ of an individual wage, $\alpha_{i}$ is an individual fixed effect, $\gamma_{t} M_{t}$ is a set of time dummies, $X_{i t} \beta$ is a set of coefficients and variables describing the workers as e.g. schooling, age, etcetera, $\sum_{k=b}^{K} D_{i t}^{k} \delta_{k}$ is a set of dummy variables indicating the time after displacement up until the end of the observation period. And $v_{i t}$ is the individual error.

Berry et al. (1998) estimate an error components model of displaced earnings. They focus on large income losses. Based on their observation that "the empirical work shows that during the period of displacement mean earnings decline and variance of earnings increases sharply", they suggest looking at the shape of the earnings distribution. Specifically they propose that displaced workers may differ in their 'ability to adjust'. Secondly, the variance of earnings may change as workers may accept greater instability of earnings in order to maintain their prior mean level of earnings. Using PSID data and non-displaced workers as a control group in which they estimate the following

$$
\begin{gathered}
\ln W_{i t}=X_{i t} \beta+\mu_{i t} \\
\mu_{i t}=\delta_{i}+\nu_{i t} \\
\nu_{i t}=\rho \nu_{i t-1}+e_{i t}
\end{gathered}
$$

where the second line specifies the unobserved heterogeneity 'individual effect' and the third equation captures the time trend of the mean earnings. They estimate this using time dummies to indicate the time before, during and following displacement, each with separate variances. The variance of income is found to increase during a displacement period, to level off towards the former pre-displacement levels two years after displacement.

Carrington and Zaman (1994) extend the model by looking into the differences across industries. They estimate the wage loss regressions separately for different industries. Neal (1995) extends this idea by looking at the transferability of knowledge of displaced 
workers. He uses tenure within the industry to measure industry specific knowledge and establishes that part of the skills can be transferred within the same industry.

The 'scarring' or lasting effect of displacement was introduced by Ruhm (1991). This is extended by Stevens (1997) to a longer time period of six years. The explanation for the persistent effect can be found in the quality of jobs that are often temporary or even part time. ${ }^{14}$ The types of jobs worker find after displacement is examined in some recent papers by McCall (1997) and Farber (1999a). McCall examines the choice between parttime and full-time employment following displacement in Canada. Women are found to have higher chances of part-time employment after displacement. Also, those workers that find work within a year of displacement have a higher proportion of part-time employment. Farber (1999a) shows that job losers in the U.S. also use "alternative and part-time" employment to cover the first period after displacement. As time goes by, the likelihood of holding these types of jobs diminishes.

\section{Adverse Selection Model}

Gibbons and Katz (1991) suggest an adverse selection model of firm hiring, in which the lay-off of a single worker contains a negative signal about the quality of the worker. This implies that lay-offs which are not selective, should not encompass this signal. Hence, displaced workers, being laid-off due to a plant closure (rather than for cause), should suffer lower wage losses than workers that were laid-off without a plant closure. They test their model using the Displaced Worker Supplement of the CPS $(1984,1986)$ and find that the displaced workers fare indeed better than workers who were simply laid off. Doiron (1995) and Grund (1999) confirm this result for Canada and Germany, respectively. Krashinsky (2002) uses NLSY data and confirms that displaced workers have slightly lower losses. However, due to the small sample size of 167 displaced workers versus 770 workers that were laid off, no significant differences could be found.

\subsection{Search Time and Wage Losses}

While the investigation into the displacement wage losses contains by now an extensive body of literature it mainly remains limited to investigations of displacement in the U.S. labor market. Few studies formally investigate the duration of unemployment. While job

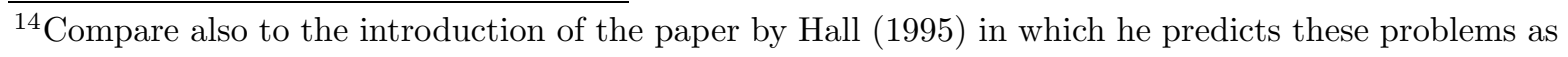
a result of displacement.
} 
search and wage losses seem to be interrelated no attempt to simultaneously investigate issues of search time and wage losses have been performed.

\subsubsection{U.S. Studies}

\section{Duration of Job Search}

One of the early studies that explicitly investigates the duration of displaced workers' job search are Kruse (1988), Podgursky and Swaim (1987), as well as Swaim and Podgursky (1990, 1991). Kruse (1988) investigates the duration of joblessness of displaced workers. He is especially interested in differences between import-competing versus non-import competing industries. On average he finds that the estimated median unemployment duration is between 38 and 41 weeks. A higher import share in the industry results in a 1.25 week increase in median duration of unemployment. Podgursky and Swaim (1987) examine the duration of joblessness for workers displaced from full-time nonagricultural jobs between 1979 and 1981 in the United States. They find that particularly the blue collar workers with lower than average education search longest. Swaim and Podgursky (1990) develop a 'sequential-regimes job search model' which allows for search prior to displacement for workers with advance knowledge of layoff, and with different search intensities before and after layoff. This enables a thorough investigation into the impact of advanced notice on the duration of job search for displaced workers. Advance knowledge is found to significantly shorten jobless duration for most labor force groups. Swaim and Podgursky (1991) estimate that the median workers has a unemployment duration of 25 to 30 weeks following layoff.

In the attempt to examine the effect of advanced notification several studies compare the duration of unemployment for displaced workers with or without advanced notice. Ruhm (1992) examines how pre-notification of displacement decreases the postdisplacement joblessness. While he finds a small increase in the chance of avoiding unemployment, it does not reduce search duration significantly. Ruhm (1994) shows that the pre-notification obtained by some displaced workers significantly increases their post-displacement earnings expectations. However, the qualification is made that the written notice is often given by those employers who also offer other assistance. Friesen (1997) exploits differences in the legislation on advanced notification across provinces in Canada. She examines the differences between jobless survival rates among displaced workers to establish the impact of advanced notification on jobless duration. She shows that the existence rather than the duration of an advance notice affects the subsequent 
chances of finding new employment quickly.

\section{Wage Losses}

The U.S. Studies of the 1970s and 1980s are summarized in Hamermesh (1989b). Table 2.6 summarizes the findings. In general some wage losses were found by workers, increasing with tenure and dependent on the occupation or industry.

A more recent survey of the U.S. displacement literature can be found in Fallick (1996). A review of the findings and consequences of displacement based on the American literature can be found in Kletzer (1998). In the recent literature it is noted that the average earning losses hide the fact that the result of displacement can be quite heterogeneous with respect to wage losses. As Kletzer (1998) concludes for the United States:

"Over the period 1981-95 real weekly earnings were 13 percent lower than pre-displacement earnings (Farber, 1997). This average masks considerable heterogeneity: approximately one-third of workers report earnings losses of 25 percent or more, while 30-40 percent report earning more on their postdisplacement job than on their pre-displacement job."

Hence, the more recent literature tries to attribute the wage losses found to worker or search specific outcomes. One example is the investigation of (partial) transferability of human capital: Neal (1995) estimates the losses of displaced workers, including a choice of changing industries. He shows that changing industries increases wage losses. This can be seen as the loss of industry specific human capital. Another example is Stevens (1997) who shows that wage losses are often the result of repeated job losses after the displacement. Looking over the entire duration of the PSID, she shows that the wage losses are persistent over time, at about 9 percent below the expected level had the worker not been displaced. She attributes those changes to repeated job losses after displacement. 
Table 2.6: Survey of Studies of Displacement

Study and Sample

Bale (1977)

Trade-displaced, 1969-1970,

interviewed in 1972

Corson and Nicholson (1981)

Permanent layoff, 1976,

interviewed in 1978-1979

Addison and Portugal (1989)

DWS, 1979-1984, full-time

Kletzer (1989)

DWS, only plant closing or position abolished

Kruse (1988)

DWS, 1979-1984,

full-time manufacturing

Madden (1987)

DWS, 1983, displaced

Podgursky and Swaim (1987)

DWS, displaced 1979-1982

Hamermesh (1987)

PSID, 1977-1981, only plant closing

Ruhm (1991)

PSID, 1971-1981, job loss, others

Blau and Kahn (1981)

NLS young men, young woman, 1969-1972, permanent layoffs, others
Results

Social loss $=\$ 1,200-\$ 7,600$ (in 1972 dollars)

Increased unemployment duration with tenure; earnings loss $=\$ 9,000$ (in 1978 dollars)

Greater wage loss with tenure, industry, or occupation change (but not location change); no age effect; negative unemployment duration dependence

Greater wage loss with tenure (but some effect of tenure on post-wage except for blue-collar) among men

Increased unemployment duration with tenure, import penetration, among blacks, less educated

Greater wage loss of women, greater tenure, less education, change industry, white

Reduced unemployment duration if plant closing, if nonunion; negative duration dependence

Lost job-specific capital $=\$ 7,000$ (in 1980 dollars) wage-tenure profile unvarying before displacement

No permanent unemployment effect of job loss; no effect of age or tenure

Greater wage loss among men, whites; lower reemployment among blacks 
Table 2.6: Survey of Studies of Displacement (continued ...)

Study and Sample

Ruhm (1991)

DWS

Jacobson et al. (1993)

Pennsylvania UI

Carrington (1993)

Carrington and Zaman (1994)

Neal (1995)

DWS 1984-1990

Stevens (1997)

Chan and Stevens (1999)

HRS, older workers
Results

Finds lasting effect of displacement on income even after several years. Wage loss is estimated to be 10-13 percent four years after displacement

Losses amount to 25 percent of pre-displacement incomes.

Even in growing industries wage losses are significant. Using local controls wage losses average 2 percent for professionals to a high of 35 percent in the mining industries.

Mean reduction over all industries is found to be around 13 percent. Losses on pre-displacement tenure are particularly strong in the primary metal industry, and weak in the construction industry.

Per 10 years of experience with one employer; industry switchers have $21 \%$ and stayers $11 \%$ higher wage losses.

Persistent income losses. Six years after displacement, workers earn 9 percent lower wages than their expected non-displaced wages.

Finds wage losses of 19 percent and decrase in assets of $17,000-34,000$ Dollars

Notes: This table is an extended and updated version of Hamermesh (1989b, Table 2, page 57). DWS is the Current Populations Survey 'Displaced Workers Supplement'. HRS is the 'Health and Retirement Study'.

\subsubsection{European Studies}

The European literature on displacement is not as extensive as the U.S. literature. Only within recent decades several studies were published. One key contribution to the European displacement literature is a volume edited by Kuhn (2002), that reports empirical studies on displaced workers in Europe and several other industrialized countries. Most 
of the findings reported here for Europe are based on chapters from this volume.

\section{Duration of Job Search}

It is striking to see that a large proportion of the displaced workers move to a new job (almost) immediately. Depending on the scale of the observation period (months, quarter, year), some workers cannot be observed to be unemployed at all. Nevertheless, we can observe positive unemployment spells for those workers who were not fortunate enough to find a new job immediately. Kuhn (2002) finds a wide variation of unemployment duration at all across countries. Abbring et al. (2002) report that only 30 percent of displaced workers they observe in the Netherlands actually experience some joblessness, compared with 85 percent in the US. Similar pictures are found among displaced in Germany (39\%) (Bender et al. 2002) and in plant closures or shrinkages in Denmark (31\%) (Albæk et al. 2002).

\section{Wage Losses}

There have not been many studies on displacement wage losses in Europe. Albæk et al. (2002) found for Belgium a wage loss of 2.6 percent three years after the displacement. ${ }^{15}$ This should be compared to a wage gain of 6 percent for other job movers in the same period. The average wage level showed a loss of 8.8 percent, and that of the other job movers a loss of 3.7 percent. For Denmark, they found that annual earnings decreased by 8.3 percent three years post displacement, while other job-movers fared slightly better with a loss of 6.8 percent. The average wage level - however - increased slightly by 0.1 percent three years after displacement, whereas that of the other job-movers was 6.8 percent less compared to their previous pay.

Borland et al. (2002) calculates an earnings loss of 9.7 percent for all displaced workers. ${ }^{16}$ However they also show that the job-to-job displaced have only slight losses, on average 1.5 percent, whereas displaced workers who do not find employment immediately have losses of 14.6 percent on average.

Abbring et al. (2002) run wage regressions in which displacement is one of the explanatory (dummy-)variables. The wage regression predicts a wage gain of 0.3 percent for all displaced and of 4.9 percent for all displaced with a tenure of more than one year.

\footnotetext{
${ }^{15}$ This is conditional on finding new employment and based on annual employment, even if only partly employed.

${ }^{16}$ Here the earnings loss is defined as the difference between current job and the previous job, regardless of any intervening spell of unemployment.
} 
Table 2.7: Earnings Losses in Europe

\begin{tabular}{|c|c|c|c|c|}
\hline Country & Dataset & Comparison Group & $\begin{array}{c}\text { Displaced } \\
\Delta \text { Wage }(\%)\end{array}$ & $\begin{array}{r}\text { Comparison Group } \\
\Delta \text { Wage }(\%)\end{array}$ \\
\hline Belgium & Soc. Sec. Data & other job movers & -2.6 & 6.0 \\
\hline Britain & BHPS & none & -9.7 & \\
\hline Denmark & Gov. Data & other job movers & -8.3 & -6.8 \\
\hline \multirow[t]{7}{*}{ Germany } & IAB & continuously employed & -1.46 & 4.6 \\
\hline & & $\begin{array}{l}\text { wage regression } 1 \text { year } \\
\text { after displacement }\end{array}$ & 1.5 & n.a. \\
\hline & & $\begin{array}{l}\text { wage regression } 4 \text { years } \\
\text { after displacement }\end{array}$ & \pm 0 & n.a. \\
\hline & IAB+GSOEP & $\begin{array}{l}\text { compared to all employ- } \\
\text { ees }\end{array}$ & 3 & 4.7 \\
\hline & & wage regression & -3.64 & n.a. \\
\hline & GSOEP & & -13.5 & in 1 st year \\
\hline & ('91-'96) & & -6.5 & in 2 nd year \\
\hline Netherlands & LFS & wage regression & 0.3 & n.a. \\
\hline
\end{tabular}

Notes: All studies of the table work with a comparison group. Wage changes of displaced workers (col. 4) are to be evaluated relative to the wage changes of the comparison group (col. 5). 


\section{Literature}

Bender et al. (2002) found no wage loss for displaced workers that find a job within two years after displacement. However, they also found that workers who were displaced did have pre-displacement wage drops compared to other workers. Those workers who did not find a job two years after displacement have an additional (post-)displacement wage drop of 7.3 percent on average. For Germany they found a wage drop of 1.46 percent for those displaced workers who were at least one week unemployed, i.e. excluding the job-to-job displaced. This should be compared to a 4.6 percent increase in earnings for those continuously employed over the same period. However, they also note that the wage losses could be due to a composition effect of the displaced workers, since the effect of displacement almost disappeared in a wage regression correcting for worker characteristics. Only if the period of unemployment was longer than a year, a significant wage drop of 19 percent could be identified. These numbers can be compared to those of Burda and Mertens (1998), who identified displacement through a probit regression on the GSOEP, but used the same IAB data-set for the wage loss calculations. They identify a wage growth of 3 percent for the displaced, which should be compared to 4.7 percent wage growth of the continuously employed. Using a wage regression their dummy 'displaced' explains a wage loss of 3.64 percent. They also note that there are some workers having positive wage growth post displacement. The 1st quartile of the wage-region has positive wage growth if they get displaced, while all others have negative wage growth.

Couch (2001) estimates annual wage losses and the annual number of unemployed months based on the West-German GSOEP data from 1991-1996. The estimation strategy includes both displaced and the 'control group' of all other workers in an annual wage equation. Additionally a tobit estimation of the number of months unemployed was used. ${ }^{17}$ Couch finds that the reduction in earnings in the year of displacement amounts to 13.5 percent, ${ }^{18}$ which drops down to 6.5 percent of the pre-displacement earnings in the subsequent year. The number of months unemployed also increases significantly in the year of displacement and the year following displacement, to level off afterwards.

\subsubsection{Open Questions}

What we can conclude from these studies is that the outcome of displaced workers varies quite a lot between countries. However, these differences can be partly attributed to the differences in set-up between the studies. In general we can find some slight wage losses

\footnotetext{
${ }^{17}$ This is similar to Ruhm (1991).

${ }^{18}$ Only workers that eventually did find employment were used.
} 
for displaced workers compared to the wage-development of workers who did not lose their job. Compared to other job-movers the evidence is mixed, but if the comparison is with other 'fired' workers, usually the displaced workers fare better.

It seems also that the wage loss is significantly higher for those workers who are unable to find a new job within a certain time period. The big losses are associated with those who do not find a job within the first one to two years. However, estimation of wage losses combined with the duration of unemployment are usually not performed. The trade-off between searching longer or accepting wage losses at some earlier stage is thus in need of investigation.

Furthermore, there is some evidence that average wage losses hide a significant divergence in the distribution of losses (and gains), which remains unexplained. So far the transferability of firm or industry specific human capital has been established. However, this had to be done using the tenure within the firm or industry as a proxy for embodied human capital. Neal (1995)[pp. 669-670] already suggest to measure on the job level rather than using industries: "[T]he results $[\ldots]$ reflect the importance of skills that are not truly specific to given industries, but rather specific to a set of jobs that are associated with the intersection of certain occupations and industries."

Another area in which some insights have been won is the post-displacement employment relationships. Some of the wage losses can be attributed to inferior jobs or job arrangements. Alternatively, the new jobs are not as stable as the pre-displacement job, increasing the risk of subsequent unemployment.

There remains a large heterogeneity of wage losses and duration outcomes among displaced workers. Existing variables that were used explain only some part of the wage losses. In the chapters 7 and 8, we will use the detailed data on the career of the workers in one firm and the detailed information on their post-displacement labor market experience to shed some light on these open issues. In particular, the influence of a career and the position upon displacement on subsequent wage losses can be examined. Part of the returns to tenure are rewarded within a firm by a promotion to a higher position, which we can observe in our data. Further, we have information on the breadth of a workers positions, i.e. did a worker specialize or rotate over several different departments.

Given that we are dealing with one firm and that all workers are displaced at the same time ensures that no heterogeneity come forth from differences in firms or timing. Also, we can establish how the interaction among workers influences their post-displacement outcomes. 



\section{Monkey Bars and Ladders: Internal Labor Markets}

"[I]t can be said that the amount of mobility found, whether derived from any of the three mobility measures developed or from the study of life-time careers, was high. It was high in the sense that large numbers of workers would, in reflection upon their careers, have asserted that they had led successful, productive lives and reaped rewards in the form of enhanced standards of living and, in many cases, enhanced status. [...] It would be surprising, however, if there were not considerable intellectual returns from focusing our attention upon the two most prevalent characteristics of labor mobility, namely job changes within firms and the relative reluctance of workers to be mobile between firms. "

(Gitelman, 1966 , pp. 64-65) 


\subsection{Introduction}

An important impulse for the development of an "internal labor market" (ILM) literature within the labor economics literature was Doeringer and Piore's (1971) seminal work. They emphasized the institutional character of employment relations arguing that administrative rules and procedures, i.e. personnel policies, govern employment relationships. As a result, the pricing and allocation of labor that contrast sharply with the predictions of traditional labor economics. Part of this ILM literature has been devoted to study the design and effects of such personnel policies (e.g. Prendergast, 1993; Prendergast and Topel, 1996; Milgrom and Roberts, 1988), while a substantial body of the theoretical literature focuses on job ladders, career movements, promotions, and their relationship to compensation (e.g. Lazear and Rosen, 1981; Waldman, 1984; Gibbons and Waldman, 1999a). ${ }^{1}$

Despite a growing empirical literature that studies firm personnel records, theories of the internal workings of firms are still based on the little empirical evidence derived from personnel data available that record job positions and compensation in firms. Early exceptions include Osterman (1979), Medoff and Abraham (1980), Lazear (1992) and Baker, Gibbs and Holmstrom (1994a and 1994b). The most detailed empirical study of wage and career dynamics in internal labor markets so far is that of Baker, Gibbs and Holmstrom (1994a, b), who analyze a yearly panel of personnel data of management employees from a large U.S. company, which expands over the observation period. Many of their findings - including that career paths are important for the allocation of workers to jobs, that there is a substantial amount of wage variation within job levels in spite of the strong relation between hierarchical levels and compensation, and that there is no evidence of distinct ports of entry and exit as predicted by Doeringer and Piore (1971) - are confirmed by contemporary studies (e.g. Ariga et al., 1999; Seltzer and Merrett, 2000; Lima, 2000; Gibbs and Hendricks, 2001; Treble et al., 2001).

We complement this literature by analyzing ten years of personnel records from the Dutch aircraft manufacturer Fokker in order to assess whether these empirical "facts" are valid for a different firm, in a different industry, over a different period, and in a different economy. While doing so, we provide answers to a number of questions that were advocated by Gibbons (1997) to facilitate the composition of a broader picture of internal labor markets for which individual studies provide pieces of a puzzle based on firm-level data which are often collected in different ways and measure different variables.

\footnotetext{
${ }^{1}$ See Gibbons and Waldman (1999b) for a recent survey of this literature.
} 
We shed light on issues that have not been addressed in this literature so far: The exceptional feature that the data set covers an episode of corporate growth as well as an episode of corporate decline allows us to explore how personnel decisions of the firm differ between periods of growth and decline. We investigate the consequences of a changing corporate environment for promotion dynamics and organizational stability. We can distinguish between production workers on the one hand and managers and engineers on the other hand. We can thus examine whether the internal workings of the firm differ with respect to worker type. In addition, we can study whether such differences exist across different fields of activity within the firm, as for instance Production, R\&D, Sales \& Customer Relations or Administration. Finally, in contrast to existing studies, which commonly rely on year-end panel data, we analyze event history data which record the exact timing of all events related to wage or position changes. The knowledge of the exact timing of all events not only allows us to explore whether wage and position changes occur simultaneously, but it allows us also to look at all events that happen, including those that would remain hidden between two cross-sections of personnel records. Information that would be lost in yearly cross-sections turns out to be substantial, in particular with respect to temporary worker re-allocation and downward mobility.

Our main findings are as follows. Job mobility is substantial in our firm and an important determinant of wages. Although we find somewhat lower upward transition rates than related studies, we do observe a substantial number of lateral transitions. Job transitions are the major source for sustained wage growth as wages are strongly related to job levels, even though wage changes do not always occur simultaneously with upward job transitions. However, wages are not tied to jobs in a strict sense. Considerable wage spread is found in all job levels, and wage distributions of adjacent job levels overlap. We also find that downward mobility almost never results in nominal wage cuts, yet it frequently coincides with degradation in wage scales and hence a reduced prospect of future wage growth. Real wage decreases, on the other hand, are common, especially during downsizing when nominal wages are not changed for most workers for more than two years.

The chapter is organized as follows. Section 3.2 describes the firm and its personnel data. Section 3.3 depicts the hierarchical structure of the firm and the procedure used to identify those hierarchical levels. Section 3.4 analyzes the job mobility pattern. It portrays entry and exit as well as job transitions within the firm. Section 3.5 examines the relationship between wages and hierarchical job positions. Section 3.6 takes a closer look at wage growth and its relation to job transitions. Section 3.7 investigates career 
paths within the firm and shows that both careers across hierarchies as well as within hierarchical positions exists. Section 3.8 concludes.

\subsection{The Firm and its Personnel Data}

\subsubsection{The Firm}

We have personnel data from the Dutch national aircraft builder N.V. Fokker over the period from January 1, 1987, when the firm introduced its electronic personnel system, until March 15, 1996, when the firm was officially declared bankrupt. ${ }^{2}$ N.V. Koninklijke Nederlandse Vliegtuigenfabriek Fokker was structured in an administration unit (Fokker Administration B.V.), an aircraft production unit (Fokker Aircraft B.V.) with plants in three different locations as well as four other subsidiaries at different locations. The majority of the workforce was affected by the bankruptcy of the holding company, the production unit, and the administration unit, which formed the core business of aircraft manufacturing. The other viable parts of the firm did not enter the bankruptcy procedure and were eventually sold. Most of the organizational structure remained unchanged until the day of the bankruptcy, except for one division, Fokker Space, that was spun off in December $1995 .^{3}$

We analyze the data until the bankruptcy date. This might prompt the criticism that the firm is not a representative example of a downsizing firm as it fails eventually. This could be problematic if the demise was expected and if behavior was brought into line with the anticipation of the failure. However, there is reason to believe that the bankruptcy came suddenly and unexpectedly for most of the employees. ${ }^{4}$

\subsubsection{The Data}

We use information on each employee's job, compensation, and demographics. The job position file records every worker's job code, job title, organization code, organization

\footnotetext{
${ }^{2}$ The data were made available to us for academic purposes by the company's bankruptcy trustees. The report of the bankruptcy trustees is publicly available (see Deterink et al., 1997).

${ }^{3}$ Workers employed at this division leave our data files on that date.

${ }^{4}$ Most analysts expected even in September 1995 that Fokker would survive when the majority shareholders, the Dutch government and Deutsche Aerospace AG (DASA), started negotiating a bailout plan. A comment in the Wall-Street Journal on September 4, 1995, describes the market sentiment: "Few, however, expect DASA, the aerospace arm of German industrial giant Daimler-Benz AG, will let Fokker go bust. The Dutch company [...] fills a key niche in a market segment expected to show strong growth in the next few years." (du Bois, 1995)
} 
name, the activity his job belongs to, the plant name, as well as the starting and end date of all his job positions within the company during the observation period. The wage files contain information on the salary grade, the nominal wage rate, the start and ending date of the wage contract, the reason for a change in the wage contract, and a performance measure that refers to performance in the previous year. In addition, we know the schooling and the vocational degree of most employees. The file of demographic characteristics has the date of birth, gender, marital status, and the hiring date for every employee. We merged these raw data files into one event history data file. Since we know the exact timing of job changes and wage changes, we can detect whether job changes and wage changes occur simultaneously. Another advantage of our data structure is that we do not lose information about events that happen in the time-span between two cross-sections of panel data.

\subsubsection{Development of the Workforce}

The time period spanned by the data can be divided into a period of workforce expansion and one of workforce reduction. The number of employed workers with permanent contracts rises from 10275 in January 1987 to 12852 at the peak in February 1991. During the subsequent period, which is marked by a series of reorganizations with employment reductions and mass layoffs, the number of employed workers falls to 7141 on the day before the bankruptcy.

Figure 3.1 plots the number of workers employed at the beginning of each month from January 1987 until March 1996 stacked by ten broad activities into which jobs are categorized. Most workers are employed in one of the five production activities: Assembly (F), Support \& Supplies (G), Production Preparation (D), Planning \& Coordination (E), and Quality (M). Employment changes in production activities increasing steadily from 6684 workers in January 1987 to a peak of 8838 workers in June 1991, and then falling to 4651 workers on the day before the bankruptcy account for the largest part of the workforce expansion and the subsequent contraction. Employment in the three administrative activities Finances and Administration (K), Human Resources \& Support (H), and Management \& Information Processing (S) rises from 1966 workers in January 1987 to 2252 workers in February 1991 and falls subsequently to 1113 workers in March 1996. Employment in R\&D (C) and in Sales \& Customer Relations (B), on the other hand, grows for a prolonged period (peaking not until the second quarter 1993), and declines only moderately until the end of 1995. As a result, the employment share of 
Figure 3.1: Development and Composition of the Workforce by Activities

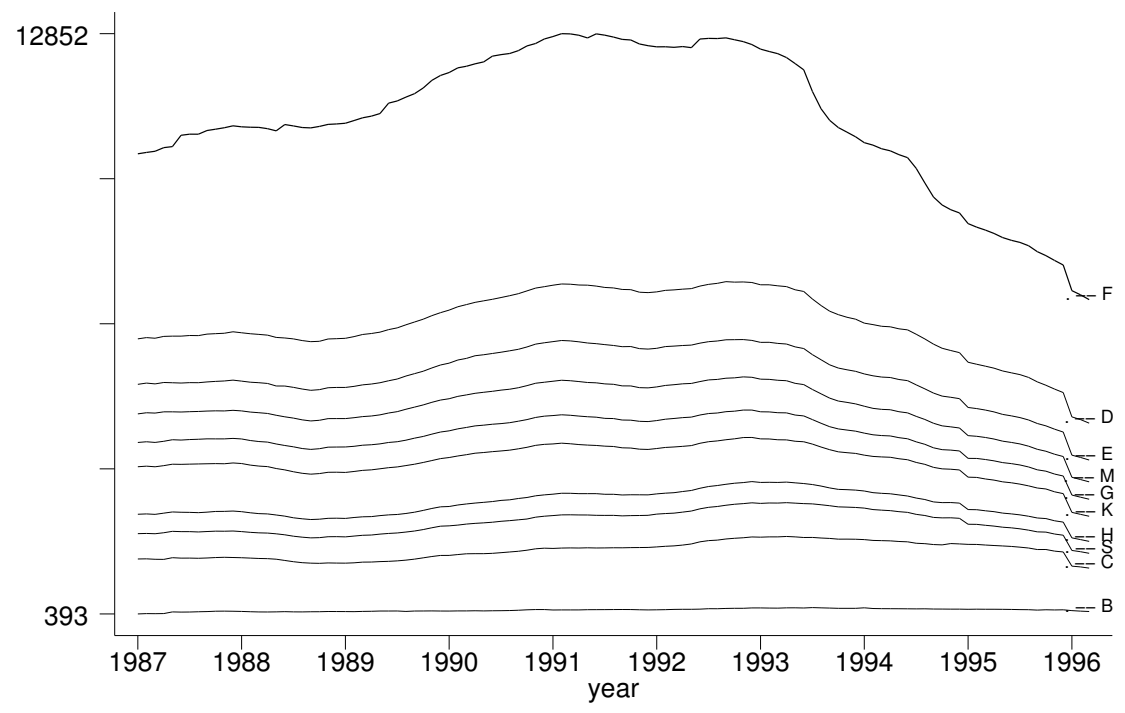

Notes: The figure plots the number of workers with a permanent contract employed at the beginning of each month from January 1987 until March 1996 stacked by the different job activities defined in the data. Job activities comprise: Sales \& Customer Relations (B), R\&D (C), Management \& Information Processing (S), Human Resources \& Support (H), Finances and Administration (K), Support \& Supplies (G), Quality (M), Planning \& Coordination (E), Production Preparation (D), and Assembly (F). Labels are in parentheses. The distance to the next lower line represents the number of workers in a particular job activity. Total employment at the firm is, therefore, characterized by the top line, labelled as "F".

production related activities falls during the episode of downsizing from a peak of $68.8 \%$ in mid 1991 to $62.3 \%$ in December 1995 and that of administrative activities falls from $17.1 \%$ in mid 1991 to $15.9 \%$ by the end of 1995 .

\subsection{The Corporate Hierarchy}

\subsubsection{Identification of Levels}

We relied on job transitions, job titles, reporting relations and team composition - but we did not use information from the wage files - in order to identify the hierarchical job structure of the firm. ${ }^{5}$ There are 6085 different job codes and 6318 different job names in the data. ${ }^{6}$ Fortunately, the number of levels could be inferred easily from transitions

\footnotetext{
${ }^{5}$ The methodology of assigning job codes is in line with that of Baker, Gibbs and Holmstrom (1994a). ${ }^{6}$ Some codes correspond to more than one name, which sometimes reflects typos, abbreviations in names, or a change from a Dutch to an English name. On the other hand, some job names are not unique to a single job code which often reflects the fact that codes have changed over time, while the
} 
between a few important job titles that account for a large portion of the workforce. ${ }^{7} \mathrm{We}$ identified 10 hierarchical levels. Production workers, supporting workers (e.g. cleaning, catering or transportation staff), and lower-level clerical workers are organized in the bottom three levels. We refer to this group of workers as blue-collar workers. Higher level clerical workers form level 4 of the hierarchy. Management and the remaining whitecollar workforce are organized in six management levels (levels 5-10). ${ }^{8}$ The 'Executive Board', which consisted of a group of 3 managers most of the time, forms the top of the hierarchy (level 10). Directors of subdivisions and plants are in level 9. For confidentiality reasons, we lack salary information for those employees in levels 9 and 10. ${ }^{9}$ Consequently, analyses involving compensation are only for the bottom 8 levels of the corporate hierarchy. Moreover, due to the small number of employees in the top 3 levels, we group these levels together in our job transition analyses. Level 8 comprises heads of departments. Levels 5, 6, and 7 comprise managers who report to those in level 8 and head or work in lower level departments of the firm. Besides, a large fraction of employees in levels 4 to 6 are engineers or specialists.

Suggestive job titles confirmed the hierarchical structure inferred from job transitions. For example, "Assemblers" or "Lathe Operators" are organized in level 1 in production, whereas team leaders (e.g. "Team Leader Assembly" or "Team Leader Lathe Operation") are in level 2, and group chiefs (e.g. "Group Chief Assembly" or "Group Chief Lathe Operation") in level 3. Similarly, job titles confirmed our assignment of job codes to higher hierarchical levels. For example, we observe transitions from "Specialist" to "Senior Specialist", or from "Engineer" to "Senior Engineer". These suggestive job titles also facilitated the assignment of minor job codes comprising only one or very few persons, who sometimes had no transition to or from another job code during the observation period. Finally, we exploited information about the composition of teams or subdivisions to assert that the hierarchical structure inferred from job transitions is consistent with the organization of teams in the sense that a team leader is assigned to a higher hierarchical level than the team members reporting to him.

\footnotetext{
job itself remained unchanged.

${ }^{7}$ The largest 30 job codes comprise $35 \%$ of the workforce, and the largest 130 job codes encompass $50 \%$ of the workforce.

${ }^{8}$ Additional information on the firm's organizational structure of management — which is provided by Deterink et al. (1997) — confirmed that we inferred the correct number of levels for white-collar employees from job transitions.

${ }^{9}$ Wages for level 8 employees that exceed 200,000 guilders annually are also not recorded.
} 
Table 3.1: Hierarchical Composition, 1987-1996

\begin{tabular}{l|rrrrrrrrrr}
\hline & \multicolumn{10}{|c}{ Year } \\
Level & 1987 & 1988 & 1989 & 1990 & 1991 & 1992 & 1993 & 1994 & 1995 & 1996 \\
\hline 1 & 51.3 & 52.9 & 53.7 & 54.1 & 53.0 & 52.3 & 50.4 & 45.2 & 42.3 & 43.9 \\
2 & 16.2 & 15.6 & 15.4 & 14.8 & 14.6 & 14.4 & 14.4 & 15.6 & 15.7 & 16.0 \\
3 & 9.0 & 8.6 & 8.6 & 7.9 & 8.3 & 8.5 & 8.7 & 9.2 & 9.7 & 9.8 \\
4 & 11.1 & 10.9 & 10.6 & 11.4 & 11.9 & 11.8 & 12.6 & 13.4 & 13.4 & 12.9 \\
5 & 6.2 & 6.0 & 5.8 & 5.9 & 6.2 & 6.6 & 7.2 & 8.3 & 9.1 & 8.2 \\
6 & 3.4 & 3.4 & 3.3 & 3.3 & 3.5 & 3.7 & 4.0 & 5.2 & 6.2 & 5.6 \\
7 & 1.3 & 1.2 & 1.2 & 1.3 & 1.2 & 1.4 & 1.4 & 1.5 & 1.9 & 1.7 \\
8 & 1.0 & 1.0 & 1.0 & 1.0 & 1.0 & 1.0 & 1.1 & 1.3 & 1.4 & 1.6 \\
$9-10$ & 0.4 & 0.4 & 0.4 & 0.3 & 0.3 & 0.3 & 0.2 & 0.3 & 0.3 & 0.3 \\
\hline Total & 100.0 & 100.0 & 100.0 & 100.0 & 100.0 & 100.0 & 100.0 & 100.0 & 100.0 & 100.0 \\
\hline
\end{tabular}

Notes: The table shows for each year the percentage of employees in each of the 10 hierarchical job levels on March 14 of every year. Levels 9 and 10 are combined for confidentiality reasons.

\subsubsection{Structural Stability and the Size of Levels}

Table 3.1 reveals the pyramid structure of the hierarchy with "sub-pyramids" for bluecollar and white-collar job levels. We find that many features of this hierarchical job structure are remarkably stable over the entire period. The number of levels in the hierarchy is unchanged and the main job titles in each level in 1987 remain in the respective levels until the bankruptcy. ${ }^{10}$ Corresponding with Baker et al. (1994a), who report stable relative sizes of hierarchical levels for an expanding firm, we also find that the relative size of levels is largely unaffected by the workforce expansion from 1987 until 1991 (see Table 3.1). However, relative level sizes change markedly during the period of employment reduction from 1991 until 1996, when the blue-collar share of total employment (levels 1-3) declines from $75.9 \%$ in 1991 to $67.7 \%$ in 1995.

\subsection{Mobility}

\subsubsection{Entry and Exit}

Turnover is comparatively low during the first five years of our observation period so that we can confidently speak of an internal labor market: The average annual exit rate equals 7.1\% from January 1987 until March 1991, whereas Baker et al. (1994a) find exit

\footnotetext{
${ }^{10}$ It is noteworthy, however, that the firm apparently reorganized certain divisions during downsizing. For example, different engineering jobs are summarized in one job code in 1992.
} 
Table 3.2: Entry into Hierarchical Levels, 1987-1996

\begin{tabular}{l|rrrrrrrrrr}
\hline & \multicolumn{10}{|c}{ Year } \\
Level & 1987 & 1988 & 1989 & 1990 & 1991 & 1992 & 1993 & 1994 & 1995 & 1996 \\
\hline 1 & 76.8 & 76.6 & 70.9 & 70.3 & 72.0 & 55.5 & 24.3 & 45.2 & 44.1 & 45.8 \\
2 & 6.1 & 8.5 & 7.8 & 6.9 & 7.1 & 5.8 & 15.9 & 5.5 & 13.6 & 12.5 \\
3 & 2.9 & 2.9 & 3.6 & 5.1 & 4.1 & 7.3 & 11.2 & 11.0 & 5.9 & 8.3 \\
4 & 10.1 & 7.3 & 12.1 & 12.2 & 10.8 & 20.6 & 19.6 & 11.0 & 8.5 & 8.3 \\
5 & 2.4 & 2.6 & 3.7 & 4.2 & 3.8 & 8.2 & 15.9 & 9.6 & 16.1 & 0.0 \\
6 & 0.9 & 1.1 & 0.7 & 0.9 & 0.8 & 1.1 & 5.6 & 6.8 & 6.8 & 16.7 \\
7 & 0.5 & 0.2 & 0.8 & 0.2 & 0.8 & 0.6 & 4.7 & 4.1 & 2.5 & 4.2 \\
8 & 0.3 & 0.6 & 0.3 & 0.1 & 0.4 & 0.8 & 0.9 & 4.1 & 1.7 & 4.2 \\
$9-10$ & 0.1 & 0.1 & 0.1 & 0.0 & 0.2 & 0.1 & 1.9 & 2.7 & 0.8 & 0.0 \\
\hline Total & 100.0 & 100.0 & 100.0 & 100.0 & 100.0 & 100.0 & 100.0 & 100.0 & 100.0 & 100.0 \\
\hline
\end{tabular}

Notes: The table shows for each year the percentage of just hired employees that entered into the respective level. Levels 9 and 10 are combined for confidentiality reasons.

rates of $10 \%$ and more when their firm grows at a similar rate as ours.

We do not find evidence of a completely closed internal labor market. There is entry into all levels in all years as Table 3.2 shows. Yet, entry is concentrated in the bottom levels of blue-collar employment (level 1) and of white-collar employment (level 4) especially during the episode of corporate expansion when $70.3 \%-76.8 \%$ of all beginners, or $85.5 \%-89.5 \%$ of all newly hired blue-collar workers enter level 1 and when $60.1 \%$ $71.1 \%$ of all newly hired white-collar workers enter level 4 (see Table 3.2). Entry rates into blue-collar ranks are markedly lower during downsizing and entry measured relative to level size is generally less concentrated in bottom ranks from 1992 onwards, possibly because hiring then takes place to staff vacancies in existing slots that cannot be filled from within, rather than to hire into slots that are newly created during expansion.

Hiring and firing takes place at all times. Monthly inflow rates are higher and more erratic (with peaks occurring commonly in May) than outflow rates during corporate expansion, while the opposite holds for the episode of corporate downsizing (see Figure 3.2). Early during downsizing, in 1991 and 1992, the workforce reduction is mainly accomplished by a fall in the inflow rate, while the outflow rate rises only slightly. The dramatic decline in employment during 1993-1996, however, is brought about by a substantial increase in the outflow rate and a further drop of the inflow rate. ${ }^{11}$ Remarkable

\footnotetext{
${ }^{11}$ The total number of hirings in the period of downsizing is less than a third of the inflow during expansion. Hiring rates into white-collar ranks fall by less than hiring rates into blue-collar employment (cf. lower part of Table 3.3).
} 
Figure 3.2: Inflow- Outflow and Employment Growth Rates

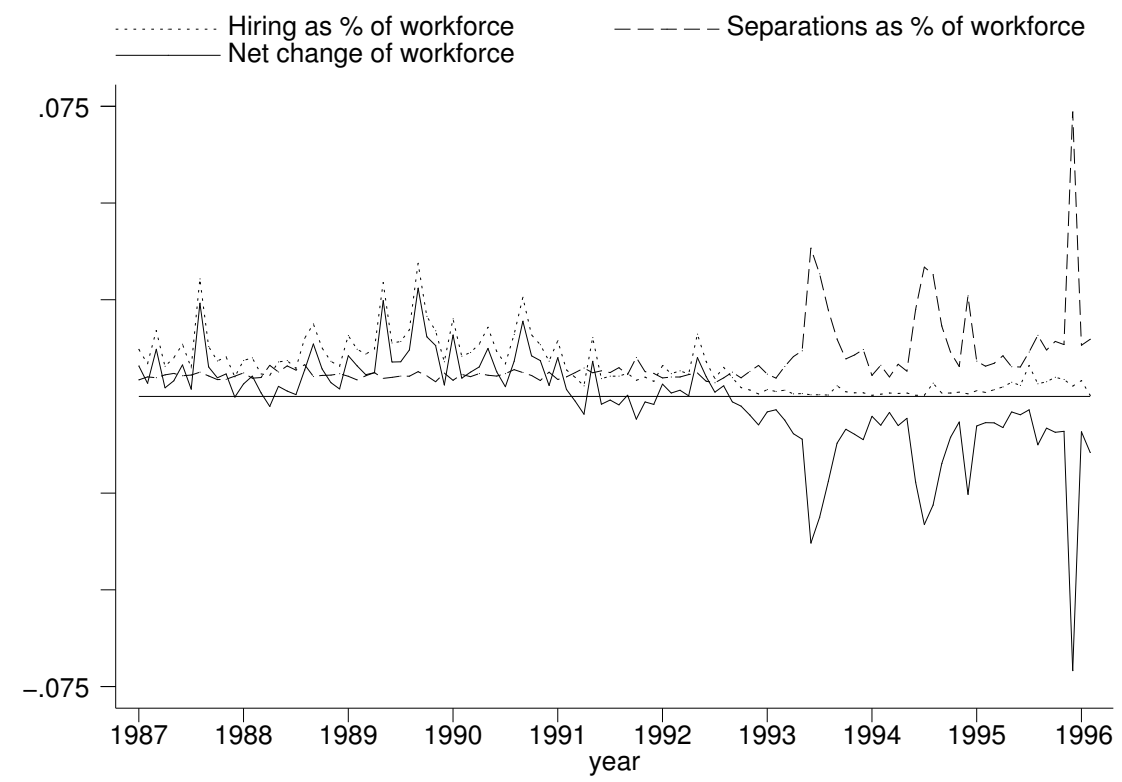

Notes: The figure plots the monthly hiring rate, the separation rate, and the net employment growth rates.

are the enormous jumps in outflow in June 1993, June - August 1994, December 1994, and December 1995, which follow downsizing announcements in April 1993, April 1994, and January 1995, respectively.

Exit rates are highest out of level 1 in the period of downsizing (see Table 3.3). Blue-collar workers, particularly those in level 1, separate first during downsizing. Exit rates from level 1 jump most during the 1993 downsizing episode, the first with mainly involuntary dismissals (see Table 3.3). Higher exit rates out of the bottom level of bluecollar employment can partly be ascribed to higher turnover rates among workers with short tenure who predominately entered in level 1 and separate before having made an upward transition. But even controlling for tenure and other characteristics, Dohmen and Pfann (2000) find that corporate downsizing affects exit rates of blue-collar and white-collar workers differently. While job separations are, if anything, more frequent for white-collar employees than for blue-collar workers during the period of corporate expansion, workers in the lower ranks become more likely to separate during downsizing, which is also revealed in Table 3.3. It is not until late 1995 that exit rates from the top 5 levels of the hierarchy increase markedly. This seems to indicate a shift in layoff policy. 
Table 3.3: Exit from Hierarchical Levels, 1987-1996

\begin{tabular}{l|rrrrrrrrrr}
\hline & \multicolumn{10}{|c}{ Year } \\
Level & 1987 & 1988 & 1989 & 1990 & 1991 & 1992 & 1993 & 1994 & 1995 & 1996 \\
\hline 1 & 54.0 & 49.2 & 64.0 & 66.1 & 63.7 & 63.6 & 73.4 & 60.5 & 42.2 & 43.0 \\
2 & 10.9 & 14.8 & 11.5 & 11.9 & 11.3 & 10.8 & 9.7 & 13.2 & 18.1 & 13.8 \\
3 & 8.8 & 7.7 & 4.4 & 4.4 & 6.3 & 6.6 & 5.0 & 5.9 & 7.4 & 9.5 \\
4 & 16.1 & 13.4 & 10.0 & 9.3 & 10.7 & 8.4 & 7.3 & 12.1 & 15.9 & 14.7 \\
5 & 6.4 & 6.6 & 3.2 & 3.7 & 4.9 & 5.0 & 2.1 & 4.5 & 7.4 & 9.0 \\
6 & 1.7 & 4.6 & 3.7 & 1.5 & 1.8 & 2.5 & 1.6 & 2.0 & 5.8 & 6.3 \\
7 & 1.2 & 1.5 & 1.5 & 1.3 & 0.6 & 1.7 & 0.4 & 0.7 & 1.3 & 1.8 \\
8 & 0.6 & 1.7 & 1.1 & 1.0 & 0.3 & 1.0 & 0.4 & 0.7 & 1.5 & 1.7 \\
$9-10$ & 0.3 & 0.5 & 0.6 & 0.9 & 0.3 & 0.4 & 0.2 & 0.4 & 0.4 & 0.3 \\
\hline Total & 100.0 & 100.0 & 100.0 & 100.0 & 100.0 & 100.0 & 100.0 & 100.0 & 100.0 & 100.0 \\
\hline
\end{tabular}

Notes: The table shows for each year the percentage of separating workers that exit the firm from $a$ given level. Levels 9 and 10 are combined for confidentiality reasons.

\subsubsection{Vertical Job Mobility}

Since the relative sizes of hierarchical levels remain stable during the episode of workforce expansion in spite of entry concentrated in the bottom levels of blue-collar and whitecollar employment but similar exit rates across levels, there must be transitions from lower to higher ranks in the hierarchy. We record 5704 upward moves and 1627 downward moves over the entire period which amounts to an average upward (downward) annual mobility rate of $5.6 \%$ (1.6\%) over the entire period. ${ }^{12}$ Of all the 17610 workers employed at some time during the observation period, 4543 enjoy at least one upward hierarchical transition, 1536 workers are demoted at least once, but a large fraction of them (1121) are also promoted at some time during the observation period. We observe no vertical transition in the hierarchy for 12652 workers, and 7584 of them - who are mostly in level $1(70.4 \%)$ and rarely in levels $7-10(1.7 \%)$ - have the same job code throughout while they are in the sample.

Upward mobility in our firm is lower than in organizations analyzed in related studies, despite the fact that these studies are commonly based on year-end data and, therefore, miss offsetting vertical moves of stayers as well as all job changes of separating workers that take place during the year. Using year-end data (and including the cross-section the day before the bankruptcy as 1996 year-end data), we would miss $18.7 \%$ of promotions and $27.0 \%$ of demotions. Offsetting vertical movements that occur within 365 days (but

\footnotetext{
${ }^{12}$ Summing up the length of all employment spells at the firm from January 1, 1987, until the bankruptcy yields a total of 102,147 employment years.
} 
not necessarily in the same calendar year) account for $21.6 \%$ of all demotions. Such temporary reassignments across job levels might either result from correcting previous mis-assignments or might be due to interim assignments to fill vacant positions temporarily. It should be noted that $12.9 \%$ of demoted workers leave the firm within a year after the demotion. Their demotions potentially remain unobserved when panel data at yearly frequencies are examined.

The fact that related studies commonly consider only white-collar jobs partly explains why upward mobility is lower in our firm as a whole: Job transition rates for white-collar workers are also higher in our firm in both periods. The average annual promotion (demotion) rate for white-collar workers is $7.7 \%$ (2.7\%) during expansion and $6.4 \%$ $(2.6 \%)$ during contraction, but $6.4 \%$ (1.0\%) during expansion and $3.9 \%$ (1.4\%) during downsizing for blue-collar workers.

Tables 3.4 and 3.5 summarize the vertical job transition pattern for different groups of workers for the episodes of workforce expansion and downsizing by comparing their hierarchical position at the beginning of the period to that at the end. ${ }^{13}$ The tables are divided into four blocks. The upper two blocks contain transition patterns of workers who were employed at the beginning of the period as shares of incumbent workers, while the lower two describe transition patterns of all workers entering during the period as shares of all new entrants at given entry levels during the respective period. The rows of the blocks depict what shares of workers assigned to a given level at the beginning of the period (upper blocks) - or the beginning of the employment relation for new entrants (lower blocks) - are employed in different levels at the end of the period (left blocks) and what shares left after having reached a particular level (right blocks). For example, $65.1 \%$ of all workers who were employed at level 1 on January 1, 1987, are still employed at level 1 on March 1, 1991; 11.1\% have advanced to level 2, 2.6\% to level 3, and $0.6 \%$ to level $4 ; 20.6 \%$ separated during the period and the vast majority of them had not been promoted. Only $1 \%$ of all workers employed at level 1 at the beginning of the period had been promoted prior to their separation.

A comparison of Tables 3.4 and 3.5 reveals important facts: Firstly, a larger fraction of workers who separate in the second period had progressed to higher levels before their employment relation ends. Secondly, upward mobility is lower in the period of downsizing so that substantially fewer workers staying with the firm are promoted to higher levels. An obvious explanation is that less slots become vacant in higher positions when

\footnotetext{
${ }^{13}$ Clearly, this only gives an incomplete picture on total vertical mobility as it ignores offsetting vertical movements which occur when a worker is promoted and demoted within the period.
} 
Table 3.4: Transition Matrix 1987 - 1991

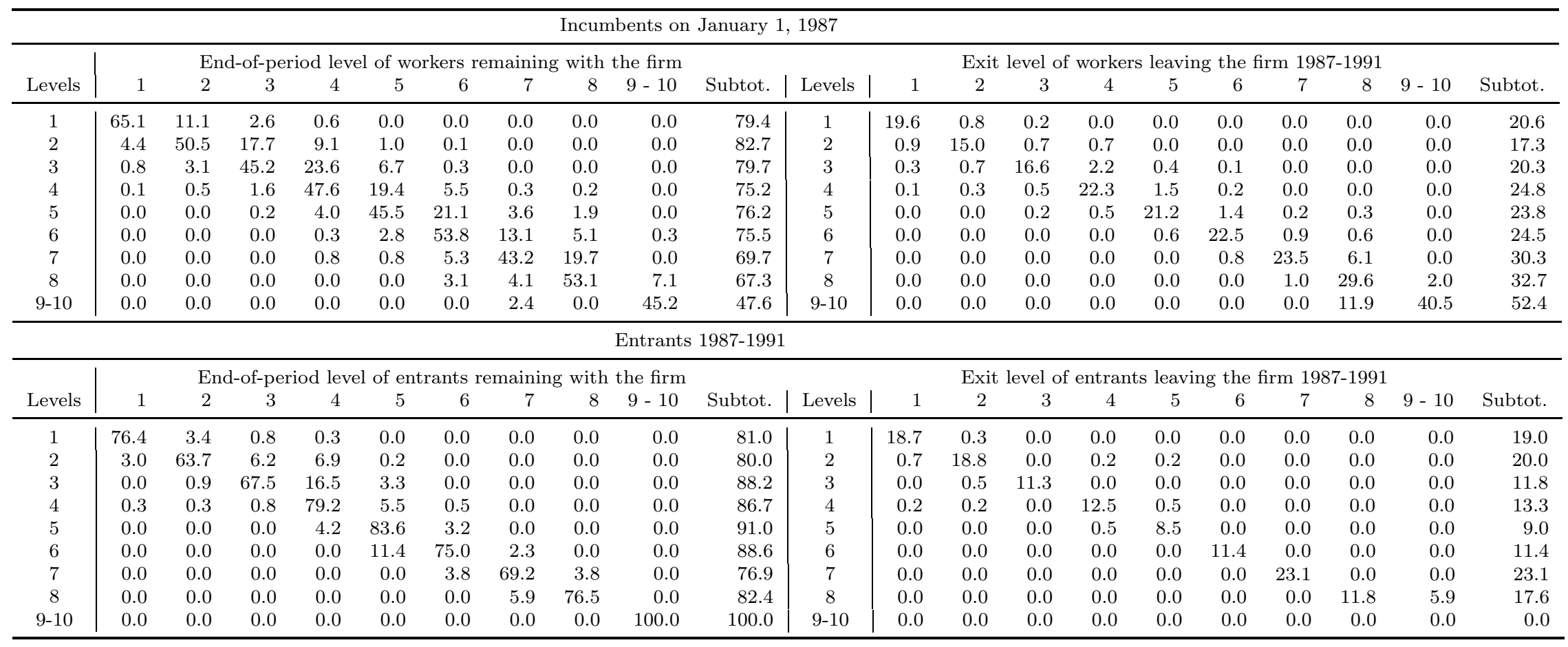

Notes: The table summarizes the transition pattern between January 1, 1987, and March 1, 1991, for all workers employed at any time during this period. The initial level at the beginning of the period (row) is either the job level of incumbent workers on January 1, 1987 (upper blocks), or the entry level of beginners (lower blocks). The final level (column) refers to the job level on March 1, 1991, for workers remaining with the firm (left blocks) or to the exit level of workers separating during the period (right blocks). Rows sum to 100 as the numbers are calculated as percentages of incumbent workers on January 1, 1987 (upper blocks), or new hirings (lower blocks) in respective levels. 
Table 3.5: Transition Matrix 1991 - 1996

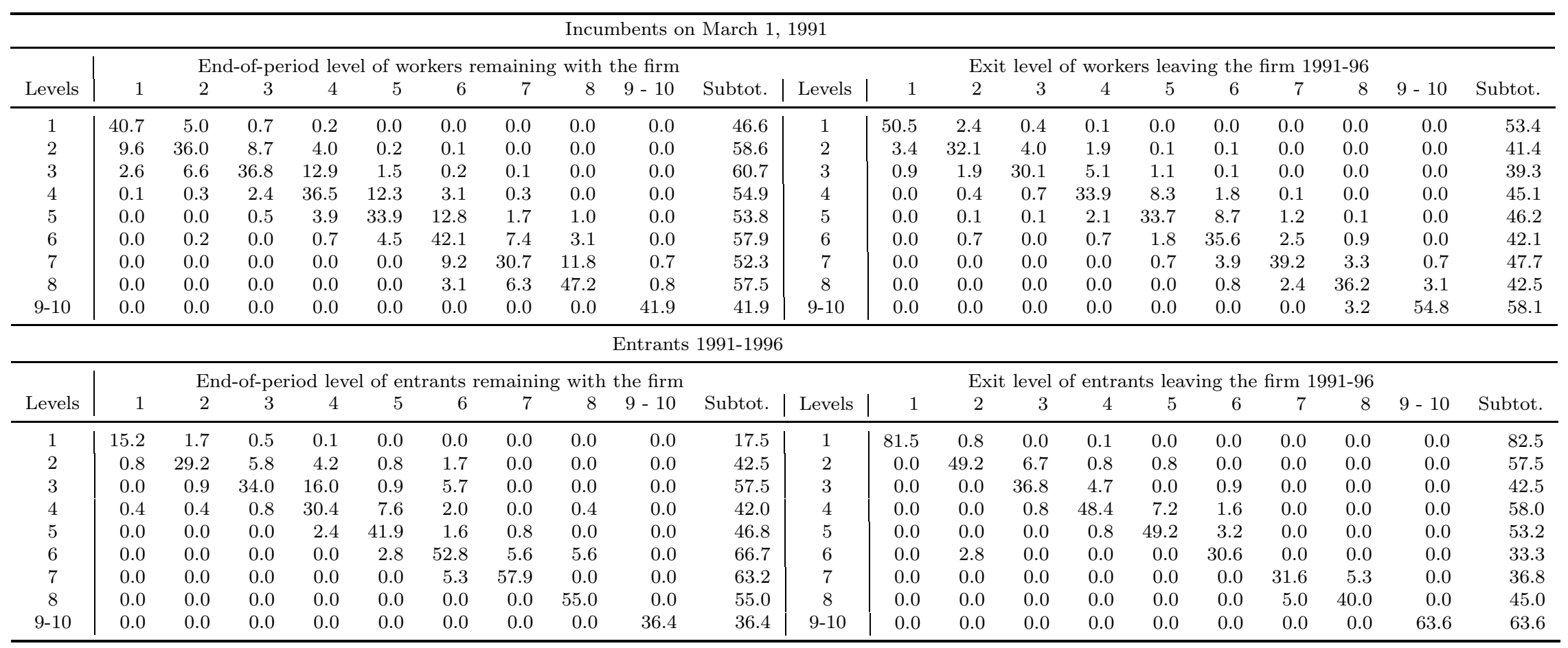

Notes: The table summarizes the transition pattern between March 1, 1991, and March 14, 1996, for all workers employed at any time during this period. The initial level at the beginning of the period (row) is either the job level of incumbent workers on March 1, 1991 (upper blocks), or the entry level of beginners (lower blocks). The final level (column) refers to the job level on March 14, 1996, for workers remaining with the firm (left blocks) or to the exit level of workers separating earlier during the period (right blocks). Rows sum to 100 as the numbers are calculated as percentages of incumbent workers on March 1, 1991 (upper blocks), or new hirings (lower blocks) in respective levels. 
the company reduces employment, especially as the employment reduction is not proportional to level size. The fact that many workers who were promoted during downsizing separate also suggests that "talented" workers leave the firm, possibly because of reduced further career prospects in a downsizing firm. More evidence that promotion rates are inversely related to exit rates comes from the fact that promotion rates fall, especially for blue-collar workers who also experience a more severe increase in separation rates. While $14.9 \%$ of all blue-collar workers and $20.0 \%$ of white-collar workers move upward in the hierarchy between January 1987 and March 1991, only 11.6\% blue-collar workers and $21.1 \%$ of white-collar workers have proceeded to a higher hierarchical positions in the longer period between March 1991 and the bankruptcy or their separation date. Consequently, relative upward mobility falls for blue-collar worker during downsizing. ${ }^{14}$

Separating workers have lower upward mobility than remaining workers, but similar downward mobility in both periods. ${ }^{15}$ Not correcting for the length of the employment spell, upward mobility rates are smaller for beginners than for the incumbent workforce. But workers who enter after January, 1987, and remain with the firm have higher upward mobility rates than entrants who separate before the end of 1991. Tables 3.4 and 3.5 also show that more workers are demoted in the second period and that a substantial fraction of them leave. Although the downward mobility rate remains higher in the upper segment of the hierarchy downward moves become relatively more common for blue-collar workers.

The mobility pattern indicates interrelations between vertical internal job mobility and turnover rates. Upward mobility is lower during downsizing and seems to be related to the scale of workforce reductions (upward mobility falls most in blue-collar jobs where exit is concentrated). Downward mobility is higher during periods of workforce reductions and upward mobility is positively correlated with entry rates. Figure 3.3 plots the entry rate, exit rate, promotion rate and demotion rate. Not only are promotion rates higher when entry is high, but promotion rates follow entry rates in the sense that they rise when entry in the previous months had been unusually high as is evident from the period from the second half of 1988 until the beginning of downsizing in 1991. This implies that corporate expansion initiates a reassignment of workers to jobs, consistent with the theory of internal labor markets where entry is concentrated in some jobs, while the remaining jobs are predominately filled from within. Similarly,

\footnotetext{
${ }^{14}$ These percentages are calculated based on the absolute numbers of transitions underlying Tables 3.4 and 3.5, but cannot be readily inferred from the tables as these average percentages for the fraction of all blue-collar workers and white-collar workers are weighted by the size of the levels.

${ }^{15}$ Note that they have less time for vertical moves.
} 
Figure 3.3: Monthly MoBility

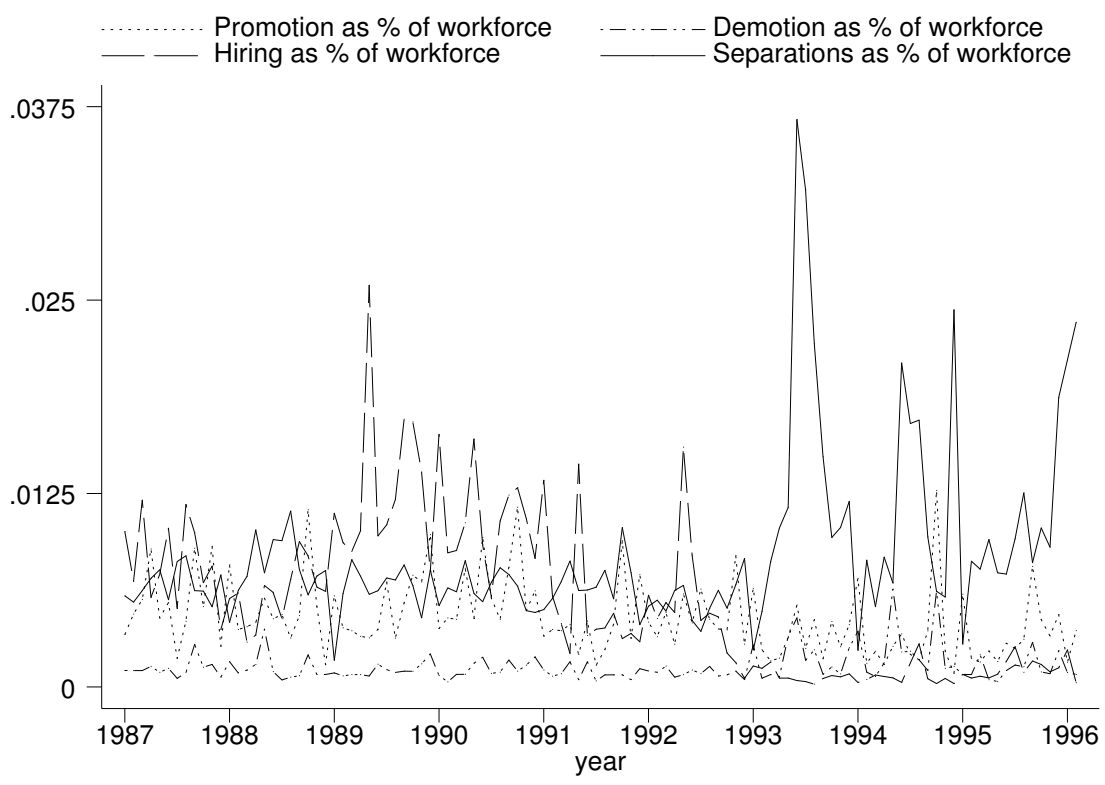

Notes: The figure plots monthly promotion and demotion rates - calculated as the number of transitions relative to the number of incumbent workers - along with the hiring rate and the separation rate from Figure 3.2.

the demotion rate usually peaks shortly before the exit rate. Finally, we notice that promotion and demotion rates are positively correlated (correlation coefficient of 0.48). The graph suggests that this result is to some degree driven by the co-movement of the promotion rate and demotion rate in periods with severe employment reductions, as is reflected in the coincidence of local peaks in both rates in May 1988, January and June 1993, January, May and October 1994, and September 1995. This suggests that such reorganizations trigger reassignments across job levels.

\subsubsection{Lateral Job Mobility}

We observe a substantial number (13636) of lateral job transitions, which we define as changes in job codes of jobs belonging to the same hierarchical level. Admittedly, some fraction of these are spurious job transitions due to the fact that codes might be changed over time, while the content of the job remains the same. But the largest fraction of these lateral transitions relates to changes in the job description. About one quarter of all lateral job transitions involves a transition to a different field of activity within the firm. Table 3.6 reports for each job level the shares of lateral transitions that involve a job change to a different field of activity. 
Table 3.6: Lateral Job Transitions to a Different Field of Activity

\begin{tabular}{l|ccccccccc}
\hline & \multicolumn{1}{c}{ Job Level } & & \\
& 1 & 2 & 3 & 4 & 5 & 6 & 7 & 8 & $9-10$ \\
\hline Number & 1515 & 426 & 336 & 525 & 227 & 159 & 62 & 83 & 19 \\
Percent & 23.1 & 23.1 & 30.1 & 26.4 & 22.1 & 23.6 & 32.0 & 40.3 & 46.3 \\
\hline
\end{tabular}

Notes: This table reports for each job level the absolute number of lateral job transitions that involve a job change to a different field of activity (row 2) and their percentage share (row 3) of all lateral transitions at the respective level. Levels 9 and 10 are combined for confidentiality reasons.

This suggests an interesting additional dimension in the analysis of job change, promotion dynamics, and wage dynamics. Lateral transitions may occur across different fields of activities within the firm to prepare for subsequent upward mobility thereby increasing career prospects. For instance, an assembly worker might be assigned to quality assessment or to production preparation to widen his knowledge on the entire production process, which is crucial in higher level jobs. Such reassignments are usually referred to as job rotation. If the acquisition of a wider portfolio of skills that might be required in higher level jobs is the motive, the probability of an upward move increases for workers who have held different jobs at the same level. ${ }^{16}$ On the other hand, job rotation might be used to screen workers or learn about their optimal assignment (Ortega, 2001), in which case lateral transitions do not entail a priori information on career perspectives. ${ }^{17}$ Besides, a lateral transition might entail a career step in itself, both in terms of wage growth and in terms of characteristics of the job. Finally, workers might be transferred laterally because they do not qualify for upward mobility.

An inspection of the job titles gives rise to the conjecture that such "flatter" careers exist since job titles often suggest differences in qualification requirements or responsibilities. Some apparent examples include movements from "Secretary of departmental chef" to "Secretary of the Head of the Department", from "Assembly Worker" to "Aircraft Mechanic", or from "Assembler Electrical Assembly A" to "Assembler Electrical Assembly B". These three examples all involve transitions to a job in which the median wage scale is higher. $45.0 \%$ of lateral movements are to jobs with a higher median wage scale, while $19.1 \%$ are to jobs with a lower median wage scale.

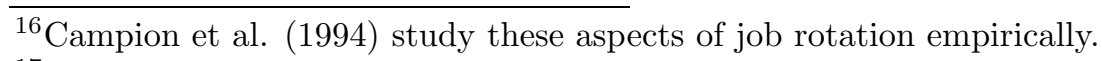

${ }^{17}$ Eriksson and Ortega (1994) find limited support for the employer learning hypothesis, but no favorable evidence for job rotation theories of employee learning and employee motivation in data from Danish private sector firms.
} 
There is evidence that a fraction of lateral reassignments lasts only for a short time - $31 \%$ of all lateral movements are not observed in a year-end panels. This possibly results from temporarily staffing crucial vacancies, from intended job rotation in order to learn about a worker's performance at different jobs or to stimulate the accumulation of different skills, or from correcting 'mistakes' in assignment, when an intended lateral move turns out to have resulted in an inefficient allocation.

\subsection{Wages and the Hierarchy}

Since internal labor markets are characterized by substantial fixed costs of hiring, screening or training, which become sunk upon a separation, internal labor markets foster longterm relations between workers and the firm. Wages no longer have to equal marginal productivity at every moment during the employment relation in presence of such fixed costs, even with competitive labor markets (see Oi, 1962). Although external labor market conditions potentially constrain the internal wage structure, for example, by affecting hiring wages, competitive forces do not restrict wage determination to a unique outcome in internal labor markets. Exploiting this indeterminacy of wages, the firm can design the wage structure to encourage long-term relations, shield workers from external conditions or accomplish other goals, as, for example, the provision of incentives to elicit optimal effort levels.

In the tournament model of Lazear and Rosen (1981), workers supply the optimal level of effort competing for a promotion which is associated with a sufficiently higher wage. This model, as well as the models by Rosen (1982) and Calvo and Wellisz (1979), predicts that wage differences between hierarchical levels increase towards the top of the hierarchy. ${ }^{18}$ These predictions concern the vertical wage structure, i.e. differences between wage rates among workers in different job levels. Other theories make predictions about the horizontal wage structure, i.e. about wage differentials for individuals in the same job. Lazear (1979) illustrates, for example, how deferred compensation schemes can provide non-shirking incentives. In that case, wages are not solely determined by jobs, but depend on worker characteristics like age and tenure, too.

Formal rules and procedures might play an important role in wage determination. Such rules might improve efficiency, for example, by solving hold-up problems, which

${ }^{18}$ Baker, Gibbs and Holmstrom (1994a) find evidence of a strong relation between wages and hierarchical levels and a convex relationship between hierarchical levels and wages in their data set. 
arise when wages are set or renegotiated after firm-specific investments (e.g. including firm-specific training or broadly defined organization-specific capital, Prescott and Visscher, 1980) have been made. A contractual arrangement which fixes wages in advance can serve as a commitment device and help resolve the hold-up problem (MacLeod and Malcomson, 1993b). Moreover, the existence of favoritism (Prendergast and Topel, 1996) would give rise to rules in the wage setting process to limit discretion. Consequently, we should expect the wage structure to be governed by contractual arrangements and administrative rules.

In the following paragraphs, we analyze the wage structure of the firm in some depth to shed light on whether wage determination is governed by administrative rules and whether theses rules are binding; whether the wage structure is stable; whether wages are attached to jobs; and what the vertical and horizontal wage structure looks like.

\subsubsection{Administrative Rules in Wage Setting}

Doeringer and Piore (1971) argue that wages in internal labor markets are determined by formal, impersonal administrative procedures. Strong evidence for such rules is the existence of wage scales in our firm. There are 10 blue-collar scales (scales 2-11) and 8 white-collar scales (scales 12-19). A range of wages exists in each white-collar wage scale. Minimum, maximum and mean wages are increasing in subsequent scales, ${ }^{19}$ but wage ranges of subsequent scales overlap.

All blue-collar workers are covered by collective bargaining agreements (CAO) between unions and employer federations. ${ }^{20}$ The collective bargaining agreement defines, among other things, nominal wages for each of the (up to 9) wage grades within all blue-collar wage scales. ${ }^{21}$ Firms can pay above these wages, and Fokker does so. The wage grades can be interpreted as a contractual tenure-wage profile since workers commonly climb the within-scale wage ladder at distinct, mostly yearly, intervals. This structure of wage grades and wage scales is usually not changed in yearly bargaining. Instead, a percentage nominal wage increase, pertaining to all wages in blue-collar scales, is negotiated to adjust wages for aggregate conditions (e.g. inflation, technological progress, etc.). Fokker usually adjusts white-collar salaries by the same percentage, thereby shifting its entire

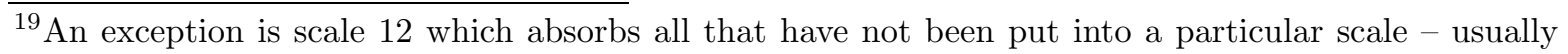
recently recruited employees - so that the maximum wage in scale 13 might be lower than the maximum wage in scale 12 .

${ }^{20}$ There is a high degree of coordination between unions and employer federations in the Netherlands (see Teulings and Hartog, 1998).

${ }^{21}$ Nominal contracts are characteristic for the Dutch labor market.
} 
wage frame keeping the wage structure stable.

As is common in the Netherlands (see Teulings and Hartog, 1998), wage increases can be decomposed into three components: Firstly, a worker is usually awarded a yearly raise according to the contractual experience-wage or tenure-wage profiles defined in the collective wage agreement until the highest wage in the scale is achieved. Secondly, contractual initial increases adjust all wages to changes in aggregate conditions. ${ }^{22}$ Thirdly, incidental wage increases relate to any other type of wage increase including promotions. The latter type of wage contract changes might occur throughout the year, but the bulk of wage changes, pertaining to collectively negotiated wage adjustments or contractual periodical increases take place at the turn of the year and are usually administered in our data set in the last week of December or the first week of January.

\subsubsection{Job Levels and Wages}

The existence of a formal wage system provokes the question of whether formal bureaucratic rules actually constrain individual compensation by attaching wages to jobs, or whether they leave scope for sufficient managerial flexibility in rewarding individual worker characteristics. The correlation between job levels and salary scales (0.92 in the entire sample, or 0.68 and 0.81 in the blue-collar and white-collar scales respectively) indicates a strong relation between wages and jobs. This is confirmed by Figure 3.4 which plots mean nominal, full-time equivalent within-job-level wages over time. ${ }^{23}$

The vertical wage structure is remarkably stable throughout in the sense that the magnitude of differences in average wages between job levels persists. Only average nominal wages in levels 1 and 4 rise somewhat faster during downsizing mainly because of the entry and exit patterns that change the within-level wage distribution. Table 3.7 illustrates, for example, that new hires predominately start off in the lowest decile of the within-level wage distribution. ${ }^{24} \mathrm{~A}$ considerable fraction of separating workers also comes from the lower deciles of the wage distribution (see Table 3.8), so that average within-level wages increase when the hiring rate falls and the separation rate rises.

Such changes in within-level wage distributions explain why average nominal job level wages - especially in levels 1 and 4 (see Figure 3.4) where exit is concentrated and hiring drops the most — rise after 1993 although it was agreed in collective bargaining not to

\footnotetext{
${ }^{22}$ The nature of wage determination and the existence of fixed nominal wage contracts, which can be adjusted to aggregate conditions, helps solving hold-up problems in the way described by Teulings and Hartog (1998).

${ }^{23}$ Averages are taken over wage contracts active on March 14 of each year.

${ }^{24}$ Entry wages are much more variable in higher levels (levels 6 to 8), especially during downsizing.
} 
Table 3.7: Distribution of Pay for New Hires in Wage Deciles

\begin{tabular}{|c|c|c|c|c|c|c|c|c|c|c|c|c|}
\hline \multirow[b]{2}{*}{ Level } & \multirow[b]{2}{*}{$\mathrm{N}$} & \multicolumn{10}{|c|}{ Decile in Job Level Wage Distribution } & \multirow[b]{2}{*}{ All } \\
\hline & & $1 \mathrm{st}$ & 2nd & $3 \mathrm{rd}$ & 4 th & 5 th & 6th & 7 th & 8th & 9 th & Top & \\
\hline 1 & 4270 & 33.1 & 20.0 & 16.9 & 14.2 & 7.7 & 4.2 & 2.5 & 0.7 & 0.6 & 0.2 & 100.0 \\
\hline 2 & 405 & 52.1 & 22.7 & 8.4 & 4.0 & 2.5 & 3.7 & 1.5 & 1.0 & 2.2 & 2.0 & 100.0 \\
\hline 3 & 212 & 49.5 & 9.4 & 17.9 & 10.4 & 4.2 & 3.3 & 1.4 & 0.9 & 0.9 & 1.9 & 100.0 \\
\hline 4 & 602 & 35.5 & 18.4 & 22.8 & 6.3 & 4.7 & 2.8 & 3.0 & 2.7 & 2.3 & 1.5 & 100.0 \\
\hline 5 & 189 & 53.4 & 9.0 & 9.5 & 6.3 & 2.6 & 4.2 & 5.8 & 0.5 & 4.2 & 4.2 & 100.0 \\
\hline 6 & 45 & 33.3 & 13.3 & 4.4 & 20.0 & 6.7 & 4.4 & 2.2 & 2.2 & 6.7 & 6.7 & 100.0 \\
\hline 7 & 24 & 20.8 & 25.0 & 12.5 & 4.2 & 0.0 & 12.5 & 4.2 & 16.7 & 4.2 & 0.0 & 100.0 \\
\hline 8 & 12 & 25.0 & 0.0 & 16.7 & 0.0 & 8.3 & 25.0 & 0.0 & 0.0 & 0.0 & 25.0 & 100.0 \\
\hline \multicolumn{13}{|c|}{$1991-1996$} \\
\hline & \multicolumn{11}{|c|}{ Decile in Job Level Wage Distribution } & \\
\hline Level & $\mathrm{N}$ & $1 \mathrm{st}$ & 2nd & $3 \mathrm{rd}$ & 4 th & 5 th & 6 th & 7 th & 8 th & 9 th & Top & All \\
\hline 1 & 926 & 58.9 & 18.3 & 9.9 & 5.1 & 3.6 & 1.4 & 1.3 & 1.1 & 0.2 & 0.3 & 100.0 \\
\hline 2 & 111 & 35.1 & 16.2 & 14.4 & 7.2 & 8.1 & 5.4 & 4.5 & 5.4 & 0.9 & 2.7 & 100.0 \\
\hline 3 & 102 & 58.8 & 9.8 & 10.8 & 6.9 & 2.0 & 2.0 & 2.9 & 1.0 & 1.0 & 4.9 & 100.0 \\
\hline 4 & 243 & 43.6 & 33.3 & 7.0 & 3.3 & 3.3 & 0.8 & 1.2 & 3.7 & 2.1 & 1.6 & 100.0 \\
\hline 5 & 120 & 76.7 & 8.3 & 6.7 & 3.3 & 0.0 & 0.8 & 1.7 & 0.8 & 0.8 & 0.8 & 100.0 \\
\hline 6 & 31 & 35.5 & 16.1 & 6.5 & 9.7 & 0.0 & 0.0 & 3.2 & 6.5 & 6.5 & 16.1 & 100.0 \\
\hline 7 & 14 & 21.4 & 7.1 & 14.3 & 7.1 & 0.0 & 14.3 & 7.1 & 0.0 & 0.0 & 28.6 & 100.0 \\
\hline 8 & 9 & 11.1 & 0.0 & 22.2 & 0.0 & 11.1 & 0.0 & 22.2 & 0.0 & 22.2 & 11.1 & 100.0 \\
\hline
\end{tabular}

Notes: The two blocks of the table show for the periods from January 1, 1987, until March 1, 1991 (upper block), and from from March 1, 1991, until March 14, 1996 (lower block), the number of entrants into each level (column 2). Columns 3-12 of the blocks show the percentage shares of workers entering in a given job level whose starting wage is in a particular decile of the respective job level wage distribution. Wage distributions are based on hourly wages for all workers employed in the relevant job level and period and calculated dates following contract wage adjustments due to inflation compensation and (semi-)annual raises. For privacy reasons, there is no salary information for levels 9 and 10 in the personnel files. 
Table 3.8: Distribution of Pay for Separating Workers in Wage Deciles

\begin{tabular}{|c|c|c|c|c|c|c|c|c|c|c|c|c|}
\hline \multirow[b]{2}{*}{ Level } & \multirow[b]{2}{*}{$\mathrm{N}$} & \multicolumn{10}{|c|}{ Decile in Job Level Wage Distribution } & \multirow[b]{2}{*}{ All } \\
\hline & & 1 st & $2 \mathrm{nd}$ & $3 \mathrm{rd}$ & 4 th & 5 th & 6 th & 7 th & 8 th & 9 th & Top & \\
\hline 1 & 1835 & 11.0 & 15.5 & 15.9 & 11.9 & 11.1 & 10.1 & 6.7 & 6.0 & 5.4 & 6.4 & 100.0 \\
\hline 2 & 376 & 19.4 & 12.5 & 10.1 & 6.9 & 6.6 & 4.5 & 8.5 & 7.7 & 9.3 & 14.4 & 100.0 \\
\hline 3 & 202 & 17.8 & 10.9 & 6.9 & 6.9 & 4.0 & 6.9 & 5.0 & 8.9 & 13.4 & 19.3 & 100.0 \\
\hline 4 & 356 & 17.1 & 10.7 & 9.8 & 7.0 & 7.9 & 5.9 & 10.7 & 8.7 & 5.6 & 16.6 & 100.0 \\
\hline 5 & 172 & 16.3 & 8.1 & 8.1 & 10.5 & 12.2 & 5.2 & 7.0 & 4.1 & 14.0 & 14.5 & 100.0 \\
\hline 6 & 92 & 15.2 & 12.0 & 12.0 & 8.7 & 7.6 & 9.8 & 6.5 & 7.6 & 5.4 & 15.2 & 100.0 \\
\hline 7 & 42 & 9.5 & 11.9 & 7.1 & 4.8 & 7.1 & 9.5 & 9.5 & 7.1 & 9.5 & 23.8 & 100.0 \\
\hline 8 & 31 & 3.2 & 3.2 & 3.2 & 12.9 & 3.2 & 6.5 & 19.4 & 6.5 & 25.8 & 16.1 & 100.0 \\
\hline
\end{tabular}

1991-1996

\begin{tabular}{|c|c|c|c|c|c|c|c|c|c|c|c|c|}
\hline \multirow[b]{2}{*}{ Level } & \multirow[b]{2}{*}{$\mathrm{N}$} & \multicolumn{10}{|c|}{ Decile in Job Level Wage Distribution } & \multirow[b]{2}{*}{ All } \\
\hline & & 1 st & 2nd & $3 \mathrm{rd}$ & 4 th & 5 th & 6 th & 7 th & 8 th & 9 th & Top & \\
\hline 1 & 4271 & 16.1 & 13.6 & 13.0 & 11.9 & 10.0 & 8.7 & 7.0 & 4.6 & 8.2 & 7.0 & 100.0 \\
\hline 2 & 865 & 13.8 & 11.4 & 10.8 & 9.7 & 7.3 & 8.6 & 9.8 & 6.0 & 9.2 & 13.4 & 100.0 \\
\hline 3 & 484 & 14.5 & 11.0 & 8.1 & 8.7 & 9.3 & 3.1 & 10.5 & 14.0 & 5.6 & 15.3 & 100.0 \\
\hline 4 & 765 & 12.9 & 13.5 & 10.6 & 8.5 & 7.2 & 6.1 & 10.7 & 8.8 & 3.8 & 17.9 & 100.0 \\
\hline 5 & 502 & 14.1 & 13.3 & 10.0 & 8.0 & 11.2 & 8.4 & 6.0 & 2.2 & 15.9 & 11.0 & 100.0 \\
\hline 6 & 287 & 11.5 & 12.2 & 8.7 & 11.5 & 7.7 & 1.0 & 10.5 & 9.8 & 10.5 & 16.7 & 100.0 \\
\hline 7 & 92 & 12.0 & 10.9 & 12.0 & 3.3 & 20.7 & 5.4 & 6.5 & 1.1 & 7.6 & 20.7 & 100.0 \\
\hline 8 & 66 & 7.6 & 10.6 & 6.1 & 6.1 & 12.1 & 6.1 & 13.6 & 3.0 & 28.8 & 6.1 & 100.0 \\
\hline
\end{tabular}

Notes: The two blocks of the table show for the periods from January 1, 1987, until March 1, 1991 (upper block), and from from March 1, 1991, until March 14, 1996 (lower block), the number of exits from each level (column 2). Columns 3-12 of the blocks show the percentage shares of workers exiting from a given job level whose final wage is in a particular decile of the respective job level wage distribution. Wage distributions are based on hourly wages for all workers employed in the relevant job level and period and calculated dates following contract wage adjustments due to inflation compensation and (semi-)annual raises. Only the first accession to the firm of a worker is considered, so that re-hiring is neglected. For privacy reasons, there are no salary information for levels 9 and 10 in the personnel files. 
Figure 3.4: MEAN WAGE

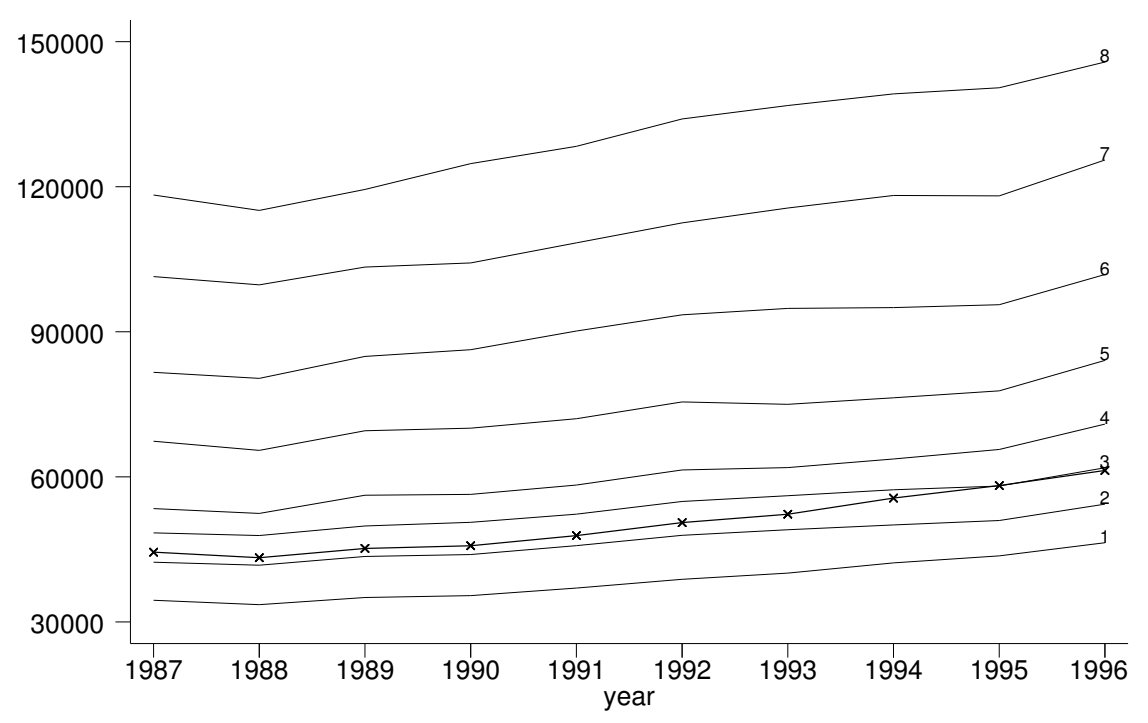

Notes: The figure plots average full-time equivalent nominal wages of incumbent workers in the hierarchical job levels 1 through 8, which are labelled accordingly. The thick crossed line reflects average full-time equivalent nominal wages at the firm-level. Means are calculated based on cross-sections taken at the beginning of a year.

adjust wage scales at the firm for inflation because of the firm's depressed economic condition. Such inflation corrections persist since January 1, $1996 .{ }^{25}$ However, the rise in average firm-level wages can be mainly attributed to the rise in the employment share in higher hierarchical levels resulting from the relative lower separation rates of high-wage workers discussed in section 3.4.1.

Separating Workers are more evenly distributed over the wage distribution than new hires (compare Tables 3.7 and 3.8). A substantial fraction of workers moves up in the job-level wage distribution before separating. This provokes the question of how big the spread in job-level wage distributions is, i.e. how much wage growth is associated with moving up a decile in the job-level wage distribution. Kernel density estimates of the within-level wage distributions in Figure 3.5 reveal substantial wage variation. The wage distributions in the figure refer to 1991, but their main features are the same in all years ${ }^{26}$ : Wages rise on average with job-levels, but wage distributions of successive

\footnotetext{
${ }^{25}$ This is the result of a collective bargaining outcome which underlines the importance of coordination between unions and employer federations in the Netherlands.

${ }^{26}$ Differences pertain to the remarkable fact that the 5 th percentile wage in level 3 exceeds the 5 th percentile wage in level 4 in every year until 1991, but never in later years. The substantial number of new hired white-collar workers during expansion, who typically enter level 4 and earn starting wages
} 
Figure 3.5: Job Level Wage Distributions in 1991

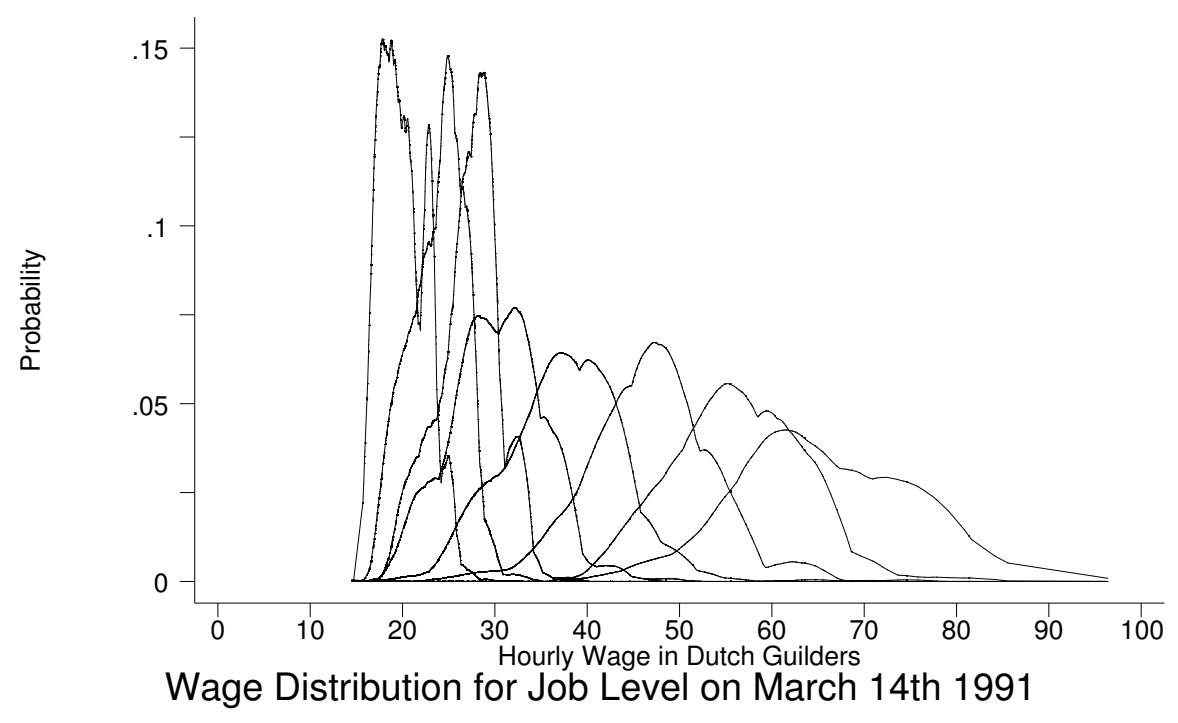

Notes: The figure plots kernel density estimates of the within job-level distribution of hourly full-time equivalent wages on March 14, 1991. Observed annual wages are truncated at 200,000 Dutch Guilders. This truncation affects only very few workers in level 8, but should not bias estimates of the wage distribution in level 8 significantly.

hierarchical levels overlap. Wages are definitely related to job levels as the correlation between job levels and wage scales already suggested, but wages are not tied to jobs in a strict sense as substantial within-job-level wage variation remains.

Within-level wage variation generally increases in hierarchical levels, ${ }^{27}$ but wage distributions for blue-collar job levels have a markedly smaller variance. This disparity in the pay structure most likely results from more stringent formal rules in blue-collar wage setting as a consequence of collective bargaining. The higher wage variation for white-collar workers suggests that there is scope for individual negotiation in spite of the formal wage system.

Still, the existence of pay ranges for jobs indicates that such scope is limited, certainly for blue-collar workers. For example, 99\% of assembly workers' wage contracts (the largest job code) are in wage scales $4-8$ (95\% are in 5-8). Within that pay range, individual wages depend on experience and tenure. The tenure-wage profile, however, is

in the bottom deciles of the within-level wage distribution, cause the left tail of the wage distribution in level 4 to stretch out in these years. A similar pattern holds for level 1 wage distribution which is also more skewed to the right during years of substantial entry.

${ }^{27}$ Note that we do not observe wages for those workers in level 8 whose annual wages exceed a 200,000

Dutch guilders, so that the observed wage distribution is truncated. 
again governed by the contractual wage system. The firm seems to have some discretion to reward workers below the top of the within-job pay range with higher wage growth by awarding more than 1 periodical increase at a time or granting a wage in a higher wage scale. However, once the highest wage in the job has been reached, additional wage growth - exceeding wage adjustments to aggregate conditions as fixed in collective bargaining agreements - can only result from job change. ${ }^{28}$

A transition to a higher paying job need not necessarily entail an upward transition in the hierarchy, as wage ranges differ for different jobs at the same hierarchical level. For example, catering staff, assembly workers and quality controllers are all in level 1, but the wage range is scales 3-4 (97\%) for catering jobs, scales 4-8 for assembly workers, and scales 5-9 (95\%) for quality controllers. This explains some of the within-level wage distribution depicted by Figure 3.5, but it also implies that lateral job mobility can be a source of wage growth. Potentially "flatter" career paths, which involve lateral job transitions associated with upward wage-mobility, exist. Before we consider this issue in section 3.6, we analyze the relation between wage growth and job transitions in more depth.

\subsection{Wage Growth and Job Transitions}

\subsubsection{How are Promotions and Demotions Defined?}

In the tournament model of Lazear and Rosen (1981), a promotion entails a transition to a higher hierarchical level and is associated with a substantial wage increase. But what a promotion really is, is not so clear. We have already seen that a transition to a job on the same hierarchical level with a higher median wage is another source of wage growth. Moreover, pure "wage-promotions" exist, when workers keep the same job, but progress to a higher wage scale and enjoy a steeper within-job wage profile than defined by the contractual tenure-wage profile. Information on the reason for a wage contract change reveals that contract changes are frequently coded as "promotion" when they coincide with job transitions to a higher level. Similarly, movements down the hierarchical ladder are often coded as demotions. ${ }^{29}$ Therefore, we refer to upward hierarchical transitions as

\footnotetext{
${ }^{28}$ In fact, a letter was sent to workers informing them once they had reached the highest wage in the job. Unfortunately, we lack the information when and to whom such a letter was sent, but we can infer such situations from the data.

${ }^{29}$ When such transitions occur on the date when contractual wage increases are awarded, a transition may not be coded as a promotion, but instead as a "yearly increase" or "price compensation" since only one reason for wage-contract change is recorded.
} 
promotions and to downward movements as demotions in the remainder of the chapter. Still, it is not obvious that such promotions are associated with wage growth as many theories predict, an issue to which we turn in the next section.

\subsubsection{Wages and Promotions}

Since wages are positively correlated with hierarchical levels, we expect wages to rise upon a promotion. The large difference in mean job-level wages unveiled by Figure 3.4 might suggest that promoted workers enjoy substantial wage gains. On the other hand, Figure 3.5 shows that wage distributions of successive levels overlap so that promotions might not be associated with nominal wage increases at all. We find that wage contracts are changed simultaneously with upward transitions in $51.6 \%$ of the cases. Nominal wages rise in these cases by an average of $5.2 \%$ and these upward job transition are mostly (in $72 \%$ of the cases) associated with climbing at least one wage scale. Wages change for the majority of the remaining $48.4 \%$ of upward movers occur within 3 months after the upward job transition. ${ }^{30}$ However, fewer of them $(29.9 \%)$ proceed to a higher wage scale and average wages grow less $(3.1 \%)$. Table 3.9 discloses that average wage increases upon promotions are substantially lower than the gap between mean wages of successive levels in both periods and for all levels.

This observation triggers the conjecture that workers only receive a new job title in order to grant them additional wage growth when they have reached the upper range of wages in their current job, which implies that workers are always promoted out of the top decile of their job-level wage distribution. Table 3.10 shows for each level what fraction of workers was promoted out of a given decile of that level's wage distribution and how promoted workers are distributed in the new level's wage distribution.

The table illustrates that promotees were predominantly, but not exclusively, in the upper deciles of their previous level wage distribution and mostly earn below median wages in their new job-level. In a more detailed analysis than is documented in Table 3.10 , we find that workers promoted out of the bottom three deciles of their job level wage distribution move predominately to the lowest decile of the wage distribution in the new job, workers from the 4th and 5 th decile move predominately to the 2 nd decile, from the 6 th and 7 th decile to the 3rd decile, and from the 8th, 9th, and 10th decile to the 4 th, 5th, and 6 th decile respectively. The transitions in the wage distributions of promoted workers are remarkably similar in both periods. We interpret this as evidence

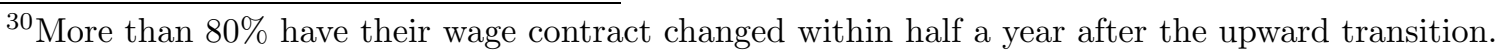


Table 3.9: Salary Premium of Promotion

\begin{tabular}{|c|c|c|c|c|c|c|}
\hline \multirow[b]{3}{*}{ Level } & \multicolumn{3}{|c|}{ 1987-1991 } & \multicolumn{3}{|c|}{ 1991-1996 } \\
\hline & \multicolumn{2}{|c|}{ Premium (\%) } & \multirow[t]{2}{*}{$\%$ diff. means } & \multicolumn{2}{|c|}{ Premium (\%) } & \multirow[t]{2}{*}{$\%$ diff. means } \\
\hline & immediate & later & & immediate & later & \\
\hline $1-2$ & $\begin{array}{c}4.7 \\
(2.4)\end{array}$ & $\begin{array}{c}2.7 \\
(2.1)\end{array}$ & 24.4 & $\begin{array}{c}4.4 \\
(2.7)\end{array}$ & $\begin{array}{c}2.9 \\
(1.9)\end{array}$ & 20.4 \\
\hline $2-3$ & $\begin{array}{c}4.4 \\
(2.2)\end{array}$ & $\begin{array}{c}3.1 \\
(2.3)\end{array}$ & 14.8 & $\begin{array}{c}4.4 \\
(2.4)\end{array}$ & $\begin{array}{c}2.9 \\
(1.8)\end{array}$ & 14.4 \\
\hline $3-4$ & $\begin{array}{c}5.4 \\
(4.3)\end{array}$ & $\begin{array}{c}3.1 \\
(3.0)\end{array}$ & 10.7 & $\begin{array}{c}4.9 \\
(3.1)\end{array}$ & $\begin{array}{c}3.7 \\
(2.4)\end{array}$ & 12.1 \\
\hline $4-5$ & $\begin{array}{c}5.7 \\
(3.1)\end{array}$ & $\begin{array}{c}3.7 \\
(2.7)\end{array}$ & 24.6 & $\begin{array}{c}5.6 \\
(3.5)\end{array}$ & $\begin{array}{c}3.4 \\
(1.9)\end{array}$ & 20.6 \\
\hline $5-6$ & $\begin{array}{c}5.6 \\
(2.4)\end{array}$ & $\begin{array}{c}3.2 \\
(2.3)\end{array}$ & 23.0 & $\begin{array}{c}6.3 \\
(7.0)\end{array}$ & $\begin{array}{c}3.4 \\
(2.2)\end{array}$ & 24.4 \\
\hline $6-7$ & $\begin{array}{c}6.5 \\
(4.2)\end{array}$ & $\begin{array}{c}3.2 \\
(1.9)\end{array}$ & 22.9 & $\begin{array}{c}8.4 \\
(10.9)\end{array}$ & $\begin{array}{c}2.6 \\
(1.9)\end{array}$ & 21.8 \\
\hline $7-8$ & $\begin{array}{c}8.3 \\
(6.9)\end{array}$ & $\begin{array}{c}1.8 \\
(1.8)\end{array}$ & 15.9 & $\begin{array}{c}8.5 \\
(11.4)\end{array}$ & $\begin{array}{c}2.9 \\
(1.9)\end{array}$ & 18.5 \\
\hline Total & $\begin{array}{c}5.2 \\
(3.3)\end{array}$ & $\begin{array}{c}3.1 \\
(2.5)\end{array}$ & 19.5 & $\begin{array}{c}5.2 \\
(4.9)\end{array}$ & $\begin{array}{c}3.2 \\
(2.1)\end{array}$ & 18.9 \\
\hline
\end{tabular}

Notes: The table shows salary premiums as percentage gains relative to the wage before the promotion. Workers either receive a wage increase on the day of promotion (immediate) or in the months following the promotion (later). Average premiums are calculated for both groups separately and are reported in the columns labelled "immediate" and "later". The columns labelled "\% diff. means" reports the percentage difference between the mean wage of adjacent job levels. Standard deviations are printed in parentheses below the means. For privacy reasons, there are no salary information for levels 9 and 10 in the personnel files. 
Table 3.10: Distribution of Pay for Promotees in Salary Deciles Before and After Promotions

\begin{tabular}{|c|c|c|c|c|c|c|c|c|c|c|c|c|}
\hline & & Bottom & $2 \mathrm{nd}$ & $3 \mathrm{rd}$ & 4 th & 5 th & 6 th & 7 th & 8 th & 9 th & Top & All \\
\hline Level 1 & before Promotion & 2.0 & 4.0 & 6.7 & 9.3 & 11.5 & 11.2 & 10.3 & 14.3 & 11.4 & 19.3 & 100.0 \\
\hline Level 2 & after Promotion & 27.7 & 19.7 & 16.3 & 12.1 & 9.9 & 6.5 & 3.2 & 2.5 & 1.4 & 0.7 & 100.0 \\
\hline Level 2 & before Promotion & 3.5 & 7.3 & 9.4 & 8.6 & 8.9 & 7.5 & 9.2 & 15.2 & 10.7 & 19.6 & 100.0 \\
\hline Level 3 & after Promotion & 18.4 & 17.8 & 15.6 & 18.0 & 11.6 & 8.4 & 4.5 & 2.6 & 2.1 & 1.2 & 100.0 \\
\hline Level 3 & before Promotion & 7.6 & 10.7 & 9.5 & 10.4 & 8.3 & 6.6 & 9.8 & 9.0 & 15.1 & 13.0 & 100.0 \\
\hline Level 4 & after Promotion & 10.5 & 15.4 & 15.6 & 17.6 & 16.6 & 9.7 & 7.9 & 3.6 & 1.8 & 1.4 & 100.0 \\
\hline Level 4 & before Promotion & 3.2 & 5.5 & 7.9 & 8.6 & 9.4 & 9.2 & 9.6 & 13.5 & 15.9 & 17.2 & 100.0 \\
\hline Level 5 & after Promotion & 17.6 & 21.4 & 17.7 & 16.4 & 12.3 & 7.5 & 2.7 & 1.6 & 1.9 & 1.0 & 100.0 \\
\hline Level 5 & before Promotion & 2.5 & 5.6 & 7.0 & 10.1 & 9.9 & 11.0 & 14.3 & 9.3 & 11.8 & 18.4 & 100.0 \\
\hline Level 6 & after Promotion & 29.2 & 25.3 & 16.8 & 8.9 & 8.1 & 2.3 & 3.5 & 3.1 & 1.9 & 1.0 & 100.0 \\
\hline Level 6 & before Promotion & 3.9 & 4.6 & 9.9 & 9.2 & 11.8 & 5.9 & 11.2 & 11.8 & 13.2 & 18.4 & 100.0 \\
\hline Level 7 & after Promotion & 36.2 & 23.7 & 9.2 & 7.2 & 13.2 & 5.9 & 0.0 & 2.6 & 0.7 & 1.3 & 100.0 \\
\hline Level 7 & before Promotion & 1.3 & 8.8 & 3.8 & 8.8 & 8.8 & 12.5 & 10.0 & 16.3 & 6.3 & 23.8 & 100.0 \\
\hline Level 8 & after Promotion & 16.3 & 21.3 & 13.8 & 7.5 & 18.8 & 10.0 & 7.5 & 2.5 & 1.3 & 1.3 & 100.0 \\
\hline
\end{tabular}

Notes: The table shows percentage shares of promoted workers' wages across deciles of the respective job level wage distribution before and after their promotion. Wage distributions are based on hourly wages for all workers employed in the relevant job level and period. We calculated the wage deciles of the current wage distribution on different dates on which the bulk of wage contracts were adjusted, e.g. because of (semi-)annual inflation compensation, during the period. The table only summarizes information of workers promoted to the next higher level. For privacy reasons, there are no salary information for levels 9 and 10 in the personnel files. 
Table 3.11: Serial Correlation in Wage Growth

\begin{tabular}{|c|c|c|c|}
\hline & \multicolumn{3}{|c|}{ Dependent Variable: $\Delta \ln (W)$} \\
\hline$\Delta \ln (W)_{t-1}$ & $\begin{array}{r}0.424 \\
(0.017)^{*}\end{array}$ & $\begin{array}{r}0.416 \\
(0.017)^{*}\end{array}$ & $\begin{array}{r}-0.013 \\
(0.006)\end{array}$ \\
\hline Promotion & & $\begin{array}{r}0.033 \\
(0.001)^{*}\end{array}$ & $\begin{array}{r}0.026 \\
(0.001)^{*}\end{array}$ \\
\hline Promotion $_{t-1}$ & & $\begin{array}{r}-0.001 \\
(0.001)\end{array}$ & $\begin{array}{r}0.005 \\
(0.000)^{*}\end{array}$ \\
\hline Controls for Individual Characteristics & No & No & Yes \\
\hline Year Dummies & Yes & Yes & Yes \\
\hline Observations & 75772 & 75772 & 75772 \\
\hline R-squared & 0.36 & 0.40 & 0.61 \\
\hline
\end{tabular}

Notes: The dependent variable in all estimations is the log differences of annual hourly wages $(\Delta \ln (W))$. Reported coefficients are marginal effects evaluated at the mean of the explanatory variables. Standard errors are in parentheses. An asterisk denotes that the coefficient is significant at the 1 percent level. Controls for individual characteristics include binary variables for nine education categories, yearly age dummies, tenure, dummies for hierarchical levels, and binary variables for the six performance evaluation scores.

that the principal reason for a vertical job transition is not to merely grant higher wages, but to assign workers to more complex jobs with more responsibility or span of control.

In addition, our results concerning the relation between wages and upward job transitions do not suggest that tournaments as described in Lazear and Rosen (1981) explain promotions in levels 1-8 well. For one thing, Table 3.9 does not provide evidence of a convex relation between the logarithm of wages and hierarchical levels. The percentage differences between mean wages of adjacent levels are similar across levels, and if anything, slightly decreasing in job levels in both blue-collar and white-collar ranks. ${ }^{31}$ Unfortunately, we do not observe wages for workers in the two top levels where one would expect tournaments more likely to be relevant. Although immediate wage increases upon promotions are much smaller than tournament theory would predict, the discounted value of expected future wages might rise substantially. A promotion entails an improved perspective of future wage growth beyond the immediate wage rise enjoyed upon the promotion, because those workers may climb the wage ladder in their new job.

\footnotetext{
${ }^{31}$ The difference in level 7 and level 8 mean wages is, of course, an underestimate of the true difference since wages of some workers in level 8 are not reported as the distribution of reported wages is truncated at 200,000 guilders.
} 
Table 3.12: Promotion and Wage Growth

\begin{tabular}{l|rrr}
\hline & Dependent & Variable: Promotion \\
\hline$\Delta \ln (W)_{t-1}$ & 0.413 & 0.719 & -0.101 \\
& $(0.045)^{*}$ & $(0.062)^{*}$ & $(0.06)$ \\
Promotion $_{t-1}$ & & -0.088 & -0.08 \\
& & $(0.003)^{*}$ & $(0.003)^{*}$ \\
& & & No \\
Controls for Individual Characteristics & No & Yes & Yes \\
Year Dummies & Yes & Yes \\
\hline Observations & 39728 & 39728 & 39521 \\
\hline
\end{tabular}

Notes: The dependent variable in all estimations is a binary variable indicating a promotion. $\Delta \ln (W)$ denotes the log differences of annual hourly wages. Reported coefficients are marginal effects evaluated at the mean of the explanatory variables. Standard errors are in parentheses. An asterisk denotes that the coefficient is significant at the 1 percent level. Controls for individual characteristics include binary variables for nine education categories, yearly age dummies, tenure, and binary variables for the six performance evaluation scores.

We find evidence that wage growth rates are persistent. For every year, we calculated the wage growth distribution separately. Workers with wage growth in the upper (lower) quartile of the wage growth distribution are likely to be in the upper (lower) quartile in subsequent years. Regression results reported in Table 3.11 show a positive effect of lagged wage growth on current wage growth (column 2) even if we control for recent promotions (column 3). This strong effect disappears if we control for the concavity of the tenure-wage profile, individual characteristics, such as age and education, and job characteristics (column 4). ${ }^{32}$ These results raise the question of whether wage increases predict promotions as workers who are candidates for higher level positions might already be rewarded for better than average performance by higher than usual wage increases in their current job. Moreover, if promotion fast-tracks (Rosenbaum 1984) exist and if promotions are associated with wage growth (see previous section), past wage increases should identify career movers and predict future promotions. In order to test the predictive power of previous wage increases for a promotion, we estimate probit models in cross-sections of the data, in which promotions are explained by past wage growth, and individual characteristics.

The results reported in Table 3.12 show that past wage growth has a positive effect on

${ }^{32}$ These regression results portray the pattern of serial correlation in individual wage growth well. Yet, we are aware that more sophisticated econometric techniques and estimators could improve the results along various dimensions, e.g. increase efficiency, account for learning effects (see Farber and Gibbons, 1996), etc. 
the probability to be promoted (column 2 and 3), but that this effect works through the impact of individual characteristics on wage growth, as the direct effect of wage growth on promotion probability disappears if we include controls for tenure, age, education, and performance evaluation (column 4).

\subsubsection{Wages and Demotions}

The logic of the previous section which established that promotions are associated with nominal (and real) wage growth suggest wage cuts at demotions. However, nominal wage cuts are extremely rare. Only 197 nominal hourly wage rate cuts are recorded, which amounts to 0.1 percent of all wage contract changes. ${ }^{33}$ Ninety percent of those experiencing nominal cuts remain in the same function. Moreover, most nominal wage cuts (117 out of 197) occur between January 1993 and January 1995 and are concentrated (105 out of 117) at a single plant (ELMO). ${ }^{34}$ The absolute number of observed wage cuts would obviously be smaller if we had data at yearly frequency, due to attrition and within-year contract changes. ${ }^{35}$ Real wage cuts become more frequent during downsizing. In 1994 and 1995, 33.8 percent and 42.5 percent of employees, respectively, do not receive nominal wage increases. ${ }^{36}$ Nominal wages are rarely cut (only 8 out of 1957 times) when a worker is demoted. This partly results from rules in collective bargaining agreements which prescribe that the nominal wages of workers demoted to a lower job level can only be lowered after a period of advance notice which depends on the worker's age and tenure. But we observe that demoted workers are downgraded in the salary scales, which reduces their prospect of future wage growth.

\subsection{Careers}

Careers are a crucial characteristic of internal labor markets. According to the theory of internal labor markets careers help foster long-term employment relations and shield workers from external labor market conditions. We saw already in section 3.4 that most workers do not move up in the hierarchy during five-year periods, and that only few workers move up more than 1 level. This triggers a number of questions. Are

\footnotetext{
331309 further contracts entail nominal wage cuts because of changes in working hours.

${ }^{34}$ Wage drops are due to fewer shifts at ELMO during downsizing, i.e. result from reduced working hours.

${ }^{35}$ If we base our analysis on a yearly panel in which the cross-sections are taken on March 14 in each year, we would observe only 134 nominal wage cuts.

${ }^{36}$ Nominal wage freezes are more frequent for workers affected by collective bargaining agreements.
} 
Table 3.13: Age And Tenure: New Hires versus Promoted Incumbents

\begin{tabular}{|c|c|c|c|c|c|c|}
\hline \multirow[b]{3}{*}{ Level } & \multicolumn{4}{|c|}{ Age } & \multicolumn{2}{|c|}{ Tenure } \\
\hline & \multicolumn{2}{|c|}{$1987-1991$} & \multicolumn{2}{|c|}{ 1991-1996 } & $1987-1991$ & 1991-1996 \\
\hline & Entree & Promotee & Entree & Promotee & Pro & otee \\
\hline 1 & $\begin{array}{r}24.5 \\
(6.8)\end{array}$ & & $\begin{array}{c}25.2 \\
(6.6)\end{array}$ & & & \\
\hline 2 & $\begin{array}{c}26.4 \\
(6.4)\end{array}$ & $\begin{array}{c}30.3 \\
(7.2)\end{array}$ & $\begin{array}{c}28.2 \\
(6.8)\end{array}$ & $\begin{array}{c}31.3 \\
(7.1)\end{array}$ & $\begin{array}{r}7.2 \\
(6.7)\end{array}$ & $\begin{array}{r}8.3 \\
(6.9)\end{array}$ \\
\hline 3 & $\begin{array}{c}27.8 \\
(6.0)\end{array}$ & $\begin{array}{r}35.0 \\
(8.2)\end{array}$ & $\begin{array}{c}28.4 \\
(7.4)\end{array}$ & $\begin{array}{c}34.9 \\
(7.2)\end{array}$ & $\begin{array}{c}11.1 \\
(9.1)\end{array}$ & $\begin{array}{c}11.8 \\
(8.4)\end{array}$ \\
\hline 4 & $\begin{array}{r}27.5 \\
(4.8)\end{array}$ & $\begin{array}{c}35.4 \\
(8.6)\end{array}$ & $\begin{array}{r}26.7 \\
(4.9)\end{array}$ & $\begin{array}{c}34.9 \\
(7.2)\end{array}$ & $\begin{array}{c}10.5 \\
(9.6)\end{array}$ & $\begin{array}{c}10.6 \\
(8.8)\end{array}$ \\
\hline 5 & $\begin{array}{r}30.6 \\
(6.7)\end{array}$ & $\begin{array}{c}34.4 \\
(7.2)\end{array}$ & $\begin{array}{c}28.1 \\
(4.4)\end{array}$ & $\begin{array}{r}34.7 \\
(6.8)\end{array}$ & $\begin{array}{r}8.5 \\
(8.0)\end{array}$ & $\begin{array}{r}8.3 \\
(7.4)\end{array}$ \\
\hline 6 & $\begin{array}{c}33.5 \\
(6.2)\end{array}$ & $\begin{array}{r}38.1 \\
(7.5)\end{array}$ & $\begin{array}{c}35.1 \\
(8.7)\end{array}$ & $\begin{array}{r}36.9 \\
(6.4)\end{array}$ & $\begin{array}{c}10.8 \\
(8.5)\end{array}$ & $\begin{array}{c}10.4 \\
(8.0)\end{array}$ \\
\hline 7 & $\begin{array}{r}39.3 \\
(6.6)\end{array}$ & $\begin{array}{c}39.1 \\
(6.1)\end{array}$ & $\begin{array}{r}39.3 \\
(6.1)\end{array}$ & $\begin{array}{c}39.8 \\
(6.1)\end{array}$ & $\begin{array}{r}11.2 \\
(6.8)\end{array}$ & $\begin{array}{c}11.8 \\
(7.6)\end{array}$ \\
\hline 8 & $\begin{array}{c}44.6 \\
(6.3)\end{array}$ & $\begin{array}{r}42.5 \\
(7.1)\end{array}$ & $\begin{array}{r}40.9 \\
(7.2)\end{array}$ & $\begin{array}{c}41.4 \\
(5.4)\end{array}$ & $\begin{array}{c}14.0 \\
(9.7)\end{array}$ & $\begin{array}{c}13.0 \\
(7.0)\end{array}$ \\
\hline
\end{tabular}

Notes: The table compares entry ages and firm tenure of promoted incumbents and workers hired into the same level for the episodes of workforce expansion (1987-1991) and workforce contraction 19911996). Columns 2-5 show the mean ages of workers respective levels and provide standard deviations in parentheses below the respective means. Columns 6-7 report firm tenure of promoted workers. When judging the magnitude of the standard deviations, it should be taken into account that the age and tenure distributions are very skewed.

there career paths within job levels along which workers transfer to jobs on the same hierarchical level? Are such jobs more attractive, both in terms of wages and the amount of shielding from external conditions? We begin, however, by investigating whether firmspecific capital is important in our firm by assessing whether workers hired from outside into a job level differ in their characteristics from workers who are promoted to the same level from within.

\subsubsection{New Hires versus Incumbents}

To shed light on the question of whether specific-capital is important in our firm, we compare age and education levels of new hires to a given level and workers promoted from inside to the same level. Table 3.13 shows that new hires into levels $2-5$ are on average 4.5 to 7 years younger than incumbent workers who have been promoted to the 
same hierarchical level. Age differences are smaller in higher levels and almost negligible in levels 7 and 8 . The pattern does not differ between periods. The two right-most columns show that promoted workers have on average been employed in the firm for 7 to 12 years. ${ }^{37}$ If firm-specific capital is important in the firm, promoted workers should have accumulated sizable levels of firm-specific capital during their elapsed tenure and new hires should compensate by either having more experience - which is unlikely given that they are substantially younger on average - or higher levels of education. Table 3.14 reveals that new beginners indeed hold higher level general and vocational schooling degrees than promoted incumbent workers. So new hires seem to make up for lower levels of firm-specific capital with higher levels of general capital.

\subsubsection{Job Ladders Across Hierarchical Levels}

An important characteristic of our firm is the existence of different career paths, which sometimes span different hierarchical levels. The distribution of workers across levels in different fields of activities provides evidence of such "pyramids within the hierarchical pyramid". For example, more than $80 \%$ of workers in "Production" (F) are in level 1 and $97.8 \%$ are blue-collar workers. This might be contrasted with "Sales" where $85 \%$ of the employees are in management levels. Two classes of career tracks can be identified in the white-collar ranks of "R\&D". The first type is a classical engineering career which involves concentration on technical aspects and specialization therein. These careers typically span levels $4-6 .{ }^{38}$ Workers on this career track typically start as a staff member of engineering on level 4, then they may become a specialist or engineer on level 5, and finally be promoted to a lead engineer or senior specialist (commonly in aircraft design) on level 6. The second type of career is management career in which workers concentrate on supervision handling of the day-to-day business. Positions in the management career track include "Design Division Leader" on level 4, "Project Leader" or "Chief of Engineering Group" on level 5, and "Head of Division" on level 6. Finally, it should be mentioned that careers on lower ranks also exist in R\&D. About $16 \%$ are employed in these ranks, working predominately as designing engineers.

A typical career path in "Sales \& Customer Relations" which may lead to a position on level 8 as "Area Manager" or "Area Sales Manager" starts on level 4 as an "Air-

\footnotetext{
${ }^{37}$ Average tenure in the table escalates with level because the table reports average years of tenure since accession to the firm and not the average years spent in the lower hierarchical level, which is smaller for those who experience more than one promotion.

${ }^{38}$ Roughly $70 \%$ of the entire workforce in the activity field "R\&D" are employed in these levels. The number varies somewhat over time.
} 
Table 3.14: Education Level: New Hires versus Promoted Incumbents

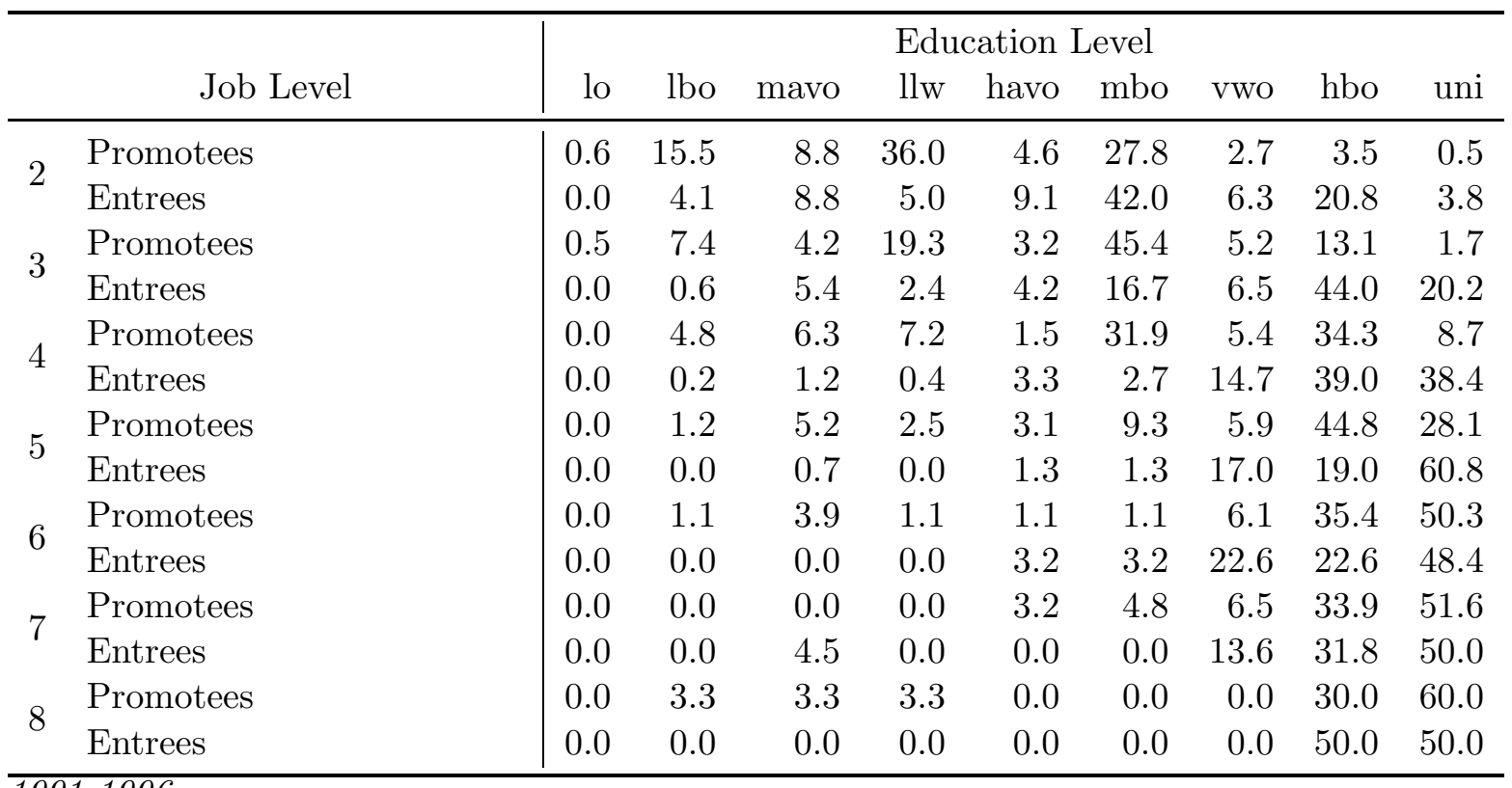

1991-1996

\begin{tabular}{|c|c|c|c|c|c|c|c|c|c|c|}
\hline \multirow{2}{*}{\multicolumn{2}{|c|}{ Iob }} & \multicolumn{9}{|c|}{ Education Level } \\
\hline & & lo & lbo & mavo & llw & havo & mbo & vwo & hbo & uni \\
\hline \multirow{2}{*}{2} & Promotees & 0.4 & 10.4 & 10.9 & 33.0 & 4.9 & 35.4 & 2.1 & 2.7 & 0.2 \\
\hline & Entrees & 0.0 & 0.0 & 8.3 & 1.7 & 5.0 & 43.3 & 13.3 & 20.0 & 8.3 \\
\hline \multirow{2}{*}{3} & Promotees & 0.7 & 5.8 & 5.1 & 20.7 & 5.1 & 49.5 & 0.4 & 10.5 & 2.2 \\
\hline & Entrees & 0.0 & 1.8 & 0.0 & 0.0 & 1.8 & 8.9 & 14.3 & 55.4 & 17.9 \\
\hline \multirow{2}{*}{4} & Promotees & 0.0 & 5.0 & 3.1 & 10.0 & 4.6 & 36.4 & 2.3 & 28.7 & 10.0 \\
\hline & Entrees & 0.0 & 0.6 & 0.6 & 0.0 & 2.3 & 6.3 & 13.1 & 43.8 & 33.5 \\
\hline \multirow{2}{*}{5} & Promotees & 0.0 & 1.3 & 2.5 & 2.3 & 1.5 & 12.4 & 7.9 & 44.4 & 27.7 \\
\hline & Entrees & 0.0 & 0.0 & 0.0 & 0.0 & 1.2 & 1.2 & 13.1 & 14.3 & 70.2 \\
\hline \multirow{2}{*}{6} & Promotees & 0.0 & 0.9 & 3.6 & 1.4 & 2.7 & 6.3 & 10.8 & 34.2 & 40.1 \\
\hline & Entrees & 0.0 & 0.0 & 0.0 & 6.3 & 0.0 & 0.0 & 6.3 & 31.3 & 56.3 \\
\hline \multirow{2}{*}{7} & Promotees & 0.0 & 1.4 & 2.9 & 0.0 & 0.0 & 2.9 & 7.1 & 34.3 & 51.4 \\
\hline & Entrees & 0.0 & 0.0 & 0.0 & 0.0 & 0.0 & 0.0 & 0.0 & 37.5 & 62.5 \\
\hline \multirow{2}{*}{8} & Promotees & 0.0 & 0.0 & 3.0 & 0.0 & 3.0 & 9.1 & 9.1 & 21.2 & 54.5 \\
\hline & Entrees & 0.0 & 0.0 & 0.0 & 0.0 & 0.0 & 0.0 & 100.0 & 0.0 & 0.0 \\
\hline
\end{tabular}

Notes: The table compares highest obtained schooling degrees of promoted and workers hired into the same level for the episodes of workforce expansion (1987-1991, upper block) and workforce contraction 1991-1996, lower block). The cells show the percentages of promotees or entrants with a given schooling degree so that rows sum to 100. 
craft Analyst" or "Account Manager" and involves transitions to "Market Development Engineer" (level 5), "Account Development Manager" (level 6), and "Sales Manager" (level 7). Career tracks in lower levels also exist and are predominately followed by higher-ranked blue-collar workers who transfer from production. In particular, "Basic Instrument Experts" (level 2 in production) proceed to become "Instructors" (level 3) in "Sales \& Customer Relations" and may be promoted to become a "Technical Representative" on level 4. (We also observe inflow into this job from level 3 - production workers.) Workers on this career track proceed to "Resident Technical Representative", but most careers that we observe end there. Only one person goes on to level 6 as "Customer Support Manager". Two persons make further careers by entering different jobs after having been a "Technical Representative".

A substantial fraction of the inflow into both activities described above - R\&D and Sales \& Customer Relations - has experience elsewhere in the firm. Only $35.2 \%$ of workers who enter "Sales \& Customer Relations" from January 1987 until March 1991 are hired from outside. Those who enter from within the firm come predominately from "R\&D". Similarly, only $56.2 \%$ of new entrants into "R\&D" are new hires. Workers who transfer from other activities come predominately from production (73.6\%). This finding underpins the importance of firm-specific knowledge, not least knowledge of the sophisticated product of the firm. The degree to which such firm-specific knowledge is important varies between different activities as one would expect. There is substantially less inflow from within relative to inflow from outside in administrative activities (K, H, S). Between 1987 and 1991, when all non-production activities of the firm (Administrative activities (K, H, S), R\&D (C), and Sales \& Customer Relations (B)) grew at a similar rates (see Figure 3.1), 64.5\% of all new entrants into administrative activities were recruited from outside.

The existence of jobs that require knowledge acquired in other jobs in the firm implies that careers are important in the firm's internal labor market. This conjecture is confirmed when we examine job transitions across the five activities within production (Assembly (F), Support \& Supplies (G), Production Preparation (D), Planning \& Coordination (E), and Quality (M)). Of all 4184 workers who are hired into production during expansion, 3062 enter into "Assembly", a share that is substantially larger than the relative size of "Assembly" within production at all times. Only 309 enter "Assembly" from a job elsewhere in the firm, and only 140 of them enter into a job on level 1 , where more than $80 \%$ of workers in this activity are employed. Many more workers (818) leave "Assembly" for jobs in other activities of the firm during the same period, 
and most of them (578) change jobs to one of the other 4 production related activities.

In contrast, 362 workers are hired into "Production Preparation", but 651 are transferred from within (267 of whom come from Assembly). "Quality" is the activity where hiring from outside (122) relative to transfers from within (327) is lowest. Most of the workers (208) who enter "Quality" worked in "Assembly" before and remain on the same job level (189). But they usually climb a wage scale upon the transition. Hence, these lateral transitions reflect careers within a job level. Other examples of such career monkey bars are discussed in the next section.

$28.8 \%$ of all job changes - and $24.5 \%$ of lateral transitions - involve transitions to different fields of activity. Yet, we observe that the inflow from outside diminishes with further advancement in career tracks, implying that career decisions are for the most part taken early on, and career changes become rarer later in the employment relation.

\subsubsection{Monkey Bars Within Hierarchical Levels}

Careers within hierarchical levels are important. In fact, wriggling the monkey bars of a within-level career is a more common phenomenon than climbing the career ladder by upward hierarchical job transitions. As already mentioned, examples include transitions from assembly workers to quality controllers, but also exist within more narrowly defined fields of activities. One particular, but typical, example is the transition from "Assembler Electrical Assembly A" to "Assembler Electrical Assembly B" which commonly does result in an immediate advancement in wage scales, but does so eventually as the median wage scale is higher for the latter job. Roughly two thirds of lateral movements are transitions to jobs with a higher mean wage scale. ${ }^{39}$ More interesting, we observe 251 transitions from the first to the latter job, but only one worker is hired from outside to the latter job during the entire observation period. Jobs towards the higher end of within-job career tracks are less frequently filled from outside.

Within-level careers are also typical for secretaries ${ }^{40}$ Lateral career movements frequently involve a transition from secretary of a section chief to secretary of a department head. For secretarial jobs, there is, however, substantially more entry from outside into positions further down the career path than for jobs in production or quality control. An obvious explanation is the greater importance of firm-specific knowledge in the latter jobs. But still, even for secretaries we find that positions for secretaries of

\footnotetext{
${ }^{39}$ As for vertical job mobility, lateral career paths are no one-way route and "demotions" occur.

${ }^{40}$ Secretaries account for $2.2 \%$ to $2.5 \%$ of the workforce at all times and $3.7 \%$ of all observed workers have been a secretary at some point in time.
} 
department heads are most frequently filled by job transitions from within. Two other features that seem to be important for careers in general can be illustrated with the help of the 'secretary example': First, lateral movements are sometimes stepping stones for upward transitions: either within the secretary career or to other jobs within the firm. Secretaries can move upward to become the secretary of a division director or even of the Executive Board. But we also observe transitions to supervisory jobs (mostly in data processing) to higher-level administrative workers and eventually to lower level managers (mostly with tasks related to human resource management).

\subsection{Conclusion}

Our analysis confirms the existence of an internal labor market and the importance of lateral and vertical job mobility therein. Since wages are related to job levels, transitions are material for workers' wage growth. Although immediate gains upon promotions are small - often job transitions and wage changes do not even coincide - compared to the average difference in wages for adjacent job levels, promoted workers can look forward to a period of sustained wage growth as they move up in their new job level's wage distribution. The spread of these job-level wage distributions is substantial so that wages in job levels overlap. Therefore, wages are not strictly tied to jobs as there remains considerable scope to reward workers individually. Wriggling the monkey bars in within-level careers is another valuable means for workers to secure wage growth. Lateral job changes are a significant phenomenon, which can be explained by firmspecific capital requirements in particular jobs, involving more workers and more job changes than vertical job transitions.

For the firm, the staffing of positions from within is essential especially in jobs which require firm-specific knowledge. Such organizational or firm-specific capital seems crucial in a number of jobs. Workers hired from outside must make up for the lack of firm-specific capital by obtaining higher completed schooling degrees than workers promoted from within. Even though entry occurs at all levels, entry rates are substantially smaller in some career tracks for jobs further down the career path. We find that the firm's hierarchy of job levels is relatively stable throughout periods of expansion and contraction. The hierarchical job pyramid is neither augmented by job levels during expansion nor diminished during contraction. However, relative sizes of job levels change during downsizing when the firm becomes top-heavy. This is most likely the result of sizeable differences in adjustment costs for different workers, particularly when firm- 
specific capital is substantial in jobs further down a career path and future growth is expected as was the case at our firm. Changes in firm size in general and changes in relative entry and exit rates have considerable impact on job transition rates. Promotion rates fall and demotion rates rise the more the net employment growth rates fall. 


\section{Ranks, Organizational Change, and Worker Heterogeneity}

"The hierarchical decomposition principle can thus be stated as follows: internal organization should be designed in such a way as to effect quasi-independence between parts, the high frequency dynamics (operating activities) and the low frequency dynamics (strategic planning) should be clearly distinguished, and incentives should be aligned within and between components so as to promote both local and global effectiveness"

(Williamson, 1981, p. 1550) 


\subsection{Introduction}

One of the central roles of firms is monitoring employees, and the design of hierarchies is reflected by the number of ranks and the associated span of control to do so efficiently $^{1}$. Structural changes in information, communication and production technology can prompt adaption in organizational design, especially when the adaption to shocks require changes in specialization ${ }^{2}$.

Hierarchies in organizations have been found to be firm-specific, stable through time, and seemingly independent of demand cycles $^{3}$. Despite a long tradition of insightful research on the economics of hierarchical structures, surprisingly little is known about the role hierarchies play in the firm's decision to restructure its workforce. Much of what we learned about the relationship between individual workers' characteristics and mass layoffs in hierarchical organizations so far can be summarized simply through the observation that fewer jobs are cut for high skilled and managerial employees.

This chapter investigates the role of organizational structure on workforce reorganizations. The firm makes decisions under uncertainty and faces irreversible costs of changing sizes of ranks. The menu costs model produces sharp predictions on how ranks and worker characteristics produce differences in restructuring propensities across ranks. These predictions are comparable to those derived from menu costs rules for durable and investment goods. ${ }^{4}$ The empirical application uses data from the aircraft industry. Specifically, we ask whether the decision makers responsible for the 1996 reorganization of Fokker Aircraft in the Netherlands have been applying such rules when deciding how to adjust the company's organizational structure and which workers to select to stay. The econometric - hierarchical elimination - model, that is derived for testing the theory's predictions, is based on an extreme value structure that generalizes into a nested multinomial logit (NMNL) model. The NMNL model is consistent with profit maximization under uncertainty (McFadden 1984).

The chapter is organized as follows. Section 2 presents the theoretical model of downsizing under uncertainty. Section 3 presents the data and discusses the construction of some of the variables used in the econometric analysis. Section 4 presents the econometric model. Section 5 presents the estimation results and the tests of different model specifications. In Section 6, we show that a reorganization of the workforce that modifies

\footnotetext{
${ }^{1}$ Alchian and Demsetz (1972), Calvo and Wellisz (1979), MacLeod and Malcomson (1988)

${ }^{2}$ Radner (1992), Garicano (2000), Carroll and Hannan (2000).

${ }^{3}$ Marschak and Radner (1972), Williamson (1973), Rosen (1982), Baker et al. (1994a).

${ }^{4}$ Eberly (1994), Caballero and Engel (1999).
} 
the composition of ranks within skills groups while input ratios remain constant, can arouse increased wage inequality between skills groups. Section 7 concludes.

\subsection{A theoretical model of hierarchical workforce reorganization}

A multi skill-level hierarchical firm produces output with a given production technology $Y=f\left(L_{1}, . ., L_{S}\right)$, where $L_{s}, s=1, . ., S$ is the input of workers with skill level $s$. Each skill group's production is organized in ranks of size $L_{r s}$, so that skill group $s$ is $L_{s}=\sum_{r=1}^{R_{s}} L_{r s}$, where $r=1$ refers to the lowest rank, and $r=R_{s}$ corresponds to the highest rank of skill group $s$. The size of the firm is $N=\sum_{s=1}^{S} \sum_{r=1}^{R_{s}} N_{r s}$.

The number of ranks is fixed, but for each skill group the composition between ranks can change, e.g. as a result of a reorganization. The firm's decision problem for every level $s$ and rank $r$ is to select $N_{r s}<L_{r s}$ workers as to maximize the discounted future value profits $V\left(\Pi_{r s}\right), i=1, . ., N_{r s}$, with $V\left(\Pi_{r s}\right)$ being monotonous in rank-specific profits $\Pi_{r s}$.

The firm invests $Q_{r s}$ in each rank. The investments produce rank-specific productivity $Y_{r s}^{Q}$ in addition to the general productivity $Y_{r s}^{G}$ in absence of $Q_{r s}$. The additional remuneration costs of this firm-specific productivity is $W_{r s}^{Q}$. The firm and the workers share the rent of this specific investment, so that $Y_{r s}^{Q}>W_{r s}^{Q}$ iff $Q_{r s}>0 .{ }^{5}$ Profits obtained from investing $Q_{r s}$ is defined as

$$
\Pi_{r s}^{*}=Y_{r s}^{G}-W_{r s}^{G}+Y_{r s}^{Q}-W_{r s}^{Q}
$$

with $\Pi_{r s}^{*} \geq 0$ iff $Q_{r s}>0$. The return is concave in the number of workers for which the firm invested in firm-specific productivity. Moreover, the specific profit structure is such that for each rank the returns per worker are maximized at some optimal investment level $Q_{r s}^{*}<\infty$, so that $\partial \Pi_{r s}^{*} / \partial Q_{r s}^{*} \geq 0$ and $\partial^{2} \Pi_{r s}^{*} / \partial\left(Q_{r s}^{*}\right)^{2}<0$. We assume that $W_{r s}^{Q}>0$ is fixed. The stochastic part of the future rank-specific profits is then defined as

$$
\Pi_{r s}^{=} Y_{r s}^{G}-W_{r s}^{G}+Y_{r s}^{Q}
$$

Diffusion of shocks — such as a shock in communication technology or skill biased

\footnotetext{
${ }^{5}$ The possibility to obtain stocks and bonds as part of the employment contract is not considered in this model.
} 
innovations - renders profits $\Pi_{r s}$ more uncertain the longer the time horizon is over which the returns of the investments will be discounted. Let $\Pi_{r s}^{L}$ be defined as the firm's unobserved rank-specific profit cut-off boundary. An expression for $\Pi_{r s}^{L}$ yields ${ }^{6}$

$$
\Pi_{r s}^{L}=\left(\frac{\rho-\mu_{r s}}{\rho}\right)\left(\frac{\lambda_{r s}}{\lambda_{r s}-1}\right)\left(W_{r s}^{Q}-\rho F_{r s}\right)
$$

where $\rho$ is the real interest rate which we assume constant. $W_{r s}^{Q}$ is the rank-specific rents from firm-specific productivity. The higher $W_{r s}^{Q}$, the lower the rents that flow to the firm. $F_{r s}$ represents firing costs at skills level $s$ in rank $r$. Firing costs are nonlinear functions of the wage, the number of hours worked, and the age/tenure structure. We expect the impact of firing costs to differ across ranks. The expected growth of rankspecific profits is denoted as $\mu_{r s} ; \lambda_{r s}$ is a non-linear function of $\rho, \mu_{r s}$, and the future uncertainty of $\mu_{r s}$, denoted as $\sigma_{r s}^{\mu}$. With $\rho>\mu_{r s} ; \lambda_{r s}<0$, and $W_{r s}^{Q}-\rho F_{r s}>0$, the minimum profit cut-off value $\Pi_{r s}^{L}$ is always positive.

The hierarchical structure of skills groups is defined by the following property

$$
\Pi_{r s}^{L}>\Pi_{r-1, s}^{L} \text { for all } 2<r \leq R_{s}, \text { given } s
$$

Equation 4.4 states that workers in higher ranks are more valuable to the firm (e.g. Lazear and Rosen (1981)).

When a firm has reached a state of insolvency, the option to choose the optimal size and time to reorganize has expired. The menu costs rules still apply, but the waiting time is foregone. This provides the opportunity of studying the workings of the menu costs rules by observing reorganization decisions. The firm's reorganization policy can be written in terms of partial derivatives. Theoretical predictions are as follows:

(P1): $\Pi_{s}^{\mu} \equiv \partial \Pi_{r s}^{L} / \partial \mu_{r s}$ with $\Pi_{s}^{\mu}<0$.

P1 states that if $\mu$ increases the firm will restructure its workforce such that profits will be shifted from lower to higher ranks. For every skills type $s$ the reorganizing firm is more likely to retain workers in ranks with higher expected within-firm profit growth. Rank specificity can result in changes in the relative sizes of ranks, even in the case that the labor input ratios of skills levels $s$ remain unchanged.

(P2) $\Pi_{s}^{W} \equiv \partial \Pi_{r s}^{L} / \partial W_{r s}^{Q}$ with $\Pi_{s}^{W}>0$.

$\mathrm{P} 2$ shows that lower shares in the firm's rents - higher $W_{r s}^{Q}$ — induces the firm to

${ }^{6}$ The derivation of this expression can be found in note called "Random Profit Maximization under Menu Costs Rules" and can be obtained upon request. The expression for $\lambda_{r s}$ yields

$$
\lambda_{r s}=-\left(\frac{\mu_{r s}}{\sigma_{r s}^{\mu}}-\frac{1}{2}\right)-\sqrt{\left(\frac{\mu_{r s}}{\sigma_{r s}^{\mu}}-\frac{1}{2}\right)^{2}+\frac{2 \rho}{\sigma_{r s}^{\mu}}}<0 .
$$


reduce ranks. The firm is inclined to reduce the size of ranks with the highest $W_{r s}^{Q}$.

(P3) $\Pi_{s}^{F} \equiv \partial \Pi_{r s}^{L} / \partial F_{r s}$ with $\Pi_{s}^{F}<0$.

Higher firing costs reduce the risk of decreasing the size of the rank. Consequently, workers employed in ranks that are characterized by a distribution reflecting relatively high firing costs are less likely to be displaced. The first three predictions are rather obvious. The fourth and last prediction is surprising and needs some intuition. It yields

(P4) $\Pi_{s}^{\sigma} \equiv \partial \Pi_{r s}^{L} / \partial \sigma_{r s}^{\mu}$ with $\Pi_{s}^{\sigma}<0$.

$\mathrm{P} 4$ states that ranks associated with more uncertainty about future profit growth are less likely to be reduced in size; in volatile parts of the production process the firm prefers to hold a larger share of workers as it is reluctant to exercise the irreversible decision (keeping the option open) and laying off workers that may be needed in the near future.

\subsection{Econometric specification of the hierarchical decision model}

Figure 4.1 shows the tree structure and the ordering of the hierarchical restructuring problem. It suggests that discrete choice analysis and more specifically the hierarchical elimination model based on a generalized extreme value structure that generalizes into a nested multinomial logit (NMNL) model would be the natural candidate for its econometric evaluation. The NMNL model is consistent with profit maximization under uncertainty (McFadden 1984).

In the hierarchical form, the first decision represents the multinomial choice of input ratios of workers with skills level $s \in S$. The labor input ratios, $L_{s} / L_{s+1}$, are determined by the production technology. The theory allows for reorganizations that affect the ratios. This would result, for example, from workforce adjustments to skill-biased technological shocks. If the production technology remains unchanged then so will the factor input ratios and the eventual skill groups' sizes are implicitly pre-determined overall size the workforce reduction. In that situation the probability of choosing skill group $s$ is a given $\operatorname{Pr}(S=s)$, and labor input ratios are fixed. ${ }^{7}$

The second decision is to determine the rank structure (span of control) for each skill group $s$. This is an ordered choice problem. For the determination of restructured rank sizes we need to evaluate the cut-off points $\Pi_{r s}^{L}<\Pi_{r+1, s}^{L}$. Rather than the non-linear

\footnotetext{
${ }^{7}$ In the case of perfect competition and for a Cobb-Douglas production technology with constant returns to scale $\operatorname{Pr}(S=s)$ will be equal to the marginal productivity of skill group $s$.
} 
Figure 4.1: The Tree Structure of the Firm's Restructuring Problem

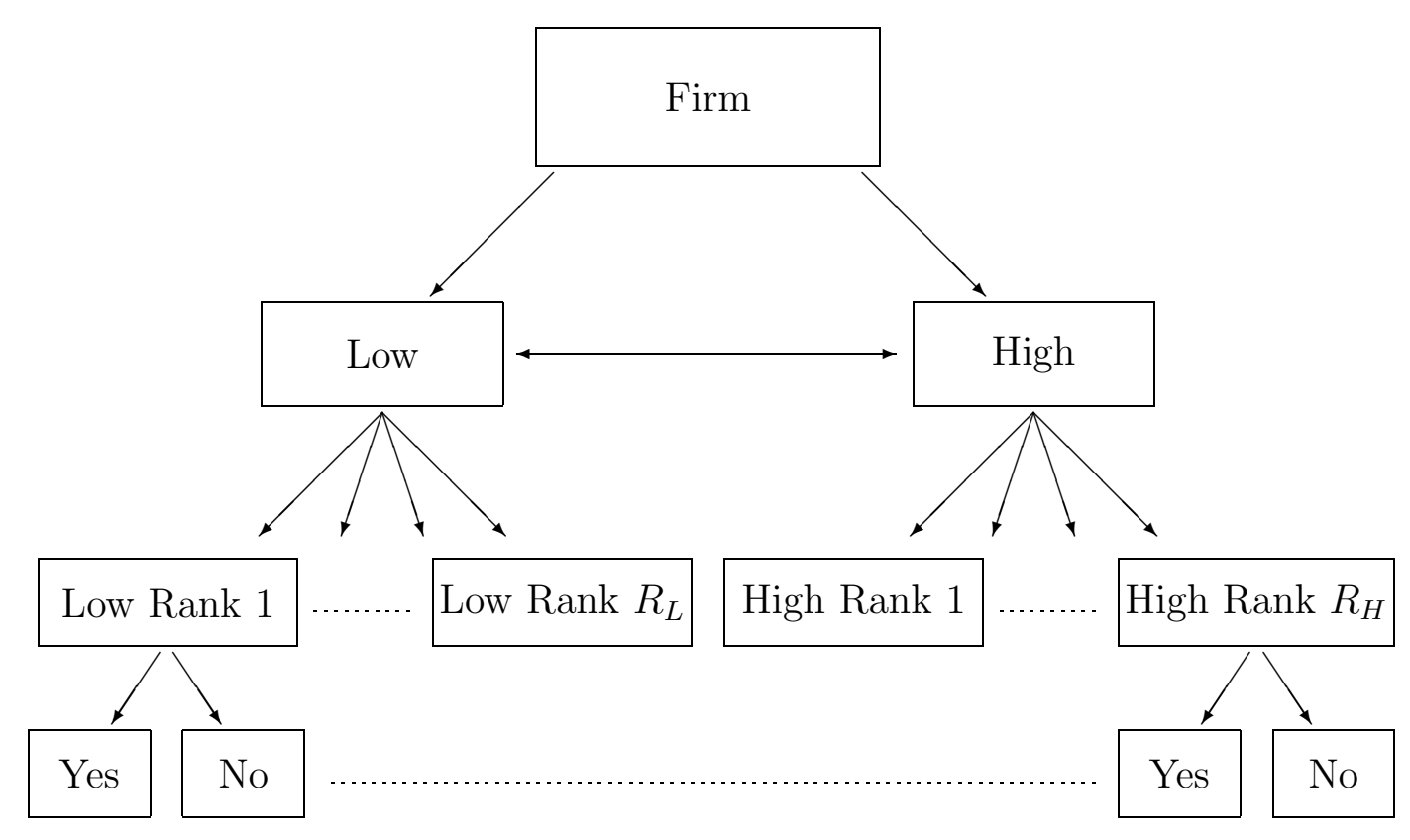


expression 4.4 for $\Pi_{r s}^{L}$ for practical purposes we suggest to use a linearized decision rule. It is the simple first-order Taylor series approximation without cross-terms, and yields

$$
\begin{aligned}
& \Pi_{r s}^{L}=\Pi_{s}^{\rho} \rho_{s}+\Pi_{s}^{\mu} \mu_{r s}+\Pi_{s}^{\sigma} \sigma_{r s}^{\mu}+\Pi_{s}^{W} W_{r s}^{Y}+\Pi_{s}^{F} F_{r s} \quad+\eta_{r s} \equiv Z_{r s} \zeta_{s}+\eta_{r s} \\
& (+) \quad(-) \quad(-) \quad(+) \quad(-)
\end{aligned}
$$

The signs below the equation in brackets are the theoretical predictions derived in Section 2. It is quite plausible that unobserved preferences or characteristics will affect choices among alternative ranks in similar ways. Moreover, as the observed decision rules are a discrete representation of the underlying continuous model presented in Section 2, formally this implies that correlation among unobserved profit components for alternative choices can arise from dependency among unobserved characteristics of several of those choices.

The hierarchical ordering imposed by 4.4 requires that $\Pi_{1 s}^{L}<\Pi_{2 s}^{L}<\ldots<\Pi_{R_{s} s}^{L}$, or $\operatorname{Pr}\left(\Pi_{k s}^{L}>\Pi_{j s}^{L} ; \forall k>j\right)$ for any given rank from the choice set $j, k \in\left\{R_{s}\right\}$. This imposes an additional ordered structure that is uncommon to the standard NMNL model. Note that the common ordering in the generalized nested logit model is $\operatorname{Pr}\left(\Pi_{k s}>\Pi_{j s} ; \forall k \neq j\right)$. It also varies from the ordered generalized extreme value model, introduced by Small (1987), because our model does not have subsets of choices that overlap. If $\eta_{r s} \mid Z_{r s} \sim G_{s}$, where $G_{s}$ is a cumulative distribution function that is the same for all ranks, then the probability of being in rank $r$ of skill group $s$ is an ordered probability function. The conditional probabilities yield

$$
\begin{gathered}
\operatorname{Pr}(\text { Rank }=r \mid s)=\operatorname{Pr}\left(\Pi_{r s}^{L} \leq Z_{r s} \zeta_{s}+\eta_{r s}<\Pi_{r+1, s}^{L} \mid s\right), \text { for } r=1, \ldots, R_{s}-1 \\
\operatorname{Pr}\left(\operatorname{Rank}=R_{s} \mid s\right)=\operatorname{Pr}\left(Z_{R_{s} s} \zeta_{s}+\eta_{R_{s} s}>\Pi_{R_{s} s}^{L} \mid s\right)
\end{gathered}
$$

If sizes of ranks have been determined, what remains is to decide which workers to keep or to fire. This is done on the basis of individual workers' idiosyncratic profits $\pi_{i r s}$ that are functions of worker's personal characteristics. Would $\pi_{i r s}$ be known for all workers, then the firm could order all workers by the observed $\pi_{i r s}$ and select those $N_{r s}$ workers with the largest expected value to the firm from the sorted $(s * r)$ arrays. But $\pi_{i r s}$ cannot be observed directly. Thus we add a third and final sub-decision that is a multivariate binary choice to decide which workers should stay or leave. We write the latent idiosyncratic profit function $\pi_{i r s}$ as the sum of a vector of observable idiosyncratic 
Table 4.1: The Structure of Labor Input Before and After Restructuring

\begin{tabular}{l|rrrrrr}
\hline Workers & \multicolumn{2}{|c}{ Low Skill } & \multicolumn{2}{c}{ High Skill } & \multicolumn{2}{c}{ Total } \\
\hline Total & 3594 & $.66 / 1.0$ & 1875 & $.34 / 1.0$ & 5469 & $1.0 / 1.0$ \\
Selected & 767 & $.67 / .21$ & 374 & $.33 / .20$ & 1141 & $1.0 / .21$ \\
Displaced & 2827 & $.65 / .79$ & 1501 & $.35 / .80$ & 4328 & $1.0 / .79$ \\
\hline
\end{tabular}

characteristics $\left(x_{i r s}\right)$, unobserved ability $\left(\varepsilon_{i r s}^{w}\right)$, and a random component $\left(u_{i r s}\right)$ as follows

$$
\pi_{i r s}=x_{i r s} \beta_{r s}+\alpha_{r s} \varepsilon_{i r s}^{w}+u_{i r s}
$$

The parameter $\alpha_{r s}$ is the contribution of a worker's idiosyncratic ability to the firm's value of future profits. The vector $\beta_{r s}$ consists of constant parameters. In skill group $s$ workers in rank $r$ are displaced if $\pi_{i r s} \leq 0$ and retained if $\pi_{i r s}>0$. The variable $1 \pi_{i r s}(0,1)$ indexes this binary choice. The probability that worker $i$ of skills level $s$ in rank $r$ is retained can be written as the product of the three probabilities:

$\operatorname{Pr}(S=s) \cdot \operatorname{Pr}($ Rank $=r \mid s) \cdot \operatorname{Pr}\left(1 \pi_{\text {irs }}=1 \mid r, s\right)$.

\subsection{Personnel data}

To investigate this general model detailed firm-specific personnel data are needed. We use data of all workers employed by the Dutch aircraft manufacturer, Fokker. The company filed for bankruptcy on Friday, March $15^{t h}$, 1996. The trustees restructured the company during the weekend immediately following the bankruptcy. Before the bankruptcy, the company existed of six subsidiaries of which three were located at plants in different parts of Holland and were dedicated to aircraft design and construction, whilst after the three plants were drastically reduced in size, the other three were left practically unchanged. The newly created organization, comprising the three remaining subsidiaries and the adjusted aircraft division, was later sold to another Dutch industrial firm. The data set that we use here incorporates the records of all tenured workers on the day of the bankruptcy. ${ }^{8}$ The firm employed two types of workers: production workers and non-production workers $(s=2)$. Each skill group had its own level of entry (see Chapter 3). Table 4.1 presents the structure of the factor inputs before and after the adjustment of the workforce. It shows that the factor input ratio of $2: 1$ between production and non-production workers remained unchanged as a result of the reorganization.

\footnotetext{
${ }^{8}$ Except those of the firm's management team (5 persons).
} 
Table 4.2: Organizational Change

\begin{tabular}{|c|c|c|c|c|}
\hline \multirow{3}{*}{ Hierarchical Level } & \multicolumn{4}{|c|}{ Low Skill Workers } \\
\hline & \multicolumn{2}{|c|}{ Before Reorganization } & \multicolumn{2}{|c|}{ After Reorganization } \\
\hline & Size & Span of Control & Size & Span of Control \\
\hline 1: Production Worker & 2281 & - & 496 & \\
\hline 2: Team Leader & 765 & 2.98 & 187 & 2.65 \\
\hline \multirow[t]{4}{*}{ 3: Head Production Team } & 548 & 1.40 & 84 & 2.23 \\
\hline & \multicolumn{4}{|c|}{ High Skill Workers } \\
\hline & \multicolumn{2}{|c|}{ Before Reorganization } & \multicolumn{2}{|c|}{ After Reorganization } \\
\hline & Size & Span of Control & Size & Span of Control \\
\hline 1 : Assistant Engineer & 803 & - & 148 & \\
\hline 2 : Engineer & 505 & 1.59 & 107 & 1.38 \\
\hline 3 : Senior Engineer & 360 & 1.40 & 65 & 1.65 \\
\hline 4 : Manager & 207 & 1.74 & 52 & 1.25 \\
\hline
\end{tabular}

Table 4.2 shows the changes in the hierarchical organization of each skill group. Production workers are organized in three hierarchical levels (production team workers, production team leaders, and heads of production teams); the productivity of the nonproduction workforce is organized in four ranks (assistant engineers, engineers, senior engineers, and managers). After the reorganization control spans are higher for production workers than for non-production workers at all ranks. Although the pyramid shapes of the two skill groups are still present after the reorganization, the within group rank sizes have changed markedly.

Table 4.3 shows summary statistics of variables explaining the ordered choices of hierarchical ranks. We distinguish between three different plants. Plant 1 operates in Amsterdam and houses a high percentage of executives. It is the company's main location and also includes its headquarters. Plants 2 and 3 are production plants that are located in other parts of the country. The hourly wage is measured for all workers at the day of the bankruptcy. The wage growth $\left(\mu_{r s}\right)$ is computed for the three years period characterizing the firms structural demise preceding its bankruptcy. The average growth rate for production workers is 7.7 percent or 2.6 percent per year. For nonproduction workers the average is 11.7 percent or 3.6 percent per year. The annual difference between the two skill groups is one percentage point. The variation in $\mu_{r s}$, denoted as $\sigma_{r s}^{\mu}$, is measured as the standard deviation of $\mu_{r s}$ among all workers with 
skills level $s$ in rank $r$. The variation in wage growth tends to grow largest at the top of the organization of each skill group. The variable $W_{r s}^{Q}$ represents workers' rents from rank-specific investments in firm-specific productivity. Here it is measured as the returns on investments in rank-specific skills. The firm invested in firm-specific productivity in the form of the provision of internal (firm-specific) as well as external (general) training courses. The within rank distribution of $W_{r s}^{Q}$ is estimated as the training profile in the rank specific hourly wage distribution.

Firing costs, $F_{r s}$, are associated with the period of notice of terminating a job contract. Job contracts may be cancelled either by the employer or the employee. The employer's term of notice $\left(T_{0} N\right)$ is legally defined in Articles 1639i and 1639j of the Netherlands Civil Code and Article 40.3 of the Bankruptcy Act. The ToN is equal to the time that passes between two consecutive earnings installments not extending beyond a period of 6 weeks. The minimum ToN for tenured workers is the number of weeks equal to the number of years the employee has worked full time for the same employer since adulthood (18 years and older), not extending beyond a period of 13 weeks. The ToN is extended with one week for every full year during which an employee has been employed after 45 years of age, not exceeding a period of 13 weeks. The legal maximum ToN is thus 26 weeks. Firing costs are large - on average 25 percent of annual earnings. They are - not surprisingly — higher for non-production workers and increasing with each hierarchical level.

Table 4.4 shows for each rank in both skill groups the variables explaining the binomial layoff decisions. The usual suspects explaining heterogeneous displacement characteristics included in the vector $x_{i r s}$ are age, tenure, education, a dummy for vocational specialization, hours worked, gender, and marital status. Our data are from a typical industrial firm (mostly full-time workers; predominantly male workers; a large proportion had vocational specialization and is married). We have to bear that in mind when drawing conclusions from the empirical model. Most notable outcomes are that the the ratio of female workers decreases with each rank and tenure and age differences between ranks are less than two years.

In addition we have information on all workers' last annual performance evaluation scores, numbers of internal as well as external training courses, commuting distances, and percentages of those being disabled prior to the bankruptcy. We find that production workers in higher ranks have had more training courses, whereas non-production workers had less; and disability decreases with rank in both skill groups.

Some workers are still more productive than their pay indicates, and when forced 
Table 4.3: Variables Describing Rank Specific Profits

\begin{tabular}{|c|c|c|c|c|c|c|c|c|}
\hline & \multirow[b]{2}{*}{ Rank } & \multicolumn{3}{|c|}{ Low Skill Workers } & \multicolumn{3}{|c|}{ High Skill Workers } & \multirow[b]{2}{*}{4} \\
\hline & & 1 & 2 & 3 & 1 & 2 & 3 & \\
\hline Total & & 2281 & 765 & 548 & 803 & 505 & 360 & 207 \\
\hline Plant 1 & Proportion & .48 & .70 & .79 & .90 & .93 & .94 & .95 \\
\hline Plant 2 & of Rank & .36 & .20 & .15 & .06 & .04 & .03 & .02 \\
\hline Plant 3 & & .16 & .10 & .06 & .04 & .03 & .03 & .03 \\
\hline $\begin{array}{l}\text { Hourly Wage } \\
\text { (in Dff) })^{1}\end{array}$ & Levels & $\begin{array}{l}24.56 \\
(2.74)\end{array}$ & $\begin{array}{r}28.43 \\
(2.86)\end{array}$ & $\begin{array}{l}35.52 \\
(3.37)\end{array}$ & $\begin{array}{r}37.17 \\
(4.59)\end{array}$ & $\begin{array}{l}44.04 \\
(6.09)\end{array}$ & $\begin{array}{r}53.34 \\
(7.18)\end{array}$ & $\begin{array}{r}69.84 \\
(10.32)\end{array}$ \\
\hline $\begin{array}{l}\text { Wage Growth } \\
(1993-1996)\end{array}$ & $\begin{array}{l}\text { in Levels } \\
\operatorname{Rate}\left(\mu_{r s}\right)\end{array}$ & $\begin{array}{l}1.68 \\
.073\end{array}$ & $\begin{array}{l}2.17 \\
.082\end{array}$ & $\begin{array}{l}2.68 \\
.089\end{array}$ & $\begin{array}{l}3.99 \\
.118\end{array}$ & $\begin{array}{l}4.80 \\
.121\end{array}$ & $\begin{array}{l}5.52 \\
.117\end{array}$ & $\begin{array}{l}6.54 \\
.106\end{array}$ \\
\hline Wage Growth Variation ${ }^{2}$ & $\sigma_{r s}^{\mu} * 100$ & .204 & .190 & .241 & .278 & .341 & .710 & .648 \\
\hline $\begin{array}{l}\text { Contribution of Training } \\
\text { to } \ln (\text { Hourly Wage Profile) }\end{array}$ & $W_{r s}^{Q}$ & .020 & .013 & .009 & .003 & .016 & -.011 & -.019 \\
\hline $\begin{array}{l}\text { Firing Costs } \\
\text { in } 1000 \mathrm{Dfl}\end{array}$ & $F_{r s} * 1,000$ & $\begin{array}{l}10.75 \\
(4.66)\end{array}$ & $\begin{array}{l}12.77 \\
(5.26)\end{array}$ & $\begin{array}{l}15.64 \\
(6.42)\end{array}$ & $\begin{array}{r}15.45 \\
(7.61)\end{array}$ & $\begin{array}{r}19.11 \\
(10.27)\end{array}$ & $\begin{array}{r}26.02 \\
(12.13)\end{array}$ & $\begin{array}{r}37.59 \\
(16.98)\end{array}$ \\
\hline
\end{tabular}

${ }^{1}$ Standard deviations are given between brackets

2 in $\%$ points 
Table 4.4: Variables Explaining Multivariate Binomial Layoff Decisions

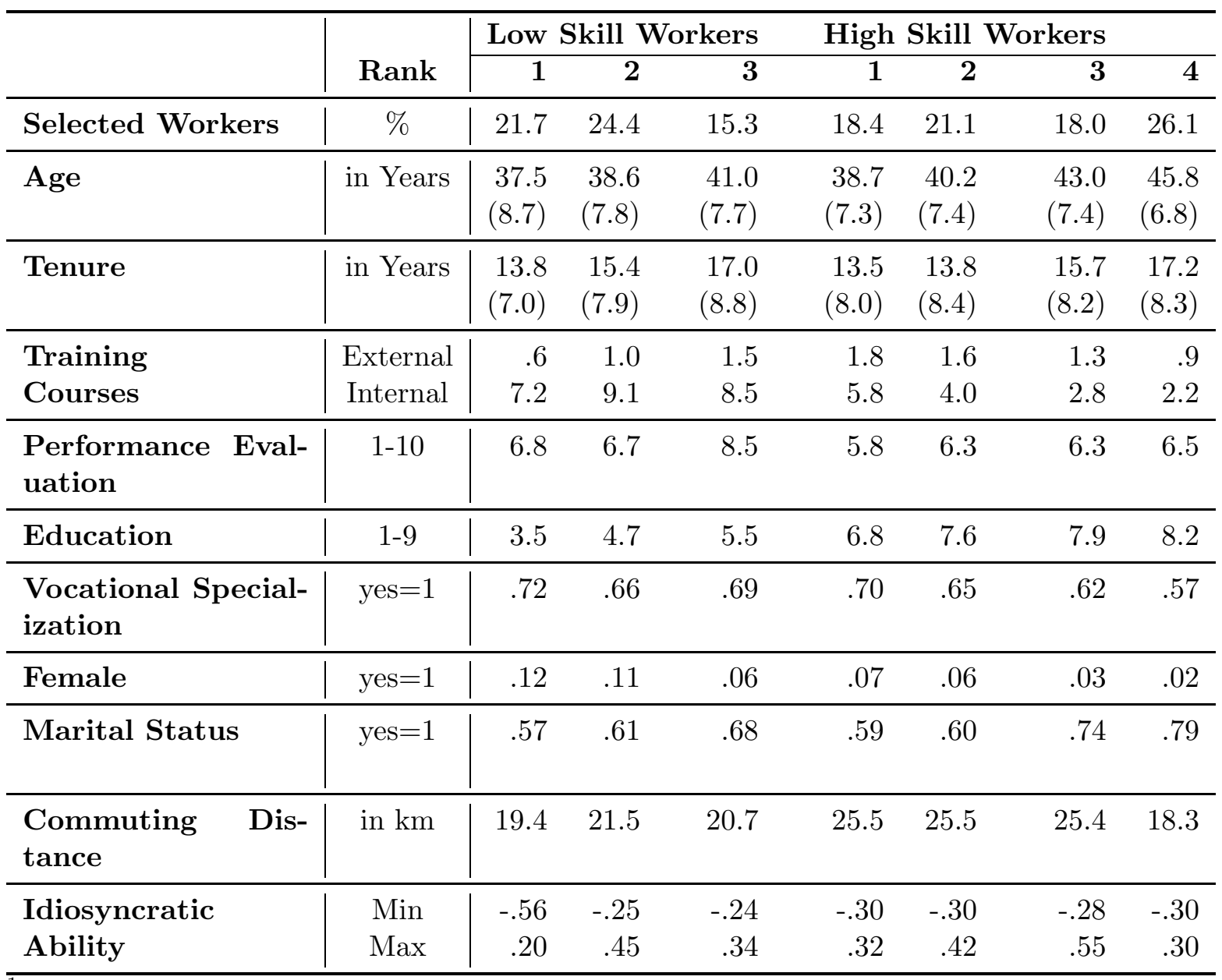

${ }^{1}$ Standard deviations are given between brackets 
to let people go, the firm keeps those workers. If that is the case, then the residual of the hourly wage equation regressed on the usual suspects indicates worker-specific profits. The firm wants to preserve its best matches, and high wage residuals signals good matches. In the model we added a variable $\varepsilon_{i r s}^{w}$, being workers' idiosyncratic ability measured as the individual worker's residual of a skills and rank specific hourly wage regression that was also used to compute $W_{r s}^{Q}$. The last row of Table 4.4 shows the spread in $\varepsilon_{i r s}^{w}$ for each rank.

\subsection{Estimating the hierarchical model and testing hypotheses}

In a model where the labor input ratios are fixed, we can write the lay-off probability of worker $i$ in rank $r$ of skills level $s$ as:

$$
\operatorname{Pr}\left(1 \pi_{i r s}=1 \mid r, s\right)=G\left(x_{i r s} \beta_{r s}+\alpha_{r s} \varepsilon_{i r s}^{w}\right)
$$

Defining the variable $J_{r s}$ as the inclusive value summarizing the workers' characteristics in rank $r s$, for a multivariate binomial choice with a Type I extreme value distribution function this yields:

$$
J_{r s}=\ln \sum_{i \in\{r, s\}} \exp \left(x_{i r s} \beta_{r s}+\alpha_{r s} \varepsilon_{i r s}^{w}\right)
$$

The size of each hierarchical level is represented by an ordered choice as:

$$
\operatorname{Pr}(R a n k=r \mid s)=G\left(Z_{r s} \zeta_{s}+J_{r s} \kappa_{r s}-\gamma_{r s}\right)-G\left(Z_{r s} \zeta_{s}+J_{r s} \kappa_{r s}-\gamma_{r-1, s}\right)
$$

with $\gamma_{0, s}=-\infty$; and $\gamma_{R_{s}, s}=+\infty$. For the threshold parameters it holds that $\gamma_{r-1, s}<$ $\gamma_{r s}$, reflecting the fact that $\Pi_{r-1, s}^{L}<\Pi_{r s}^{L}$. The parameter $\kappa_{r s}$ is often referred to as the parameter measuring the independence of alternatives within sub-ranks. McFadden (1984) noted that $0<\kappa_{r s}<1$ must hold for the hierarchy to be correctly specified. If $\kappa_{r s}$ is outside the unit interval, this may indicate that the assumed profit ordering $\Pi_{r-1, s}^{L}<\Pi_{r s}^{L}$ does not hold. Note that the independence parameter $\kappa_{r s}$ and the threshold parameter $\gamma_{r s}$ are not identified separately. The identifying restriction $J_{r s} \kappa_{r s}-\gamma_{r s}=0$, or $\kappa_{r s}=\gamma_{r s} / J_{r s}$ can be used as a model specification test, for $r=1, . ., R_{s}-1$. 
Table 4.5: Parameter Estimates

\begin{tabular}{lll}
\hline \multicolumn{3}{c}{ Low skilled workers } \\
\hline $\begin{array}{l}\hat{\gamma}_{11}=3.76 \\
(\text { s.e. }=0.20)\end{array}$ & $\hat{J}_{11}=7.65$ & $\begin{array}{l}\hat{\kappa}_{11}=0.56 \\
(\text { s.e. }=0.03)\end{array}$ \\
\hline $\begin{array}{l}\hat{\gamma}_{21}=5.44 \\
(\text { s.e. }=0.22)\end{array}$ & $\hat{J}_{21}=6.70$ & $\begin{array}{l}\hat{\kappa}_{21}=0.81 \\
(\text { s.e. }=0.03)\end{array}$ \\
\hline \multicolumn{3}{c}{ High skilled workers } \\
\hline$\hat{\gamma}_{12}=4.40$ & $\hat{J}_{12}=6.73$ & $\begin{array}{l}\hat{\kappa}_{12}=0.65 \\
(\text { s.e. }=0.25)\end{array}$ \\
\hline$\hat{\gamma}_{22}=6.07$ & $\hat{J}_{22}=6.36$ & $\begin{array}{l}\left.\hat{\kappa}_{22}=0.04\right) \\
(\text { s.e. }=0.27)\end{array}$ \\
\hline$\hat{\gamma}_{32}=8.27$ & & $($ s.e. $=0.04)$ \\
$($ s.e. $=0.31)$ & $\hat{J}_{32}=6.00$ & $\begin{array}{l}\hat{\kappa}_{32}=1.38 \\
(\text { s.e. }=0.05)\end{array}$ \\
\hline
\end{tabular}

In the empirical model there are two skill levels (low and high skill workers; $s=1,2$ ). Low skilled work is organized in three ranks $\left(R_{1}=3\right)$. High skilled work is organized in four ranks $\left(R_{2}=4\right)$. The estimates for the threshold parameters, the inclusive values, and the independence parameters are given in Table 4.5.

Only $\hat{\kappa}_{32}$ lies outside the unit interval. This suggests that the hierarchical composition of profits at the two highest levels of the organization are not as clear-cut as in the lower regions of the organization. There can be several reasons for this. Although explaining these results is beyond the scope of this chapter, we can give two ideas. One is that the theoretical model does incorporate the possibility for workers to receive stocks and bonds as part of the employment contract. Secondly, $\Pi_{r s}^{L}$ is in essence an equilibrium outcome. A possible way to extend the model is to incorporate that explicitly adding an equilibrium search framework.

The parameter estimates for the multivariate binomial layoff decisions are in line with what is found elsewhere in the literature. Low skill workers with lower displacement probabilities are younger males with a general rather than a technical educational degree, who have better job performance evaluations; they followed fewer internal training courses, and have higher worker specific profits (unobserved heterogeneity). High skilled workers with lower displacement probabilities are younger married employees with higher tenure; they have higher job performance evaluations; they followed fewer external training courses, and they live further away from work. Specific profits (idiosyncratic ability) do not contribute to a significant decrease in the likelihood of getting displaced for high 
Figure 4.2: The Effects of a Profit Growth Shock on the Hierarchical Structure of the Workforce
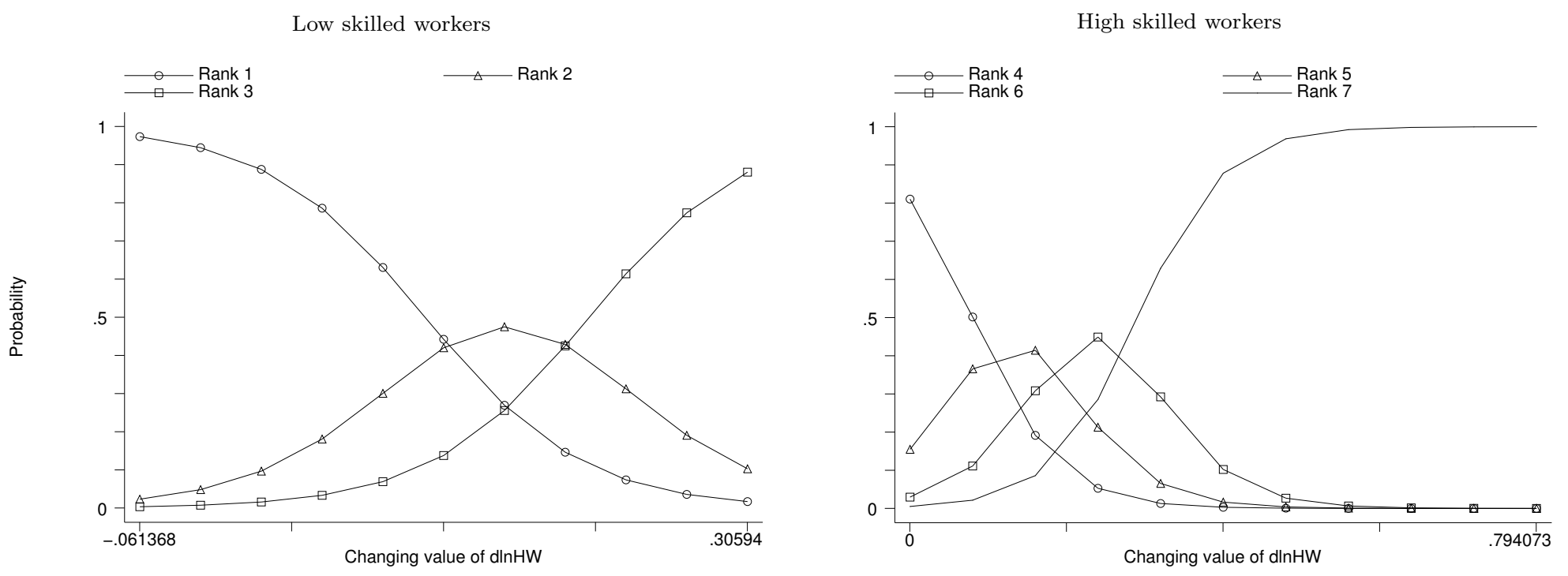
skilled workers.

The goal of this chapter has been to present and test a theory of organizational change in the case of workforce restructuring. In section 2 four predictions were derived, which can be tested with our data. The results of the estimation results on the predictions (P1) to (P4) are shown in Figures 4.5 to 4.5. The effects shown are all highly significant. Figure II-a shows the effects profit growth shocks - innovations, productivity-enhancing technology shocks - may have on organizational changes. Theory predicts that $\Pi_{s}^{\mu}<0$, or if $\mu$ increases the firm will restructure its workforce so that profits will be shifted from low to high ranks. This is rational behavior of the firm because profits in higher ranks are higher. Figure II-a confirms this prediction and also shows how the restructuring takes place. If $\mu$ is small the hierarchical structures of both types of labor input will be characterized by a broad lowest rank and very small middle and high ranks. When $\mu$ gets larger, the firm will initially increase all higher hierarchical levels at the cost of the lowest rank, with the largest increases in the middle ranks. After some point of inflection the firm will start discarding all lower ranks in favor of the highest rank only. Eventually a flat hierarchy will remain with workers employed only in the upper ranks of both skills groups.

Figure 4.5 shows the effects of volatility shocks — increased uncertainty — on probable changes in the hierarchical structures of the skill groups. Although theory predicts that $\Pi_{s}^{\sigma}<0$, or ranks associated with more uncertainty about profit growth are less likely to be reduced in size, the empirical outcomes show differences across skill groups. For low skill workers, increases in uncertainty do not change the hierarchical structure by much. If $\sigma_{s=1}^{\mu}$ increases, the hierarchy will change little, slightly broadening the lowest rank. For high skill workers the change in the organizational structure is different. An increase in $\sigma_{s=2}^{\mu}$ will rapidly crowd out all high ranks in favor of the bottom rank. This is probably due to the fact that the lowest ranks are characterized by higher volatility. These ranks are composed of young workers with less tenure and they are largest in size. Low ranks thus embody the best promise to gain maximally from unexpected positive surprises - while negative surprises can always be dealt with through layoffs.

Figure 4.5 shows the effects of shocks changing shared rents — skill-specific economy wide labor demand shocks - on the firm's inclination to adjust its composition between ranks within skill groups. Theory predicts $\Pi_{s}^{W}>0 . W^{Q}$ is the share of rents that flows towards the workers. If $W^{Q}$ increases the per worker profit for the firm decreases. When that occurs, the firm will restructure its workforce so that profits will be shifted from higher to lower ranks in order to maximize profits at the broadest ranks. This is shown 
Figure 4.3: The Effects of a Volatility Shock on the Hierarchical Structure of the Workforce
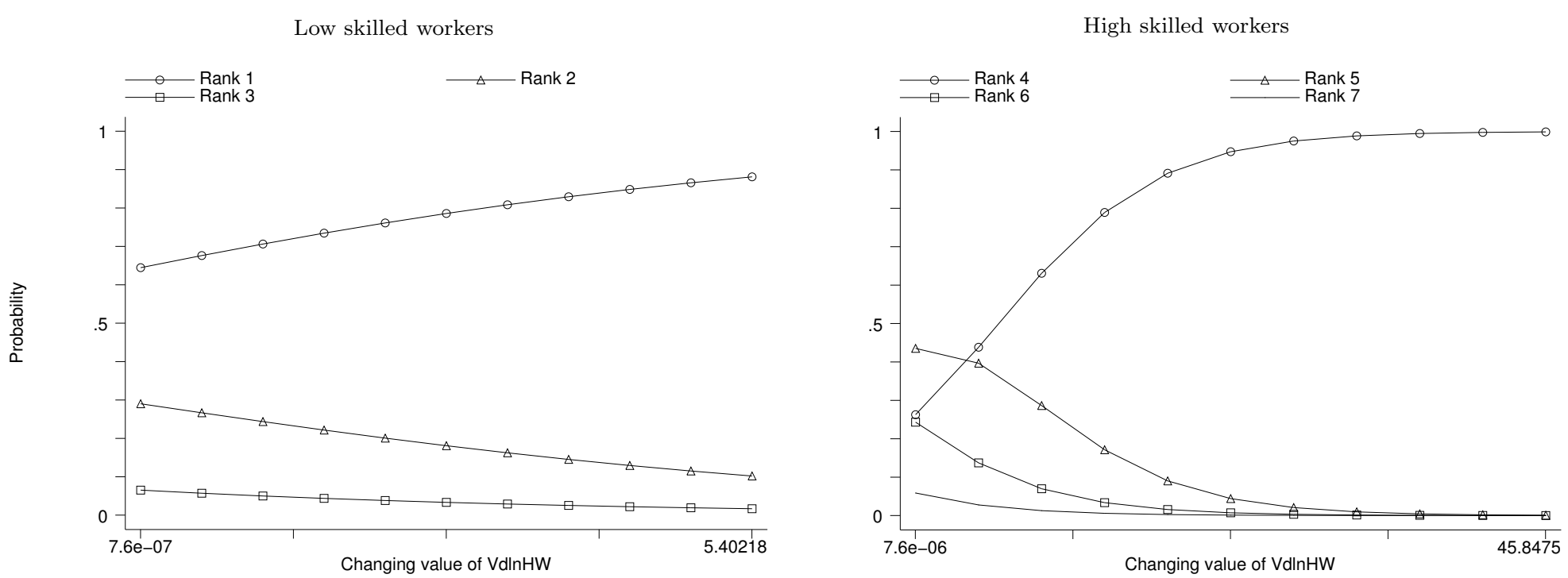
Figure 4.4: The Effects of a Shock in Rent Shares on the Hierarchical Structure of the Workforce
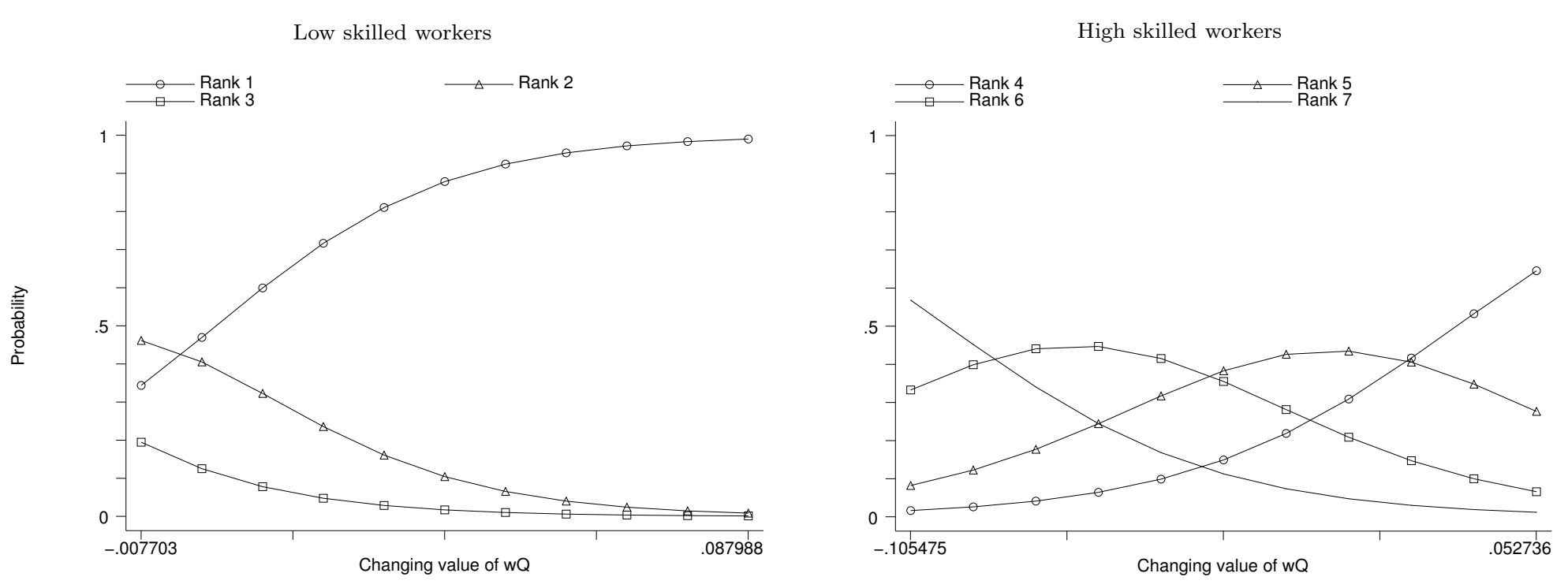
in Figure 4.5. How that reorganization takes place, however, varies between the two skill groups. High skill work is reorganized gradually, shifting the hierarchical structure from one with a high probability of top rank managers to one with only a few. For low skill workers this process goes much more rapidly and is more pronounced.

Figure 4.5, finally, shows the effects shocks that change firing costs - e.g. UI policy shocks - on the firm's reorganization propensity. Theory predicts that $\Pi_{s}^{F}<0$, or if $F$ increases the firm will restructure its workforce so that profits will be shifted from low to high ranks for the simple reason that firing workers in higher ranks is more costly. Figure II-d confirms that prediction and also shows that the restructuring that will take place is comparable to what could happen when changes occur in the expected profit growth (productivity enhancing technology shocks).

\subsection{Restructuring and wage inequality within the firm}

The econometric results allow us to investigate changing wage inequality between low and high skilled workers within the firm resulting from workforce restructuring propensities. Our analysis is based on a production technology of which factor input ratios remain unchanged as a result of the reorganization. The results we find are not due to substitution effects between skill groups, but rather they reflect changes due to restructuring the composition of ranks within skill groups. We show that this can give rise to changes in wage inequality between skill groups within the firm

The simulation exercise is conducted as follows. For all ranks we computed the average hourly wage. The weights presented in Figure 4.5-4.5 then allow us to compute the composite hourly wage for each skill group and how it changes subject to shocks in profit growth, volatility, rent shares, and firing costs. Changes in wage inequality thus originate from modifying compositions of ranks within skill groups. Assuming shocks are similar in size across skill groups we can portray how inequality across skill groups can change due to those shocks.

Results are given in Figure 4.6. The reported hourly wages are in 1996 Dutch guilders ( $1 \mathrm{Dfl}=0.45$ Euro). We find that $(i)$ positive profit growth shocks - innovations, productivity shocks - increase hourly wages for low and high skilled workers, but also increase the wage inequality between both groups. The underlying mechanism that produces this result is that the highest ranks in both skill groups have the lowest probability of being reduced in size, because compared to other ranks in the same skill group their profits are highest (Equation 4.4). Moreover, the wage inequality between the top ranks 
Figure 4.5: The Effects of a Shock in Firing Costs on the Hierarchical Structure of the Workforce
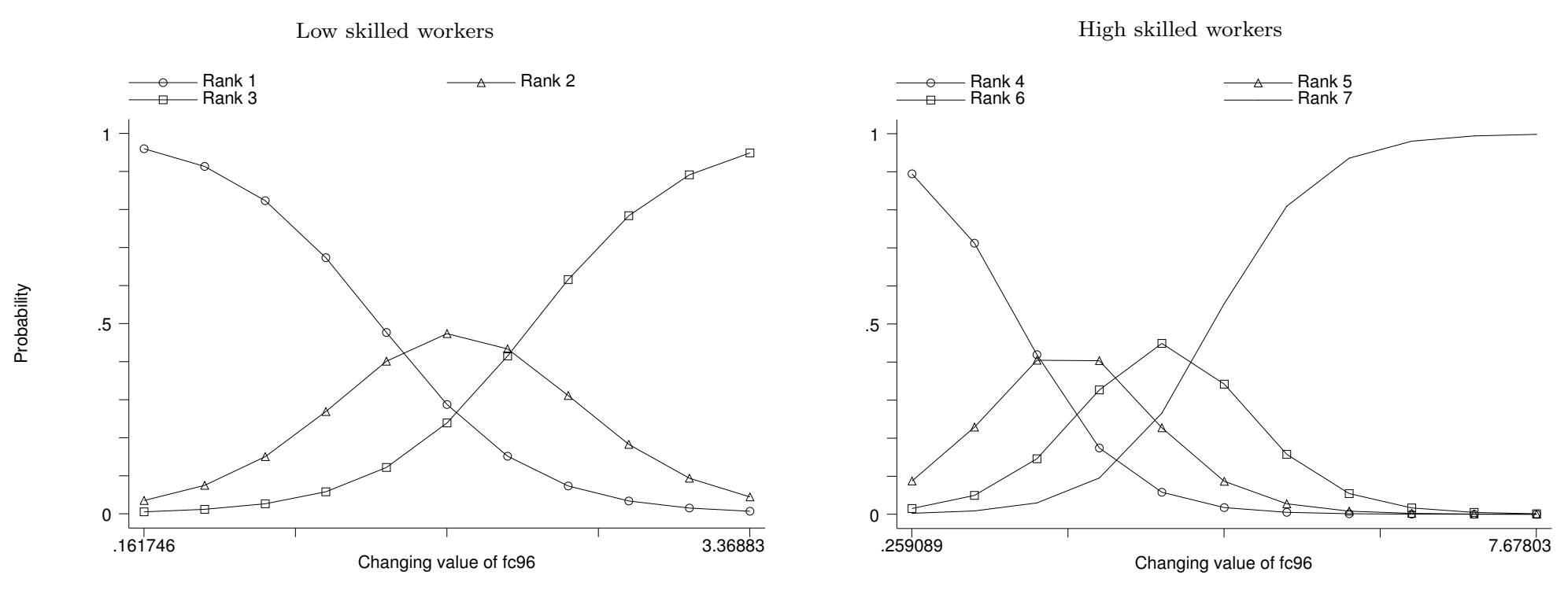
Figure 4.6: Workforce Restructuring and Wage Inequality
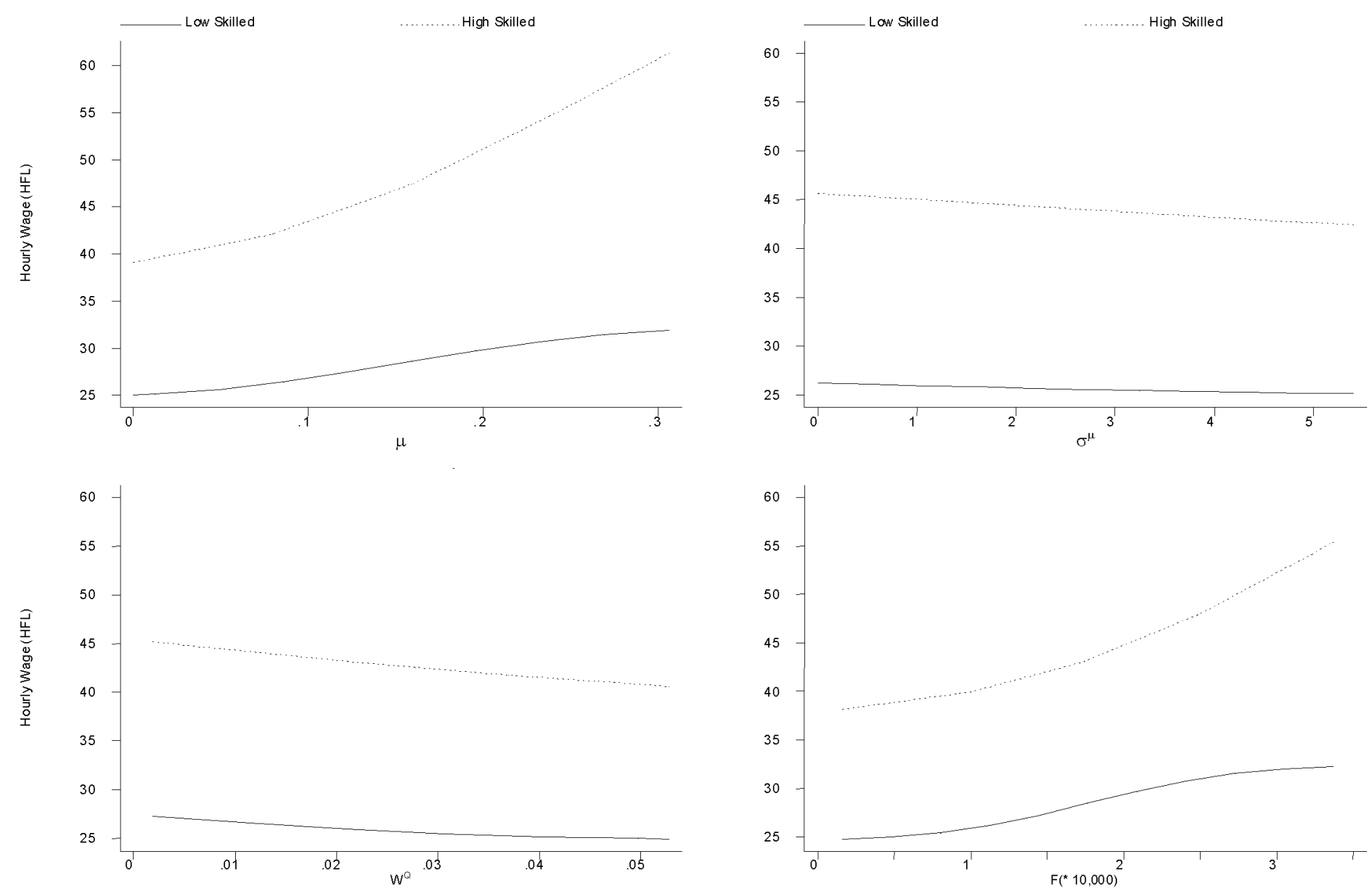
of the two skill groups is larger than that at the bottom of the hierarchical structure; (ii) volatility shocks - increased uncertainty - decrease hourly wages as well as wage inequality. The reason is that ranks with relatively little volatility will be reduced more. These ranks are usually composed of older and more experienced workers; (iii) worker rents increase labor market shocks - increased union power, increased aggregate demand for specific skills - decrease profits flowing to the firm. This leads to lowering wages and a decrease in wage inequality; ( $i v$ ) firing costs increase shocks - UI policy shocks - boost hourly wages of all workers, and increase wage inequality between low and high skill groups.

\subsection{Conclusions}

We have studied the role of a firm's organizational structure on the decision to restructure the firm's workforce. We modeled a hierarchical firm's optimal downsizing decisions. The model's predictions have been tested using personnel data of a single industrial firm. We found that changes in the organizational structure can be described by a hierarchical menu costs model. If the firm's input of workers comprises different skill groups, and if the production of each of these skill groups is organized in ranks, then the ranks' contributions to the future value of the firm determines their size. In the case of a reorganization rank-specific cut-off values determine changes in the firm's hierarchical structure. Factors that explain the cut-off values are rank-specific expected future profit growth, the uncertainty surrounding that growth, rent-sharing rules, as well as firing costs. The theoretical predictions, that profit growth and increases in firing costs lead to increases in higher ranks at the expense of lower ranks, and that increased uncertainty and worker rents broaden the bottom ranks of the hierarchical structure, are supported by the data.

We find that reorganizations that modify the composition of ranks within skill groups can give rise to increased wage inequality between skill groups. We have shown that productivity-enhancing technology shocks as well as policy shocks that increase firing costs lead to increases in wage inequality between low and high skilled workers. Important to note is that this holds true while the company-wide input ratio of both skill groups remains unchanged. We also found evidence of shocks that give rise to organizational change that will lead to decreasing wage inequality. Increased uncertainty about future profit growth increases the firm's propensity to hold a larger share of workers in ranks that contribute most to this uncertainty, because the firm is reluctant to exercise 
the irreversible decision (keeping the option open) of whether to lay off workers that may be needed in the near future. Finally, shocks that increase the workers' share of firm-specific rents, such as increased union power or aggregate positive demand shocks, will increase negotiation power of workers and decrease profits flowing to the firm. If such shocks lead to reorganization of the workforce, the restructuring is such that it will lead to a decrease in wage inequality between low and high skilled workers. 



\section{Development and Conduct of the 'Fokker Survey'}

"Why should economics differ from other sciences, where researchers spend much of their time collecting data? It is not healthy for a science to isolate itself from its subject of study, especially for a field that is highly contentious and where reality is constantly changing. In economics, it is all too easy to believe what one wants to believe, since theories become intertwined with political values and truly pertinent information is hard to obtain."

(Bewley, 1999, p. 15) 
When we obtained the personnel files from Fokker and the support of the bankruptcy trustees for the conduct of a survey among the displaced workers, we were in the unique position to examine a bankruptcy displacement among a specific group of workers from whom we had already obtained specific (career) information before they were displaced. The intention of the survey was to fill the gap of information for the time that passed between the lay-off and distributing the questionnaire. In essence, we filled three years of labor market information from 1996 to 1999, which we defined as the post displacement years. In addition we wanted to find out about the circumstances of the bankruptcy as the respondents experienced it. This survey gave us the opportunity to combine a fairly long duration of post-displacement observation (3 years), with unique data on the career before displacement (10 years, as described in chapter 3 ).

This chapter will deal with all issues of developing, testing and conducting the survey. We will describe the post-survey examination into non-response.

\subsection{Development}

\subsubsection{Population}

\section{The Respondents' Situation}

Before constructing and conducting the survey we should consider the respondents' situation. The target population of our survey had been employed by Fokker until the bankruptcy. Most of them were not selected into 'Fokker Aviation', rendering them jobless, searching for new employment. The bankruptcy came as a shock to most employees. While many were aware of the difficulties, which had also resulted in several reorganizations within the last ten years, most workers hoped that Fokker would survive and that their future lay within the firm. They were proud of the product they built and about the fact that they worked for a company they identified with.

Following the time we conducted the survey, most respondents had subsequently found new employment during the successive three years, but many would have still preferred to work at Fokker and still have considered themselves to be part of the 'Fokker family' organizing themselves in several clubs of former Fokker employees.

We thus knew that the respondents had undergone drastic and dramatic changes in their life. They were searching for explanations of whether the bankruptcy was really necessary, and searching for the persons responsible that the company eventually went bankrupt. We could not offer them any direct benefit for their economic nor work 
situation as a result of the study. It was also not the intention of the study to offer any explanation regarding the necessity of the bankruptcy or the reasons for it. The potential beneficiaries of this study might be workers that would perhaps face a similar situation some time in the future. As such the results of the study could help policy makers to make informed decisions regarding the consequences of closing down a company like Fokker. However, to only a limited extent we offered the opportunity to vent frustrations and explain the difficulties they encountered while adjusting to the new situation. The only tacit incentive we offered was a report of the results of the study.

In such a situation we had to be careful about questioning and had to make sure that the information we asked was in line with the study's goal. Otherwise respondents would either refuse to answer the survey altogether or answer only part of it. ${ }^{1}$ We asked the respondents to give detailed information about the economic impact that the displacement had had on them. This is certainly relevant to the study, yet some respondents suggested that the economic picture is only one part of story and that we missed the more psychological problems of job-loss with our survey. Broadly speaking, the survey showed two typical reactions to the situation that, surprisingly, were not necessarily related to the economic outcome after displacement: many workers did not want to be reminded too much about their time with Fokker. They dealt with the issue by quickly trying to forget about the whole situation and by building up a new work history in another firm. Others still felt part of the Fokker family. Hard feelings were rather directed towards specific organizations or person that the respondent identified as being responsible for closing down the firm they had worked for. ${ }^{2}$

Being aware of the respondents situation and possible feelings towards the bankruptcy we tried to carefully craft the survey in such a way that the 'research agenda' of the survey was clear. While we had and mentioned the support of the bankruptcy trustees, we also stressed the fact that the survey was conducted and analyzed by independent researchers for academic purposes. We allowed the respondents to tell their story limited to the economic outcome. We invited former employees at several stages to comment on the research agenda and the developed survey before we conducted the full survey.

\footnotetext{
${ }^{1}$ Nonresponse both of the full survey but also of specific items in the survey, will always take place. However, the main goal is to minimize the non-response.

${ }^{2}$ Both of these reactions seem typical for such a situation. Sennett (1998) considers them different stages of the process of coping with job loss.
} 


\section{Census versus Sample}

At this early stage a decision had to be taken to use a full census and try to have all workers that were laid-off in the bankruptcy respond, or rather draw a sample in such a way that all our questions could be answered, and concentrate our effort upon the sampled population. Usually the latter is the preferred and advised method as sampling economizes on cost, is faster and allows for more expensive modes of conduct (cf. Lohr (1990, p. 258)). However, Kish (1965, p. 18) acknowledges that if data on small units can be obtained it might be advantageous to take the full census. ${ }^{3}$ Given that we did not have the information on the internal labor markets from chapter 3 and that we did not have a priori information on which parts of the company might be important, we could not have sampled while insuring sufficient inclusion of small units. Furthermore, we could have used three modes of gathering the necessary data: Personal interviews with the workers could have been conducted in which the interviewers visit the respondents and posit questions verbally. Alternatively, a phone interview could be conducted, or finally a written mail survey. All these modes have their specific pro's and con's. Usually, the former two modes elicit higher response rates, however, well designed mail surveys which are geared to a specific group can also match those expected response rates (e.g. Dillman 2001, p. 29). Mail surveys also have the advantage that they allow people to respond in their own time, they can look up or check some answers or simply can take longer to think about the right answers. It seems that sensitive issues are also more readily answered with written surveys as compared to phone or personal interviews. ${ }^{4}$ Given the sensitive nature of some of the questions and the non-intrusiveness of mail surveys, we decided that for this research project the preferred mode was the mail survey. This also made our decision to use a sample or the full census of our research population easier. Given the many different functions and groups at Fokker, we decided to include all workers. At the time of survey development, our experience with all aspects of the internal labor market data was, however, not as far advanced as to make good and precise predictions into which groups would turn out to be the crucial ones for further study. We were in the luxurious position to take the full census and thus keep all options open without having to compromise on any follow-ups that we intended to do.

\footnotetext{
${ }^{3}$ He does this, notably in his classic text on survey sampling.

${ }^{4}$ NORC at the University of Chicago uses written or computer assisted self-administered surveys for sensitive issues as e.g. sexual behaviour in their National Health Survey to allow for the respondents privacy and to insure unbiased answers.
} 
Table 5.1: Composition of Fokker Workforce and Survey Population at the Time of the Bankruptcy

\begin{tabular}{lrr}
\hline & $\mathrm{N}$ & $\%$ \\
\hline Displaced Workers & 3991 & 70.71 \\
Bankruptcy trustees & 700 & 12.40 \\
Fokker Aviation B.V. & 953 & 16.89 \\
\hline Total & 5644 & 100.00 \\
\hline Pilot & 100 & $\cdot$ \\
Other Workers involved in the & 38 & $\cdot$ \\
development of the Survey & & \\
\hline Survey Population & 5506 & \\
\hline
\end{tabular}

\section{Coverage}

The 'Fokker Survey' covers all 5644 employees who were employed by the parent company and subsidiaries on the date of bankruptcy including the 953 workers that were offered a position at Fokker Aviation B.V. after bankruptcy. ${ }^{5}$ These workers had first received a letter of dismissal immediately followed by a letter containing a job offer at the bankruptcy spin-off Fokker Aviation B.V. The survey also includes those employees that were temporarily employed by the Bankruptcy Trustees to participate in the socalled dismantling scheme. Table 5.1 summarizes the composition of the former Fokker N.V. work force.

All former employees (both working and unemployed) were selected to participate in the survey. Current addresses of the respondents were obtained from the bankruptcy trustees. Information from the Pension Fund was used to check for deceased employees whose addresses were omitted from the address files. The final inclusion in the research population was done for us by an employee of the bankruptcy trustees, who - based upon our criteria - delivered a list of names, addresses and phone numbers from the V.I.P. files of Fokker and matched them to the files of the pension funds to eliminate those workers that had passed away. The criteria used were that the employee had to be employed at Fokker N.V. in the parts that fell under the bankruptcy procedure. We used the day of the bankruptcy as the selection date, including both those workers that were fired and immediately re-hired and those that were displaced without being rehired by the trustees. Due to the data-structure that was used in the V.I.P. files a small number

\footnotetext{
${ }^{5}$ These numbers are based upon the personnel data (these are called the V.I.P. within Fokker) from the firm that we also used in the previous chapters, however here we focus only on those workers that were recorded to be part of those organizations that fell under the bankruptcy.
} 
of workers were erroneously included in the 'working population' that were actually not working with Fokker anymore. Especially workers who were disabled due to work or early retired workers could have been (erroneously) included. However, the number of those errors is negligible and could be identified ex-post. ${ }^{6}$

\subsubsection{Instrument Development}

\section{Focus Groups}

The first step to familiarize ourselves with the bankruptcy process information was obtained through interviewing. Interviews were conducted with key decision-makers comprising Fokker N.V. board members, the CEO of Stork B.V., the bankruptcy trustees, external advisors, and personnel managers of Fokker N.V. before bankruptcy and personnel managers of Stork B.V. ${ }^{7}$ A total number of 20 persons who had been involved in the bankruptcy reorganization and the dismantling of the Fokker workforce afterwards participated in the preliminary interviewing sessions. A second step to familiarize ourselves with the situation, feelings and language of the company was done by a focus group meeting on April 8th, 1997 in Maastricht. We invited members of the unions from Fokker as well as former members of the central workers council (COR) to discuss with us on matters regarding the bankruptcy.

\section{'Concept' survey}

Armed with the knowledge of the interviews and the first focus group meeting, we examined some surveys for question content and questioning procedure in order to develop the 'Fokker Survey'. Especially the labor market surveys of Statistics Netherlands, ROA, the NLSY, ${ }^{8}$ and the 'Washington Survey of Displaced Workers' ${ }^{\text {' }}$ gave us material and ideas to incorporate into the first design of the survey instrument.

In designing a first questionnaire several aspects with respect to the respondents as well as the comparability of the questions (and hence the outcomes) have to be considered: Firstly, questions should be comparable. Comparability means that the questioning

\footnotetext{
${ }^{6}$ This was not at the time that we contacted the respondents. Thus, we also received some responses which lead us to investigate this issue. Fortunately, the amount of erroneously included workers is negligible and the problem only leads to a more inclusive population.

${ }^{7}$ This was done by Gerard Pfann at an early stage of the project.

${ }^{8}$ Chris Flinn provided us with a copy of the most recent survey instrument. Our questions on search were based on this instrument

${ }^{9}$ This survey instrument was given to us by Bob Lalonde. It is a computer assisted telephone interview conducted among displaced workers in Washington State.
} 
should - if possible - be as close to relevant questions in other labor market surveys in order to insure that the outcomes of the specific question can be related to other datasets and results derived from those other data-sets. Survey research shows that question wording, ordering of answers and also the use of categories can influence the outcome of the survey (Bradburn and Sudman 1991). Therefore, we tried to use (adapted) versions of questions that are also used in other labor surveys. Secondly, all questions were evaluated in terms of interest, difficulty, and perceived relevance from the respondents point of view. Research from survey specialists point to some avoidable pitfalls in question wording (Sudman and Bradburn, 1983), the effect of answer categories and changes therein (e.g. Schwarz and Hippler, 1991), and the use of calenders to aid recovery of past information. From the theoretical survey literature and the existing surveys a first working version of the 'Fokker Survey' was constructed.

\subsubsection{Testing the Survey Instrument}

Even though all survey specialists agree on the crucial importance of pre-testing it seems that not all surveys actually follow a full pretest strategy. Dillman (2001) suggests a four step approach

1. Review by colleagues and analysts

2. Interviews with Cognitive and Motivational Evaluation

3. Pilot

4. 'Last check-up'

In essence, we followed this approach exactly. Our first step, after the working version of the 'Fokker Survey' was written, was to circulate it and updated versions among colleagues both with and without survey experience, as well as labor and non-labor economists who helped us to shape it into a polished survey that could be presented to the target population. In this step, wording, spelling and directional errors could be eliminated as well as comments on contents and the accessability of the survey instruments incorporated.

\section{Pre-testing using Focus Groups}

In order to evaluate the impact and understandability of the instrument for our target population we asked several employees with diverse backgrounds to meet us for a 'focus 
group meeting'. This second focus-group meeting took place on the 21st December 1998 in Amsterdam. The aim of this meeting was to pre-test the questionnaire with six former employees who had been employed in different parts of Fokker N.V.

After a brief introduction outlining the aim of the Fokker project the respondents were asked to fill out a survey on the spot and report difficulties encountered. Additionally, they were asked about the general understandability of the questions, to indicate sensitive issues, discuss motivational issues and propose on how to approach these sensitive issues, and how to clarify the survey. Furthermore, we tried to establish that the respondents interpretation especially of those questions that we considered to be difficult, matched our intention. For this step we did not use cognitive interviewing (as for example Forsyth and Lessler, 1991) but rather informal retrospective interviews and discussions.

\section{The Pilot}

The last step prior to conducting the full survey was to perform a test run of the questionnaire through 100 randomly selected respondents trying out the set up of the questionnaire and giving a first impression of the survey as a whole. The respondents were asked to complete the questionnaires and to comment on any problems encountered during the process of filling them in. In addition to the 100 randomly selected respondents, 38 questionnaires were sent to those persons who had contributed to the development of the survey and to the initial set up of the questionnaire. ${ }^{10}$ The outcomes of the test run of the questionnaire and the comments made by the respondents were used to make minor last revisions to the questionnaire.

\subsubsection{The ‘Fokker Survey’ Questionnaire}

The questions asked were centered around a theme. Following the literature we introduced the survey with a simple yet relevant question (cf. Bradburn and Sudman (1991)) setting the tone for the remainder of the questionnaire. ${ }^{11}$ As the survey was introduced to examine the results of the bankruptcy, we decided to start with questions that had to do with the time period around the bankruptcy and subsequently to continue into

\footnotetext{
${ }^{10}$ The reason for using this additional group is twofold. Those employees had commented and discussed several aspects of the study extensively with us, so that their answering of the survey might have lead to a bias comparable to an interviewer bias. On the other hand these were workers from different departments with Fokker, willing and enthusiastic to help us. Hence, we could and did get quite detailed comments on the pilot together with the filled in questionnaire.

${ }^{11}$ The full survey can be found in the Appendix of this thesis.
} 
the post displacement search period. A second section deals with the (possible) employment history following the bankruptcy and any self-employment. The last section of the questionnaire asks some demographic questions which might not have been considered interesting hence leading to premature break-off and non-response.

\section{Period Prior to Displacement}

The first part of the first section (questions 1.1 to 1.5) centers around the period just prior to, or at the moment of, displacement. Opening with an innocent yet relevant question on the number of years of employment with Fokker. We then continue with any work experience before a worker started with Fokker (1.2) as well as the function that a worker performed (1.3), and the number of subordinates (1.3b). Now we considered the stage sufficiently set to introduce a question on the pre-displacement income with Fokker. Questions on income are always considered 'dangerous' as they can lead to break-off of the entire survey. However, we felt that given the nature of the research, the respondents must be aware of the fact that salary is one of the crucial aspects. Hence we could be considered to have valid reasons for asking the question. Furthermore, questions (1.1) to (1.3b) lead naturally to the question of income. Question (1.5) asking the respondent, whether he considered himself the 'head of the household' of the family, completes this picture of having valid reasons for asking income questions.

\section{Questions on Search}

Questions (1.6) to (1.14) ask the respondent some questions on the period in which he searched for new employment. Both the search intensity in terms of weekly hours searched as well as letters written is asked. The number of letters written is set in a framework of four weeks as this was the time period in which unemployment insurance (UI) agencies require the worker to report on active measures taken to find a job. A set of questions $(1.11 .1$ - 1.11.6) are asked on the number of rejected job offers. If multiple offers existed some characteristics of the best rejected job offer are asked. This part is concluded by asking for the outcome of job search and the estimated cost of job search - which can be deducted from taxable income in the Netherlands. Finally, a number of questions (1.15-1.19) are asked on the usefulness of job search assistance that was provided immediately after the bankruptcy. 


\section{Employment Calendar}

To introduce the post displacement labor market experience and to anchor and aid the respondent in recollecting the exact timing of events, a calendar of labor market activities was used (question 2.1). The respondent was asked to sort himself into one of six categories which best described his activities in a given month - starting in April 1996 and ending in March 1999. The categories encompass regular employment, self-employment, unemployment, voluntary (unpaid) work, education, and 'other'. By circling the activity a respondent is forced to remember all his employments in the context of the entire three year period. This helps to avoid tunnelling or telescoping. ${ }^{12}$ It is much harder for a respondent to give exact dates without being forced to see the entire three year period with the displacement from Fokker in 1996 as a natural reference point.

\section{Employment Activities}

Question (2.2) sorts the respondents into four categories. Workers that remained without work for the entire period 'skip' to the third section. Respondents that were solely selfemployed are directed to that section, while workers that found one or more new jobs are asked to fill in detailed questions regarding the first and last (or current) employment. The questions for the first $(2.3-2.20)$ and last employment $(2.22-2.39)$ are similar and they ask the timing at which the employment was started, the name and address of the firm, the function performed within that firm and the sector the firm is mainly working in. In the pilot, we had tried closed questions for the sector, but it turned out not to be useful as most employees were unable to properly assign the firm into its sector. Hence an open question is asked which together with the name of the firm allows the investigation of the core activity that this firm is engaged in. We also ask about the size of the firm and the type of contract under which a worker is employed. Furthermore, we ask the number of subordinates, and to give a subjective assessment of their level of responsibility in comparison to their job at Fokker. We also ask about necessary technical know-how and job experience as well as an estimate of the time (of on the job training or schooling) needed for a worker with comparable education to take over this position. Finally, we ask starting and final (current) salary and the number of hours worked. If a respondent indicates that he has stopped working for the employer we ask the date that the employment was terminated and a reason for termination.

${ }^{12}$ Tunnelling and telescoping refer to remembering an event to be earlier or more recent depending on the saliency of an event. 


\section{Self Employment}

Those workers that indicated that they were self-employed (possibly even besides other employment) were asked a set of questions (2.40 - 2.46) on the type of company they own, the income they earn from the company and how long they have been self-employed. The last is important as the Dutch (UI) law allows workers to continue working in self-employment up to the hours they have worked while they were employed without deductions on UI benefits.

\section{Demographics}

In the last section of the questionnaire we ask the respondent some demographic information. This is usually considered to be somewhat boring or possibly irrelevant for the purpose of the study by the respondents. Therefore, respondents might get discouraged if these questions are asked up front and cease prematurely.

We ask questions on education levels obtained as well as possible additional training followed by the respondent after the displacement (3.1 - 3.6). We also ask about possible schooling measures provided by for example the unemployment agencies (3.7). Beyond the education and training we ask about the number and age of children, the current marital status (and the date of the last change), as well as the income of any partner (3.8 - 3.11). Furthermore we ask whether the respondent owns or rents his or her house (3.12). Both this question and the information on the income of the partner can approximate the wealth of the household.

\section{Open or Remarks Section}

At the end of the survey we allowed four lines as an open comments section which could be filled in by the respondents to provide us with comments and further remarks. This is usual practice as it helps the respondents in completing the survey to give the 'full picture' hence it probably increases the response rate of otherwise discouraged respondents who feel that we only asked the 'wrong' questions. It is astonishing how much and how diverse the answers on this open part were. Ranging from short comments to full stories that went well beyond the four lines provided. Unfortunately, these comments could only be used incidentally for clarification and a wealth of information and emotion remains hidden in the answers of this last question. 


\subsection{Conduct}

The final questionnaire ${ }^{13}$ was sent in April 1999 to all 5506 former employees of Fokker N.V. together with a letter of explanation and a pre-paid addressed return envelope (first round). ${ }^{14}$ In June 1999, a reminder letter was sent to those employees who had not returned their completed questionnaires together with a copy of the questionnaire, and a pre-paid addressed return envelope (second round). Completed questionnaires were returned up till November 1999 and were processed in three batches: May, August and December 1999. Data Entry was performed by a specialized company that coded all closed and most of the open questions according to our criterion. A validity check was performed for variables that could be pre-categorized (for example Age was only allowed to range between 16 and 65 ).

\section{Incentives}

As mentioned before, we did not provide any up-front incentive nor did we offer any payment for the time it took the respondent to fill in the survey. We did, however, offer the respondent a report on the results of the survey - if they indicated their interest to receive it. The motivation to fill in the survey hinged therefore on the sense of duty of the individual respondent to fill in and return the survey, appealing to his group feeling toward their fellow Fokker employers. But also by being able to "tell ones story" to help research in the field of displacement in order to aid future victims of plant closures.

\subsubsection{Response and Non-Response}

For our research it is important to address the non-response issue in a way to ensure that the results of the survey are reliable, verifiable, and representative of the whole population. In case any of these prerequisites are at stake and to avoid the introduction of bias, insight into non-response is very important. Non-response could be the result of the contents of the questionnaire. In this case it would imply that the responses obtained from those who did return completed questionnaires might not be representative of the population as a whole. The worst case scenario for non-response bias would comprise results that cannot be extrapolated to the full population. Another disturbing although less notable effect could be uncertainty about the precision of the results.

\footnotetext{
${ }^{13}$ The full questionnaire as well as the accompanying letter used in the 'Fokker Survey' can be found in the Appendix.

${ }^{14}$ These were all workers of the bankruptcy, 5644, minus those of the pilot, 138 .
} 
Non-response is the failure to solicit proper responses to the survey, or in the case of item non-response to single questions. Given the fact that we have conducted a mail survey we cannot distinguish between general classes of non-response, as for example not-at-home, temporarily unavailable, refusal or unobtainable, incapacitated (due to for example illness), not found, and lost as proposed by Kish (1965, p. 533-534). Most, if not all of the above categories will be noted in a mail survey simply by the absence of a response. We have only received a few return mails with wrong addresses, or outright refusals. We therefore encompass all these categories in the broader category of nonresponse.

\section{Non-Response Bias}

How does non-response influence the results? This can be seen by examining the effect of non-response on a simple statistic as for example the mean. Imagine the situation as given in the table below:

\begin{tabular}{lccccc}
\hline Stratum & Size & Total & Mean & Variance \\
\hline Respondents & $N_{R}$ & $t_{R}$ & $\tilde{Y}_{R u}$ & $s_{R}^{2}$ \\
Non-respondents & $N_{M}$ & $t_{M}$ & $\tilde{Y}_{M u}$ & $s_{M}^{2}$ \\
\hline Entire Population & $N$ & $t$ & $\tilde{Y}_{u}$ & $s^{2}$ \\
\hline
\end{tabular}

The total population consists of $N_{R}$ - the 'willing' respondents - and $N_{M}$ the nonrespondents. Bias is the difference between the true mean:

$$
\tilde{y}_{u}=\frac{N_{R}}{N} Y_{R u}+\frac{N_{M}}{N} Y_{M u}
$$

and the estimated population mean based on the respondents only:

$$
E\left[\tilde{y}_{R}\right]-\tilde{y}_{u}=\frac{N_{M}}{N} Y_{M u}\left(\tilde{Y}_{R u}-\tilde{Y}_{M u}\right)
$$

Hence the bias is small if $\frac{N_{M}}{N}$ is small, that is if the non-response is small, or if the difference between the mean of the respondents, i.e. $\tilde{Y}_{R u}-\tilde{Y}_{M u}$ is small, so that both groups are similar.

\section{Factors Affecting Non-Response}

Lohr (1990) notes that the following factors can influence the response rate: 


\section{Development and Conduct}

- Survey content

- Time of survey

- Data collection method

- Questionnaire Design

- Respondent Burden

- Survey Introduction

- Incentives and disincentives

- Follow-up

There are several theories and models that attempt to explain survey non-response. Groves and Couper (1998) give an overview of both rational choice theory versus psychological explanations. One prominent theory is called the 'opportunity cost hypothesis'. It expects that, ceteris paribus, respondents with higher time valuation will be less willing to contribute to a survey (Groves and Couper 1998, p.123-125). However, it is unclear how respondents 'value' the participation in the survey in this model. Under the heading of 'exchange' two extensions to the rational choice model of response are made: The first is based on social exchange theories, while the second is based on social isolation. Social exchange deals with the value of long-term relations between persons (c.f. (Blau 1964)). They are used as an explanation model why the building of a relationship before the actual survey is important (pre-announcement, cover letter), and why the effort during the survey (re-mailings), have an effect on the perceived duty of the respondent to answer (the exchange). The theory of 'social isolation' postulates that a "group feeling" of a respondent is necessary. Hence, respondents are likely to respond to survey request which conform to their (perceived) group interests (Groves and Couper 1998, p. 131).

We have tried to take all these insights into account and also tried to limit the survey to 30 minutes. We introduced the study and the usefulness of the study with an introductory letter as well as a letter of support from the bankruptcy trustees. Furthermore, we gained the support of the assocation of former Fokker employees who preannounced our survey and stressed the usefulness. In the questionnaire design we made every attempt to keep the subject matter clear, interesting and as unobstrusive as possible. Yet, non-response remains an issue also in our study as we will see in the following section. 


\subsubsection{Non-Response in the Fokker Survey}

The best method to avoid the introduction of non-response bias is to avoid it altogether. However, in most studies this is not feasible. The Fokker-Survey has a response rate of $41.5 \%$, a high rate considering the fact that this was a mailed survey with no monetary incentives offered to the respondents for a response. General settings and cultural visions of surveyed populations play an important role in response behaviour. In the Netherlands the response rates for surveys are traditionally low which require estimations of the magnitude and direction of the non-response bias.

We employ two different techniques for our investigation in the non-response of the 'Fokker Survey': a first test is to find predictors for non-response given the information we have compiled on respondents and non-respondents together. A second test is to do a follow-up among a sub-sample of the non-respondents. For this a follow-up telephone survey was conducted among non-respondents with the aim to identify some key variables for this research and to ask "core questions".

\section{Testing for Non-Response}

The first test into non-response examines the effects of known variables of both respondents and non-respondents on the probability of response. Rubin (1987) categorizes data to be missing completely at random (MCAR), missing at random (MAR) and nonignorable non-response (NIN). The difference between MCAR and MAR is that data is missing depending on some external variables, or mathematically:

$$
\begin{gathered}
E(Y \mid X)=E(Y) \\
E(Y \mid X)=\operatorname{Prob}(r=1 \mid X) \cdot E\left(Y_{r=1}\right)+\left(1-\operatorname{Prob}(r=1 \mid X) \cdot E\left(Y_{r=0}\right)\right.
\end{gathered}
$$

In the second equation the outcome variable $Y$ is affected by the non-response only through the difference in composition (of the explanatory variable $X$ ) between the response and non-response variables. Correcting for the differences in composition can realign outcomes to those of surveys without non-response. We have used a simple Probit including variables from the personnel files to examine in which variables the respondents differ from the non-respondents. Having predicted a probability of survey response, it allowed us to post-stratify the sample outcomes with the inverse of the individual's response probability. 
In explaining non-response we included the following variables: age in seven categories, starting with a category of less than 30 years old to go in steps of five years to the last category 55 and older. The base category left out is 35-39 years old, the biggest category. Tenure at Fokker is also identified by a set of 8 categories allowing for possible differences between different workers vintages. Starting with 3 years or less, then 3-4 years of tenure, to then continue in steps of five years until 30 or more years of tenure. Here the tenure category of 5 to 9 years is the predominant category, and is taken as the baseline category. The education variable is identified in nine categories which represent different degrees. We distinguish between four degrees of general schooling, basic, intermediate general (MAVO), higher-general (HAVO), and pre-university school (VWO), as well as five specialized degrees, lower vocational (LBO/LTS), intermediate vocational (MBO), higher vocational (HBO), technical university (TU) and non-technical university (WO). We use the largest group, intermediate vocational degree (MBO), as reference group. The data-set comprises workers from three plants: Schiphol, the largest plant and head-office, Drechtsteden, and Ypenburg. We control for differences among plants and possible regional differences by including dummy variables for Drechtsteden as well as for Ypenburg. We also include the wage scale of a worker at the time of the bankruptcy. Wage scales run from 2, the lowest level, to scale 19, the highest level. Production workers are in the wage scales from 2 to 12 , while engineers and management start around scale 12 and go on up to scale 19.

From the personnel files an indication of the general work activity of a specific function can be derived. Jobs in production, production planning and support, quality control, $\mathrm{R} \& \mathrm{D}$, as well as management and finance, sales, and administration are being distinguished. Careers can encompass several of the job activities. However, movements in and out specific job activities are not so frequent. For this chapter we used dummies to identify the last job activities an employee performed. The information carried by the job activity variable allows us to distinguish between work that requires a relatively large degree of firm specific knowledge - a good example is quality control or R\&D who are specific to the aircraft built but also to the aircraft industry as a whole - and work that needs more general skills such as management tasks, administration and sales.

Job performance evaluation scores on a scale from one to six (one being unsatisfactory and six being excellent) are also included as dummy variables in the following way: the predominant group with a score three, 'good', are left out as the reference group. Workers offered a new job at Fokker Aviation were identified by a dummy. Two additional dummies identify female and another, married workers. 
Table 5.2: Probit Non-Response

\begin{tabular}{lrrr}
\hline Non-Response=1 & Coeff. & s.d. & $\mathrm{p}$ \\
\hline Age: $\geq 55$ & 0.544 & 0.137 & 0.025 \\
Tenure: $25-29$ & -0.262 & 0.087 & 0.003 \\
Tenure: $\geq 30$ & -0.328 & 0.106 & 0.002 \\
Evaluation: unsatisfactory & 0.381 & 0.146 & 0.009 \\
Married & -0.145 & 0.040 & 0.000 \\
Female & -0.163 & 0.082 & 0.047 \\
Job Activity: R\&D & 0.165 & 0.083 & 0.046 \\
Job Activity: Production Planning & 0.175 & 0.082 & 0.032 \\
Salary-scale: 9 & -0.151 & 0.073 & 0.040 \\
Salary-scale: 10 & -0.299 & 0.097 & 0.002 \\
Salary-scale: 11 & -0.300 & 0.121 & 0.013 \\
Aviation & 0.150 & 0.070 & 0.031 \\
\hline Observations & & 5316 & \\
\hline
\end{tabular}

Notes: Based on the 'Fokker Survey' and the Personnel Files. Probit estimates the probability of non-response (1) versus response (0). We report only those variables that are significant at a minimum level of 95 percent level. We corrected for plants, blue collar, female, tenure and age categories, education levels, evaluation scores, fte, travel distance, salary scales [2 (lowest) - 19 (highest)] and area of job activity.

Table 5.2 shows only those variables that entered the probability model that are significantly different from zero. Workers older than 55 have a higher propensity to not respond; high tenure worker have a lower propensity; workers in salary scale 9 to 11 have higher propensities to respond - those are predominantly production workers who are either team or group leaders; married workers are more likely to respond; workers selected for Aviation respond less; employees in research and development, and planning are less likely to respond than respondents who worked in the administration (the reference group); workers with the lowest evaluation scores have a smaller likelihood to respond, whereas the highest scores have higher response propensities compared to the middle reference group.

\section{Weighting Methods for Nonresponse}

As mentioned above, if we have MAR non-response, the bias is due to a compositional effect of the respondents. This composition of, $X$, can be reestablished by first estimating the influence of $X$ on non-response and to then weight the respondents according to their response probability. The probability of responding, $\theta_{i}$ is estimated for each unit in the sample using auxiliary information known for all units in the sample. The weight of a 
response is then given by $\frac{1}{\hat{\theta}_{i}}$. Weighting methods assume that the response probabilities can be estimated from variables known for all units (cf. Oh and Scheuren, 1983; Holt and Elliot, 1991).

As reported above, we predicted a probability of response to the survey and weighted every observation of the survey with the inverse of their response probability. In essence we post-stratified our respondents according to their response probability, hence respondents with a low probability of response are weighted heavier since they represent a 'larger' group of non-respondents. We employed both weighted and unweighted samples to estimate simple wage loss regressions as in chapter 7 . The weighted sample is then weighted according to the inverse of the response-probability. Since the weighted estimations do not differ much from the unweighted estimations, and given the results from the non-response follow up in the sections below, we ignore the non-response for the remainder of the estimations in this thesis.

\section{‘Core Question’ Follow Up}

Follow up within the group of non-respondents is not a new concept. Hansen and Hurwitz (1958) and Hansen et al (1953) suggested to complete two identical surveys using different modes. The idea of asking a limited number of core questions for a follow up, is initially suggested by Bethlehem and Kersten (1986) as a method to distinguish between the group of non-respondents who are simply unwilling to provide the detailed answers asked for in general or specific surveys, and those unwilling to participate for reasons related to the survey specifically.

To learn about possible non-random selection a limited number of core questions were asked to initial non-respondents by means of telephone interviews. Those responses can then be used to correct for selectivity bias when necessary. In our case it is unlikely that we would have solicited co-operation from all individuals that had not responded so far. But, given the information we already had about the respondents and non-respondents the core questions should be sufficient for identifying non-response bias. The questions are ranked in order of our expectation that a respondent will refuse to answer and the significance for the study at hand. We asked the following questions:

1. What is your current employment status?

2. For how many months have you been unemployed after the bankruptcy?

3. Is your current salary higher or lower than the income you earned at Fokker? 
4. Please specify by how much percent your current salary differs from the last salary you earned at Fokker?

The first question allows us to derive response behavior and estimate the non-response bias based on the current employment status of the non-respondent. ${ }^{15}$ The second question relates to one of the main objectives of the study that is to capture losses encountered by the displaced workers. The third and fourth question simply refine insights with respect to post-displacement earnings.

\section{Follow-up Sampling}

The follow-up part of the study was carried out among a randomly selected, stratified sample of 200 non-respondents, 53 of whom were selected for Fokker Aviation or to work for the trustees. Stratification was done by age for former employees of Fokker N.V. who were and were not selected for Fokker Aviation B.V. We have a small proportion of workers who were known to have had a job-offer from Fokker Aviation B.V. or from the Bankruptcy Trustee for at least some pre-determined time following the bankruptcy of Fokker N.V. We did not presume those selected workers to be comparable to displaced workers in general since it can be expected that their post-bankruptcy career development is different from those who were fired immediately after bankruptcy, and faced at least initial unemployment.

In order to allow for an analysis according to age groups, we stratified age over four categories. Under 30 years old, 30-39 years, 40-49, and 50+ years of age at the time of the bankruptcy. The allocation of the population of 200 was then derived using optimal allocation, ${ }^{16}$ in which the aim is to minimize the (expected) variance of the variable of interest, which here is employment status. If we denote the age strata by $h$ then the following formula gives the optimal allocation of the population $n$ over the strata:

$$
n_{h}=\frac{n S_{h} N_{h}}{N \sum_{h} W_{h} S_{h}}
$$

Where $N$ is the total population, $S$ denotes the standard deviation, and $W$ denotes the weight of a stratum, which is defined as $W_{h}=N_{h} / N$. All suffixes $h$ denote that

\footnotetext{
${ }^{15}$ An aggregate outcome of the follow up was calculated given the original stratification weights of the population.

${ }^{16}$ The actual minimization was done over the workers that were displaced (147) since they always had variation over the core variable, selected workers (53) were assigned proportionally to the displaced group. We defined employment status to be "working" (employed or self-employed) or "not-working", which was used as variable for the optimal allocation.
} 
the weight, standard deviation or population is over a specific age-stratum. Since the standard deviation of the stratum is unknown, we use the standard deviation of the stratum of the respondents. This is the best information available and commonly used in research. The expected optimal variance is then:

$$
\operatorname{var}^{*}(y)=\frac{1}{n^{*}} \sum_{h}\left(W_{h} S_{h}\right)^{2}-\frac{1}{N} \sum_{h} W_{h} S_{h}^{2}
$$

These formulas are derived in Kish (1965, Chapters 3 and 4). Note though, that we cannot get the optimal allocation directly, as the result to the optimal allocation problem is usually not an integer. Therefore the values are simply rounded up or down.

Once this optimal allocation is done we have stratified once more, this time proportionally over workers that were offered a job in Fokker Aviation B.V. or were (temporarily) employed by the bankruptcy trustees. This is done because we do not want to assume a priori that the workers who were offered a job will behave the same way to the mail survey. One could argue that the employed respondents (and non-respondents) who were displaced are similar in the response behavior to the Aviation workers. However, it becomes less clear if we want to estimate the unemployment of the Aviation workers - who initially got year contracts - given the response behavior of the unemployed displaced workers.

We did not use the optimal allocation over the completely stratified sample for two reasons: first of all the estimation that we have of the standard deviation of the aviation workers is based on the responses we had from that group. Within a stratification over age-groups some strata had no unemployed at all, hence the standard deviation is zero. Optimal allocation would then assign too little observations to this stratum. Instead we first made strata according to the age-groups and simply use the overall standard deviation per age strata to calculate the optimum allocation and subsequently the sample size is split according to size of displaced workers to workers at Aviation representing the relative proportion to each other.

\section{Results of the Non-Respondents Follow-Up}

We have been able to get a high rate of co-operation that can be seen in the high response rate of almost $85 \%$ on average. ${ }^{17}$ This has been achieved with a minimum of three recalls at different time periods if the respondent was not reached. We have also accepted answers from the spouse of the respondents since they should also have the information

\footnotetext{
${ }^{17}$ Compare table 5.4 for a full overview of the response by stratum.
} 
Table 5.3: Employment Status in 1999 - Response vs. Non-Response

\begin{tabular}{lrr}
\hline & Non-Response Study & 'Fokker Survey' \\
\hline Employed & 80.84 & 80.82 \\
Unemployed & 4.54 & 4.52 \\
Self-Employed & 3.08 & 2.50 \\
Other & 11.54 & 11.98 \\
\hline
\end{tabular}

Notes: Based on the 'Fokker Survey' and Non-Response Study. Non-response results are weighted (cf. table 5.7)

to answer the questions correctly. ${ }^{18}$ Only five percent of the respondents selected for the follow up refused to co-operate altogether. This, together with difficulties in reaching some respondents explains the remaining non-response in the follow-up study.

The percentage distribution of respondents over employment status can be found in Table 5.3, and more detailed in Tables 5.5 and 5.6 for respectively the non-response study and the 'Fokker Survey' respondents. Note though, that the non-response study actually covers the labor market status in February 2000 rather than March 1999 which the 'Fokker Survey' covers. Note also that the Categories 'Disability' and 'Pension' did not exist in the 'Fokker Survey', hence those categories should be in the "Other" category. Examining the outcome by strata we can see that the non-response survey and 'Fokker Survey' do not deviate too much. The only striking differences are a higher unemployment percentage for the 40-49 year old displaced workers in the Non-Response study versus the 'Fokker Survey' (8.11 percent versus 5.30 percent). Furthermore, the category $50+$ also has a much lower employment percentage, but that is due to a high percentage of respondents in the "Pension" category.

An aggregate outcome of the follow up was calculated given the original weights of the stratification. As has been mentioned in the main text, the distribution over the main categories; Employed, Unemployed, Self-Employed, and the remaining are encompassed under "other" category. As can be seen in tables 5.3 and 5.7 the results from the non-response follow-up show that the labor market status is comparable both for the respondents and non-respondents.

\subsection{Conclusion}

After obtaining the personnel files and investigating the possibilities for a displacement study based on both the internal firm data and the experiences of workers after the

\footnotetext{
${ }^{18}$ This is common practice in surveys.
} 
Table 5.4: Weights and response rate - Non-Response Study

\begin{tabular}{lcccc}
\hline Age-Group & $\begin{array}{c}\text { Strata-weight } \\
\%\end{array}$ & $\begin{array}{c}\text { Response } \\
\text { N }\end{array}$ & $\begin{array}{c}\text { Allocated } \\
\mathrm{n}\end{array}$ & $\begin{array}{c}\text { Response Rate } \\
\%\end{array}$ \\
\hline$<30$ & 9.37 & 10 & 13 & 76.92 \\
$30-39$ & 31.46 & 38 & 42 & 90.48 \\
$40-49$ & 22.35 & 37 & 45 & 82.22 \\
$50+$ & 12.73 & 35 & 47 & 74.47 \\
$<30$ \& Aviation & 2.54 & 4 & 5 & 80.00 \\
$30-39$ \& Aviation & 11.54 & 13 & 15 & 86.67 \\
$40-49$ \& Aviation & 7.99 & 16 & 16 & 100 \\
$50+\&$ Aviation & 2.02 & 16 & 17 & 94.12 \\
\hline Total & 100 & 169 & 200 & 84.50 \\
\hline
\end{tabular}

Table 5.5: Percentages by Strata - Non-Response Study

\begin{tabular}{lrrrrrr}
\hline Age-Group & Employed & Unemployed & Disability & Self-Empl. & Pension & Other \\
\hline Displaced & \multicolumn{7}{c}{} & & & & \\
\hline$<30$ & 100.00 & 0.00 & 0.00 & 0.00 & 0.00 & 0.00 \\
$30-39$ & 94.74 & 0.00 & 2.63 & 2.63 & 0.00 & 0.00 \\
$40-49$ & 75.68 & 8.11 & 8.11 & 5.41 & 0.00 & 2.70 \\
$50+$ & 37.14 & 14.29 & 2.86 & 2.86 & 40.00 & 2.86 \\
\hline Aviation & & & & & & \\
\hline$<30$ & 100.00 & 0.00 & 0.00 & 0.00 & 0.00 & 0.00 \\
$30-39$ & 100.00 & 0.00 & 0.00 & 0.00 & 0.00 & 0.00 \\
$40-49$ & 93.75 & 0.00 & 0.00 & 0.00 & 0.00 & 6.25 \\
$50+$ & 100.00 & 0.00 & 0.00 & 0.00 & 0.00 & 0.00 \\
\hline
\end{tabular}


Table 5.6: Percentages by Strata - Respondents 'Fokker Survey'

\begin{tabular}{lrrrrrr}
\hline Age-Group & Employed & Unemployed & Disability & Self-Empl. & Pension & Other \\
\hline Displaced & & & & & & \\
\hline$<30$ & 95.88 & 2.06 &. & 1.55 &. & 0.52 \\
$30-39$ & 94.07 & 0.94 &. & 3.37 &. & 1.62 \\
$40-49$ & 88.92 & 5.30 &. & 3.37 &. & 2.41 \\
$50+$ & 63.03 & 27.49 &. & 1.90 &. & 7.58 \\
\hline Aviation & & & & & & \\
\hline$<30$ & 100.00 & 0.00 &. & 0.00 &. & 0.00 \\
$30-39$ & 99.45 & 0.00 &. & 0.55 &. & 0.00 \\
$40-49$ & 97.86 & 0.00 &. & 1.43 &. & 0.71 \\
$50+$ & 94.44 & 2.78 &. & 2.78 &. & 0.00 \\
\hline
\end{tabular}

bankruptcy, we developed a survey among those workers that were directly affected by the bankruptcy procedure.

While the final questionnaire comprised 14 pages we were fortunate to get a high response rate. Nevertheless, the possibility of non-response bias threatened to diminish possibly interesting results from this study. Therefore, we went into detail in order to examine any possible non-response bias. To summarize the non-response section for the 'Fokker Survey', we can state that we did not find that response behavior is affected by age nor is it affected by whether or not respondents continued employment with Fokker Aviation B.V. The results from the follow-up also show that a possible effect of nonresponse bias in the 'Fokker Survey' is probably not associated with employment status (cf. Table 5.3). 
Table 5.7: Outcomes - Non-response Study

\begin{tabular}{|c|c|c|c|c|c|c|c|}
\hline Age-group & Strata-weight & Employed & Unemployed & $\begin{array}{l}\text { Disability } \\
\text { Pension }\end{array}$ & Self-Employed & $\begin{array}{l}\text { Retirement } \\
\text { Pension }^{2}\end{array}$ & Other \\
\hline \multicolumn{8}{|l|}{ Displaced workers } \\
\hline$<30$ & 9.37 & 10 & 0 & 0 & 0 & 0 & 0 \\
\hline $30-39$ & 31.46 & 36 & 0 & 1 & 1 & 0 & 0 \\
\hline $40-49$ & 22.35 & 28 & 3 & 3 & 2 & 0 & 1 \\
\hline $50+$ & 12.73 & 13 & 5 & 1 & 1 & 14 & 1 \\
\hline \multicolumn{8}{|l|}{ Fokker Aviation B.V. } \\
\hline$<30$ & 2.54 & 4 & 0 & 0 & 0 & 0 & 0 \\
\hline $30-39$ & 11.54 & 13 & 0 & 0 & 0 & 0 & 0 \\
\hline $40-49$ & 7.99 & 15 & 0 & 0 & 0 & 0 & 1 \\
\hline $50+$ & 2.02 & 16 & 0 & 0 & 0 & 0 & 0 \\
\hline Total (percentage) & 100 & 80.84 & 4.54 & 3.86 & 3.08 & 6.19 & 1.49 \\
\hline
\end{tabular}

: Notes: ${ }^{1}$ Work disabled persons who receive a disability pension or benefit (WAO)

${ }^{2}$ Persons in the Netherlands can retire at the age of 65 years (AOW) or at a younger age using early retirement schemes(VUT). 


\section{Some Results of the Fokker Survey}

"Investeren in persoonlijke en bedrijf-gerelateerde netwerken leidt tot een aanzienlijk beter perspectief op het vinden van een baan dan Centra voor Werk en Inkomen kunnen bieden."

(Fokker Employee) 
There are two basic questions answered within the displacement literature. First, how long does it take to find a new job, or which groups encounter difficulties in finding new jobs. And second, what are the wages after displacement. Is there a break in the wage development around displacement, what constitutes wage losses, and how long does it take to catch up. A natural continuation is an investigation in what factors affect both of these outcomes. In this chapter we will look at the entire data from the survey, to broadly examine the above two questions. The labor market status and developments in employment of the respondents to the Fokker Survey are taken in to consideration at one, two, and three years after the bankruptcy to examine the duration that the displacement has on the workers with respect to their labor market status. Further, we also investigate the average wage outcome for those that find a job. We will compare unemployed and employed respondents by age and education level. To relate the findings for the displaced workers to the general situation on the Dutch labor market, comparisons are made with a 'matched' sample from Socio-Economic Panel (SEP) data .

\subsection{Labor Market Status}

\section{Method}

The respondents are categorized by age and educational level. The study distinguishes seven age groups: the first includes all respondents under the age of 30 years. The second through sixth group include ages at 5-year intervals: 30 - 35, 35 - 40, 40 - 45, 45 - 50, 50 - 55 years of age respectively. The seventh group includes all respondents over the age of 55 years.

Educational levels are assorted by differentiating between general (secondary school) education and vocational or professional training. The first group includes lower and higher general secondary school, and pre-university education: respectively MAVO including MULO and ULO —, HAVO — including MMS — , and VWO - including HBS or gymnasium. The second group consists of those who have received lower general or lower technical vocational training (LBO or LTS respectively), intermediate and higher vocational training ( $\mathrm{MBO}$ or $\mathrm{HBO}$ respectively), or university training (WO or TU). The differentiation between WO and TU can be used as a proxy for a technical study, since workers with a TU degree - having completed a degree at a technical university - are more likely to also have followed a technical study than workers with a degree from a non-technical university. 
Table 6.1: Education Levels - Fokker Survey vs. 'matched' SEP

\begin{tabular}{lrrrrr}
\hline & \multicolumn{2}{c}{ Sokker } & Survey & & SEP \\
Education & $\mathrm{N}$ & $\%$ & $\mathrm{~N}$ & $\%$ \\
\hline Basis & 26 & 1.14 &. &. \\
MAVO & 156 & 6.85 & 156 & 7.11 \\
HAVO & 53 & 2.33 & 53 & 2.41 \\
VWO & 42 & 1.84 & 42 & 1.91 \\
LBO/LTS & 382 & 16.77 & 382 & 17.40 \\
MBO & 645 & 28.31 & 645 & 29.38 \\
HBO & 586 & 25.72 & 583 & 26.56 \\
WO & 124 & 5.44 & 303 & 13.80 \\
TU & 264 & 11.59 & 31 & 1.41 \\
\hline Total & 2278 & 100.00 & 2195 & 100.00 \\
\hline
\end{tabular}

The distribution of labor market statuses is compared to the 'matched' SEP data. When comparing the consequences of displacement of former Fokker N.V. employees it is necessary to place the outcomes of the survey in a broader perspective, thus, a comparison needs to be made with a representative sample of the Dutch labor market situation at approximately the time of bankruptcy. For this purpose the data of the Socio-Economic Panel (SEP) of Statistics Netherlands (Central Bureau of Statistics, CBS) were used. The SEP was initiated in 1984 to collect information on the well being and income of individuals and households in the Netherlands. It includes variables on demographics, education, work-situation, income, living, consumption and wealth. The data are household based, representative of the Dutch population, and includes variables comparable to those in the current study. For comparison a sub-sample of the latest complete sample of SEP data from 1996 was used.

The SEP sample constitutes of the labor market participants, with an age range between 20 and 65 years old. From this sample a smaller sub-sample was selected by matching it according to the educational levels and age-categories of the former Fokker employees whom had given their response to the survey questionnaire. By matching we avoid any problems concerning composition effects due to age or education when comparing the results from the Fokker Survey to those of the matched sample of the Socio-economic panel. This sub-sample, called the 'matched' SEP sample, was chosen for optimal representation of the population of displaced Fokker workers. The 'matched' SEP sample shows the situation for the Dutch economy given that they have an age and educational level distribution comparable to Fokker N.V. employees at the time of the bankruptcy. 
Table 6.2: Age Categories - Fokker Survey vs. 'matched' SEP

\begin{tabular}{lrrrr}
\hline Age & Fokker & Survey & 'matched' SEP \\
Categories & $\mathrm{N}$ & $\%$ & $\mathrm{~N}$ & $\%$ \\
\hline$<30$ year & 240 & 10.53 & 262 & 11.94 \\
30-34 year & 449 & 19.70 & 416 & 18.95 \\
35-39 year & 494 & 21.68 & 457 & 20.82 \\
40-44 year & 406 & 17.81 & 397 & 18.09 \\
45-49 year & 384 & 16.85 & 384 & 17.49 \\
$50-54$ year & 252 & 11.06 & 226 & 10.30 \\
$55+$ year & 54 & 2.37 & 53 & 2.41 \\
\hline Total & 2279 & 100.00 & 2195 & 100.00 \\
\hline
\end{tabular}

Distributions of educational level and age in both among the respondents of the Fokker Survey as well as the 'matched' SEP sample have been provided in Tables 6.1 and 6.2 respectively. It should be noted that the SEP data represents the status in the Netherlands in 1996 while the Fokker Survey covers the years 1997, 1998, and 1999. This means that the SEP data should actually be regarded as representative of workers who were not displaced, hence giving a reference point in time. The former Fokker employees who were surveyed were fired in the large bankruptcy and will have to reorient themselves on the labor market. This can be expected to take some time until a 'normal' situation is regained.

A second analysis is performed to examine the development with regard to labor market status over time. Since there are three points of observation for the labor market status $(1997,1998$, and 1999) it is possible to study how the change between categories is evolving over the three years. For example, it can be expected that immediately after the bankruptcy many people were unemployed. Slowly but increasingly the majority of former Fokker N.V. employees find new jobs thus gradually changing the labor market status from unemployed in 1997 to employed in 1999.

In the matching procedure for the SEP sample no distinction is made between WO or TU university degree holders. TU degree holders are heavily represented among the former employees of a firm such as Fokker N.V., but they are not so heavily represented in the socio-economic panels of the Dutch economy as a whole.

Those employees who do not classify themselves as unemployed because they have either started their own business (self-employment), are structurally involved in voluntary activities or other types of unpaid work, receive work disability pensions or have retired since bankruptcy are excluded from the analysis. 
Table 6.3: Labor Market Status — Aggregated a. Fokker Survey Status

\begin{tabular}{lrrrrrrr}
\hline Status & \multicolumn{2}{c}{1997} & \multicolumn{1}{c}{1998} & \multicolumn{2}{c}{1999} \\
& $\mathrm{~N}$ & $\%$ & $\mathrm{~N}$ & $\%$ & $\mathrm{~N}$ & $\%$ \\
\hline Working & 1758 & 77.1 & 1882 & 82.6 & 1934 & 84.9 \\
Self-employed & 43 & 1.9 & 51 & 2.2 & 57 & 2.5 \\
Unemployed & 226 & 9.9 & 142 & 6.2 & 97 & 4.3 \\
Other & 85 & 3.7 & 54 & 2.4 & 50 & 2.2 \\
Missing & 167 & 7.3 & 150 & 6.6 & 141 & 6.2 \\
\hline Total & 2279 & 100.0 & 2279 & 100.0 & 2279 & 100.0 \\
\hline
\end{tabular}

b. 'matched' SEP sample

\begin{tabular}{lrr}
\hline Status & 'matched' SEP sample \\
& $\mathrm{N}$ & $\%$ \\
\hline Working & 1890 & 86.1 \\
Self-employed & 164 & 7.5 \\
Unemployed & 121 & 5.5 \\
Other & 20 & 0.9 \\
\hline Total & 2195 & 100.0 \\
\hline
\end{tabular}

Notes: Categories 1997, 1998, and 1999 are based on the status in April of that year. The 'matched' SEP sample contains the a sub-sample, randomly drawn from the labor force sample of the 1996 SEP wave, matching the representation of the respondents of the "Fokker Survey" with respect to age-categories and educational levels.

The data from the SEP sample distinguishes between four categories of employment status: working, self-employed, unemployed, and other. The category "unemployed" captures those workers who are not working. This group includes persons taking (fulltime) courses or persons on temporary (long-term) sickness leave. The Fokker Survey includes a fifth category "niet ingevuld" which denotes workers who filled in the survey questionnaire but skipped this section for unknown reasons. As this does not necessarily mean that they are not working or are engaged in activities as defined as "other" they cannot be included under "unemployed" or "other" so therefore they are considered as a separate group.

\section{Labor Market Status - The Aggregate View}

An overview of the aggregate distribution over the different labor market statuses of a cross-section of former employees of Fokker N.V. at one, two and three years following 
the bankruptcy and of the SEP data are given in Table 6.3. The labor market situation in the Netherlands in 1996 is reflected in the 'matched' SEP sample (Table 6.3.b). As shown, approximately 86.1 percent of the labor force are employed, about 7.5 percent are self-employed, and 5.5 percent are unemployed.

The situation in 1997 is that 77.1 percent is employed, 1.9 percent is self-employed, while 9.9 percent are unemployed. 3.7 percent are in the category not employed, which could mean that they e.g. follow courses (see above). Comparing this to the Dutch situation, as described by the SEP data, one can conclude a much higher rate of unemployment - almost double that of the SEP figure. Also the category "other" is significantly higher, 3.7 percent in the Fokker case versus 0.9 percent in the matched SEP data. It is not surprising, though, that the rate of self-employed is much lower in the case of former Fokker-employees. Most of the self-employed in the SEP data did also not start a new business within the last year; they were already self-employed already for many years. Fokker employees can only become full-time self-employed if they started their private company after the bankruptcy.

If we look at the development in 1998 and 1999 we can see that the number of people finding employment is increasing. There are also more people self-employed than in 1997. In percentages the employment rate increases to 84.9 percent in the year 1999, and this is due to a flow from people out of unemployment - which is reduced from 9.9 percent in 1997, through 6.2 percent in 1998, to a level of 4.3 percent in 1999. But also the number of people of the category "not employed" is decreasing from 3.7 percent, through 2.4 percent in 1998, to 2.2 percent in 1999. Note that these percentages are again calculated taking into account that between 6.2 (in 1999) and 7.3 (in 1996) percent of the respondents did not complete this part of the survey.

\section{Labor Market Status by Age and Educational Levels}

In this section the two groups of employed versus unemployed are examined more closely. We differentiate by age-categories and by educational levels. As described in the methods section, the age-categories will usually span a period of five years, and the educational levels give the highest degree attained, either general (school) education or vocational training and university degrees. As in the aggregate case there is also a comparison over time, i.e. look at the situation one, two, and three years after the bankruptcy. There is also a comparison to the 'matched' SEP sample representing the Dutch situation matched for age and education composition. 
Figure 6.1: Educational Levels over Employed in 1997, 1998, 1999

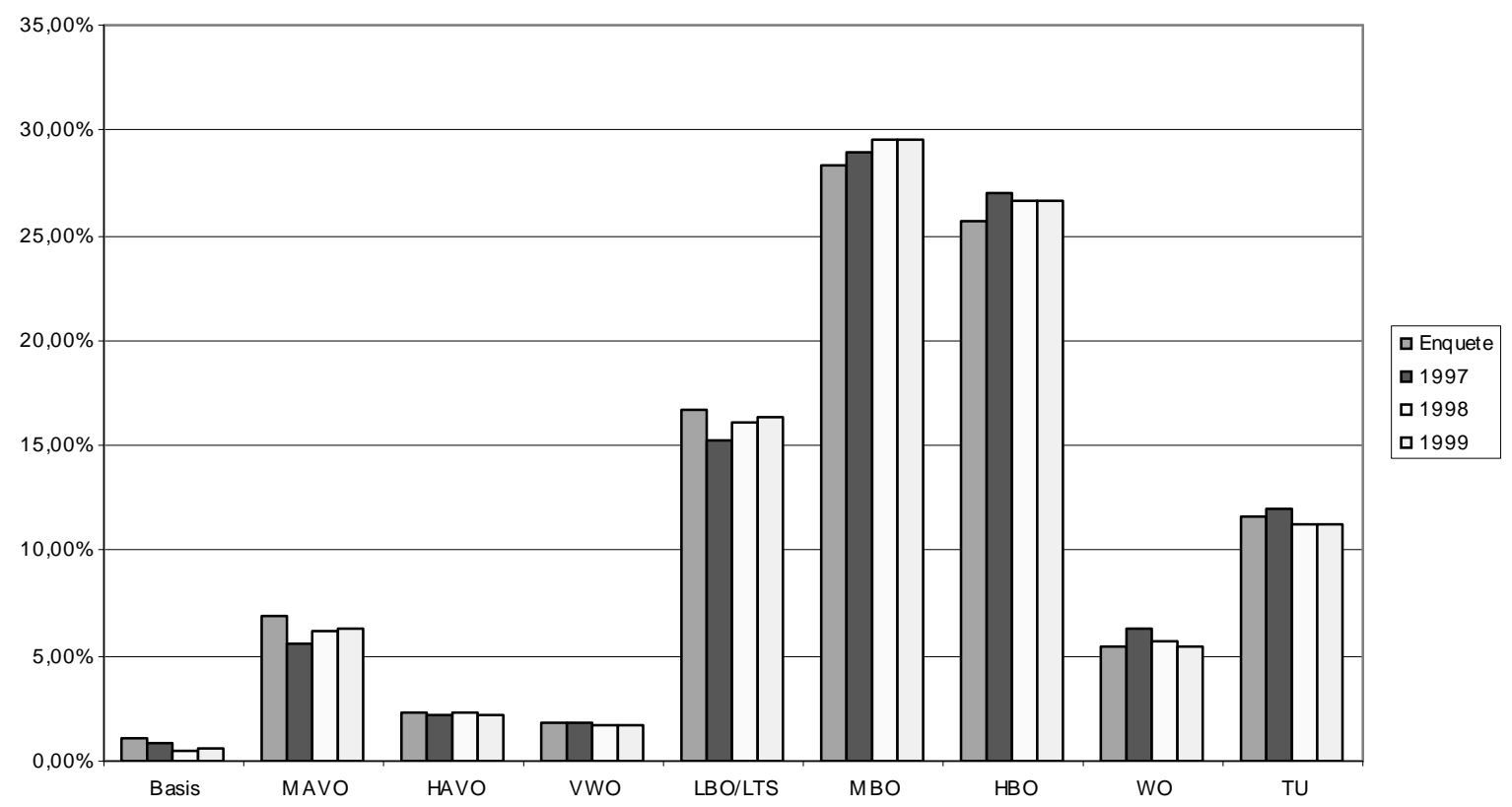


Figure 6.2: Educational Levels over Unemployed in 1997, 1998, 1999

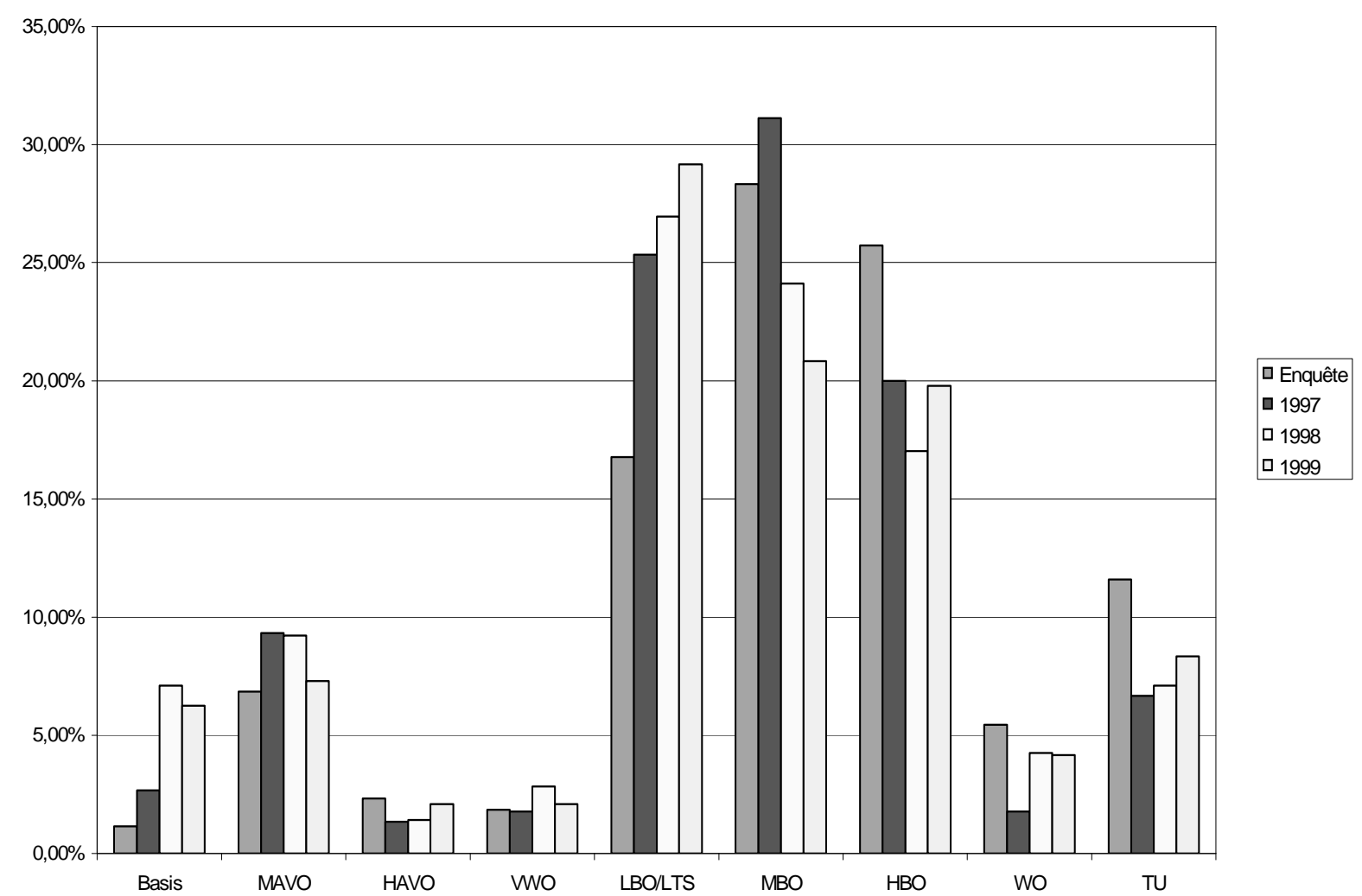




\section{Educational Levels}

The distribution of employed workers over the educational levels are presented in Figure 6.1 and Table 6.4. Tables 6.4 and 6.5 provided information on labor market status for persons with different educational backgrounds among the former Fokker N.V. employees as well as representatives in the 'matched' SEP sample. Figure 6.1 combines the percentage distribution shown in Table 6.3 and the percentage distribution over educational levels of the respondents through consecutive years $(1997,1998$, and 1999) as given in Table 6.1.

In short, the first bar — of sets of four — indicates the percentage of respondents with specific educational background who have answered the survey — whether they are employed or not - thus giving the distribution over the specified educational levels. The following three bars show the percentage of all the employed workers during that year given the specified educational level. For example, of workers with Basis, MAVO, HAVO, VWO, LBO/LTS, MBO, HBO, WO, and TU educational background 1.14, 6.85, $2.33,1.84,16.77,28.31,25.72,5.44$, and 11.59 percent respectively returned a completed questionnaire. The second bar shows that $0.85,5.63,2.22,1.76,15.30,28.90,27.02,6.31$, and 12.00 percent respectively had found new employment in 1997. From the data in Table 6.5 it is apparent that persons with only elementary education ("Basis") as well as those within the MAVO, HAVO, VWO and LBO/LTS category have reduced chances or opportunity to find new jobs compared to the average former Fokker N.V. employee. Those with $\mathrm{MBO}, \mathrm{HBO}, \mathrm{WO}$ and $\mathrm{TU}$ have more opportunities on the labor market compared to the average former Fokker N.V. employees as indicated by the increase in height of their respective bars (as presented in Figure 6.1).

When compared to the SEP data the percentages for "employed" by education category show the distribution of education degrees achieved over the employed labor force in the Netherlands. Here the best comparison is the 'matched' SEP sample since we would otherwise see only the differences between the educational levels of former Fokker workers which is typically different from the representative sample of the Dutch population. The 'matched' SEP sample also shows that the educational levels with lower employment rates are in general those workers with degrees from general educational levels (especially MAVO) and with lower vocational training such as LBO/LTS.

Table 6.5 gives the distribution of unemployed workers over educational levels. Due to matching it is likely to find the mirror image of the results from the distribution over the employed workers. Figure 6.2 represents the percentage distribution of all unemployed one, two, and three years after the bankruptcy. It should be noted the percentages are 
Table 6.4: Labor Market Status by Educational Levels — Employed

\begin{tabular}{|c|c|c|c|c|c|c|c|c|c|c|}
\hline \multirow[t]{2}{*}{ Highest educational level } & \multicolumn{2}{|c|}{ Survey } & \multicolumn{2}{|c|}{1997} & \multicolumn{2}{|c|}{1998} & \multicolumn{2}{|c|}{1999} & \multicolumn{2}{|c|}{ 'matched' SEP } \\
\hline & $\mathrm{N}$ & $\%$ & $\mathrm{~N}$ & $\%$ & $\mathrm{~N}$ & $\%$ & $\mathrm{~N}$ & $\%$ & $\mathrm{~N}$ & $\%$ \\
\hline Basis & 26 & 1.14 & 15 & 0.85 & 10 & 0.53 & 11 & 0.57 & & \\
\hline MAVO & 156 & 6.85 & 99 & 5.63 & 116 & 6.16 & 121 & 6.26 & 118 & 6.24 \\
\hline HAVO & 53 & 2.33 & 39 & 2.22 & 43 & 2.28 & 42 & 2.17 & 49 & 2.59 \\
\hline VWO & 42 & 1.84 & 31 & 1.76 & 32 & 1.70 & 33 & 1.71 & 36 & 1.90 \\
\hline LBO/LTS & 382 & 16.77 & 269 & 15.30 & 303 & 16.10 & 316 & 16.34 & 314 & 16.61 \\
\hline $\mathrm{MBO}$ & 645 & 28.31 & 508 & 28.90 & 556 & 29.54 & 572 & 29.58 & 562 & 29.74 \\
\hline $\mathrm{HBO}$ & 586 & 25.72 & 475 & 27.02 & 502 & 26.67 & 515 & 26.63 & 528 & 27.94 \\
\hline WO & 124 & 5.44 & 111 & 6.31 & 107 & 5.69 & 106 & 5.48 & 256 & 13.54 \\
\hline TU & 264 & 11.59 & 211 & 12.00 & 213 & 11.32 & 218 & 11.27 & 27 & 1.43 \\
\hline Total & 2278 & 100.00 & 1758 & 100.00 & 1882 & 100.00 & 1934 & 100.00 & 1890 & 100.00 \\
\hline
\end{tabular}


Table 6.5: Labor Market Status by Education Levels — Unemployed

\begin{tabular}{lrrrrrrrrrr}
\hline Highest educational level & \multicolumn{3}{c}{ Survey } & \multicolumn{1}{c}{1997} & \multicolumn{1}{c}{1998} & \multicolumn{1}{c}{1999} & 'matched' SEP \\
& $\mathrm{N}$ & $\%$ & $\mathrm{~N}$ & $\%$ & $\mathrm{~N}$ & $\%$ & $\mathrm{~N}$ & $\%$ & $\mathrm{~N}$ & $\%$ \\
\hline Basis & 26 & 1.14 & 6 & 2.67 & 10 & 7.09 & 6 & 6.25 &. \\
MAVO & 156 & 6.85 & 21 & 9.33 & 13 & 9.22 & 7 & 7.29 & 23 & 19.01 \\
HAVO & 53 & 2.33 & 3 & 1.33 & 2 & 1.42 & 2 & 2.08 & 2 & 1.65 \\
VWO & 42 & 1.84 & 4 & 1.78 & 4 & 2.84 & 2 & 2.08 & 3 & 2.48 \\
LBO/LTS & 382 & 16.77 & 57 & 25.33 & 38 & 26.95 & 28 & 29.17 & 37 & 30.58 \\
MBO & 645 & 28.31 & 70 & 31.11 & 34 & 24.11 & 20 & 20.83 & 25 & 20.66 \\
HBO & 586 & 25.72 & 45 & 20.00 & 24 & 17.02 & 19 & 19.79 & 17 & 14.05 \\
WO & 124 & 5.44 & 4 & 1.78 & 6 & 4.26 & 4 & 4.17 & 13 & 10.74 \\
TU & 264 & 11.59 & 15 & 6.67 & 10 & 7.09 & 8 & 8.33 & 1 & 0.83 \\
\hline Total & 2278 & 100.00 & 225 & 100.00 & 141 & 100.00 & 96 & 100.00 & 121 & 100.00 \\
\hline
\end{tabular}


Table 6.6: Number of Different Employers by Education Level at 3 Years after the Bankruptcy

\begin{tabular}{lrrrrrrrrrrrrr}
\hline Education & \multicolumn{1}{c}{$\begin{array}{l} \\
\end{array}$} & $\mathrm{N}$ & $\%$ & $\mathrm{~N}$ & $\%$ & $\mathrm{~N}$ & $\%$ & $\mathrm{~N}$ & $\%$ & $\mathrm{~N}$ & $\%$ & $\mathrm{~N}$ & $\%$ \\
\hline Basis & 2 & 0.23 & 4 & 0.66 & 0 & 0.00 & 1 & 1.82 & 1 & 2.63 & 8 & 0.45 \\
MAVO & 54 & 6.10 & 31 & 5.12 & 9 & 4.59 & 8 & 14.55 & 3 & 7.89 & 105 & 5.90 \\
HAVO & 20 & 2.26 & 11 & 1.82 & 5 & 2.55 & 2 & 3.64 & 2 & 5.26 & 40 & 2.25 \\
VWO & 20 & 2.26 & 9 & 1.49 & 2 & 1.02 & 0 & 0.00 & 1 & 2.63 & 32 & 1.80 \\
LBO/LTS & 138 & 15.59 & 86 & 14.19 & 38 & 19.39 & 9 & 16.36 & 11 & 28.95 & 282 & 15.84 \\
MBO & 235 & 26.55 & 183 & 30.20 & 72 & 36.73 & 21 & 38.18 & 15 & 39.47 & 526 & 29.55 \\
HBO & 239 & 27.01 & 185 & 30.53 & 45 & 22.96 & 11 & 20.00 & 5 & 13.16 & 485 & 27.25 \\
WO & 68 & 7.68 & 26 & 4.29 & 8 & 4.08 & 0 & 0.00 & 0 & 0.00 & 102 & 5.73 \\
TU & 109 & 12.32 & 71 & 11.72 & 17 & 8.67 & 3 & 5.45 & 0 & 0.00 & 200 & 11.24 \\
\hline Total & 885 & 100.0 & 606 & 100.0 & 196 & 100.0 & 55 & 100.0 & 38 & 100.0 & 1780 & 100.0 \\
\hline
\end{tabular}


based on absolute numbers but these absolute numbers are decreasing over time (225 unemployed respondents in 1996 to 96 unemployed in 1999). Thus, the absolute number of unemployed in 1999 is much smaller which means that the categories cells consist of only few observations, which can lead to big percentage changes as the result of a single switch between categories.

Table 6.6 gives the number of employers a worker had after displacement as a result of the Fokker N.V. bankruptcy. Of interest are those workers that have paid working positions three years after the bankruptcy. From the table it is apparent that so-called "job-hopping" to find new suitable work exists in all educational levels. This is not a surprising finding since a displaced worker will aim to find a new job, without necessarily finding a good match initially. Alternatively, the available jobs are only temporary positions. It is notable that workers with only school education (with the exception of VWO) are more likely to go through several employers until they find long-term employment. This is also true for LBO/LTS, MBO. However, workers with HBO and university degrees are more likely to have one, or at most two jobs post displacement, indicating that they have fewer job changes.

\section{Age Categories}

A similar analysis can also be performed with age-categories. It could be expected that the older displaced workers have more difficulties to find new positions. Firms usually prefer younger workers since they are cheaper in wages and stay longer with the hiring firm. On the other hand, younger workers are more likely to change their employment into a totally different direction since they have not yet invested time in specific job experience and skills.

From the results of the Fokker Survey it is apparent that these expectations can also be found in the case of Fokker N.V: the higher age groups have more difficulties in finding new jobs. In addition, the older workers have more time to search for suitable employment since their unemployment benefits are paid out over a longer period. We compare the three annual observations to the general age distribution of the respondents and also to the sample from the Socio-economic panel (SEP).

Both Figure 6.3 and Table 6.7 show clearly higher employment rates for younger workers after the first year following bankruptcy. This is true for all age-categories up to 44 years old. Workers over 44 years of age are clearly underrepresented with regard to employment relative to the distribution of the respondents: in the age category of 45-49 years, 11.06 percent of all respondents, 7.39 percent of the former Fokker N.V. 
Table 6.7: Age Categories — Employed Workers

\begin{tabular}{|c|c|c|c|c|c|c|c|c|c|c|}
\hline \multirow[t]{2}{*}{ Age } & \multicolumn{2}{|c|}{ Survey } & \multicolumn{2}{|c|}{1997} & \multicolumn{2}{|c|}{1998} & \multicolumn{2}{|c|}{1999} & \multicolumn{2}{|c|}{ 'matched' SEP } \\
\hline & $\mathrm{N}$ & $\%$ & $\mathrm{~N}$ & $\%$ & $\mathrm{~N}$ & $\%$ & $\mathrm{~N}$ & $\%$ & $\mathrm{~N}$ & $\%$ \\
\hline$<30$ years & 240 & 10.53 & 215 & 12.23 & 225 & 11.96 & 226 & 11.69 & 225 & 11.90 \\
\hline 30-34 years & 449 & 19.70 & 381 & 21.67 & 405 & 21.52 & 411 & 21.25 & 370 & 19.58 \\
\hline 35-39 years & 494 & 21.68 & 433 & 24.63 & 448 & 23.80 & 453 & 23.42 & 399 & 21.11 \\
\hline 40-44 years & 406 & 17.81 & 312 & 17.75 & 350 & 18.60 & 357 & 18.46 & 332 & 17.57 \\
\hline 45-49 years & 384 & 16.85 & 267 & 15.19 & 307 & 16.31 & 322 & 16.65 & 336 & 17.78 \\
\hline 50-54 years & 252 & 11.06 & 130 & 7.39 & 130 & 6.91 & 148 & 7.65 & 183 & 9.68 \\
\hline $55+$ years & 54 & 2.37 & 20 & 1.14 & 17 & 0.90 & 17 & 0.88 & 45 & 2.38 \\
\hline Total & 2279 & 100.00 & 1758 & 100.00 & 1882 & 100.00 & 1934 & 100.00 & 1890 & 100.00 \\
\hline
\end{tabular}


Table 6.8: Age Categories — Unemployed Workers

\begin{tabular}{lrr|rrrrrrrr}
\hline Age & \multicolumn{2}{c}{ Survey } & \multicolumn{2}{c}{1997} & \multicolumn{1}{c}{1998} & \multicolumn{1}{c}{1999} & \multicolumn{2}{c}{ 'matched' SEP } \\
& $\mathrm{N}$ & $\%$ & $\mathrm{~N}$ & $\%$ & $\mathrm{~N}$ & $\%$ & $\mathrm{~N}$ & $\%$ & $\mathrm{~N}$ & $\%$ \\
\hline$<30$ years & 240 & 10.53 & 8 & 3.54 & 1 & 0.70 & 3 & 3.09 & 16 & 13.22 \\
30-34 years & 449 & 19.70 & 18 & 7.96 & 5 & 3.52 & 2 & 2.06 & 18 & 14.88 \\
35-39 years & 494 & 21.68 & 18 & 7.96 & 11 & 7.75 & 4 & 4.12 & 29 & 23.97 \\
40-44 years & 406 & 17.81 & 42 & 18.58 & 19 & 13.38 & 12 & 12.37 & 21 & 17.36 \\
45-49 years & 384 & 16.85 & 59 & 26.11 & 30 & 21.13 & 18 & 18.56 & 19 & 15.70 \\
$50-54$ years & 252 & 11.06 & 73 & 32.30 & 68 & 47.89 & 48 & 49.48 & 18 & 14.88 \\
$55+$ years & 54 & 2.37 & 8 & 3.54 & 8 & 5.63 & 10 & 10.31 & 0 & 0.00 \\
\hline Total & 2279 & 100.00 & 226 & 100.00 & 142 & 100.00 & 97 & 100.00 & 121 & 100.00 \\
\hline
\end{tabular}


Figure 6.3: Age Categories - Employed versus Survey Respondents

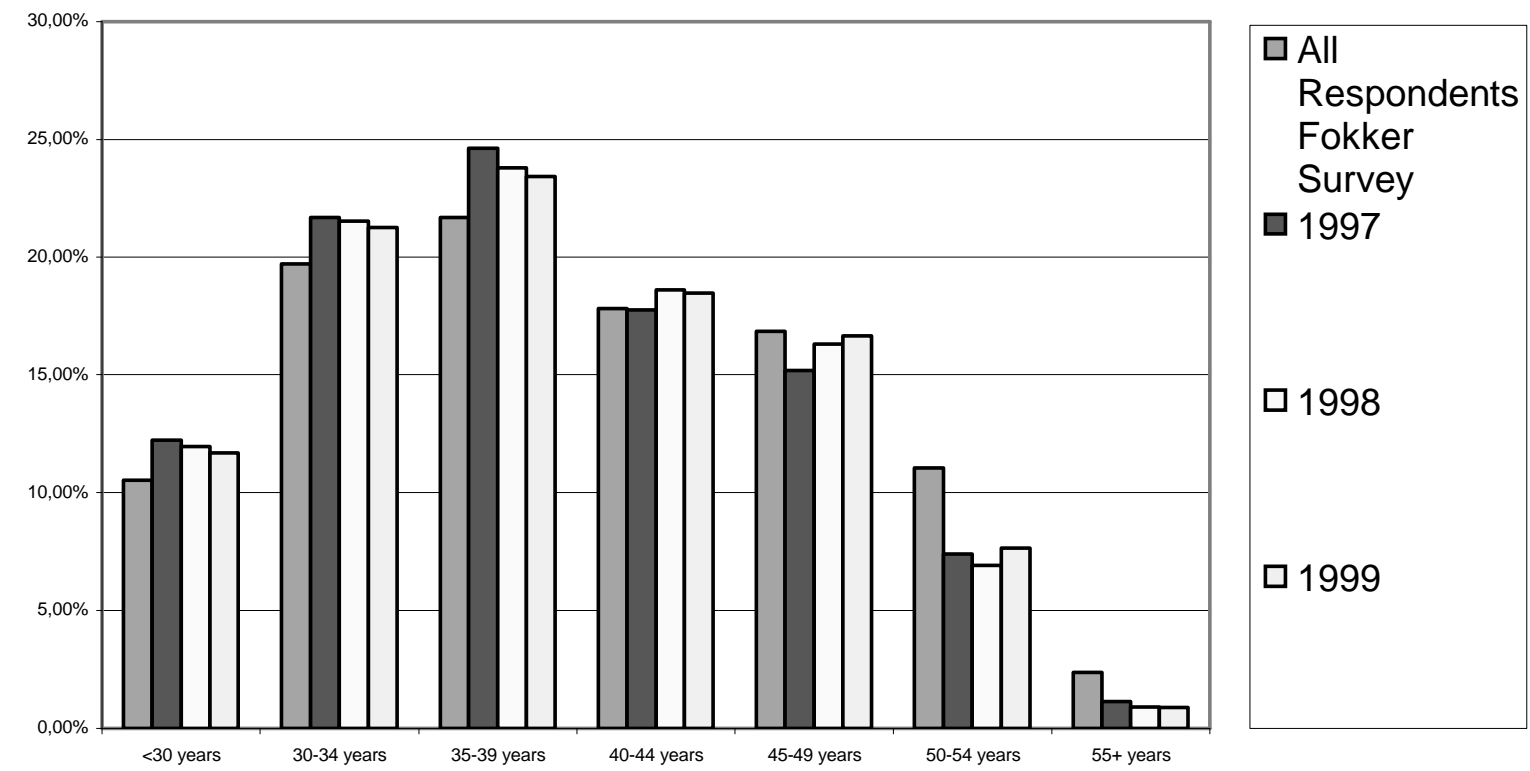

employees are working one year after the bankruptcy. This clearly shows they are underrepresented in the working population. This situation does not change much over time: after three years former employees of Fokker N.V. in the age groups of 45 years and older remain less represented among the former Fokker N.V. employees who do have paid job. It is apparent that the older workers have more difficulties in finding new jobs after displacement.

Similar findings come from comparison with the 'matched' SEP sample: the younger former Fokker N.V. employees are over represented among those working while the older are underrepresented. This does not imply that older workers become unemployed more often but once unemployment is eminent it is much harder for persons within these age groups (45 years and older) to find new employment. This means that as a result of the bankruptcy of Fokker N.V. the persons of 45 years and older have been hit much harder than the younger workers. 
Table 6.9: Searching Time per Week — Employed in 1999

\begin{tabular}{|c|c|c|c|c|c|c|c|c|c|c|c|c|c|c|}
\hline \multirow[t]{3}{*}{ Education } & \multicolumn{14}{|c|}{ Hours searching per week } \\
\hline & \multicolumn{2}{|c|}{0} & \multicolumn{2}{|c|}{$<5$} & \multicolumn{2}{|c|}{$<10$} & \multicolumn{2}{|c|}{$<20$} & \multicolumn{2}{|c|}{$<40$} & \multicolumn{2}{|c|}{$40+$} & \multicolumn{2}{|c|}{ Total } \\
\hline & $\mathrm{N}$ & $\%$ & $\mathrm{~N}$ & $\%$ & $\mathrm{~N}$ & $\%$ & $\mathrm{~N}$ & $\%$ & $\mathrm{~N}$ & $\%$ & $\mathrm{~N}$ & $\%$ & $\mathrm{~N}$ & $\%$ \\
\hline Basis & 0 & 0.00 & 4 & 1.23 & 1 & 0.41 & 1 & 0.31 & 0 & 0.00 & 0 & 0.00 & 6 & 0.42 \\
\hline MAVO & 13 & 5.96 & 23 & 7.06 & 24 & 9.84 & 17 & 5.26 & 13 & 4.53 & 0 & 0.00 & 90 & 6.37 \\
\hline HAVO & 3 & 1.38 & 15 & 4.60 & 5 & 2.05 & 4 & 1.24 & 4 & 1.39 & 0 & 0.00 & 31 & 2.20 \\
\hline VWO & 7 & 3.21 & 5 & 1.53 & 3 & 1.23 & 3 & 0.93 & 5 & 1.74 & 0 & 0.00 & 23 & 1.63 \\
\hline LBO/LTS & 21 & 9.63 & 72 & 22.09 & 57 & 23.36 & 58 & 17.96 & 35 & 12.20 & 0 & 0.00 & 243 & 17.21 \\
\hline MBO & 58 & 26.61 & 108 & 33.13 & 79 & 32.38 & 111 & 34.37 & 82 & 28.57 & 4 & 28.57 & 442 & 31.30 \\
\hline $\mathrm{HBO}$ & 60 & 27.52 & 60 & 18.40 & 56 & 22.95 & 83 & 25.70 & 92 & 32.06 & 9 & 64.29 & 360 & 25.50 \\
\hline WO & 17 & 7.80 & 16 & 4.91 & 5 & 2.05 & 16 & 4.95 & 13 & 4.53 & 0 & 0.00 & 67 & 4.75 \\
\hline $\mathrm{TU}$ & 39 & 17.89 & 23 & 7.06 & 14 & 5.74 & 30 & 9.29 & 43 & 14.98 & 1 & 7.14 & 150 & 10.62 \\
\hline Total & 218 & 100 & 326 & 100 & 244 & 100 & 323 & 100 & 287 & 100 & 14 & 100 & 1412 & 100 \\
\hline
\end{tabular}


Table 6.10: Searching Time per Week — Unemployed in 1999

\begin{tabular}{|c|c|c|c|c|c|c|c|c|c|c|c|c|c|c|}
\hline \multirow[t]{3}{*}{ Education } & \multicolumn{10}{|c|}{ Hours searching per week } & \multirow{2}{*}{\multicolumn{2}{|c|}{$40+$}} & \multirow{2}{*}{\multicolumn{2}{|c|}{ Total }} \\
\hline & \multicolumn{2}{|c|}{0} & \multicolumn{2}{|c|}{$<5$} & \multicolumn{2}{|c|}{$<10$} & \multicolumn{2}{|c|}{$<20$} & \multicolumn{2}{|c|}{$<40$} & & & & \\
\hline & $\mathrm{N}$ & $\%$ & $\mathrm{~N}$ & $\%$ & $\mathrm{~N}$ & $\%$ & $\mathrm{~N}$ & $\%$ & $\mathrm{~N}$ & $\%$ & $\mathrm{~N}$ & $\%$ & $\mathrm{~N}$ & $\%$ \\
\hline Basis & 0 & 0 & 1 & 4 & 1 & 4 & 2 & 8 & 1 & 9 & 0 & 0 & 5 & 6 \\
\hline MAVO & 0 & 0 & 3 & 12 & 2 & 9 & 1 & 4 & 0 & 0 & 0 & 0 & 6 & 7 \\
\hline HAVO & 0 & 0 & 0 & 0 & 1 & 4 & 0 & 0 & 1 & 9 & 0 & 0 & 2 & 2 \\
\hline VWO & 1 & 100 & 0 & 0 & 0 & 0 & 1 & 4 & 0 & 0 & 0 & 0 & 2 & 2 \\
\hline LBO/LTS & 0 & 0 & 10 & 38 & 8 & 35 & 7 & 27 & 2 & 18 & 0 & 0 & 27 & 31 \\
\hline $\mathrm{MBO}$ & 0 & 0 & 4 & 15 & 6 & 26 & 7 & 27 & 2 & 18 & 0 & 0 & 19 & 22 \\
\hline $\mathrm{HBO}$ & 0 & 0 & 5 & 19 & 3 & 13 & 4 & 15 & 3 & 27 & 1 & 100 & 16 & 18 \\
\hline WO & 0 & 0 & 1 & 4 & 1 & 4 & 2 & 8 & 0 & 0 & 0 & 0 & 4 & 5 \\
\hline $\mathrm{TU}$ & 0 & 0 & 2 & 8 & 1 & 4 & 2 & 8 & 2 & 18 & 0 & 0 & 7 & 8 \\
\hline Total & 1 & 100 & 26 & 100 & 23 & 100 & 26 & 100 & 11 & 100 & 1 & 100 & 88 & 100 \\
\hline
\end{tabular}


Table 6.11: Number of Letters per Four Weeks — Employed in 1999

\begin{tabular}{|c|c|c|c|c|c|c|c|c|c|c|c|c|c|c|}
\hline & \multicolumn{14}{|c|}{ Number of application letters } \\
\hline & \multicolumn{2}{|r|}{0} & \multicolumn{2}{|r|}{1} & \multicolumn{2}{|c|}{$<5$} & \multicolumn{2}{|c|}{$<10$} & \multicolumn{2}{|c|}{$<20$} & \multicolumn{2}{|c|}{$20+$} & \multicolumn{2}{|c|}{ Total } \\
\hline & $\mathrm{N}$ & $\%$ & $\mathrm{~N}$ & $\%$ & $\mathrm{~N}$ & $\%$ & $\mathrm{~N}$ & $\%$ & $\mathrm{~N}$ & $\%$ & $\mathrm{~N}$ & $\%$ & $\mathrm{~N}$ & $\%$ \\
\hline Basis & 1 & 0.40 & 0 & 0.00 & 2 & 0.45 & 4 & 1.09 & 2 & 0.87 & 2 & 0.39 & 11 & 0.58 \\
\hline MAVO & 15 & 6.05 & 6 & 7.14 & 30 & 6.80 & 22 & 5.99 & 11 & 4.78 & 36 & 6.94 & 120 & 6.35 \\
\hline HAVO & 3 & 1.21 & 2 & 2.38 & 13 & 2.95 & 5 & 1.36 & 5 & 2.17 & 12 & 2.31 & 40 & 2.12 \\
\hline VWO & 6 & 2.42 & 1 & 1.19 & 9 & 2.04 & 3 & 0.82 & 3 & 1.30 & 11 & 2.12 & 33 & 1.75 \\
\hline LBO/LTS & 28 & 11.29 & 12 & 14.29 & 91 & 20.63 & 80 & 21.80 & 29 & 12.61 & 71 & 13.68 & 311 & 16.46 \\
\hline $\mathrm{MBO}$ & 65 & 26.21 & 25 & 29.76 & 139 & 31.52 & 132 & 35.97 & 67 & 29.13 & 129 & 24.86 & 557 & $29.4 \mathrm{c}$ \\
\hline $\mathrm{HBO}$ & 69 & 27.82 & 24 & 28.57 & 96 & 21.77 & 85 & 23.16 & 75 & 32.61 & 150 & 28.90 & 499 & 26.42 \\
\hline WO & 21 & 8.47 & 4 & 4.76 & 17 & 3.85 & 7 & 1.91 & 16 & 6.96 & 39 & 7.51 & 104 & 5.51 \\
\hline $\mathrm{TU}$ & 40 & 16.13 & 10 & 11.90 & 44 & 9.98 & 29 & 7.90 & 22 & 9.57 & 69 & 13.29 & 214 & 11.3 \\
\hline Total & 248 & 100.00 & 84 & 100.00 & 441 & 100.00 & 367 & 100.00 & 230 & 100.00 & 519 & 100.00 & 1889 & 100.00 \\
\hline
\end{tabular}


Table 6.12: Number of Letters per Four Weeks - Unemployed in 1999

\begin{tabular}{|c|c|c|c|c|c|c|c|c|c|c|c|c|c|c|}
\hline & \multicolumn{14}{|c|}{ Number of application letters } \\
\hline & \multicolumn{2}{|r|}{0} & \multicolumn{2}{|r|}{1} & \multicolumn{2}{|c|}{$<5$} & \multicolumn{2}{|c|}{$<10$} & \multicolumn{2}{|c|}{$<20$} & \multicolumn{2}{|c|}{$20+$} & \multicolumn{2}{|c|}{ Total } \\
\hline & $\mathrm{N}$ & $\%$ & $\mathrm{~N}$ & $\%$ & $\mathrm{~N}$ & $\%$ & $\mathrm{~N}$ & $\%$ & $\mathrm{~N}$ & $\%$ & $\mathrm{~N}$ & $\%$ & $\mathrm{~N}$ & $\%$ \\
\hline Basis & 0 & 0.00 & 0 & 0.00 & 3 & 6.52 & 2 & 7.14 & 0 & 0.00 & 1 & 11.11 & 6 & 6.38 \\
\hline MAVO & 0 & 0.00 & 0 & 0.00 & 4 & 8.70 & 2 & 7.14 & 0 & 0.00 & 1 & 11.11 & 7 & 7.45 \\
\hline HAVO & 0 & 0.00 & 0 & 0.00 & 1 & 2.17 & 1 & 3.57 & 0 & 0.00 & 0 & 0.00 & 2 & 2.13 \\
\hline VWO & 1 & 50.00 & 0 & 0.00 & 1 & 2.17 & 0 & 0.00 & 0 & 0.00 & 0 & 0.00 & 2 & 2.13 \\
\hline LBO/LTS & 0 & 0.00 & 1 & 16.67 & 18 & 39.13 & 5 & 17.86 & 2 & 66.67 & 2 & 22.22 & 28 & 29.79 \\
\hline $\mathrm{MBO}$ & 0 & 0.00 & 2 & 33.33 & 8 & 17.39 & 8 & 28.57 & 1 & 33.33 & 0 & 0.00 & 19 & 20.21 \\
\hline $\mathrm{HBO}$ & 1 & 50.00 & 2 & 33.33 & 6 & 13.04 & 7 & 25.00 & 0 & 0.00 & 2 & 22.22 & 18 & 19.15 \\
\hline WO & 0 & 0.00 & 0 & 0.00 & 1 & 2.17 & 2 & 7.14 & 0 & 0.00 & 1 & 11.11 & 4 & 4.26 \\
\hline $\mathrm{TU}$ & 0 & 0.00 & 1 & 16.67 & 4 & 8.70 & 1 & 3.57 & 0 & 0.00 & 2 & 22.22 & 8 & 8.51 \\
\hline Total & 2 & 100 & 6 & 100 & 46 & 100.0 & 28 & 100 & 3 & 100 & 9 & 100 & 94 & 100 \\
\hline
\end{tabular}




\section{Searching for Work}

The Fokker Survey included questions with regard to the amount of time per week spent searching for a new position after bankruptcy, the number of letters written per month, and the time period from bankruptcy until the first job after displacement was accepted. Table 6.9 gives an overview of searching time per educational level for persons employed in 1999. The extreme value of "no hours" should be regarded with some caution as it may indicate that the respondent got an immediate job offer after displacement. Persons who were definitely offered a job immediately after bankruptcy are also part of this group. From the table it is apparent that there is a slight tendency among respondents with higher vocational training to spend more hours searching for new work. Persons with lower vocational training and general school education are more evenly distributed over the amount of time spent searching for a new job. Especially when comparing to the group of workers who do not have a paid job three years after displacement (1999) no significant difference can be found. However, this last effect can also be due to the small cell-size of the latter group as there are only 352 unemployed respondents at that time period which were distributed over 63 cells.

The other indicator of search input from the respondent is the number of letters written per four weeks while unemployed. An overview of output has been given in Table 6.11. Again, the category of "no letter" and "one letter" should be regarded with some caution since these groups also represent persons who found employment immediately upon their first "job application interview". Here, the number of letters written increases with higher educational levels. This does not necessarily reflect a higher search effort of higher educational levels. It could also be an indication that this form of written applications is more common among workers with higher education.

\section{Help with Finding a New Position}

After bankruptcy Fokker N.V. employees were offered short training sessions to help them orient on the labor market. The Fokker Survey included questions about two specific kinds of help: (1) training for job-applications and (2) help to get into contact with potential employees. The respondents were asked to rank the usefulness of these training schemes from "very helpful" ("veel geholpen"), to "not helpful" ("niet geholpen") on a 4 point Likert-Scale. The outcomes are shown in Tables 6.13 and 6.14 and a distinction has been made for people who had found a job after one, two and three years after the bankruptcy, for both training options. 
Table 6.13: Evaluation of Training for Job-applications

\begin{tabular}{lrrrrrrrr}
\hline \multicolumn{1}{c}{ Application Training } & & & & & \\
\hline & \multicolumn{1}{c}{1997} & & 1998 & & 1999 \\
& $\mathrm{~N}$ & $\%$ & $\mathrm{~N}$ & $\%$ & $\mathrm{~N}$ & $\%$ \\
\hline Very helpful & 124 & 26.50 & 138 & 25.79 & 141 & 25.27 \\
Helpful & 252 & 53.85 & 288 & 53.83 & 298 & 53.41 \\
Slightly helpful & 64 & 13.68 & 76 & 14.21 & 86 & 15.41 \\
Not helpful & 28 & 5.98 & 33 & 6.17 & 33 & 5.91 \\
\hline Total & 468 & 100 & 535 & 100 & 558 & 100 \\
\hline
\end{tabular}

Table 6.14: Evaluation of Help in Contacting Potential Employers

\begin{tabular}{lrrrrrrrr}
\hline & Aid Contacting Potential Employers & & & & \\
\hline & \multicolumn{1}{c}{1997} & & 1998 & & \multicolumn{1}{c}{1999} \\
& $\mathrm{~N}$ & $\%$ & $\mathrm{~N}$ & $\%$ & $\mathrm{~N}$ & $\%$ \\
\hline Very helpful & 54 & 19.35 & 59 & 18.50 & 64 & 19.05 \\
Helpful & 85 & 30.47 & 94 & 29.47 & 97 & 28.87 \\
Slightly helpful & 79 & 28.32 & 86 & 26.96 & 92 & 27.38 \\
Not helpful & 61 & 21.86 & 80 & 25.08 & 83 & 24.70 \\
\hline Total & 279 & 100 & 319 & 100 & 336 & 100 \\
\hline
\end{tabular}


Table 6.15: Participation in (Re-)Training by Education Levels, Employed in 1997, 1998, 1999

\begin{tabular}{|c|c|c|c|c|c|c|c|c|c|c|c|c|}
\hline \multirow{3}{*}{$\begin{array}{l}\text { Highest } \\
\text { Education }\end{array}$} & \multicolumn{4}{|c|}{1997} & \multicolumn{4}{|c|}{1998} & \multicolumn{4}{|c|}{1999} \\
\hline & \multicolumn{2}{|c|}{ Yes } & \multicolumn{2}{|c|}{ No } & \multicolumn{2}{|c|}{ Yes } & \multicolumn{2}{|c|}{ No } & \multicolumn{2}{|r|}{ Yes } & \multicolumn{2}{|c|}{ No } \\
\hline & $\mathrm{N}$ & $\%$ & $\mathrm{~N}$ & $\%$ & $\mathrm{~N}$ & $\%$ & $\mathrm{~N}$ & $\%$ & $\mathrm{~N}$ & $\%$ & $\mathrm{~N}$ & $\%$ \\
\hline Basis & 1 & 0.46 & 14 & 0.95 & 2 & 0.72 & 9 & 0.58 & 3 & 5.00 & 9 & 0.58 \\
\hline MAVO & 11 & 5.09 & 84 & 5.71 & 16 & 5.76 & 98 & 6.30 & 3 & 5.00 & 98 & 6.30 \\
\hline HAVO & 2 & 0.93 & 37 & 2.52 & 2 & 0.72 & 39 & 2.51 & 1 & 1.67 & 39 & 2.51 \\
\hline VWO & 2 & 0.93 & 28 & 1.90 & 5 & 1.80 & 27 & 1.74 & 2 & 3.33 & 27 & 1.74 \\
\hline LBO/LTS & 38 & 17.59 & 215 & 14.62 & 56 & 20.14 & 238 & 15.30 & 11 & 18.33 & 238 & 15.30 \\
\hline $\mathrm{MBO}$ & 80 & 37.04 & 408 & 27.74 & 105 & 37.77 & 433 & 27.83 & 25 & 41.67 & 433 & 27.83 \\
\hline $\mathrm{HBO}$ & 57 & 26.39 & 409 & 27.80 & 67 & 24.10 & 436 & 28.02 & 10 & 16.67 & 436 & 28.02 \\
\hline $\mathrm{WO}$ & 5 & 2.31 & 104 & 7.07 & 5 & 1.80 & 99 & 6.36 & 2 & 3.33 & 99 & 6.36 \\
\hline TU & 20 & 9.26 & 172 & 11.69 & 20 & 7.19 & 177 & 11.38 & 3 & 5.00 & 177 & 11.38 \\
\hline Total & 216 & 100.00 & 1471 & 100.00 & 278 & 100.00 & 1556 & 100.00 & 60 & 100.00 & 1556 & 100.00 \\
\hline
\end{tabular}


Table 6.16: Participation in (Re-)Training by Education Levels - Unemployed in 1997, 1998, 1999

\begin{tabular}{|c|c|c|c|c|c|c|c|c|c|c|c|c|}
\hline \multirow{3}{*}{$\begin{array}{l}\text { Highest } \\
\text { Education }\end{array}$} & \multicolumn{4}{|c|}{1997} & \multicolumn{4}{|c|}{1998} & \multicolumn{4}{|c|}{1999} \\
\hline & \multicolumn{2}{|c|}{ Yes } & \multicolumn{2}{|c|}{ No } & \multicolumn{2}{|r|}{ Yes } & \multicolumn{2}{|c|}{ No } & \multicolumn{2}{|r|}{ Yes } & \multicolumn{2}{|r|}{ No } \\
\hline & $\mathrm{N}$ & $\%$ & $\mathrm{~N}$ & $\%$ & $\mathrm{~N}$ & $\%$ & $\mathrm{~N}$ & $\%$ & $\mathrm{~N}$ & $\%$ & $\mathrm{~N}$ & $\%$ \\
\hline Basis & 3 & 5.00 & 3 & 1.90 & 2 & 6.67 & 7 & 6.67 & 1 & 10.00 & 5 & 6.17 \\
\hline MAVO & 3 & 5.00 & 17 & 10.76 & 3 & 10.00 & 10 & 9.52 & 0 & 0.00 & 6 & 7.41 \\
\hline HAVO & 1 & 1.67 & 2 & 1.27 & 1 & 3.33 & 1 & 0.95 & 0 & 0.00 & 2 & 2.47 \\
\hline VWO & 2 & 3.33 & 2 & 1.27 & 0 & 0.00 & 4 & 3.81 & 0 & 0.00 & 2 & 2.47 \\
\hline LBO/LTS & 11 & 18.33 & 44 & 27.85 & 5 & 16.67 & 32 & 30.48 & 1 & 10.00 & 26 & 32.10 \\
\hline MBO & 25 & 41.67 & 43 & 27.22 & 9 & 30.00 & 23 & 21.90 & 3 & 30.00 & 16 & 19.75 \\
\hline $\mathrm{HBO}$ & 10 & 16.67 & 34 & 21.52 & 6 & 20.00 & 17 & 16.19 & 4 & 40.00 & 14 & 17.28 \\
\hline WO & 2 & 3.33 & 2 & 1.27 & 1 & 3.33 & 5 & 4.76 & 1 & 10.00 & 3 & 3.70 \\
\hline $\mathrm{TU}$ & 3 & 5.00 & 11 & 6.96 & 3 & 10.00 & 6 & 5.71 & 0 & 0.00 & 7 & 8.64 \\
\hline Total & 60 & 100.00 & 158 & 100.00 & 30 & 100.00 & 105 & 100.00 & 10 & 100.00 & 81 & 100.00 \\
\hline
\end{tabular}


Table 6.17: Participation in (Re-)Training by Age Levels - All Employed

\begin{tabular}{|c|c|c|c|c|c|c|c|c|c|c|c|c|}
\hline \multirow{3}{*}{ Age } & \multicolumn{4}{|c|}{1997} & \multicolumn{4}{|c|}{1998} & \multicolumn{4}{|c|}{1999} \\
\hline & \multicolumn{2}{|c|}{ Yes } & \multicolumn{2}{|c|}{ No } & \multicolumn{2}{|c|}{ Yes } & \multicolumn{2}{|c|}{ No } & \multicolumn{2}{|c|}{ Yes } & \multicolumn{2}{|c|}{$\mathrm{No}$} \\
\hline & $\mathrm{N}$ & $\%$ & $\mathrm{~N}$ & $\%$ & $\mathrm{~N}$ & $\%$ & $\mathrm{~N}$ & $\%$ & $\mathrm{~N}$ & $\%$ & $\mathrm{~N}$ & $\%$ \\
\hline$<30$ years & 33 & 15.28 & 172 & 11.69 & 38 & 13.67 & 178 & 11.59 & 40 & 13.11 & 177 & 11.38 \\
\hline 30-34 years & 45 & 20.83 & 322 & 21.89 & 56 & 20.14 & 334 & 21.74 & 60 & 19.67 & 334 & 21.47 \\
\hline 35-39 years & 50 & 23.15 & 368 & 25.02 & 61 & 21.94 & 373 & 24.28 & 63 & 20.66 & 376 & 24.16 \\
\hline 40-44 years & 39 & 18.06 & 262 & 17.81 & 60 & 21.58 & 280 & 18.23 & 63 & 20.66 & 285 & 18.32 \\
\hline 45-49 years & 33 & 15.28 & 219 & 14.89 & 43 & 15.47 & 248 & 16.15 & 50 & 16.39 & 253 & 16.26 \\
\hline 50-54 years & 13 & 6.02 & 112 & 7.61 & 17 & 6.12 & 109 & 7.10 & 25 & 8.20 & 118 & 7.58 \\
\hline $55+$ years & 3 & 1.39 & 16 & 1.09 & 3 & 1.08 & 14 & 0.91 & 4 & 1.31 & 13 & 0.84 \\
\hline Total & 216 & 100.00 & 1471 & 100.00 & 278 & 100.00 & 1536 & 100.00 & 305 & 100.00 & 1556 & 100.00 \\
\hline
\end{tabular}


Table 6.18: Participation in (Re-) Training by Age Levels — All Unemployed

\begin{tabular}{|c|c|c|c|c|c|c|c|c|c|c|c|c|}
\hline \multirow{3}{*}{ Age } & \multicolumn{4}{|c|}{1997} & \multicolumn{4}{|c|}{1998} & \multicolumn{4}{|c|}{1999} \\
\hline & \multicolumn{2}{|c|}{ Yes } & \multicolumn{2}{|c|}{ No } & \multicolumn{2}{|c|}{ Yes } & \multicolumn{2}{|c|}{ No } & \multicolumn{2}{|c|}{ Yes } & \multicolumn{2}{|c|}{ No } \\
\hline & $\mathrm{N}$ & $\%$ & $\mathrm{~N}$ & $\%$ & $\mathrm{~N}$ & $\%$ & $\mathrm{~N}$ & $\%$ & $\mathrm{~N}$ & $\%$ & $\mathrm{~N}$ & $\%$ \\
\hline$<30$ years & 3 & 5.00 & 5 & 3.14 & 0 & 0.00 & 1 & 0.94 & 0 & 0 & 3 & 4 \\
\hline 30-34 years & 5 & 8.33 & 11 & 6.92 & 2 & 6.67 & 3 & 2.83 & 0 & 0 & 2 & 2 \\
\hline 35-39 years & 7 & 11.67 & 11 & 6.92 & 3 & 10.00 & 8 & 7.55 & 0 & 0 & 4 & 5 \\
\hline 40-44 years & 13 & 21.67 & 28 & 17.61 & 4 & 13.33 & 13 & 12.26 & 2 & 20 & 8 & 10 \\
\hline $45-49$ years & 14 & 23.33 & 42 & 26.42 & 7 & 23.33 & 22 & 20.75 & 3 & 30 & 14 & 17 \\
\hline $50-54$ years & 15 & 25.00 & 57 & 35.85 & 12 & 40.00 & 53 & 50.00 & 3 & 30 & 43 & 52 \\
\hline $55+$ years & 3 & 5.00 & 5 & 3.14 & 2 & 6.67 & 6 & 5.66 & 2 & 20 & 8 & 10 \\
\hline Total & 60 & 100 & 159 & 100 & 30 & 100 & 106 & 100 & 10 & 100 & 82 & 100 \\
\hline
\end{tabular}


Table 6.19: Channels of Successful Job Search

\begin{tabular}{lrrrrrr}
\hline & \multicolumn{5}{c}{ Employment found in Year } \\
& 1997 & & 1998 & & 1999 \\
& $\mathrm{~N}$ & $\%$ & $\mathrm{~N}$ & $\%$ & $\mathrm{~N}$ & $\%$ \\
\hline Employment Office & 89 & 5.9 & 104 & 6.4 & 111 & 6.6 \\
Manpower Organization & 186 & 12.2 & 219 & 13.4 & 235 & 14.0 \\
Commercial Employment Offices & 49 & 3.2 & 53 & 3.2 & 55 & 3.3 \\
Open solicitation & 96 & 6.3 & 101 & 6.2 & 106 & 6.3 \\
Specific solicitation & 253 & 16.6 & 269 & 16.5 & 282 & 16.7 \\
Former colleague from Fokker & 151 & 9.9 & 160 & 9.8 & 162 & 9.6 \\
Contacts from Fokker & 199 & 13.1 & 199 & 12.2 & 205 & 12.2 \\
Family & 19 & 1.3 & 22 & 1.3 & 23 & 1.4 \\
Friends & 86 & 5.7 & 96 & 5.9 & 101 & 6.0 \\
Other & 392 & 25.8 & 412 & 25.2 & 404 & 24.0 \\
\hline Total & 1520 & 100 & 1635 & 100 & 1684 & 100 \\
\hline
\end{tabular}

The training for job-applications was valued higher than the help offered with finding new employers. One has to bear in mind that a positive evaluation of the worker does not necessarily constitute an effective training scheme. The positive experience may be the result of feelings related to practical issues such as writing the curriculum vitae, letters of application, and other application of the newly learned skills. Help in establishing contact with potential employers, on the other hand, is usually evaluated in terms of direct benefit such as the offer of a new job.

Another active labor market policy implemented for former employees of Fokker N.V. is the training or retraining of the workers. The outcomes have been analyzed for working and unemployed respondents relative to educational levels (Tables 6.15 and 6.16) and age-categories (Table 6.17 and 6.18) respectively. For both the employed and the unemployed workers it is apparent that predominantly workers with LBO/LTS and MBO, and to a lesser extend VWO degree received the additional training or retraining. Younger employees $(<30$ years old) in particular participated in retraining and additional training. But also the persons in the age group of 40-44 year old followed relatively more training than the other age groups. This is also true for the workers who are unemployed (Table 6.18). This means that up to the age of 44 years old relatively more workers use training to increase their employment chances. 
Table 6.20: Search Cost by Education Level

\begin{tabular}{lrr}
\hline Education & \multicolumn{2}{c}{ Search Costs in HFL } \\
Level & Median & Standard deviation \\
\hline Basis & 93 & 1728 \\
MAVO & 300 & 1059 \\
HAVO & 225 & 1141 \\
VWO & 500 & 2360 \\
LBO/LTS & 100 & 826 \\
MBO & 250 & 959 \\
HBO & 500 & 1720 \\
WO & 500 & 1539 \\
TU & 500 & 1668 \\
\hline
\end{tabular}

\section{Finding the First job}

The entire chapter so far has dealt with the labor market status of former employees of Fokker N.V. after the bankruptcy and the search behavior of the workers to find new jobs. A crucial issue is to find that first job and therefore the Fokker Survey included a question as to which channels this first job was found. Table 6.19 gives an overview of the responses sub-divided by positions filled after one, two and three years. Informal networks of families, former colleges, and friends, as well as contacts from the work at Fokker play a very important role for former Fokker employees. These informal networks fair even better than the specialized 'formal institutions' as the Employment Office and the manpower agencies. Other important sources are direct applications on job-advertisements and open applications.

Finally, attention is paid to the search-costs associated with finding the first jobs. ${ }^{1}$ Table 6.20 gives the median search costs and their standard deviation by educational level and age-categories. They seem to be increasing with educational level (both in terms of general schooling and in terms of vocational training). With the exception of the age group of 55 years and older it is also increasing in the age-categories (cf. Table 6.21). The exception of the $55+$ category can easily be explained by the fact that they are not required to search for a new job (application obligations) to receive their unemployment insurance payments (benefits)

\footnotetext{
${ }^{1}$ These search costs are self-reported in the questionnaire, see question 1.14 in the questionnaire.
} 
Table 6.21: Search Cost by Age Level

\begin{tabular}{lrr}
\hline Age & \multicolumn{2}{c}{ Search Costs in HFL } \\
& Median & Standard deviation \\
\hline$<30$ years & 100 & 631 \\
$30-34$ years & 200 & 976 \\
$35-39$ years & 250 & 1257 \\
$40-44$ years & 400 & 1530 \\
$45-49$ years & 500 & 1647 \\
$50-54$ years & 500 & 1653 \\
$55+$ years & 100 & 190 \\
\hline
\end{tabular}

Table 6.22: Size of the New Employer — Displaced Workers in Fokker Survey

\begin{tabular}{lrrrrrrr}
\hline Size Company & \multicolumn{2}{c}{ 1st job } & \multicolumn{2}{c}{ Current Job } & \multicolumn{2}{c}{ SEP sample } \\
& $\mathrm{N}$ & $\%$ & $\mathrm{~N}$ & $\%$ & $\mathrm{~N}$ & $\%$ \\
\hline $1-19$ & 139 & 17.89 & 157 & 11.23 & 297 & 16.61 \\
$21-50$ & 123 & 15.83 & 140 & 10.01 & 166 & 9.29 \\
$50-99$ & 111 & 14.29 & 192 & 13.73 & 164 & 9.17 \\
$100+$ & 404 & 51.99 & 909 & 65.02 & 1161 & 64.93 \\
\hline Total & 777 & 100.00 & 1398 & 100.00 & 1788 & 100.00 \\
\hline
\end{tabular}

\section{The Size of the Firms}

Coming from a relatively large firm with more than 100 employees, the displaced employees of former Fokker N.V. find employment in firms of all sizes. For comparison the 'matched' SEP sample provides an insight into the general distribution of the Dutch workers over different sized firms.

Table 6.22 gives an overview of the absolute number and the respective percentages of first and current jobs of former employees of Fokker N.V. as well as an overview of the 'matched' SEP sample. Note that the current job can also be the first job of the respondent. Those respondents who had initially found employment with either the bankruptcy trustee or with Fokker Aviation B.V. were excluded from this part of the analysis.

As can be seen in Table 6.22 the initial employment positions following the bankruptcy of Fokker N.V. were proportionally higher with smaller firms. This proportion has dropped considerably for the current jobs of the respondents. Bigger firms $(100+)$ are underrepresented with regard to the first job of the respondents. There may be two explanations for this phenomenon. Firstly, those workers who initially get employed in a bigger firm $(100+)$ are not likely to leave this firm within three years while the smaller 
Table 6.23: Type of Employment Contract — Fokker Survey

\begin{tabular}{lrrrr}
\hline \multicolumn{1}{c}{ Type of Contract } & \multicolumn{2}{c}{ 1st } & \multicolumn{3}{c}{ Current Job } \\
& $\mathrm{N}$ & $\%$ & $\mathrm{~N}$ & $\%$ \\
\hline Call-to-Call basis & 43 & 5.36 & 16 & 1.14 \\
Temporary, no long-term perspective & 302 & 37.66 & 101 & 7.18 \\
Temporary, with long-term perspective & 237 & 29.55 & 189 & 13.43 \\
Trial Period & 56 & 6.98 & 28 & 1.99 \\
Contract & 164 & 20.45 & 1073 & 76.26 \\
\hline Total & 802 & 100.00 & 1407 & 100.00 \\
\hline
\end{tabular}

firms are used as stepping stones for eventual moves to bigger firms. Secondly, smaller firms are more likely to offer temporary jobs due to an increased reluctance among these sizes of firms to offer long-term or indefinite contracts. They typically offer employment for fixed periods of time up to 5 years. When comparing the first job firms size with the 'matched' SEP sample it is apparent that the bigger firms are underrepresented, while this appears to even out over time there is no difference for the distribution of workers over different sizes of firms when looking at the current jobs.

In this context it is worthwhile to look into the types of contracts that were issued. Table 6.23 gives an overview of the types of contracts issued to the former Fokker N.V. employees for their first and current jobs. Quite a high proportion of the jobs that were initially accepted were of temporary nature, often even without the prospect to subsequently gain either a full time or other more permanent type of contract. This has changed significantly looking at the current job situation three years after the bankruptcy. Now more than 75 percent of the employed former Fokker N.V. workers have obtained full time employment with indefinite contracts.

\section{Schooling, Experience and Responsibility}

The level of a job, the required knowledge and skills, can roughly be characterized by two indicators: (1) the minimum schooling needed to qualify for the job, and (2) the number of years of working. The Fokker Survey focuses on these two indicators in the questionnaire.

Table 6.24 and 6.25 give the results for both the required schooling and experience. They point towards an increase in the number of higher level jobs, requiring higher educational levels, relative to the requirements for the first job accepted after displacement. The results in Table 6.25 show that particularly the combination of working experience 
Table 6.24: Schooling Requirements for Acquiring a Job

\begin{tabular}{lrrrr}
\hline Months of schooling & \multicolumn{3}{c}{ 1st Job } & \multicolumn{3}{c}{ Current Job } \\
necessary to fill in job & $\mathrm{N}$ & $\%$ & $\mathrm{~N}$ & $\%$ \\
\hline None & 49 & 10.23 & 70 & 8.09 \\
1 month & 73 & 15.24 & 80 & 9.25 \\
1-3 months & 87 & 18.16 & 175 & 20.23 \\
- 6 months & 97 & 20.25 & 210 & 24.28 \\
6-12 months & 84 & 17.54 & 170 & 19.65 \\
- 2 years & 45 & 9.39 & 83 & 9.60 \\
- 3 years & 18 & 3.76 & 22 & 2.54 \\
3 - 4 years & 18 & 3.76 & 29 & 3.35 \\
More than 4 years & 8 & 1.67 & 26 & 3.01 \\
\hline Total & 479 & 100.00 & 865 & 100.00 \\
\hline
\end{tabular}

Table 6.25: The Importance of Work Experience in Getting the New Job

\begin{tabular}{lrrrr}
\hline Importance of previous & \multicolumn{2}{c}{ 1st Job } & \multicolumn{2}{c}{ Current Job } \\
work experience & $\mathrm{N}$ & $\%$ & $\mathrm{~N}$ & $\%$ \\
\hline Yes, especially the work experience & 148 & 18.50 & 302 & 21.56 \\
Yes, especially the technical experience & 40 & 5.00 & 55 & 3.93 \\
Yes, both work and technical experience & 265 & 33.13 & 526 & 37.54 \\
No, but helpful & 172 & 21.50 & 303 & 21.63 \\
No, not necessary & 175 & 21.88 & 215 & 15.35 \\
\hline Total & 800 & 100.00 & 1401 & 100.00 \\
\hline
\end{tabular}


and technical experience was referred to as essential in finding the new economic position. This was apparent for the current position held but of less importance for the first job. Technical experience by itself did not comply with the qualifications needed to obtain a job, while working experience by itself did. From the results it is clear that the prerequisites for the current job are on average higher. Often, a first job was accepted which did not demand or require specific job or technical experience. The current job appears to be more demanding and required the experience of the employee. This indicates that among the initial jobs accepted after the displacement, the knowledge and skills acquired at Fokker N.V. were probably not taken into consideration. However, for the current jobs it is apparent that knowledge and working experience were important assets in acquiring the job.

In order to obtain insight into current job levels versus the former job levels at Fokker N.V. prior to bankruptcy the Fokker Survey respondents were asked to evaluate their current responsibility to the responsibilities at Fokker N.V. The responses were subdivided over three different groups: (1) Bankruptcy Trustees, (2) Aviation, and (3) the other displaced workers. Those workers who continued to work for either the Bankruptcy Trustees or Fokker Aviation B.V. maintained their level of responsibilities. A small percentage of these workers perceived the newly acquired position as slightly more responsible. The picture looks quite different for the displaced workers. In this group more than forty percent initially accept employment with lower responsibilities compared to their previous work at Fokker N.V. This phenomenon appears to have a temporary character, as it becomes proportionally less with the current job. Less than twenty percent of the respondents report current jobs with responsibility levels below their job at Fokker N.V., while approximately 48 percent report higher responsibilities than in their job with Fokker N.V. This is especially true for the workers recruited by Fokker Aviation B.V. and, to a lesser extent, for the workers recruited by the Bankruptcy Trustees who appear to have similar developments as the displaced workers. An overview of the results has been given in Table 6.26.

\subsection{Wages after the Bankruptcy}

One of the key variables of paid work is salary. Wages often reflect the value of a worker for a company, productivity, and indispensability. When displacement is eminent, the loss of employment goes hand in hand with the shattering of career expectations within the downsizing company, and subsequently a reorientation is needed in finding new 
Table 6.26: Current Responsibility Compared to Responsibilities at Fokker N.V.

a. 1st Job with Bankruptcy Trustees

\begin{tabular}{lrrrrr}
\hline Responsibility compared & \multicolumn{2}{c}{ Bankruptcy } & Trustees & \multicolumn{2}{c}{ Current Job } \\
to the work at Fokker & N & $\%$ & N & $\%$ \\
\hline Much more & 16 & 8.29 & 36 & 15.00 \\
More & 55 & 28.50 & 81 & 33.75 \\
Same & 93 & 48.19 & 69 & 28.75 \\
Less & 19 & 9.84 & 40 & 16.67 \\
Much Less & 10 & 5.18 & 14 & 5.83 \\
\hline Total & 193 & 100.00 & 240 & 100.00 \\
\hline
\end{tabular}

b. 1st Job with Fokker Aviation

\begin{tabular}{lrrrr}
\hline Responsibility compared & \multicolumn{2}{c}{ Fokker Aviation } & \multicolumn{2}{c}{ Current Job } \\
to the work at Fokker & $\mathrm{N}$ & $\%$ & $\mathrm{~N}$ & $\%$ \\
\hline Much more & 12 & 8.51 & 66 & 21.22 \\
More & 39 & 27.66 & 99 & 31.83 \\
Same & 69 & 48.94 & 106 & 34.08 \\
Less & 18 & 12.77 & 33 & 10.61 \\
Much Less & 3 & 2.13 & 7 & 2.25 \\
\hline Total & 141 & 100.00 & 311 & 100.00 \\
\hline
\end{tabular}

c. 1st Job neither with Bankruptcy Trustees nor with Fokker Aviation

\begin{tabular}{lrrrr}
\hline Responsibility compared & & 1st Job & \multicolumn{3}{c}{ Current Job } \\
to the work at Fokker & $\mathrm{N}$ & $\%$ & $\mathrm{~N}$ & $\%$ \\
\hline Much more & 62 & 7.64 & 252 & 17.92 \\
More & 137 & 16.89 & 444 & 31.58 \\
Same & 257 & 31.69 & 441 & 31.37 \\
Less & 224 & 27.62 & 201 & 14.30 \\
Much Less & 131 & 16.16 & 68 & 4.84 \\
\hline Total & 811 & 100.00 & 1406 & 100.00 \\
\hline
\end{tabular}


employment opportunities with comparable perspectives and wages. Of course, there are other variables that explain the importance or value of one job compared to another. There are numerous reasons why apparently similar jobs may differ in remuneration. This section of the study focuses on wage developments for workers who have served one or more different employers before accepting the current position. The question is how the previous jobs may affect the remuneration of the current job.

Furthermore, we can say that part of the loss that the workers incur after the bankruptcy is the loss in terms of earnings forgone. They either had no job, or might have to accept jobs with lower wages than what they had before. This is by no means a complete picture of the loss. Many costs were not included and some are difficult to quantify in monetary terms. A number of costs not taken into account are costs of searching for a new job, costs of relocation, costs due to the loss of vacation days, and non-wage extras paid in one firm but not the other. In order to estimate the value of non-wage costs it is important to realize that quite a number of workers are currently earning more in comparison to their earnings at Fokker N.V before its bankruptcy. It is not clear why they refrained from switching jobs at an earlier stage, but actually waited until the bankruptcy was eminent and displacement inevitable. This could be an indication that they valued their work at Fokker highly enough to make up for the difference in income they could have earned in another firm. Many respondents of the Fokker Survey indicated that loosing salary was only one part of the story. The other part of the explanation for their loyalty towards Fokker N.V was that they enjoyed their work and that they were involved in the building of a product to be proud of.

\section{Aggregate View}

Figure 6.4 shows the development of the aggregate wages of all respondents of the Fokker Survey if they were employed. All respondents who were not employed were excluded from the graph for the time of non-employment. The graph gives the average monthly wage from month 0 - the last earned wages at Fokker N.V. - up to three years after the bankruptcy, month 36 .

Respondents who have a job do not - on average — suffer from a wage drop. On the contrary, the wages are actually higher in the first few months post displacement. This may be due to the strict definition that was applied: only employed workers were used in calculating average wages. Thus, the initial increase in average wages can be explained by the fact that the displaced workers accepted relatively well paid jobs after the bankruptcy of Fokker N.V. The decrease in average wages after several months following bankruptcy 
Figure 6.4: Wage Index - Fokker N.V. Versus All Industry

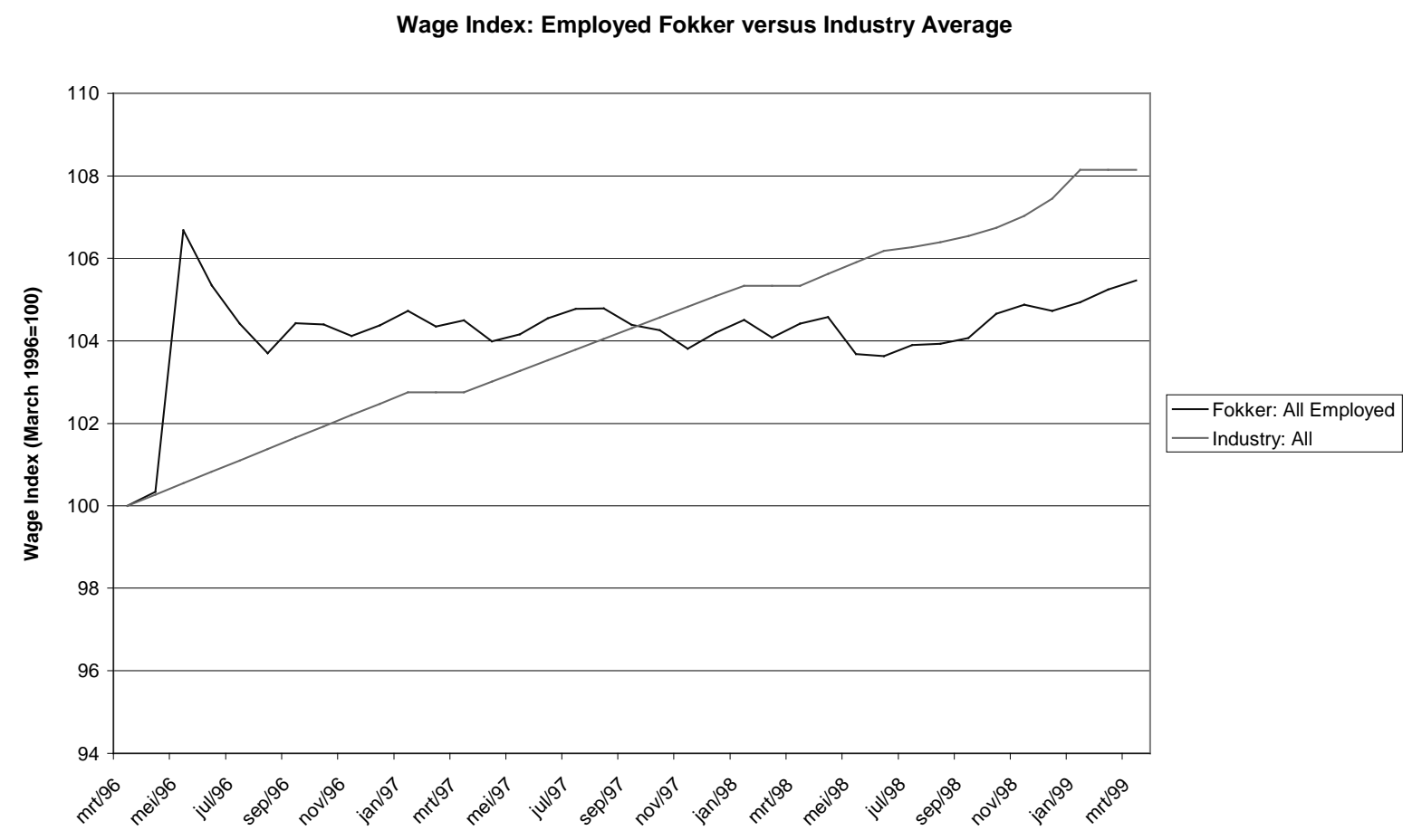

Source: Fokker Survey and CBS Labor Statistics 1997-1999

Table 6.27: Aggregate Income Post-Displacement

\begin{tabular}{lrrrrr}
\hline & \multicolumn{5}{c}{ Mean Monthly Income in HFL } \\
Year & Mean & St. Dev. & Pos. Diff. & Neg. Diff. & Total \\
\hline 1997 & 6125 & 2993 & 553 & 702 & 1255 \\
1998 & 6121 & 3105 & 658 & 714 & 1372 \\
1999 & 6182 & 3237 & 791 & 776 & 1567 \\
\hline
\end{tabular}

Notes: St. Dev. is the standard deviation of all incomes; Pos. Diff. gives the number of workers that gained in income compared to their salary before displacement, whereas Neg. Diff. counts those that lost or stayed the same. 
Figure 6.5: Index of Respondents' Income Versus Industry wages

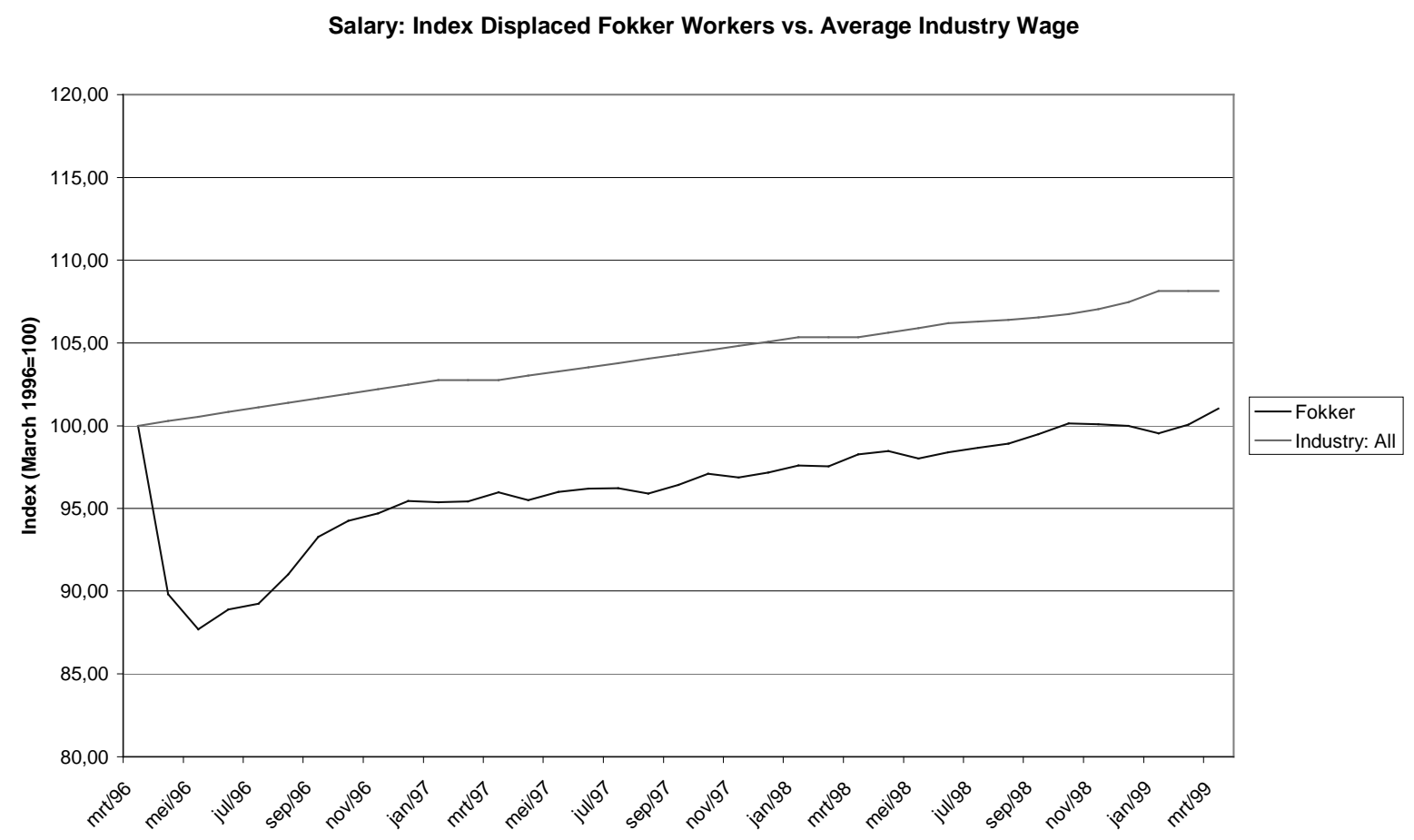

Source: Fokker Survey and CBS Labor Statistics 1997-1999 
Table 6.28: Aggregate Income Post-Displacement incl. Benefits

\begin{tabular}{rrrrrr}
\hline \multirow{2}{*}{ Year } & \multicolumn{5}{c}{ Mean Monthly Income incl. Benefits in HFL } \\
& Mean & St. Dev. & Pos. Diff. & Neg. Diff. & Total \\
\hline 1997 & 5626 & 3026 & 553 & 920 & 1473 \\
1998 & 5759 & 3178 & 658 & 851 & 1509 \\
1999 & 5922 & 3313 & 791 & 872 & 1663 \\
\hline
\end{tabular}

indicates that an increasing number of former Fokker N.V. employees are being employed and that the workers start to accept job offers even though they may earn lower wage premiums as compared to their income at Fokker N.V.

In the context of a displacement the income losses are most important and include those workers who remain unemployed and depend on unemployment insurance payments or social security benefits. Table 6.28 gives an overview of the average income of all respondents including the wages from employment, unemployment insurance (WW) for the time that workers are eligible for it, and social security benefits if a worker is no longer eligible for the unemployment benefits. A decrease in average income is apparent, with a minimum occurring at around two to three months after the bankruptcy. This is due to the fact that some workers receive their wages from Fokker N.V. for up to 19 weeks post displacement, depending on their age and tenure. The recovery of the average income for all respondents is slow, and only after 30 months the mean income level, equalling the former mean income level at Fokker N.V. is reached. However, no corrections were made for inflation or wage increases in comparable industries. Thus, after three years the former level of average income is reached. This outcome however does not discriminate between differences in income between employed and unemployed former Fokker N.V. workers. Some of these workers have actually found employment that pays much more than their previous wages while others have not (yet) found suitable employment since the bankruptcy of the Dutch aeroplane manufacturer and remain dependant upon unemployment insurance or social security benefits only.

To allow for comparison an index of the industry wages from 1996 to 1999 was used in which the quarterly increases over the entire year were smoothed. This comparable wage increase across the entire industry can be set against the wage development of the Fokker N.V. workers post displacement. A clear effect is shown on the costs of displacement for those workers who did not find employment immediately after bankruptcy. The index of displaced Fokker N.V. workers, including the social security benefits and the unemployment insurance payments, remains well below the index of industry wages and 
does not show recovery (Figure 6.5). When looking at the wages of currently employed persons it is clear that the ones having found a new job quickly after bankruptcy have higher wage increases compared to the average industry wage developments. For them the displacement provided the opportunity which allowed them to move on to better paid positions. However, as soon as the vast majority of the workers finds employment the index is pulled down by the wages of those workers who have had to accept lower paid jobs.

Tables 6.27 and 6.28 give the mean wages for all workers and all respondents respectively at one, two, and three years after the bankruptcy. The tables also give the standard deviation of the wages. Bigger standard deviations show an increase in the spread of wages, and a similar indication can be taken from the number of workers with a positive wage (income) difference versus the workers with a negative wage (income) difference. Here, the absolute wage difference at the specific time period was calculated. All positive salaries indicate increases in wages while negative salaries indicate loss of income. A number of 553 workers have positive wage increases 12 months after the bankruptcy while 702 workers have a negative wage difference.

What can be seen in both figures is that one has to be careful in the definition of what one considers a wage loss. In a strict sense one should make a distinction between income and wages. Where income includes also transfer payments as unemployment benefits, whereas wages purely give the income through employment. In Table 6.27 the number of workers with positive wage development shows an increase indicating that an increasing number of workers are able to regain or surpass the level of salary formerly received from Fokker N.V. However, the standard deviation, indicating the spread of incomes, is also increasing over the three-year period. If we compare this to the Table 6.28, we can see that the lower mean salary is due to the inclusion of the transfer payment recipients. Again, we can see that the spread of income is increasing over the three year period, even though the number of workers with positive wage difference is increasing while the number of workers with negative difference is decreasing.

\section{Education Levels}

One of the explanations for the differences in wages may be found in the different chances an employee has in finding a new job. Two indicators explaining the different chances in finding a new job are educational levels achieved and age. Wage developments are analyzed over the different educational levels.

Incomes appear to increase with the level of educational degrees, both for the general 
Table 6.29: Income by Education Levels

\begin{tabular}{|c|c|c|c|c|c|c|}
\hline \multirow[b]{2}{*}{ Year } & \multirow[b]{2}{*}{ Education } & \multicolumn{4}{|c|}{ Mean Income } & \multirow[b]{2}{*}{ Total } \\
\hline & & Mean & St. Dev. & Pos. Diff. & Neg. Diff. & \\
\hline \multirow{9}{*}{1997} & Basis & 3491 & 233 & 1 & 4 & 5 \\
\hline & MAVO & 4578 & 1785 & 23 & 38 & 61 \\
\hline & HAVO & 4843 & 1671 & 12 & 16 & 28 \\
\hline & VWO & 8940 & 6945 & 14 & 8 & 22 \\
\hline & LBO/LTS & 3969 & 802 & 47 & 136 & 183 \\
\hline & $\mathrm{MBO}$ & 4874 & 1479 & 136 & 227 & 363 \\
\hline & $\mathrm{HBO}$ & 7129 & 2753 & 178 & 177 & 355 \\
\hline & WO & 9123 & 3287 & 53 & 31 & 84 \\
\hline & $\mathrm{TU}$ & 8241 & 3483 & 89 & 65 & 154 \\
\hline \multirow{9}{*}{1998} & Basis & 4452 & 1384 & 3 & 3 & 6 \\
\hline & MAVO & 4772 & 2520 & 29 & 43 & 72 \\
\hline & HAVO & 4853 & 1646 & 16 & 15 & 31 \\
\hline & VWO & 8567 & 7453 & 16 & 9 & 25 \\
\hline & LBO/LTS & 4012 & 848 & 67 & 149 & 216 \\
\hline & $\mathrm{MBO}$ & 4872 & 1485 & 161 & 239 & 400 \\
\hline & $\mathrm{HBO}$ & 7252 & 2993 & 206 & 176 & 382 \\
\hline & WO & 9071 & 2812 & 61 & 23 & 84 \\
\hline & $\mathrm{TU}$ & 8453 & 3819 & 99 & 57 & 156 \\
\hline \multirow{9}{*}{1999} & Basis & 3964 & 1329 & 3 & 4 & 7 \\
\hline & MAVO & 4725 & 2262 & 40 & 52 & 92 \\
\hline & HAVO & 5106 & 1664 & 19 & 16 & 35 \\
\hline & VWO & 9001 & 7832 & 18 & 12 & 30 \\
\hline & LBO/LTS & 4038 & 828 & 80 & 168 & 248 \\
\hline & $\mathrm{MBO}$ & 4932 & 1478 & 211 & 251 & 462 \\
\hline & $\mathrm{HBO}$ & 7353 & 3018 & 244 & 188 & 432 \\
\hline & WO & 9456 & 3439 & 63 & 25 & 88 \\
\hline & $\mathrm{TU}$ & 8610 & 4194 & 113 & 60 & 173 \\
\hline
\end{tabular}


Table 6.30: Income by Education Levels incl. Benefits

\begin{tabular}{|c|c|c|c|c|c|c|}
\hline \multirow[b]{2}{*}{ Year } & \multirow[b]{2}{*}{ Education } & \multicolumn{4}{|c|}{ Mean Income } & \multirow[b]{2}{*}{ Total } \\
\hline & & Mean & St. Dev. & Pos. Diff. & Neg. Diff. & \\
\hline \multirow{9}{*}{1997} & Basis & 2686 & 848 & 1 & 10 & 11 \\
\hline & MAVO & 4038 & 1853 & 23 & 59 & 82 \\
\hline & HAVO & 4599 & 1769 & 12 & 19 & 31 \\
\hline & VWO & 7925 & 6831 & 14 & 12 & 26 \\
\hline & LBO/LTS & 3683 & 935 & 47 & 191 & 238 \\
\hline & $\mathrm{MBO}$ & 4579 & 1566 & 136 & 293 & 429 \\
\hline & $\mathrm{HBO}$ & 6690 & 2909 & 178 & 221 & 399 \\
\hline & WO & 8815 & 3521 & 53 & 35 & 88 \\
\hline & $\mathrm{TU}$ & 7717 & 3742 & 89 & 79 & 168 \\
\hline \multirow{9}{*}{1998} & Basis & 2721 & 1611 & 3 & 12 & 15 \\
\hline & MAVO & 4349 & 2541 & 29 & 56 & 85 \\
\hline & HAVO & 4656 & 1778 & 16 & 17 & 33 \\
\hline & VWO & 7672 & 7273 & 16 & 13 & 29 \\
\hline & $\mathrm{LBO} / \mathrm{LTS}$ & 3754 & 1052 & 67 & 186 & 253 \\
\hline & $\mathrm{MBO}$ & 4685 & 1591 & 161 & 271 & 432 \\
\hline & $\mathrm{HBO}$ & 6971 & 3129 & 206 & 199 & 405 \\
\hline & WO & 8606 & 3243 & 61 & 29 & 90 \\
\hline & $\mathrm{TU}$ & 8061 & 4018 & 99 & 67 & 166 \\
\hline \multirow{9}{*}{1999} & Basis & 2873 & 1545 & 3 & 10 & 13 \\
\hline & MAVO & 4504 & 2324 & 40 & 59 & 99 \\
\hline & HAVO & 4917 & 1806 & 19 & 18 & 37 \\
\hline & VWO & 8539 & 7791 & 18 & 14 & 32 \\
\hline & LBO/LTS & 3797 & 1069 & 80 & 195 & 275 \\
\hline & $\mathrm{MBO}$ & 4802 & 1582 & 211 & 271 & 482 \\
\hline & $\mathrm{HBO}$ & 7117 & 3164 & 244 & 207 & 451 \\
\hline & WO & 9114 & 3728 & 63 & 29 & 92 \\
\hline & $\mathrm{TU}$ & 8306 & 4339 & 113 & 68 & 181 \\
\hline
\end{tabular}


and specialized educational degrees. This was also the case for the time they were employed by Fokker N.V. Income ranking, according to educational degree level, appears to be of importance in finding jobs that pay similar wages as those previously earned. Again, a higher proportion of workers with a lower educational degree have to accept income cuts in comparison to their pre-displacement income level, while the higher educated are more likely to find better paid jobs than the ones they had at Fokker N.V. prior to bankruptcy. This holds true even after three years of the bankruptcy. The results are summarized in Table 6.27.

If income from transfer payments is included (Table 6.28), a similar picture emerges. Average income rises with educational level. This can be expected since both preand post-displacement earnings are shown to increase with educational level, and - at least the unemployment benefits - are based upon pre-displacement wage level. Again, higher educational levels seem helpful in finding new, better paid jobs more rapidly. Most difficulties in finding new jobs with comparable wages are encountered in the groups with LBO/LTS, MAVO and MBO degrees. In these categories there is a higher proportion of workers who are unable to find new jobs, or have to accept jobs with wages well below those of their pre-displacement level.

\section{Age Categories}

Another category of interest in wage developments is age. The respondents have been sub-divided into seven age categories, ranging from less than 30 years old (at the time of the bankruptcy) to 55 years and older. Mean wage, its standard deviation, the number of positive and negative wage differences for each age category at one, two and three years following the bankruptcy are reported in Table 6.31.

In terms of age-categories the expectation is that with increasing age it becomes more and more difficult to find a suitable job that pays a comparable salary as Fokker N.V. did. Of particular interest is the point at which it seems to become more difficult to find a new job. From the information in the tables, it appears that up to the age-category of 35-39 years old, the number of workers with positive wage difference and with negative wage difference is about equal. However, beyond the age of 40 the outcomes become increasingly tilted towards a negative wage difference. This effect is further confirmed when including the transfer payments (Table 6.32). The number of workers with a negative wage difference does not increase much for the lower age groups. Among the younger workers only a few workers actually need to use the transfer payments. On the other hand, workers of forty and older show an increased need for the use of transfer 
Table 6.31: Income by Age Categories

\begin{tabular}{rlrrrrr}
\hline \multirow{2}{*}{ Year } & Age & Mean & St. Dev. & Pos. Diff. & Neg. Diff. & Total \\
\hline \multirow{4}{*}{1997} & $<30$ & 4562 & 2419 & 81 & 52 & 133 \\
& $30-34$ & 5099 & 1787 & 128 & 140 & 268 \\
& $35-40$ & 6182 & 2317 & 150 & 165 & 315 \\
& $40-44$ & 6391 & 3277 & 92 & 148 & 240 \\
& $45-49$ & 7115 & 3434 & 70 & 122 & 192 \\
& $50-54$ & 7844 & 4071 & 28 & 65 & 93 \\
& $55+$ & 10031 & 4631 & 4 & 10 & 14 \\
\hline \multirow{4}{*}{1998} & $<30$ & 4557 & 2362 & 96 & 52 & 148 \\
& $30-34$ & 5291 & 2516 & 161 & 128 & 289 \\
& $35-40$ & 6201 & 2252 & 175 & 158 & 333 \\
& $45-49$ & 6458 & 3497 & 108 & 155 & 263 \\
& $50-54$ & 6858 & 3641 & 83 & 146 & 229 \\
& $55+$ & 7632 & 3904 & 32 & 66 & 98 \\
& $<30$ & 9623 & 3126 & 3 & 9 & 12 \\
\hline $30-34$ & 4597 & 2240 & 123 & 54 & 177 \\
& $35-40$ & 5446 & 2660 & 185 & 132 & 317 \\
1999 & $40-44$ & 6299 & 2692 & 205 & 175 & 380 \\
& $45-49$ & 6496 & 3638 & 135 & 166 & 301 \\
& $50-54$ & 6929 & 3722 & 105 & 161 & 266 \\
& $55+$ & 7418 & 3899 & 36 & 76 & 112 \\
& & 9003 & 3259 & 2 & 12 & 14 \\
\hline
\end{tabular}


Table 6.32: Income by Age Categories incl. Benefits

\begin{tabular}{rlrrrrr}
\hline \multirow{2}{*}{ Year } & Age & Mean & St. Dev. & Pos. Diff. & Neg. Diff. & Total \\
\hline \multirow{2}{*}{1997} & $<30$ & 4396 & 2447 & 81 & 60 & 141 \\
& $30-34$ & 4887 & 1916 & 128 & 157 & 285 \\
& $35-40$ & 5969 & 2429 & 150 & 183 & 333 \\
& $40-44$ & 5838 & 3320 & 92 & 189 & 281 \\
& $45-49$ & 6207 & 3458 & 70 & 178 & 248 \\
& $50-54$ & 5734 & 3928 & 28 & 135 & 163 \\
& $55+$ & 7882 & 4677 & 4 & 18 & 22 \\
\hline & $<30$ & 4537 & 2366 & 96 & 53 & 149 \\
& $30-34$ & 5228 & 2540 & 161 & 133 & 294 \\
& $35-40$ & 6054 & 2359 & 175 & 168 & 343 \\
1998 & $40-44$ & 6144 & 3577 & 108 & 174 & 282 \\
& $45-49$ & 6330 & 3738 & 83 & 175 & 258 \\
& $50-54$ & 5505 & 3994 & 32 & 131 & 163 \\
& $55+$ & 7008 & 4130 & 3 & 17 & 20 \\
\hline & $<30$ & 4548 & 2254 & 123 & 57 & 180 \\
& $30-34$ & 5422 & 2669 & 185 & 134 & 319 \\
& $35-40$ & 6250 & 2720 & 205 & 179 & 384 \\
1999 & $40-44$ & 6309 & 3689 & 135 & 178 & 313 \\
& $45-49$ & 6591 & 3829 & 105 & 179 & 284 \\
& $50-54$ & 5710 & 4194 & 36 & 123 & 159 \\
& $55+$ & 6210 & 4232 & 2 & 22 & 24 \\
\hline
\end{tabular}


Table 6.33: Average Monthly Income by Plants

\begin{tabular}{|c|c|c|c|c|c|c|}
\hline \multirow[b]{2}{*}{ Year } & \multirow[b]{2}{*}{ Plant } & \multicolumn{5}{|c|}{ Mean Income } \\
\hline & & Mean & St. Dev. & Pos. Diff. & Neg. Diff. & Total \\
\hline \multirow{3}{*}{1997} & FAC Amsterdam & 6524 & 3132 & 455 & 527 & 982 \\
\hline & FAC Drechtsteden & 4661 & 1699 & 66 & 126 & 192 \\
\hline & FAC Ypenburg & 4867 & 2123 & 32 & 49 & 81 \\
\hline \multirow{3}{*}{1998} & FAC Amsterdam & 6470 & 3233 & 535 & 550 & 1085 \\
\hline & FAC Drechtsteden & 4701 & 1769 & 82 & 117 & 199 \\
\hline & FAC Ypenburg & 5116 & 2739 & 41 & 47 & 88 \\
\hline \multirow{3}{*}{1999} & FAC Amsterdam & 6532 & 3377 & 636 & 593 & 1229 \\
\hline & FAC Drechtsteden & 4736 & 1777 & 106 & 131 & 237 \\
\hline & FAC Ypenburg & 5413 & 3117 & 49 & 52 & 101 \\
\hline
\end{tabular}

payments. Note also that, including the transfer payments, the age groups of 50 years and older seem not able to recover to their initial wage level - not even after three years. All other age groups eventually recover although some groups take considerably more time than others.

\section{Differences over Plants}

Fokker N.V. had its three main plants, Amsterdam (Schiphol), Drechtsteden and Ypenburg involved in the bankruptcy. Here we report on possible differences or similarities between the three plants over a three-year period of time. The results have been summarized in Tables 6.33 and 6.34. One of the most striking differences at first sight is that it appears that the employees of Schiphol, the largest plant, have the highest average income. However, this is more a composition effect rather then an indication of regional differences. The workers from the Drechtsteden plant seem to have the most difficulties in finding new employment with comparable salary levels, or any employment at all. The workers from the Ypenburg plant seem to have the fastest wage development following the displacement. This finding is associated with an increasing standard deviation, indicating that this is due to a specific group of workers who enjoy a significant increase in wages post-displacement. 
Table 6.34: Average Monthly Income by Plants incl. Benefits

\begin{tabular}{|c|c|c|c|c|c|c|}
\hline \multirow[b]{2}{*}{ Year } & \multirow[b]{2}{*}{ Plant } & \multicolumn{5}{|c|}{ Mean Income } \\
\hline & & Mean & St. Dev. & Pos. Diff. & Neg. Diff. & Total \\
\hline \multirow{3}{*}{1997} & FAC Amsterdam & 6027 & 3187 & 455 & 680 & 1135 \\
\hline & FAC Drechtsteden & 4296 & 1747 & 66 & 168 & 234 \\
\hline & FAC Ypenburg & 4320 & 2165 & 32 & 72 & 104 \\
\hline \multirow{3}{*}{1998} & FAC Amsterdam & 6133 & 3320 & 535 & 640 & 1175 \\
\hline & FAC Drechtsteden & 4351 & 1872 & 82 & 151 & 233 \\
\hline & FAC Ypenburg & 4763 & 2730 & 41 & 60 & 101 \\
\hline \multirow{3}{*}{1999} & FAC Amsterdam & 6275 & 3462 & 636 & 661 & 1297 \\
\hline & FAC Drechtsteden & 4536 & 1871 & 106 & 149 & 255 \\
\hline & FAC Ypenburg & 5069 & 3168 & 49 & 62 & 111 \\
\hline
\end{tabular}

\section{Conclusion}

The labor market status of the employees of former Fokker N.V. was - of course - severely affected by the displacement resulting from bankruptcy. Regaining a normal level of employment is one of the key issues after such a shock. From the information obtained from the Fokker Survey it is apparent that some groups can quickly regain employment, while others take a longer time period. Even after the three years following the bankruptcy, the employment status shows the effects of the displacement. Nevertheless it can be stated that the main recovery has taken place within the time frame of three years. Workers with only elementary schooling, lower general education (MAVO), or lower vocational training (LBO/LTS) have a lesser chance of finding new employers. The same applies to persons older than 45 years. This implies that lower educated workers as well as older workers have reduced chances on the labor market.

For those employees who succeeded in finding a new job within the first year after displacement it is apparent that especially Fokker N.V. related contacts played a major role. There is a tendency towards increased employment of the former Fokker N.V. employees in bigger $(100+)$ firms in comparison to the distribution of employment for the whole Dutch economy. This is especially true for jobs held three years after bankruptcy. However, among the initial jobs that were accepted after bankruptcy, the big firms were notably underrepresented.

If previous work experience was considered an important factor in acquiring a new 
job it was in combination with technical experience rather than the technical skills and work experience specifically. In fact, technical experience alone was in most cases not sufficient for the acquisition of the new job. The results clearly show that the initial job following the displacement involved in most cases fewer responsibilities than the current job that a worker holds three years after the bankruptcy.

The groups of former employees suffering from wage losses are comparable to those described as having more difficulties in finding a job: persons with lower educational levels (Basis, MAVO, LBO/LTS and MBO) have on average higher wage losses, and encounter more difficulties to recovering their former wage level. Also, the workers of 40 years or older have on average higher wage losses and are not at all able to recover their former employment and wage level. This compared to the group of 30-40 years old who have initial wage losses (1st year), but recover quickly and usually beyond their former wage level. The age category of $55+$ is a special category in the sense that the workers are no longer required to search for a new job, hence it is to be expected that they show lower average wages. It can be seen that among the workers of 55 years and older difficulties arise in finding adequately paid jobs.

In the next chapter we will continue to investigate the question of the duration of job search and also that of income losses. We will then try to determine the factors affecting these outcomes. As we concentrate on the first job, we will confine the investigation to those workers that were actually displaced, i.e. did not get a job offer from the bankruptcy trustees of from Fokker Aviation at the displacement date. 


\section{Heterogeneity among Displaced Workers}

"The peculiarities of labor in relation to readjustments form one of the main sources of injustice and hardship in an individualist economy. The risk of loss in the value of acquired knowledge and training means a constantly impending threat of indigence. Laborers are attached to their homes and even to their work by sentimental ties to which market facts are ruthless."

(Knight, 1921, p. 346) 


\subsection{Introduction}

Displacement wage losses have been used to examine the transferability of human capital. Losses of firm specific skills are estimated as the returns to tenure at the displacing firm. The tenure variable is used as a proxy for the (specific) human capital that a worker has accumulated while working at that firm (Becker (1962); Parsons (1972)). ${ }^{1}$ Addison and Portugal (1989) criticize earlier specifications of displacement wage losses which try to estimate loss of specific human capital through pre-displacement tenure in the firm. They show that the previous tenure is 'productive' also in new jobs, implying a partial transferability of human capital. Topel (1990) examines the losses associated with changing employment after displacement. He finds that more senior workers suffer from greater reductions in earnings compared to their junior counterparts. This suggests that some human capital is built up during the career which is (partly) destroyed upon displacement. Farber (1997) interprets this as economic redundancy of skills. In a later paper Farber (1999b) finds that 30 percent of the return to tenure can be explained by heterogeneity while the other 70 percent should be seen as returns to specific investments. Neal (1995) examines the transferability of specific investments in human capital by examining industry specific returns to tenure. He finds that some returns to tenure are industry specific. Workers who continue their career after displacement within the same industry face lower wage losses. Dustmann and Meghir (2001) find positive returns to experience and firm tenure for skilled, but not for unskilled workers in Germany. PostelVinay and Robin (2002) also find wage variation being explained by person-specific effects that vary across skill groups in France.

In this study, we analyze the effects of displacement for workers from a single large firm in the Netherlands. Because of the firm's bankruptcy, all workers are officially informed about their lay-off at the same date. The data we use contains detailed information on the accumulated human capital in relation to the occupation held and the career developed within the firm. Together with the workers' hierarchical positions, their job characteristics, job rotations, and promotions, we are able to thoroughly investigate the composition of wage differences before and after the demise of the firm. Moreover, using a post-displacement survey, we can combine workers' pre-displacement occupational and career characteristics with specific information on the search process and the eventual new job characteristics.

We find that wage losses are functions of characteristics of jobs before and after dis-

\footnotetext{
${ }^{1}$ This is different from Chapter 4 in which we use training as indicator for specific capital. Here we follow the general displacement literature.
} 
placement. Tenure with the firm, rank or job does not explain wage losses. Significant pre-displacement variables are the type of job, the number of job rotations in the last rank, performance evaluation scores, as well as a measure of idiosyncratic ability. Post-displacement co-variates explaining wage losses are industry-specific characteristics, changes in responsibility on the job and carried over job-related know-how.

The combination of detailed pre- and post-displacement information of job characteristics, wages, and search history also allows us to develop and estimate a simple model of dynamic updating of idiosyncratic reservation wages. The updating is a product of learning from information about successful matches obtained from former colleagues with similar characteristics. The idea is based on the observation that after the bankruptcy many former employees became members of clubs where people met regularly (see also Rees (1966); Granovetter (1974)). The updating model is strongly supported by the data.

The chapter is organized as follows. In Section two we describe the data, including the development of the post-displacement survey. In Section three we analyze variation in search time needed to find the first job. Pre- and post-displacement earnings differences are evaluated in Section four. In Section five, we propose a dynamic updating model to perform an integrated analysis of search time and wage losses. Section six concludes.

\subsection{The Displaced Worker Survey and Personnel Data}

The displacement literature has long recognized the role of heterogeneity among workers in understanding observed post-displacement search time and pre- and post-displacement earnings differences among workers. Compared to regular lay-offs displaced workers should be able to distinguish themselves as they are not specifically selected into unemployment but part of a firm that closed down. This should, according to Gibbons and Katz (1991)), lead to better labor market prospects compared to the average unemployed worker. The analysis of losses from displacement presented in this chapter primarily focuses on worker-specific heterogeneity.

In the U.S. wage losses of 10 to 30\% for displaced workers are reported (Ruhm (1991) and Kletzer (1998)). Jacobson et al. (1993) use (unemployment insurance) administrative data to show that displaced workers do not only suffer from wage losses upon displacement but also lag behind in average wage growth several years before being dis- 
Table 7.1: Composition of Fokker Workforce and Survey Population at the Time of the Bankruptcy

\begin{tabular}{lrr}
\hline & $\mathrm{N}$ & $\%$ \\
\hline Displaced Workers & 3991 & 70.71 \\
Bankruptcy trustees & 700 & 12.40 \\
Fokker Aviation B.V. & 953 & 16.89 \\
\hline Total & 5644 & 100.00 \\
\hline Pilot & 100 & $\cdot$ \\
Other Workers involved in the & 38 & $\cdot$ \\
development of the Survey & & \\
\hline Survey Population & 5506 & \\
\hline
\end{tabular}

placed. For Europe the following picture emerges from the currently available literature: Earnings losses range from nothing at all (Abbring et al. (2002), Bender et al. (2002)) to somewhat less than 10\% (Albæk et al. (2002); Borland et al. (2002); Burda and Mertens (1998)). ${ }^{2}$ Several explanations for these differences have been offered. An institutional one is that European countries offer generous social security payments which allow displaced workers to search for new jobs using the social security cushion. Compared to their American counterparts European workers are less likely to be forced into accepting lower paid jobs. This increases the observed search time and the probability of finding a better match. But the administrative data used in the European studies do not contain information sufficiently detailed to properly estimate the variation of displacement wage losses across individuals, and how that variation depends on careers, job rotations, rank tenure and other specifications of the jobs held before as well as after displacement.

The year 1996 marked the end of a proud history of more than 75 years of aircraft production by the Dutch company Fokker. Founded by one of the pioneers of aviation and aircraft design, Anthony Fokker, the company first blossomed in the 1920s when it became the world leader in aircraft construction, producing in both the Netherlands and the United States. After the destruction of the production facilities during the Second World War, Fokker remained one of the smaller players in the world aircraft industry, producing predominantly civilian mid-range airplanes of 50 to 100 seats. In March 1996 it filed for bankruptcy and 5644 workers lost their tenured jobs. The bankruptcy trustees created a new company, called Fokker Aviation, which contained the viable remains of the old firm. A total of 953 workers were simultaneously fired from the bankrupt firm

\footnotetext{
${ }^{2}$ One recent exception is Couch $(2001)$, who finds in the German GSOEP data that annual earning (not wages) of displaced workers declined by 13.5 percent in the year following plant closure.
} 
and hired by Fokker Aviation. Another group of 700 workers was offered a contract to continue working for the trustees to finish building airplanes already sold to airline companies; 3991 workers were permanently displaced (Table 7.1). ${ }^{3}$

We use data from two sources. Fokker's electronic personnel data system provided information about workers'pre-displacement careers inside the firm. In 1999 post-displacement information was gathered through a mail survey among all workers who were laid off after the firm's bankruptcy. Current addresses of the respondents were obtained from the bankruptcy trustees. Information from the Fokker Pension Fund was used to check upon deceased employees. The addresses of deceased former employees were omitted from the address files used for the survey. The 'Fokker Survey' collected data on the labor market experience for the three years following the workers' displacement. This survey data has been linked to the information from the personnel files.

\subsubsection{The Personnel Data}

From Fokker's personnel files we obtained information on each employee's type of job, compensation, and demographics. Demographic characteristics include date of birth, gender, education, marital status, and the hiring date of each employee. The average tenure at the time of bankruptcy was 15 years. The firm's hierarchy distinguishes 8 different levels below top management. The highest observable step, the eighth level, is just below the top management and the Board of Directors. For reasons of possible identification, the two upper levels (9 and 10) were left out of the data-set.

The hierarchical structure roughly reflects the division of unskilled versus skilled workers as well as the organization of supervision. Production workers are located in levels 1 to 3. Managers, engineers, and aircraft designers belong to levels 4 to 8. ${ }^{4}$ Every position is 'allocated' to a job activity. These activities are Administration, Sales, Management, Human Resources, R\&D as well as Production Preparation, Production Planning, Support, Production and Quality Control. Job rotation is defined as the number of lateral job changes within a given hierarchical level. The lateral job change is a movement across job activities without changing the hierarchical position to a higher (or lower) level job. In addition to the normal tenure variable, we observe tenure within the hierarchy and tenure within a specific position (job). The latter two tenure variables were measured in months rather than years for the last position held before lay-off.

\footnotetext{
${ }^{3}$ The bankruptcy trustees sold Fokker Aviation to STORK in 1997. For a complete description see Trustee report (Deterink et al. 1997).

${ }^{4}$ For a detailed description of the company's structure in 1987-1996 see Chapter 3.
} 
We have calculated the unemployment insurance benefits paid to the worker, as well as the duration for which they were eligible. These calculations were according to the Dutch regulations: On the day of the bankruptcy every worker faces a six week firing period in which they receive their salary. ${ }^{5}$ Older workers are entitled to a longer firing period. The original six weeks are extended by one week per year of tenure while the worker was older than 45 years. The maximum firing period after a bankruptcy is 19 weeks. After the firing period workers receive unemployment insurance benefits. The unemployment insurance pays 70 percent of the former salary, with a maximum of 55000 Dutch guilders. This implies a replacement ratio of 0.7 for all workers receiving less than 78752 Dutch guilders annually. Sixteen percent of our sample received annual salaries above this amount leading to lower replacement ratios for those workers. The length of the UI payments depends on the labor market experience of the worker. A worker is entitled to UI payments if he has worked 4 out of the 5 years prior to becoming unemployed. Workers who worked for 4 years are entitled to 6 months of UI payments. After 5 years worked, this rises to a total of 9 months, and to a total of 12 months after 10 years worked. Beyond 10 years of labor market experience a workers' entitlement increases by an additional 6 month for every additional 5 years he worked. The maximum entitlement is 60 months.

\section{A Measure of Idiosyncratic Ability}

Learning models (Farber and Gibbons (1996); Altonji and Pierret (2001)) suggest that idiosyncratic worker ability is not readily observable and that the residual of an unrestricted regression of a wage equation is a martingale. In time-series representations of wage equations that martingale is often found to be of order I(1) (see for example Pfann and Palm (1993), for Dutch as well as UK wage models). This implies that the model's first-order Koyck transformation - the wage growth - is stationary and that the residual distribution of a regression - corrected for selective separations (quits and lay-offs) measures the distribution of idiosyncratic worker ability revealed to the employer but not to the econometrician.

We compare the 1993-1996 residuals of an unrestricted regression of the wage growth during the last three years at the firm as a proxy of the distribution of idiosyncratic worker ability at the time of the mass lay-off. If this measurement is indeed a good proxy for unobserved ability we expect it to be negatively correlated with search time,

\footnotetext{
${ }^{5}$ The salary payments after a bankruptcy are paid out by the Dutch social security offices. They are guaranteed regardless of the expected bankruptcy outcome.
} 
uncorrelated with starting wages, and positively correlated with earnings three years after displacement.

Alternatively, however, positive residual wage growth of the final years at the firm could also result from increased 'risk' premiums paid to some workers to entice them to stay and fight the firm's demise. If such premiums are based on unobserved firm-specific skills only, we should expect that the residual is uncorrelated with search time after displacement and negatively correlated with the starting wage as well as with the wage earned after three years.

\subsubsection{The 'Fokker Survey'}

The mail-survey covers the labor market history of the three years after the displacement. The questionnaire was sent out in April 1999 to all 5506 workers in the survey population (see Table 7.1). In total, 2279 ex-Fokker workers returned completed questionnaires (response rate equals 41.4 percent. $^{6}$ ) In chapter 5 we report results of the non-response analysis. The survey results are of high quality for a self-administered mail survey. We could validate some of the given information by comparing the reported salary earned with Fokker to the information available from the administrative files. Many respondents were able to fill in the exact amount of gross monthly salary which they earned three years prior to the survey. In a validation study for the PSID, Bound, Brown, Duncan and Rodgers (1994) also find reported wages to be rather accurate on average. The mean error of log earnings found in Bound et al. (1994) is 0.007. This is of the same magnitude as the mean error of 0.006 in our study. The standard deviation of our sample is 0.34 . This is only slightly higher than the standard deviation of 0.32 reported by Bound et al. (1994).

The survey asked for information on the first and the current job. Respondents reported the date at which they started to work in the new position, their starting wage and hours worked. Information was also collected on the type of firm. We categorize new employers as belonging to the aircraft industry, other manufacturing industries, or non-manufacturing. The respondents were asked to assess their responsibility in their new job compared to that before displacement. On a five point scale, the middle cat-

\footnotetext{
${ }^{6}$ Surveys in the Netherlands have low response rates compared to the rest of Europe. Statistics Netherlands report 50\% and $60 \%$ response for the 'Quality-of-Life' and the 'Labor Force Survey' respectively. Labor Force Surveys in other European countries have response rates between 82 and 93\% (cf. Geuzinge, van Rooijen and Bakker (2000)).
} 
egory reflecting a similar level of responsibility, they could indicate 'more', and 'much more' responsibility on the one hand, or 'less' and 'much less' on the other hand. Furthermore, we collected information on the prerequisites for the new job - as perceived by the respondent -. Here the answer categories were: 'both their work experience and their technical knowledge obtained while working with Fokker was necessary to obtain the new job', 'only the work experience' or 'only the technical knowledge' was necessary, a category in which neither their experience nor their technical knowledge was strictly necessary, and finally as last category, neither work experience nor technical knowledge was necessary at all.

\subsection{Post Displacement Search Time}

In the survey a question asking for the labor market status of every month until three years after displacement was included. This information allows us to examine the time needed to find new employment. In the analysis presented we focus on the time it takes to find the first job after displacement. Following Meyer (1990) we included the remaining duration of unemployment benefits. Theoretically, the remaining duration of the unemployment benefits should have an effect on the duration of unemployment: unemployment benefits are the 'returns' during the search process. The higher they are the longer one can sustain searching for a job while maintaining a high reservation wage. Unemployment insurance covers some percentage of the former salary (the replacement ratio). The duration of the payments depends in our data on the employment history. Near the exhaustion point of the unemployment insurance payments, workers face the prospect of lower benefits. Hence, workers are more likely to accept any job offered. We include the remaining duration of the unemployment benefits for each worker in the form of splines. Note that the duration of benefits are pre-determined and known to the worker. In our sample the average duration of the benefits is 88 weeks.

Other explanatory variables are education, age, tenure, type of job activity while working with Fokker, and the hierarchical level achieved before displacement. A career can be identified by the hierarchical level achieved, but also within a hierarchy by the amount of lateral movements - i.e. across departments. The latter reflects job rotation intensity and can be interpreted as the workers' breadth of job experience. To capture this element we include the number of lateral movements within the last hierarchy achieved. Workers who do not find any employment in the period of 36 months are right censored. 
Table 7.2: Survival Analysis: Timing of First Employment after Displacement

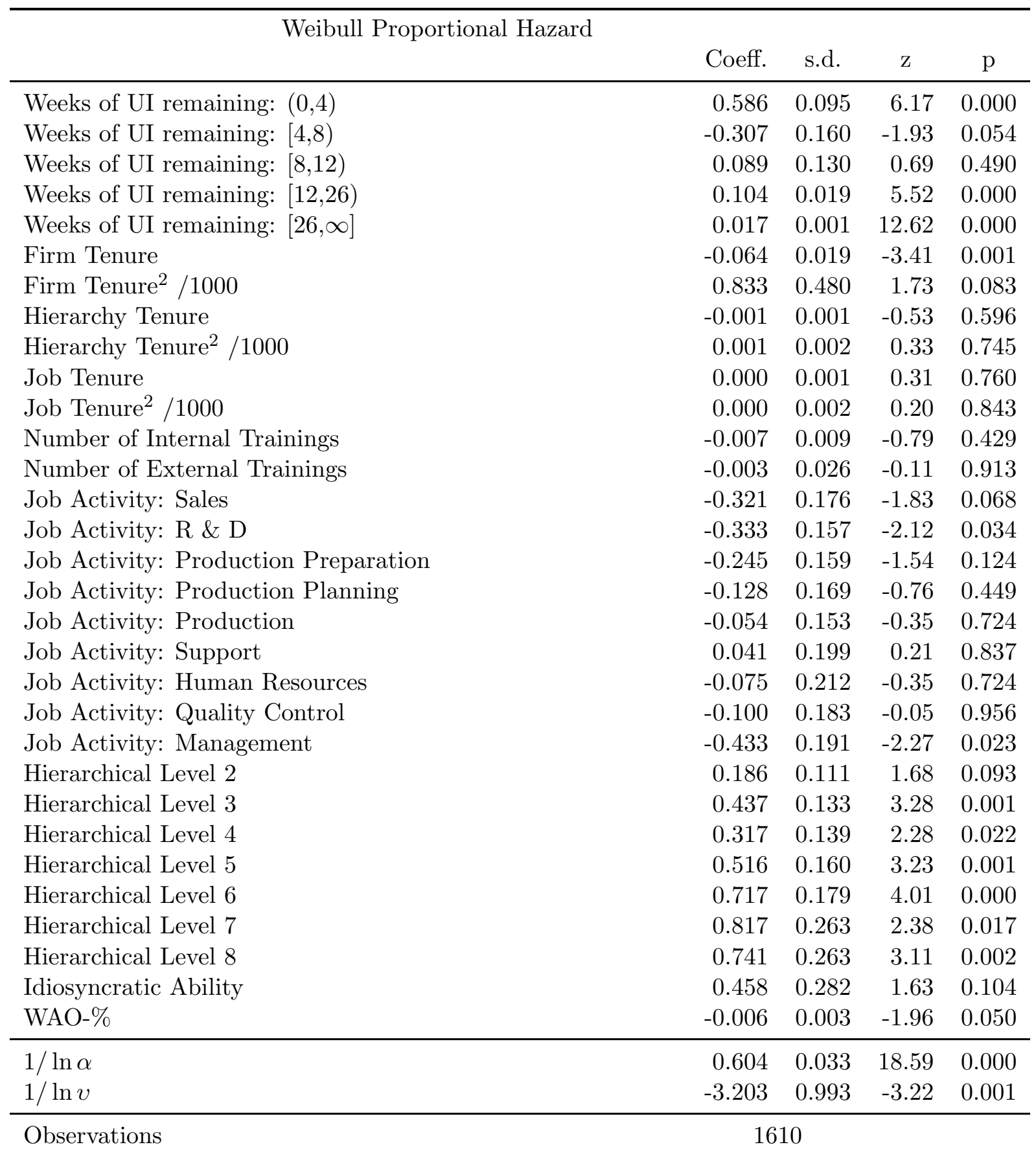

Notes: Weibull proportional hazard model with gamma frailty. The hazard is specified as $v \cdot \alpha t^{\alpha-1} \exp \left(\beta_{0}+X \beta\right)$. Where $v$ is assumed to follow a gamma distribution and $\alpha$ is the coefficient of the Weibull distribution. Failure event is the timing of first employment past the bankruptcy for all displaced workers. We control also for plant location and evaluation scores, age and education. Further we include dummies for gender and for marital status. Hierarchical levels 1 to 3 are blue collar production workers, 4-8 are white collar workers. Level 8 corresponds to a hierarchical level below the top-management. 
In the empirical analysis of the period of time it takes to find the first job, all workers who were offered a contract from the bankruptcy trustees are left out as they experience no initial unemployment spell. Additionally, we exclude those employees who do not classify themselves in the survey as unemployed because they have either started their own business ${ }^{7}$ (self-employment, $2.5 \%$ of sample), are full-time involved in voluntary activities or other types of unpaid work, receive disability pensions, or have retired since bankruptcy (together $2.2 \%$ of the sample).

Table 7.2 presents the estimation results of a proportional hazard Weibull model with gamma correction for unobserved heterogeneity. The data replicate the standard patterns found in the empirical literature. In summary we find the following results. ${ }^{8}$ Search time increases with age. Younger workers find new jobs faster. High-tenure worker also have longer search periods. With the exception of a shorter search time for graduates from technical universities, educational levels are insignificant. The hierarchical position is found to explain some of the time needed to find the first new job after displacement. Compared to the baseline category of the lowest hierarchy all (higher) hierarchical levels show shorter search periods, other things equal.

The remaining duration of unemployment benefits (in weeks) turns out to shorten the search time around the expiration time (Table 7.2). It does not have a significant effect for the splines of 4-8, or 8-12 weeks. The splines capturing the effects of UI benefits for periods longer than 12 weeks also indicate a shorter search time for longer remaining benefits. This last effect shows that not only around the exhaustion point, but also during the time in which benefits do not (threaten to) run out, new jobs are accepted. In our sample with high tenure workers and with a generous UI system many workers simply do not come near the exhaustion point. The average UI entitlement in our sample is 88 weeks which explains that many workers find employment while the remaining UI entitlement is still much longer than 12 weeks.

Search time is found to be inversely related to level of exit on the hierarchical ladder. More pre-displacement job responsibility increases the probability of finding new work after displacement. Workers higher in the hierarchy also found new jobs faster. Job

\footnotetext{
${ }^{7}$ Self-employment is one route out of unemployment. Given that the self-employment decision is complex and given that the self-employment income seems to differ significantly from wage outcomes of comparable employed individuals, we decided to exclude this group of workers. In fact Hamilton (2000) concludes: "[...] self-employment offers significant nonpecuniary benefits, such as 'being your own boss.' Many entrepreneurs have not only lower initial earnings than employees with the same observed characteristics but also lower earnings growth Hamilton (2000, page 628). In the specific data-set we use the incidence rate into self-employment is far below the usual numbers. We will thus disregard the small group of self-employed in this chapter.

${ }^{8}$ These estimates are not included in Table 7.2
} 
rotations do not show a significant effect with respect to the duration of subsequent unemployment.

In the previous Section 7.2 we argued that idiosyncratic ability is either negatively correlated with search time (general unobserved ability) or uncorrelated with search time (firm-specific risk premiums). Table 7.2 reports insignificance of the ability measure. This is evidence in favor of the idea that the firm in demise pays increasing risk premiums to workers to entice them to stay.

\subsection{Displacement Losses}

The wage difference between the pre-and post-displacement earnings is defined as

$$
\Delta W_{i} \equiv W_{i}^{a}-W_{i}^{F}
$$

where $W_{i}^{a}$ is the log monthly wage earned at the first new job by worker $i$ and $W_{i}^{F}$ is the log of the last monthly wage earned before displacement. The wage difference can be explained by observable characteristics $Z_{i}$ as follows.

$$
\Delta W_{i}=Z_{i} \beta+u_{1 i}
$$

where $\beta$ is a constant vector and $u_{1 i}$ is the residual unexplained by $Z_{i}$.

When post-displacement wages, $W_{i}^{a}$, are not available or unobserved, $\Delta W_{i}$ cannot be computed. The literature suggest to use as an upper bound of firm-specific human capital that can be lost upon transition from one firm to another the Mincer/Becker Ushaped tenure profile instead. Our data can replicate the standard tenure results. The fitted model of log wages at the day of displacement on tenure profiles, holding constant for education, age, and gender $\left(\hat{\alpha} X_{i}\right)$ yields (t-statistics are given in brackets):

$$
\begin{aligned}
& \ln \left(W_{i}^{F}\right)=.02 \text { Tenure }-.28 \text { Tenure }^{2} / 1000+\hat{\alpha} X_{i} \text {, with } R^{2}=.58 \\
& \text { (5.05) (-3.47) }
\end{aligned}
$$

We observe $\Delta W_{i}$ only for workers who found employment. For those workers the offered wage $W^{a}$ was above the reservation wage when the offer arrived. We thus only observe $\Delta W_{i}$ if

$$
\Delta W_{i}^{*} \equiv W_{i}^{a}-W_{i}^{R} \geq 0
$$

and write

$$
\Delta W_{i}^{*}=\Omega_{i} \gamma+u_{2 i}
$$


Where $\Omega_{i}$ is a vector of characteristics determining the reservation wage of worker $i$ and $u_{2 i}$ is a residual. We do not observe the reservation wage, but we do observe whether or not the worker found work as well as the starting salary $W_{i}^{a}$ at the new job. We also know $W_{i}^{F}$. We assume that

$$
\begin{gathered}
u_{1 i} \sim N(0, \sigma) ; \\
u_{2 i} \sim N(0,1) ; \\
\operatorname{corr}\left(u_{1 i}, u_{2 i}\right)=\rho .
\end{gathered}
$$

Then, the set of selection equations (7.3) and (7.4) can be written as the probability of having found an acceptable match as a linear function of characteristics $\Omega_{i}$ (Heckman 1979). To account for possible selection bias caused by non-randomness in finding new work, we need to identify differences between $Z_{i}$ and $\Omega_{i}$. $\Omega_{i}$ includes variables unobserved by the outside employers but known by the worker and to the former employer. The identifying variables should affect the worker's reservation wage but not the outside wage offer $W_{i}^{a}$. Two variables are used. One variable records short spells of temporary inability to work (WAO) while being employed at Fokker during the period 1987-1996. We assume that asymmetric information on individual well-being lowers the reservation wage but not the outside offer. The other variable included records the last job performance evaluation score at Fokker in 1996. Performance scores, unobserved by potential employers, are positively correlated with reservation wages as they are associated with the quality of work and possibly with the quality of search. But they are assumed to be unrelated to the distribution of outside offers.

\subsubsection{Displacement Losses: The First Job}

Table 7.3 displays results from simultaneously estimating the earnings difference equation (7.2) and the selection equation (7.4). We included pre-displacement job characteristics (panel a) as well as post-displacement job characteristics (panel b). Both types of variables are important in explaining variation in observed wage losses. In the Regression, we also controlled for the standard tenure profiles at the firm, rank, as well as at the job level. Once we have controlled for old and new job specifications, none of these experience profiles contribute to explaining observed wage losses.

The average wage loss predicted for the median worker in the sample is found to be 11.9 percent. This number is much closer to the loss found in the US based on individual workers' data, and much larger than the numbers reported for Europe based on administrative data. This may be due to the fact that these workers are very high 
Table 7.3: Estimates of Wage Differences

(a) Pre-Displacement Variables

\begin{tabular}{|c|c|c|c|c|c|}
\hline & Marg. Effect & s.e. & $\mathrm{t}$ & $\mathrm{p}$ & Mean \\
\hline Firm Tenure & -0.003 & 0.003 & -1.07 & 0.287 & 15.286 \\
\hline Firm Tenure $^{2} / 1000$ & 0.052 & 0.085 & 0.61 & 0.543 & 0.300 \\
\hline Hierarchy Tenure & 0.000 & 0.000 & 0.72 & 0.472 & 335.086 \\
\hline Hierarchy Tenure ${ }^{2} / 1000$ & -0.000 & 0.000 & -1.03 & 0.304 & 136.805 \\
\hline Job Tenure & -0.000 & 0.000 & -0.15 & 0.877 & 230.559 \\
\hline Job Tenure $^{2} / 1000$ & 0.000 & 0.000 & 0.40 & 0.689 & 77.705 \\
\hline Number of Internal Trainings & -0.001 & 0.002 & -0.84 & 0.400 & 2.232 \\
\hline Number of External Trainings & -0.004 & 0.005 & -0.74 & 0.458 & 0.579 \\
\hline Job Activity: Administration & \multicolumn{4}{|c|}{ - Reference - } & 0.067 \\
\hline Job Activity: Sales & -0.010 & 0.031 & -0.32 & 0.749 & 0.070 \\
\hline Job Activity: R \& D & -0.071 & 0.030 & -2.37 & 0.018 & 0.188 \\
\hline Job Activity: Production Preparation & -0.070 & 0.030 & -2.29 & 0.022 & 0.121 \\
\hline Job Activity: Production Planning & -0.046 & 0.032 & -1.44 & 0.151 & 0.068 \\
\hline Job Activity: Production & -0.063 & 0.030 & -2.12 & 0.034 & 0.269 \\
\hline Job Activity: Support & -0.061 & 0.038 & -1.61 & 0.108 & 0.038 \\
\hline Job Activity: Human Resources & 0.000 & 0.038 & 0.01 & 0.991 & 0.031 \\
\hline Job Activity: Quality Control & -0.083 & 0.035 & -2.38 & 0.017 & 0.070 \\
\hline Job Activity: Management & -0.004 & 0.030 & -0.13 & 0.893 & 0.078 \\
\hline Hierarchical Level 1 & \multicolumn{4}{|c|}{ - Reference - } & 0.469 \\
\hline Hierarchical Level 2 & -0.005 & 0.022 & -0.21 & 0.833 & 0.127 \\
\hline Hierarchical Level 3 & 0.025 & 0.026 & 0.96 & 0.336 & 0.113 \\
\hline Hierarchical Level 4 & 0.022 & 0.028 & 0.79 & 0.432 & 0.173 \\
\hline Hierarchical Level 5 & 0.054 & 0.032 & 1.71 & 0.088 & 0.111 \\
\hline Hierarchical Level 6 & 0.031 & 0.035 & 0.86 & 0.389 & 0.090 \\
\hline Hierarchical Level 7 & -0.037 & 0.049 & -0.76 & 0.445 & 0.022 \\
\hline Hierarchical Level 8 & 0.053 & 0.053 & 1.00 & 0.316 & 0.022 \\
\hline Number of lateral movements & 0.032 & 0.012 & 2.76 & 0.006 & 0.236 \\
\hline Idiosyncratic Ability & -0.011 & 0.004 & -2.55 & 0.011 & 0.084 \\
\hline
\end{tabular}


(b) Post-Displacement Variables

\begin{tabular}{|c|c|c|c|c|c|}
\hline & Marg. Effect & s.e. & $\mathrm{t}$ & $\mathrm{p}$ & Mean \\
\hline New Job: Much more responsibility & 0.011 & 0.018 & 0.60 & 0.548 & 0.123 \\
\hline New Job: More responsibility & 0.016 & 0.014 & 1.14 & 0.253 & 0.240 \\
\hline New Job: Same responsibility & \multicolumn{4}{|c|}{ - Reference - } & 0.313 \\
\hline New Job: Less responsibility & -0.048 & 0.014 & -3.31 & 0.001 & 0.210 \\
\hline New Job: Much less responsibility & -0.101 & 0.018 & -5.52 & 0.000 & 0.114 \\
\hline Not Industry & \multicolumn{4}{|c|}{ - Reference - } & 0.571 \\
\hline Other Industry & 0.020 & 0.012 & 1.61 & 0.107 & 0.269 \\
\hline Aircraft Industry & 0.042 & 0.015 & 2.69 & 0.007 & 0.160 \\
\hline $\begin{array}{l}\text { Technical knowledge and job experience neces- } \\
\text { sary }\end{array}$ & 0.027 & 0.017 & 1.64 & 0.100 & 0.208 \\
\hline Technical knowledge necessary & 0.063 & 0.027 & 2.32 & 0.020 & 0.041 \\
\hline Job experience necessary & 0.045 & 0.015 & 3.02 & 0.003 & 0.355 \\
\hline Technical knowledge \& experience useful & \multicolumn{4}{|c|}{ - Reference - } & 0.212 \\
\hline Neither experience nor technical knowledge & -0.037 & 0.017 & -2.18 & 0.029 & 0.184 \\
\hline$\hat{\rho}$ & 0.018 & 0.135 & & & \\
\hline Observations & & 1641 & & & \\
\hline Predicted $\Delta \log (\mathrm{W})$ & & -0.119 & & & \\
\hline
\end{tabular}

Note: Sample consists of all workers that were neither employed by the bankruptcy trustees nor by Aviation. Age, education, plant location, gender, and marital status are held constant in this regression. All wages are corrected to reflect gross monthly full time wages. 
tenured, quite old, and also probably worked for a high-wage firm. Given this, these results are probably not inconsistent with other European studies that look at a more representative set of displacements (see Kuhn (2002)).

The (pre-displacement)job characteristics variables reveal large differences in estimated wage losses due to different types of work. Compared to an administrative worker — who lost 11.9 percent — , R\&D workers lost 7.1 percent more, production workers lost 6.3 percent more, while workers in production preparation faced a higher wage loss of 7.0 percent. Quality control workers lost 8.3 percent more. Workers in sales, planning, support, human resources and management did not encounter significantly higher wage losses than administrative workers. Hierarchical levels do not explain variation in wage losses.

The variable indicating the number of lateral movements between job activities on the same hierarchical levels turns out to lower wage losses significantly. This is an indication that job rotation within the same hierarchical level lowers wage losses by 3.2 percent per 'rotation'. This result is very interesting. It suggests that not the level itself is important for finding a good match, but that the obtained level of generality within each level cushions displacement losses. This is most likely a result from the fact that workers who experienced more job rotations in the displacing firm have more opportunities to find similar jobs in a larger variety of firms.

For the post-displacement jobs characteristics we find that workers remaining with the same industry suffer less wage losses. Compared to workers leaving industrial jobs altogether, staying in the aircraft industry reduces wage losses by 4.2 percent. Compared to workers switching to other types of industries it can reduce wage losses by 2.2 percent. This corroborates results found for the US (Neal 1995). Workers who take on jobs for which their technical knowledge or their work experience was necessary see their wage losses diminish by 6 and 4 percent respectively. Note that job experience does not reflect (a) the time of the experience, nor (b) the specific firm where that experience was gained. Having jobs with lower responsibility increases wage losses. Somewhat lower responsibility translates to 5 percent wage losses, while much lower responsibility leads to 10 percent higher wage losses.

Idiosyncratic ability enters the wage loss equation significantly negatively. This is consistent with our prediction that Fokker had to pay a 'risk' premium to make workers stay during the period of demise. 
Table 7.4: Wage Losses Three Years after Displacement

\begin{tabular}{lrcrcc}
\hline & Marg. Effect & s.e. & $\mathrm{t}$ & $\mathrm{p}$ & $\mathrm{X}$ \\
\hline Months unemployed & -0.007 & 0.001 & -6.49 & 0.000 & 5.026 \\
Number of employers: 0 & -0.023 & 0.024 & -0.96 & 0.336 & 0.179 \\
Number of employers: 2 & 0.034 & 0.013 & 2.55 & 0.011 & 0.278 \\
Number of employers: 3 & 0.043 & 0.019 & 2.26 & 0.024 & 0.092 \\
Number of employers: 4 & 0.070 & 0.031 & 2.27 & 0.023 & 0.032 \\
Number of employers: $>4$ & 0.012 & 0.039 & 0.30 & 0.763 & 0.020 \\
Idiosyncratic Ability & -0.336 & 0.054 & -6.25 & 0.000 & 0.000 \\
Observations & & 1574 & & & \\
\hline Predicted $\Delta \log (\mathrm{W})$ & -0.025 & & \\
\hline
\end{tabular}

Note: We control also for age, firm, hierarchical and job tenure, as well as number of trainings, job activity, hierarchical level, lateral movements, new job responsibility, education, required knowledge, gender and marital status.

\subsubsection{Three Years Later: Testing the Ranking Model}

Until now, we have only considered the characteristics of the first job after the bankruptcy. In order to examine effects of wage losses over time and of the length of unemployment we re-estimate the wage loss regression, but now using the wage that was earned three years after the bankruptcy, at the time the survey was conducted.

The estimate of $\Delta W=W_{i}^{S}-W_{i}^{F}$ (where $W_{i}^{S}$ is the wage at the time of the survey) provides the opportunity to test Blanchard and Diamond's (1994) hypothesis of the ranking effect. The ranking effect assumes that firms receiving multiple acceptable applications hire the worker who has been unemployed for the shortest period.

The reason is that short unemployment spells signal — according to this theory good, but unobservable, behavior. Ranking and non-ranking models show similar unemployment dynamics and equilibrium wage outcomes, but different wage dynamics. The ranking model can be tested because in our survey we explicitly asked the respondents for detailed information on their employment history between the time of displacement and the time of the survey.

We define two additional variables in our model:

- the total amount of time unemployed between displacement and the date of the survey.

- the number of different employers between displacement and current job $(0=$ unemployed, 1 = current job is first job, 2 = current job is second job, etc.)

Both the ranking and the non-ranking model predict that the total time not worked 
enters the wage difference equation significantly negative. In the ranking model long unemployment duration signals below average skills. The ranking model assumes that the longer the inactive spell the lower the probability that a worker will be hired by another firm that can choose from multiple applicants. The ranking model would also predict the second variable to enter the wage difference equation significantly, whereas the non-ranking model would not. According to Blanchard and Diamond, given the unemployment duration having multiple employers reduces a worker's possibility to acquire a badge of good behavior. Thus multiple employers lower the matched wage. The non-ranking model would not predict the effect of multiple employers on wages to be that negative. Table 7.4 shows the effects of the two additional variables on wage losses after three years of displacement. The longer a worker was unemployed the higher the observed wage losses. This is consistent with the predictions of the ranking model as well as the non-ranking model. Every month of unemployment adds 0.65 percentage point to the observed wage loss. But having multiple employers is not harmful. Quite the contrary, having had more employers reduces wage losses. This is a refutation of the ranking model.

Idiosyncratic ability turns out to be significantly negative, and the effect is much higher than that estimated for the first job after employment. This is not in line with the prediction that unobserved ability would have a negative effect upon first employment which is subsequently diminished over time as the new employer learns about the ability of the new worker.

We rather find support for the alternative prediction of the effect of 'risk premium' that Fokker paid to keep workers whom they needed to stay in the period of demise. As other firms do not face distress they do not need to offer such a risk premium.

\subsection{Updating the Reservation Wage over Time}

Table 7.5 shows the evolution of the nominal wages of observed matches after the bankruptcy. It reflects the downward sloping curve so often portrayed in the search literature, and suggested to result from the endogenous interaction between search, duration of UI, adaptation of reservation wages, and hyperbolic discounting by the individual worker (Postel-Vinay and Robin 2002). How the adaptation of the reservation wage over time actually takes place is not well explained in the literature. Although often referred to as 'learning' and modelled as a stochastic process accordingly, it remains unclear how updating of the reservation wage actually occurs. Many view the 
Table 7.5: Average Salary and Number of Matches per 3 Month Period

\begin{tabular}{|c|c|c|c|c|c|c|c|c|c|c|c|}
\hline \multirow{2}{*}{$\begin{array}{l}\text { Time } \\
\text { period }\end{array}$} & \multirow{2}{*}{$\begin{array}{r}\operatorname{tp} 1 \\
<6 / 96\end{array}$} & \multirow{2}{*}{$\begin{array}{r}\operatorname{tp} 2 \\
<9 / 96\end{array}$} & \multirow{2}{*}{$\begin{array}{r}\text { tp } 3 \\
<12 / 96\end{array}$} & \multicolumn{3}{|c|}{$\operatorname{tp} 4$} & \multirow[b]{2}{*}{$<12 / 97$} & \multicolumn{4}{|c|}{ time period 5} \\
\hline & & & & $<3 / 97$ & $<6 / 97$ & $<9 / 97$ & & $<3 / 98$ & $<6 / 98$ & $<9 / 98$ & $\geq 9 / 98$ \\
\hline matches & 835 & 393 & 191 & 68 & 58 & 43 & 23 & 20 & 15 & 8 & 25 \\
\hline avg salaris & 5845 & 5237 & 5177 & 4964 & 4896 & 4120 & 3780 & 4225 & 3637 & 3543 & 4353 \\
\hline at risk & 1679 & 844 & 451 & 260 & 192 & 134 & 91 & 68 & 48 & 33 & 25 \\
\hline
\end{tabular}

Notes: The first three time periods refer to a three month period. I.e. < 6/96 refers to the period from March 1996 to June 1996.

The period geq 9/98 refers to the period September 1998 until the 1st of April 1999, when the survey was conducted. 
adaptation process as random, some say it depends on individual wealth (Bloemen and Stancanelli 2001). Randomness is often assumed to result from trial and error. In fact, for this to work a job-seeker needs the input of a large sequence of job-interviews. But invitations for interviews are rare, and once invited for an interview the rejection probability is remarkably low: 26.75 percent receive an offer which is rejected, however most of those workers have received multiple offers around the same time. If anything, the process should be one that is based on - often unobserved - unsuccessful applications that determine the reduction of reservation wages over time until a successful match is found.

We propose a different method of updating. It is based on the observation that after the bankruptcy many former employees became members of clubs where people meet regularly. Most of these clubs have a recreational purpose - we counted 14 different clubs, varying from a bowling club to a yoga club - and two more general interest organizations that are responsible for the clubs' activities. These are the Association of Former Fokker Employees, with 2,000 members, and the Community of Interests of Ex-Employees of Fokker, that had 1,100 members at the time we conducted our survey. Our assumption is simple. Rather than basing the consideration of when and by how much to adjust your reservation wage on idiosyncratic experiences alone we suggest that people in these clubs and organizations are informed about the successes and failures of people similar to them and that that information is used for updating. Although we do not have information on who was a member and how often people met, we do observe for every worker in the sample the characteristics of successful matches. The process of peer updating is modelled in the following way.

Each updating process needs time. We call this a period, and we assume that periods have similar lengths for all individual people. The risk set during each period consists of all workers who are job-seekers at the beginning of the period, $N_{t}$. A peer is defined as a worker with observable characteristics, $X_{i t}$, being similar to job-seeker $i$ in period t. $M_{t}>0$ workers find jobs during period $t$. Their matched wages and wage losses are observed by all other workers, and the wages of recently matched colleagues may be standing in for unobserved variations in local labor market conditions. At the beginning of each consecutive period the risk set has been reduced to $N_{t+1}=N_{t}-M_{t}$. In the first period, the relative reservation wage of worker $i$ is computed as:

$$
R W_{i 1}=f_{1}\left(\frac{W_{i 1}}{\bar{W}_{-i 1}}\right) ; i \in\left[1, N_{1}\right]
$$


where $W_{i 1}$ is the last wage earned before displacement, and $\bar{W}_{-i 1}$ is the average of all last wages earned by the other workers subject to displacement from the same firm.

In period $t>1$, we order all job-seekers in the previous period $t-1$ according to the observed successes in finding a job during that period, starting with the successful ones. Define $\hat{W}_{j t-1}$ as the observed matched wage in period $t-1$ by the individual successful worker $j, j \in\left[1, M_{t-1}\right]$, and define $W_{i t}^{*}$ as the expected wage at the beginning of period $t$ that would have been obtained by worker $i, \quad i \in\left[M_{t-1}+1, N_{t}\right]$ if a successful match is believed - by the job-seeker - to be independent of unobservable ability differences between fortunate workers and unfortunate job-seekers with similar characteristics, that is if matches would be thought of as strictly random among peers. We have

$$
\begin{gathered}
R W_{i t}=f\left(\frac{W_{i t}^{*}}{\bar{W}_{t-1}^{*}}\right), i \in\left[M_{t-1}+1, N_{t}\right], t>1 \\
W_{i t}^{*}=\operatorname{Pr}\left(I_{t-1}=1 \mid X_{i t}\right) \cdot E\left[\hat{W}_{i t-1} \mid X_{i t}\right] \\
\bar{W}_{t-1}^{*}=\operatorname{Pr}\left(I_{t-1}=1\right) \cdot \frac{1}{M_{t-1}} \sum_{j=1}^{M_{t-1}} \hat{W}_{j t-1}=\frac{1}{N_{t-1}} \sum_{j=1}^{M_{t-1}} \hat{W}_{j t-1}
\end{gathered}
$$

To calculate $R W_{i t}$ we need to specify how to obtain estimates for $\operatorname{Pr}\left(I_{t-1}=1 \mid X_{i t}\right)$ and for $E\left[\hat{W}_{i t-1} \mid X_{i t}\right]$. The first component is estimated as a simple Probit model of observed successful matches $\left(I_{t-1}=1\right)$ and unsuccessful workers $\left(I_{t-1}=0\right)$ during period $t-1$ given $X_{i t}$. The assumed randomness of successful matches among peers allows us to compute the simple OLS regression of observed matches on characteristics $X_{j t}$, and use the estimated coefficients to compute the predicted wage $E\left[\hat{W}_{i t-1} \mid X_{i t}\right]$. Finally, we assume linearity for the functional form $f_{t}(\cdot)$, so that

$$
R W_{i t}=\lambda_{t}\left(\frac{W_{i t}^{*}}{\bar{W}_{t-1}^{*}}\right)
$$

The parameters $\lambda_{t}$ will be estimated using a piecewise-constant hazard model suggested by Lancaster (1990) including the correction for heterogeneity as suggested by Murphy (1996). The likelihood function for this model is given in the Appendix of this chapter.

Table 7.6 gives the results of the estimation. The relative position of the expected wages turn out to be highly significant. All else equal they predict longer search for higher expected wages. This confirms the idea that workers learn over time and observe the matches of their coworkers rather than trying to learn from their labor market failures alone. Based on matches of their coworkers they extrapolate their chances of 
Table 7.6: Piece-wise Constant Hazard Model

\begin{tabular}{|c|c|c|c|c|}
\hline & Coeff. & s.d. & $\mathrm{z}$ & $\mathrm{p}$ \\
\hline $\mathrm{t} 1$ & -7.262 & 0.296 & -24.53 & 0.000 \\
\hline t2 & -7.532 & 0.299 & -25.20 & 0.000 \\
\hline t3 & -8.789 & 0.326 & -26.97 & 0.000 \\
\hline t4 & -6.363 & 0.293 & -21.68 & 0.000 \\
\hline t5 & -5.700 & 0.279 & -20.40 & 0.000 \\
\hline t $1 *$ relative wage position & 0.113 & 0.107 & 1.05 & 0.293 \\
\hline $\mathrm{t} 2 *$ relative wage position & 1.451 & 0.340 & 4.27 & 0.000 \\
\hline $\mathrm{t} 3{ }^{*}$ relative wage position & 6.804 & 0.591 & 11.50 & 0.000 \\
\hline $\mathrm{t} 4{ }^{*}$ relative wage position & -0.776 & 1.025 & -0.76 & 0.449 \\
\hline t $5 *$ relative wage position & 0.301 & 0.918 & 0.33 & 0.743 \\
\hline Idiosyncratic Ability & 0.484 & 0.280 & 1.73 & 0.084 \\
\hline $1 / \ln v$ & -13.881 & 185.741 & -0.07 & 0.940 \\
\hline Subjects & \multicolumn{2}{|c|}{1613} & & \\
\hline
\end{tabular}

Note: t1 to t5 represent the time specific intercepts. We also control for all other variables that are used in the first duration estimation.

finding a job and the market valuation of their skills. The first row of Figure 7.1 gives the distribution of the predicted chance that a worker will find new employment based on the observed matches of the previous period of his former colleagues. The second row presents the distribution of expected $(\log )$ wages also based on observed matches of former colleagues. The probability of employment times the expected wages - the third row - is the distribution of expected reservation wages. Note that the distribution is widely dispersed in the second time period, while it gets more concentrated in the later time periods. The estimated coefficients for the last two periods (time period four and five) are statistically insignificant.

Idiosyncratic ability is significantly negatively correlated with the first wage after displacement (Table 7.3), significantly negatively correlated with earnings three years later (Table 7.4), and positively but insignificantly correlated with search time (Table 7.6). From this we conclude that the residual of the wage growth equation does not reflect unobserved ability, but rather reflects increased 'risk' premiums paid by Fokker during the period of demise to prevent workers from leaving the firm. 
Figure 7.1: Development of Job Expectations, Predicted Wages and Wage Expectations
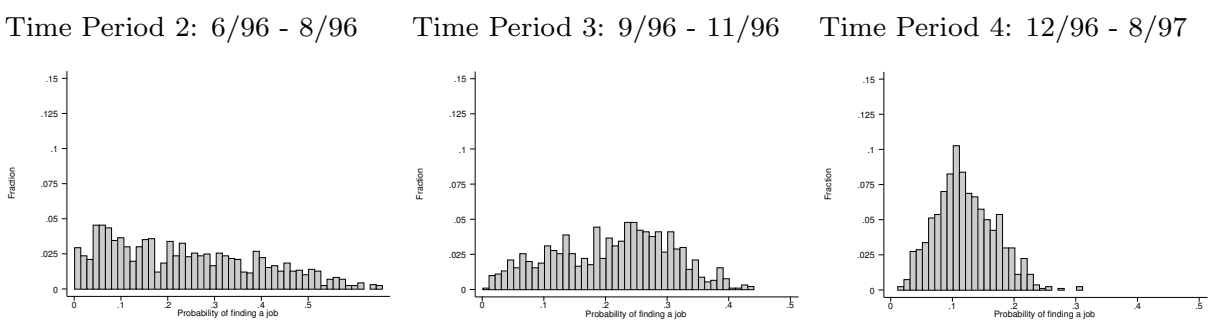

Probability of Finding a Job
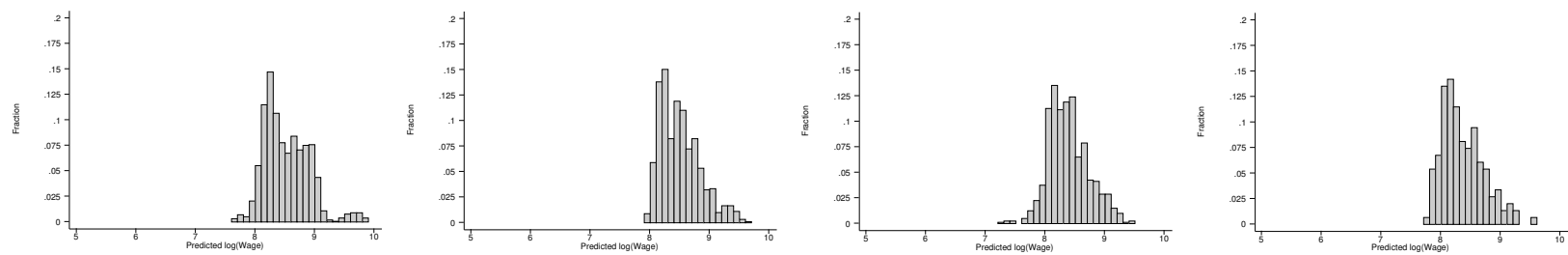

Predicted Wages

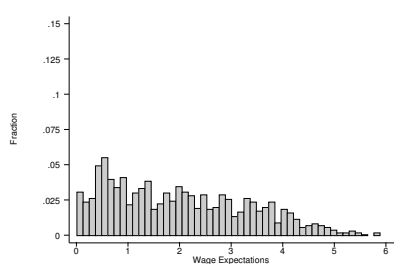

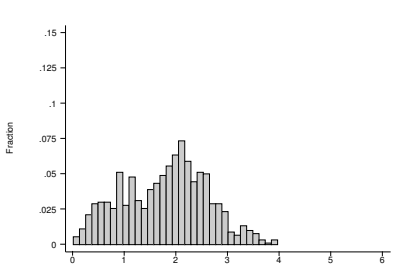
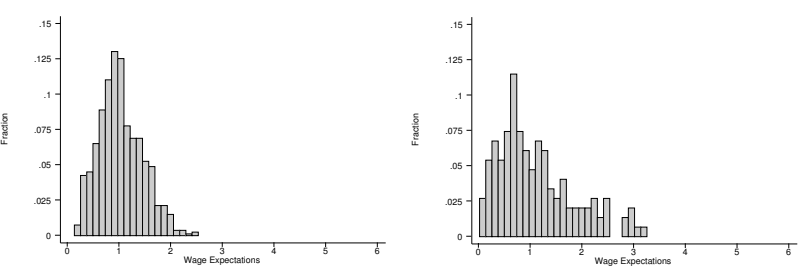

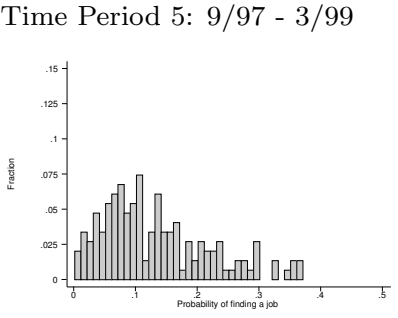

Wage Expectations 


\subsection{Conclusion}

We combined survey data from displaced workers and their personnel records from a bankrupt firm to investigate post-displacement differences in search time and earnings. We find that wage losses as a result of a displacement in the Netherlands are large and comparable to those found in the US. Since the workers in our data set are high tenured, relatively old, and probably worked for a high-wage firm, these results may not be inconsistent with other existing European studies that look at more representative sets of displacement.

Pre-displacement job-characteristics are found to be important predictors of both search time and earnings losses after displacement. Search time increases with age and tenure, whereas workers with a higher hierarchical position search significantly shorter than lower level workers. Although, the search-time seems to be largely unaffected by the specification of the job activity, it plays an important role in explaining displacement wage losses after displacement. The hierarchical level is inversely related to wage losses if employment is found within a year, while it has no effect afterwards. Pre-displacement lateral job movements reduce earnings losses by 3.2 percent per job rotation. The wagelosses of all workers together were estimated amount to 11.9 percent. Staying within the same industry decreased the initial wage losses, but this effect was insignificant after three years.

We analyzed the displacement effects of tenure with the firm, within ranks, and jobs. None of these tenure variables are found to contribute to explaining observed wage losses. Other information on characteristics of old an new jobs and how they differ nihilated the role of the variables traditionally suggested to represent firm-specific and not transferable on-the-job investments in productive human capital. This is surprising and possibly an important result. More research is needed that uses similar detailed information on pre- and post-displacement job-characteristics before we can draw further reaching conclusions. But for our data-set the explanation of firm-specific human capital to understand observed wage losses is not supported.

Our data refutes the Blanchard-Diamond (1994) ranking model. After a period of three years, workers who had multiple employers have lower wage losses.

Idiosyncratic ability, measured as the residual wage growth during the last three years at the displacing firm, turned out to be an important and insightful variable. Not because unobserved ability was found to be important to explain variation in post-displacement search time and wage losses, but because it revealed that the distressed firm had a wage 
policy of paying 'risk' premiums during its final years of existence to entice workers not to abandon the distressed firm.

Allowing workers to learn from the labor market experience of their former co-workers and basing their search strategy on matching results observed of workers similar to them is found to be an important explanation of the simultaneous dynamics of reservation wages and observed unemployment durations. Similar workers who found high wage jobs increase the unemployed peer worker's reservation wage as well as the predicted search time. Workers from higher hierarchical positions find a new job faster than their lower ranked counterparts. 


\section{Appendix A: The Econometric Specification of the Reservation Wage Updating Model}

Following Lancaster (1990) we divide the observation period into S intervals, let $c_{1}, c_{2}, \ldots, c_{S-1}$ denote the border of the interval. The hazard of a person $i$ for interval $s$ can then be written as

$$
\theta_{i}(t)=\mu_{i} e^{\lambda_{s}}, c_{s-1} \leq t<c_{s}, s=1,2, \ldots, S
$$

Let $\mu_{i}=\mu\left(X_{i}\right)=\exp \left(X_{i} \gamma\right)$ and let us define an indicator $d_{s}$ such that,

$$
d_{s}(t)=\left\{\begin{array}{l}
1 \quad \text { if } c_{s-1} \leq t<c_{s} \\
0 \quad \text { otherwise }
\end{array}\right.
$$

This indicator identifies the interval into which $t$ falls. Let us further define $D_{s}(t)=$ $\prod_{j=1}^{s}\left[1-d_{j}(t)\right], s=1,2, \ldots, S-1 ; D_{0}(t)=1$. The variable simply indicates whether $t$ falls at or after $c_{s}$.

Given possible heterogeneity due to some unobserved characteristics in the true $X^{*}$, we follow Lancaster and Nickell (1980) and Murphy (1996) in assuming that the heterogeneity can be captured in the single random variable $v$ with a distribution of function $H(v)$ and density $h(v)$. This is assumed multiplicative in the hazard which thus becomes:

$$
\theta_{i}\left(X_{i}^{*}, t\right)=v \mu_{i} \cdot e^{\lambda_{s}}
$$

The hazard rate of person $i$ for all $S$ periods then becomes:

$$
\theta_{i}\left(X_{i}^{*}, t\right)=v \mu_{i} \exp \left\{\sum_{s=1}^{S} \lambda_{s} d_{s m}\right\}
$$

The Survivor function can be written to be:

$$
\begin{aligned}
\Theta(t) & =\exp \left\{-v \int_{0}^{t} \theta_{i}(t)\right\} \\
& =\left\{\mu_{i} \sum_{s=1}^{S} e^{\lambda_{s}} d_{i m} e^{\lambda_{s}}\left[\left(t_{i}-c_{s-1}\right) d_{i s}+\left(c_{s}-c_{s-1}\right) D_{i s}\right]\right\}^{v}
\end{aligned}
$$

The likelihood contribution of person $i$ who is leaving unemployment or censored at $t_{i}$ 
is

$$
L_{i}=\delta_{i} \log \mu_{i}+\delta_{i} \log v+\delta_{i} \sum_{s=1}^{S} d_{i s} \lambda_{s}-\mu_{i} v \sum_{s=1}^{S} e^{\lambda_{s}}\left[\left(t_{i}-c_{s-1}\right) d_{i s}+\left(c_{s}-c_{s-1}\right) D_{i s}\right]
$$

With $\delta$ being an indicator variable that takes on the value one if the observation is not censored and zero otherwise. In order to write the log-likelihood more compactly, we define

$$
T_{i s}=\left[\left(t_{i}-c_{s-1}\right) d_{i s}+\left(c_{s}-c_{s-1}\right) D_{i s}\right]
$$

Then we can write the total log likelihood by summing over all $N$ observations.

$$
L=\sum_{s=1}^{S}\left[\delta_{i} \log \mu_{i}+\delta_{i} \log v\right]+\sum_{s=1}^{S} \lambda_{s} \sum_{i=1}^{N} d_{i s} \delta_{i}-\sum_{s=1}^{S} e^{\lambda_{s}} \sum_{i=1}^{N} v \mu_{i} \cdot T_{i s}
$$




\section{Job Offers, Reservation Wages and Acceptance in Local Labor Markets}

"[A recent textbook in labor economics] notes that formal intermediaries in the labor market are not widely used, and concludes that 'the worker who sets out to find employment very likely goes through a process of chasing down vague rumors or leads.' 'All too frequently,' it adds, 'the buyers and sellers, blindfolded by a lack of knowledge, simply grope about until they bump into each other.' I shall argue here that the analogies with commodity and security markets, even when qualified, are mischievous and misleading and that the effectiveness and advantages of informal networks of information have been too little appreciated. The search for information in any market has both an extensive and an intensive margin. A buyer can search at the extensive margin by getting a quotation from one more seller. He can search at the intensive margin by getting additional information concerning an offer already received. Where the goods and services sold are highly standardized, the extensive margin is the more important; when there is great variation in quality, the intensive margin moves to the forefront."

(Rees, 1966, p. 560) 


\subsection{Introduction}

In the previous chapter we have investigated how workers can learn from the experience of their peers. In this chapter this notion is pursued further on a geographical scale. We investigate the differences of the effects of displacement for workers from different regions. Using the standard search model to relate wages directly with the search time, we estimate the (reservation-)wages conditional on the search time and expected job offers.

We find an inverse relationship between percentage of the local population receiving social security and the number of job offers in a region. In a region with more firms the number of offers is also bigger. However, these effects do not have a significant impact on the 'hazard' of finding a job, implying that workers are less picky in the regions with dimmer employment prospects.

While reservation wages play a decisive role in accepting or rejecting job offers in theoretical search models, only few empirical studies have direct evidence on reservation wages. If indications of the magnitude of reservations can be obtained, it is usually based on single point surveys. Ideally, one would like to interview unemployed workers at fixed intervals and ask them for which wage they would be willing to accept a job offer. The relevant question is on the dynamics of the reservation wage, whether reservation wages decline over the course of an unemployment spell. The earliest empirical study is by Kasper (1967). His work, as those that follow in his footsteps, is to investigate the movement of reservation wage over the duration of the unemployment spell. Kasper investigates the determination of the reservation wage in relation to the last earned wage to investigate whether this reservation wage declines with longer unemployment duration. He uses information from unemployed workers informing the unemployment agency 'for which wage they would be willing to work'. He finds that those wages are generally less than those that they earned in previous jobs. Using a simple wage difference OLS regression on duration he finds that reservation wages decline by approximately 3 percent annually. Barnes (1975) uses a similar approach as Kasper but investigates the reason for this decline. He tries to identify whether the declining reservation wage is due to a decline in the expected returns to search (finite horizon) as suggested in Gronau (1971) or that it reflects a downward revision in the perceived wage offer distribution as proposed in McCall (1970). His result hints towards a 'learning explanation' for the decline in the reservation wage: workers revise their expectation of the wage offer distribution. It is this idea that we pursue in this chapter. We include in a standard equilibrium 
search model local economic conditions and former organizational relationships through which workers may learn about the labor market conditions and may receive referrals.

A second crucial element in theoretical job search models is the assumption of the distribution of offers, unemployed workers draw from. Not many studies have information on the number of job offers or model them explicitly. Notable exceptions include Stern (1989) and Jensen and Westergård-Nielsen (1987). Stern (1989) models how workers determine the optimal number of applications. Thus multiple offers per period are feasible. In a similar spirit Jensen and Westergård-Nielsen (1987) have examined the transition from school to work. Different from Stern (1989) they observe the number of offers.

In this chapter we will discuss a model of job search in which we include learning of the workers as well as information passing about local labor market conditions. Workers, being fired from their previous job, determine a reservation wage given the information on the job offer arrival rate and the mean of the wage offer distribution. Similar to Blau and Robins (1986) we have information on the number of job offers, but not their exact timing. ${ }^{1}$ We will hence follow their suit in instrumenting for the number of job offers by recovering the distribution of job offers, to then estimate the individual hazard rates. This identification of individual hazard rates allows us to recover the reservation wage distribution. Then we examine the influence of information about other job matches on the hazard finding a job and the reservation wage, as well as the influence of information passing among peers.

\subsection{Regional Job Offers}

It is quite common to assume that the offer arrival rate is a fixed Poisson process leading to a fixed (expected) number of offers arriving within a specific time period. Wolpin (1995, page 38) notes that in estimation of structural models,

"[J]ob offer probabilities tend to be low and acceptance rates high. Using different data sets and different formalizations of the job search model, Blau (1991) estimates the offer probability to be about 5 percent per week, Engberg (1991) about 2 percent and Wolpin (1987) about 1 percent per week. Acceptance rates are close to one in all of these studies." He concludes that " independently collected information on the number of rejected offers should show there to be few of them."

\footnotetext{
${ }^{1}$ We do, however, observe the exact timing of the offer that was accepted.
} 
Table 8.1: Number of Offers: Fokker Survey

\begin{tabular}{|c|c|c|c|c|c|c|c|c|c|c|c|c|c|}
\hline \multirow{2}{*}{$\begin{array}{l}\text { Local Region } \\
(2 \text { digit ZIP })\end{array}$} & \multirow[b]{2}{*}{ Obs. } & \multicolumn{6}{|c|}{ Number of Offers received } & \multicolumn{2}{|c|}{ Wage Fokker } & \multicolumn{2}{|c|}{ Wage } & \multirow{2}{*}{$\begin{array}{r}\text { Unemp. } \\
\text { mea }\end{array}$} & \multirow[t]{2}{*}{ Firms } \\
\hline & & 0 & 1 & 2 & 3 & 4 & $>4$ & mean & s.d. & mean & s.d. & & \\
\hline $10-14$ & 380 & 11.05 & 61.05 & 10.00 & 7.89 & 2.89 & 7.11 & 36 & 14 & 34 & 19 & 17.54 & 4.09 \\
\hline $15-20$ & 221 & 5.88 & 67.42 & 10.86 & 7.69 & 4.52 & 3.62 & 34 & 11 & 31 & 12 & 16.89 & 3.23 \\
\hline $21-24$ & 411 & 8.27 & 67.15 & 9.98 & 7.79 & 3.65 & 3.16 & 38 & 14 & 36 & 24 & 12.43 & 3.33 \\
\hline $25-27$ & 92 & 14.13 & 68.48 & 6.52 & 9.78 & 0.00 & 1.09 & 35 & 17 & 36 & 20 & 15.57 & 3.96 \\
\hline $28-31$ & 73 & 1.37 & 65.75 & 24.66 & 4.11 & 2.74 & 1.37 & 29 & 8 & 27 & 10 & 18.29 & 3.85 \\
\hline $32-33$ & 149 & 12.75 & 65.10 & 8.72 & 8.05 & 2.68 & 2.68 & 28 & 9 & 25 & 11 & 14.44 & 2.75 \\
\hline $34-39$ & 99 & 6.06 & 66.67 & 11.11 & 5.05 & 5.05 & 6.06 & 41 & 17 & 37 & 18 & 13.85 & 3.43 \\
\hline $40-42$ & 14 & 21.43 & 64.29 & 0.00 & 7.14 & 0.00 & 7.14 & 44 & 33 & 46 & 43 & 12.34 & 2.84 \\
\hline $47-49$ & 64 & 9.38 & 59.38 & 9.38 & 6.25 & 9.38 & 6.25 & 30 & 14 & 26 & 16 & 15.80 & 3.29 \\
\hline $43-46 \& \geq 50$ & 147 & 2.72 & 62.59 & 12.24 & 12.93 & 4.76 & 4.76 & 40 & 19 & 39 & 22 & 16.53 & 2.57 \\
\hline Total & 1650 & 8.55 & 64.85 & 10.61 & 8.00 & 3.64 & 4.36 & 35 & 15 & 34 & 20 & 16.08 & 2.93 \\
\hline
\end{tabular}

Notes: Number of Offers received gives the number of offers a worker reports he received prior to accepting his first job. Wage Fokker is the last hourly wage earned at Fokker. Wage is the hourly wage earned after displacement. Unemp. gives the proxy for unemployment. It is the population weighted percentage of inactive labor market population. Firms is a variable measuring the density of firms located in the region $(1=$ lowest $\ldots 9$ =highest $)$. 
We observe the number of offers received as well as which offers are rejected or accepted (cf. Table 8.1). Offers are identified in our data by a set of questions in the survey. A respondent is asked whether he received any specific job offer to work for an organization as well as some information on the 'best' offer rejected, if multiple offers were received. While we can see that most workers receive only one offer, a significant proportion receive multiple offers. Table 8.1 splits up the distribution of offers over two digit postal code (ZIP) areas of workers' home addresses. These areas were selected in order to form coherent geographical regions (cf. Figure 8.1). The total distribution of job offers shows that less than ten percent of the workers have not received any offer. Most workers have received only one offer, many of which have accepted this job offer. ${ }^{2}$ However, there is also a large proportion (more than 20 percent) of workers who report several job offers. The regional distribution of these job offers is also interesting. The regions, identified by the two digit postcodes 10-14, 25-27, 32-33 and 40-42 show a higher proportion of workers who did not receive any job offer.

\subsection{Role of Information}

The role of information on job search within networks of workers can be divided into two separate parts. Firstly, job searchers can be referred to new jobs, which means that not only do they get information about a possible position, but they are usually introduced to the new employer by someone that is already employed there. Secondly, job searchers can obtain information on the job market and their value by observing similar workers and job searchers. This allows the worker to get a realistic valuation of his skills upon which he can base his choice to accept or reject a job offer. We will model both effects by the ratio of job searchers to the entire network of former Fokker employees, while restricting networks to be regional. This regional restriction is done to increase the likelihood that workers met regularly and exchanged information.

\subsubsection{Job Referral}

Many jobs are filled by referral (Granovetter 1974). The advantage for the employer is that there is some screening of the new worker by an existing and known employee. One of the problems employers are facing, is that they want to find promising employees,

\footnotetext{
${ }^{2}$ Note though that respondents have the tendency to forget some job offers if they did not perceive them as attractive enough, especially if they have received such an offer several years ago, which can happen in our survey which asks questions over a retrospective time period of three years.
} 
Figure 8.1: Two digit Postcode Regions

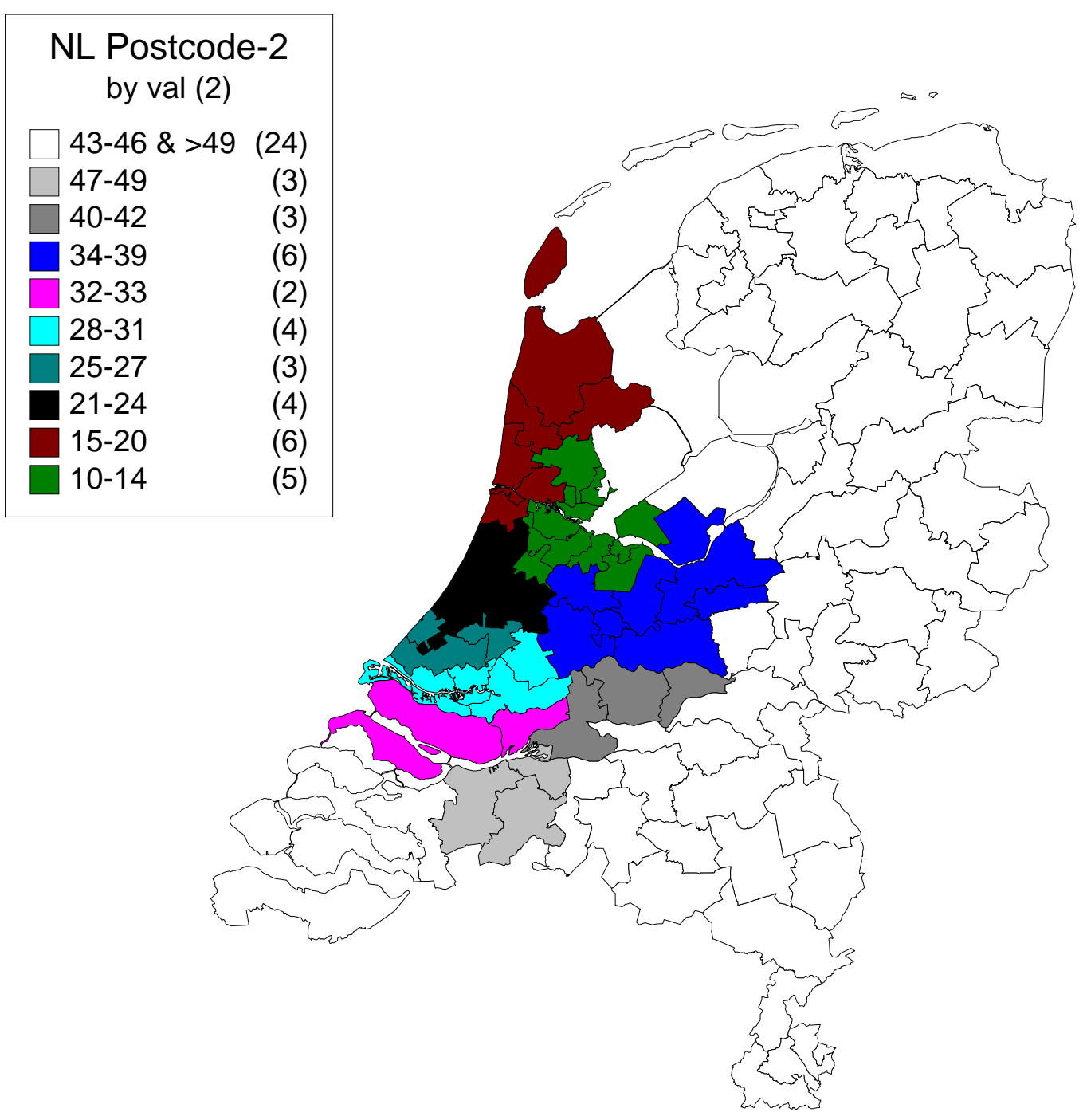

Notes: Gives all two digit postcode regions of the Netherlands. Shaded area's form regions of interest 
leading eventually to a job offer. Rees (1966) notes that referrals are one way to filter workers. Referrals are usually comparable to existing workers, hence they fit well into the company. Kugler (2003) develops an equilibrium matching model in which firms can choose to either use referrals or 'formal' methods of hiring. The former is assumed to have lower hiring costs and better suiting candidates, while the 'formal' methods are assumed to lead to more contacts, i.e. possibilities to hire. She shows that both hiring methods can coexist in equilibrium. After the displacement Fokker workers stayed in contact with each other. It is not uncommon that once a worker found employment new job offers within that firm were also transmitted to former employees of Fokker. The passing of information through 'informal' networks has been modelled by CalvóArmengol and Jackson (2001). They model information of job openings to be passed on to other members in the network by all employed workers. ${ }^{3}$ The more workers within the network are employed the higher is the likelihood that the information on job openings is passed on to the unemployed worker.

We will use the size of the fraction of those employed in the estimation of the conditional offers. A higher proportion of employed workers should lead to an increase in the amount of job offers passed through the informal channel as both the number of informants are increasing, but also the number of users - who do not pass on the information - are decreasing. We will restrict the network to be within similar hierarchical levels of the firm, as it is likely that those workers are homogenous with respect to jobs they search for, but are also likely to interact with each other. Hence, white and blue collar workers are assumed to have separate referral networks.

We will operationalize this by defining a ratio of employed and total population within the blue and white collar hierarchies identified by the subscript $l$ for every time period $t$, here measured in months:

$$
R_{l, t}=\frac{\text { Employed }_{l, t-1}}{\left(\text { Employed }+{\text { Unemployed })_{l, t-1}}\right.}
$$

We do not explicitly model the size of the network. However, as networks grow, several effects can take place: updating information through the network can be time consuming as there are many contacts made. On the other hand if information is passed on over several network nodes, we can see a "snowball" effect in the sense that information is getting accumulated regarding workers and that the information collected individually through network contacts will be passed on completely. Given sufficient time or through

\footnotetext{
${ }^{3}$ However, this is not specifically done for referrals. Rather the information flow is modelled, without any qualification or information passing other than the existence of an opening is taken into account.
} 
contacts of the network participants we would end up in a situation in which the agents have full information over all open positions available. However, as referrals also include an introduction of potential employees to employers it is doubtful that the referral network will go through several nodes.

\subsubsection{Neighborhood Networks}

Workers are not only searching for job openings, but they also have to determine their reservation wage $w^{r}$. This reservation wage is derived from the knowledge about the wage offer distribution, and their chances of getting a job offer. However, the wage offer distribution is not fixed over time, but rather changes as the economic situation and the institutional structure changes. Also, workers might not have unbiased perceptions on the wage offer distribution and tend to overestimate their chances on the labor market in the first instance, and gradually learn about their true wage offer distribution available. Böheim (2002) compares the relation of reported reservation wages of British unemployed job seekers to the predicted reservation wages. He finds that "job seekers are too optimistic relative to the model when reporting their reservation wage to an interviewer" (p. 13). These job seekers were interviewed at the beginning of their unemployment spell. They have some idea of the pay that is available for their background, but this is mostly based on experience on their previous job, rather than on actual job search (on or off the job). So it is natural for a job seeker to base his estimate of the available wage offer distribution on the wage he earned in his previous job. Only through job offers that he receives, and by informing about job offers or matches of colleagues can he adapt his expectation towards the actual wage offer distribution. ${ }^{4}$

Workers displaced from Fokker are high-tenured workers. It seems reasonable to assume that they do not have a full grasp of the wage offer distribution available to them. They will base their judgement about the expected wage offer distribution on their pre-displacement wage, and on the information they receive from offers and matches of co-workers. Many of the workers interact within their old social network of former Fokker employees; meeting former colleagues in social clubs directly or indirectly organized by their former colleagues. The three main plants employed the majority of workers and many workers settled in the vicinity of the plants, creating neighborhoods in which a high proportion was employed with Fokker. While former workers in these

\footnotetext{
${ }^{4}$ This is also in line with Bala and Goyal (1998) who theoretically model the learning process of networks. They also postulate that the agents of the network are basing themselves on their own experience and the information they receive through the network.
} 
neighborhoods did not necessarily work in associated groups within Fokker, they do have contacts and presumably exchange information on their job search experiences or successes.

The operationalization is similar to the referral network as we will again use the proportion employed. However, we will also generate an expected wage for all workers, so the information that is gathered through the neighborhoods consists of job openings that workers are alerted about, and the information on the wage distribution available to them.

$$
\begin{aligned}
I_{N, t} & =\left(\frac{\text { Employed }_{N, t-1}}{\left(\text { Employed }+{\text { Unemployed })_{N, t-1}}_{\text {Average } \text { Wages }_{N, t-1, \neq i}}\right.}\right) \\
& =\left(R_{N} ; I_{w}\right)
\end{aligned}
$$

Let us call the first part $R_{N}$ consisting of the ratio of employed over the total population of displaced workers in a neighborhood $N$. The neighborhood is identified by the two digit postal code (ZIP) as in Table 8.1. The second part $I_{w}$ gives the relative expected wage position of the displaced worker, which is derived from wages of comparable workers within the neighborhood given the probability of employment. ${ }^{5}$ We suggest that if $R_{N}$ increases, the number of job offers or job openings should also increase as more employed workers will pass information about available job openings on as they have no need for it themselves. An increase in wages paid should lead to lower acceptance rates, ceteris paribus.

\subsection{Search Model}

The underlying model is the basic model of search as in McCall (1970) and Gronau (1971). Let us define some discrete period of time $t$ and a valuation of the alternative use of a period of time $b$. A discount factor for future costs or benefits is defined as $\beta(t)$. $F(w)$ is used to denote the cumulative distribution function of the wage offers. Further, $q\left(n, t ; I_{n, t}\right)$ describes the probability distribution over the number of offers, $n$, received per period of length $t$. And let us denote the probability that the best of $n$ offers is less than or equal to $w$ given that $n \geq 1$ can be denoted by $G(w, n)$.

\footnotetext{
${ }^{5} \mathrm{~A}$ workers chance of finding employment is estimated by using a simple Probit estimation. The predicted wage is derived from a simple OLS regression of observed matches on the workers' characteristics. See also the updating process in Chapter 7
} 


$$
w=\max \left(w_{1}, \ldots, w_{n}\right)
$$

Let $W(w)$ present the value of stopping and accepting the best offer received, $w$, and working forever at that wage. $V(\cdot)$ is the value of searching during the next period, given today's information. The worker continues to search as long as $V(\Omega)>W(w)$. Where we can define the value of searching as

$$
V(\Omega)=(b-c(m)) t+\beta(t) E\left\{\max \left[V\left(\Omega\left(t_{0}+t\right)\right), w(x)\right] \mid \Omega\left(t_{0}\right)\right\}
$$

Here, $x$ is some random "best offer", $c(m)$ denotes search costs relative to search effort $m$, with cost increasing in search effort, and $\Omega\left(R_{l, t_{0}}, I_{n, t_{0}}\right)$ the information set available at time $t_{0}$, which is updated as time progresses and matches are observed. The value of searching can be solved to yield:

$$
\begin{aligned}
& V=(b-c(m)) t+\beta(t)\left[\sum_{1}^{\infty} q(n, t) \cdot \int_{0}^{\infty} \max [V, W(x)] d G(x, n)+q(0, t) V\right] \\
& \Leftrightarrow(1-\beta(t)) V=(b-c(m)) t+\left[\sum_{1}^{\infty} q(n, t) \cdot \int_{0}^{\infty} \max [V, W(x)] d G(x, n)\right]
\end{aligned}
$$

There exists a reservation wage $w^{r}$ such that

$$
W\left(w^{r}\right)=V
$$

We can rewrite the equation 8.3, the value of searching, to yield:

$$
r V=b-c(m)+\lambda \int_{0}^{\infty} \max [0, W(x)-V] d F(x)
$$

Jobs are accepted when the value of accepting the job is higher or equal to the the value of search. The wage that equalizes is called the reservation wage, denoted by $w^{r}$. Formally,

$$
r V=r W\left(w^{r}\right)=w^{r}
$$

Using the above in Equation (8.4), and after some rearrangement we get:

$$
\frac{\lambda}{r} \int_{w^{r}}^{\infty}(r W(x)-r V) d F(x)=c(m)+w^{r}-b
$$


As $r W(x)=x$ and $r V=w^{r}$, we get:

$$
\Rightarrow \frac{\lambda}{r} \int_{w^{r}}^{\infty}\left(x-w^{r}\right) d F(x)=c(m)+w^{r}-b
$$

If the participation constraint is fulfilled, which states that the expected returns of search must cover the search $\operatorname{costs} c(m)$, there is a reservation wage equalling the value of searching and higher than the alternative valuation, e.g. benefits.

$$
r V=w^{r}>b \text { iff } \frac{\lambda}{r} \int_{w^{r}}^{\infty}\left(x-w^{r}\right) d F(x)>c(m)
$$

\subsection{Data}

We use data from three sources. Fokker's electronic personnel data system provided information about workers'pre-displacement careers inside the firm. In 1999 post-displacement information was gathered through a mail survey among all workers who were laid off after the firm's bankruptcy. The 'Fokker Survey' collected data on the labor market experience for the three years following the workers' displacement. This survey data has been linked to the information from the personnel files. Finally, local labor market indicators as well as the density of plants are taken from the Statistics Netherlands' regional employment data. As an indicator of unemployment we use the population weighted average of inactive population.

\section{Regional Identification}

Regions are identified by the postal zip code. The Netherlands has a four digit zip code, in which lower level zip codes aggregate to larger regions. Two digit zip codes of workers' home addresses were necessary to aggregate sufficient respondents of the Fokker Survey while leaving a region that is still sufficiently small to allow and expect regional worker interaction. Often, several two digit zip codes were combined and compared to the remaining regions in the Netherlands. The aggregation over several ZIP codes was done in such a way that the areas form a coherent geographical region(cf. Figure 8.1 on page 204). 


\subsubsection{The Personnel Data}

From Fokker's personnel files we obtained information on each employee's type of job, compensation, and demographics. Demographic characteristics include date of birth, gender, education, marital status, and the hiring date of each employee. The average tenure at the time of bankruptcy was 15 years. The firm's hierarchy distinguishes 8 different levels below top management. The highest observable step, the eighth level, is just below the top management and the Board of Directors. For reasons of possible identification, the two upper levels (9 and 10) were left out of the data-set.

The hierarchical structure roughly reflects the division of unskilled versus skilled workers as well as the organization of supervision. Production workers are located in levels 1 to 3. Managers, engineers, and aircraft designers belong to levels 4 to $8 .^{6}$ Every position is 'allocated' to a job activity. These activities are Administration, Sales, Management, Human Resources, R\&D as well as Production Preparation, Production Planning, Support, Production and Quality Control. Job rotation is defined as the number of lateral job changes within a given hierarchical level. The lateral job change is a movement across job activities without changing the hierarchical position to a higher (or lower) level job. In addition to the normal tenure variable, we observe tenure within the hierarchy and tenure within a specific position (job). The latter two tenure variables were measured in months rather than years for the last position held before lay-off.

\subsubsection{The 'Fokker Survey'}

The survey asked for information on the first and the current job. Respondents reported the date at which they started to work in the new position, their starting wage and hours worked. Information was also collected on the type of firm. We categorize new employers as belonging to the aircraft industry, other manufacturing industries, or nonmanufacturing. The respondents were asked to assess their responsibility in their new job compared to that before displacement. On a five point scale, the middle category reflecting a similar level of responsibility, they could indicate 'more', and 'much more' responsibility on the one hand, or 'less' and 'much less' on the other hand. Furthermore, we collected information on the prerequisites for the new job - as perceived by the respondent -. Here the answer categories were: 'both their work experience and their technical knowledge obtained while working with Fokker was necessary to obtain the new job', 'only the work experience' or 'only the technical knowledge' was necessary,

\footnotetext{
${ }^{6}$ For a detailed description of the company's structure in 1987-1996 see Chapter 3.
} 
a category in which neither their experience nor their technical knowledge was strictly necessary, and finally as last category, neither work experience nor technical knowledge was necessary at all.

\subsection{Empirical Model}

As the wage offer distribution cannot be (directly) observed since we do not have information on all (rejected) wage offers, we can merely observe a wage offer $w^{0}$ if it is accepted:

$$
f\left(w^{0} \mid w^{0}>w^{r}\right)
$$

Flinn and Heckman (1982) point out that $f\left(w^{0}\right)$ can be derived from $f\left(w^{0} \mid w^{0}>w^{r}\right)$ given the conditional probability of accepting a wage offer:

$$
f\left(w^{0}\right)=f\left(w^{0} \mid w^{0} \geq w^{r}\right) \cdot\left(1-F\left(w^{r}\right)\right)
$$

Following Flinn and Heckman (1982), we assume the distribution of wage offers to be drawn from the log-normal distribution with means differing by worker based on their characteristics $(X \beta) .^{7}$

$$
\ln w_{0}=X \beta+\epsilon \text { with } \epsilon \sim N\left(0, \sigma^{2}\right)
$$

The mean of the truncated wage offer distribution is given by

$$
E\left(\ln w^{0} \mid w^{0} \geq w^{r}\right)=E\left(\ln w^{0} \mid \epsilon>\ln w^{r}-X \beta\right)=X \beta+\sigma M
$$

and the variance as

$$
V\left(\ln w^{0} \mid w^{0} \geq w^{r}\right)=V\left(\ln w^{0} \mid \epsilon>\ln w^{r}-X \beta\right)=\sigma^{2}\left(1-M\left(M+\left(X \beta-\ln w^{r}\right) / \sigma\right)\right)
$$

Where $M=f\left[\left(\ln w^{r}-X \beta\right) / \sigma\right] / F\left[\left(\ln w^{r}-X \beta\right) / \sigma\right]$. Flinn and Heckman (1982) suggest using the minimum accepted wage over the entire sample as a consistent estimator of the parameters of the untruncated wage offer distribution, $\beta$ and $\sigma^{2}$. However, this hinges on the homogeneity of the sample and is sensitive to measurement error in the wage data. Following Blau and Robins (1986) we therefore use the number of offers to

\footnotetext{
${ }^{7}$ Given the observations at or below zero, a mixture distribution might be more appropriate to accomodate for the few observations that are at or below zero. See Table 8.2.
} 
Table 8.2: Unconditional Mean Arrival Rate

\begin{tabular}{lrr}
\hline & \multicolumn{3}{c}{$\hat{\delta}$} & \\
\cline { 2 - 3 } Number of Expected Offers & Number of Workers & Percentage \\
\hline$\leq 0$ & 26 & 1.64 \\
$(0-1)$ & 383 & 24.13 \\
$(1-2)$ & 1064 & 67.04 \\
$(2-3)$ & 114 & 7.18 \\
\hline Total & 1587 & 100.00 \\
\hline
\end{tabular}

Notes: Unconditional mean arrival rate, $\hat{\delta}$, is estimated using a Tobit regression of the number of offers, correcting for the truncation at zero.

identify $\beta$ and $\sigma^{2}$.

The individual hazard can then be written to be:

$$
\tau_{i}=\delta_{i}(t) \cdot \Phi\left[\left(X_{i} \beta-\ln w_{i}^{r}(t)\right) / \sigma\right]
$$

Where $\Phi(\cdot)$ denotes the standard normal distribution function. The hazard function can in principle be estimated, however, identification of $\beta$ and $\sigma^{2}$ needs additional information. Given our data we will use information on the number of offers. Since many workers do not receive an offer, there is a mass point of observations at zero, and they are bounded from below at zero. This is the result of the truncation of offers which can be recovered using a Tobit regression for the conditional mean arrival rates:

$$
\delta_{i}(t)=P_{i} \delta+\epsilon_{1}
$$

Where $\epsilon_{1} \sim N\left(0, \sigma_{1}^{2}\right), P_{i}$ is a set of regressors. This gives us an instrument for the unconditional mean arrival rate for each worker. ${ }^{8}$ Secondly, we estimate the individual hazard rates, specified as

$$
\tau_{i}(t)=h(t) \cdot \exp \left(Z_{i} \Gamma\right)
$$

Where $Z_{i}$ includes $X_{i}$ and other observable variables that might affect the hazard rate. Using the estimated individual hazard and the estimated mean arrival rate we can calculate the acceptance probability for each worker $\left(\tau_{i}(t) / \delta_{i}(t)\right)$. The acceptance probability

\footnotetext{
${ }^{8}$ A similar methodology was also used in (Kiefer and Neuman 1979a), (Kiefer and Neuman 1979b), and (Kiefer and Neuman 1981), but with the job offer arrival rate set to one, as no information on the arrival rate was available to the authors. This was criticized by Flinn and Heckman (1982) as special case. In the more general case in which the offers are below one, recovery is impossible without additional information.
} 
allows us to recover the reservation wages from Equation (8.6):

$$
\ln w_{i}^{r}(t)=X_{i} \hat{\beta}-\hat{\sigma} \Phi^{-1}\left[\tau_{i}(t) / \delta_{i}^{c}(t)\right]
$$

The estimation thus goes through three steps. First the individual hazard is estimated. Second, using the Tobit regression, the unconditional mean arrival rate for each worker is estimated. From the individual hazard and the mean arrival rate the acceptance rate of the wage offers can be calculated. The last step is to estimate Equation (8.13) correcting for the acceptance rate.

\subsection{Empirical Results}

Before we discuss the variables on possible referral and learning, let us discuss the results of the other variables (cf. Table 8.3). First of all we have four variables indicating the time at which a worker has started to search for a new job. Workers might have anticipated their job loss - or even the closure of the firm - and hence started searching before the firm went bankrupt. From the information in the survey we constructed an indicator variable as to whether the worker started to search before the bankruptcy (Job search started before bankruptcy), and the amount of weeks searched before the bankruptcy date (Number of weeks before bankruptcy). Workers might also have started early to search for a new job several weeks after they were actually informed about the bankruptcy. This is captured in the indicator variable Job search started after the bankruptcy, and the number of weeks are used in the accompanying variable (Number of weeks after bankruptcy). As can be expected, workers that have started early to search for new employment have a higher chance of finding a new job quickly. It also increases the predicted reservation wage somewhat. Starting late, on the other hand, does not significantly increase the search time. It does however lead to lower reservation wages. The effect on the reservation wage makes sense for both variables, as in the first case, workers search while still being employed. They have a longer search horizon, and hence can afford to be selective in the jobs that are to be accepted. Workers that started to search some weeks after the bankruptcy are also aware of the fact that they did start late, and that they have a shorter time to find new employment. Hence, they adjust the expected reservation wage downward.

The expected search time is decreasing relative to the hierarchical level of a worker. Analogously, the number of (expected) offers are increasing with the level of the hierarchy. Higher hierarchical levels usually go along with more exposure of a worker to 
Table 8.3: Regression Results

\begin{tabular}{|c|c|c|c|}
\hline & $\begin{array}{r}(1) \\
\text { Time }\end{array}$ & $\begin{array}{r}(2) \\
\text { Offers }\end{array}$ & $\begin{array}{r}(3) \\
\text { Log Wage }\end{array}$ \\
\hline Local relative wage position & $\begin{array}{r}0.743 \\
(0.281)\end{array}$ & & $\begin{array}{r}0.394 \\
(0.084)\end{array}$ \\
\hline Ratio of employed workers within region & $\begin{array}{r}9.188 \\
(0.608)\end{array}$ & $\begin{array}{r}0.898 \\
(1.141)\end{array}$ & $\begin{array}{r}0.845 \\
(0.187)\end{array}$ \\
\hline Ratio of employed workers within layer ${ }^{1}$ & $\begin{array}{r}0.117 \\
(0.476)\end{array}$ & $\begin{array}{r}1.364 \\
(0.828)\end{array}$ & $\begin{array}{l}-0.089 \\
(0.121)\end{array}$ \\
\hline Job search started before bankruptcy & $\begin{array}{r}0.287 \\
(0.075)\end{array}$ & $\begin{array}{r}0.046 \\
(0.133)\end{array}$ & $\begin{array}{r}0.030 \\
(0.021)\end{array}$ \\
\hline — number of weeks before bankruptcy & $\begin{array}{r}-0.008 \\
(0.003)\end{array}$ & $\begin{array}{r}-0.001 \\
(0.006)\end{array}$ & $\begin{array}{r}0.000 \\
(0.001)\end{array}$ \\
\hline Job search started after bankruptcy & $\begin{array}{r}0.036 \\
(0.067)\end{array}$ & $\begin{array}{r}0.320 \\
(0.112)\end{array}$ & $\begin{array}{l}-0.050 \\
(0.017)\end{array}$ \\
\hline — number of weeks after bankruptcy & $\begin{array}{r}-0.020 \\
(0.006)\end{array}$ & $\begin{array}{r}-0.004 \\
(0.008)\end{array}$ & $\begin{array}{r}-0.002 \\
(0.001)\end{array}$ \\
\hline Hierarchical Level 2 & $\begin{array}{r}0.169 \\
(0.096)\end{array}$ & $\begin{array}{r}-0.009 \\
(0.157)\end{array}$ & $\begin{array}{r}0.089 \\
(0.025)\end{array}$ \\
\hline Hierarchical Level 3 & $\begin{array}{r}0.520 \\
(0.121)\end{array}$ & $\begin{array}{r}0.104 \\
(0.183)\end{array}$ & $\begin{array}{r}0.212 \\
(0.032)\end{array}$ \\
\hline Hierarchical Level 4 & $\begin{array}{r}0.585 \\
(0.151)\end{array}$ & $\begin{array}{r}0.134 \\
(0.198)\end{array}$ & $\begin{array}{r}0.348 \\
(0.041)\end{array}$ \\
\hline Hierarchical Level 5 & $\begin{array}{r}0.733 \\
(0.198)\end{array}$ & $\begin{array}{r}0.330 \\
(0.232)\end{array}$ & $\begin{array}{r}0.450 \\
(0.057)\end{array}$ \\
\hline Hierarchical Level 6 & $\begin{array}{r}0.658 \\
(0.264)\end{array}$ & $\begin{array}{r}0.369 \\
(0.258)\end{array}$ & $\begin{array}{r}0.491 \\
(0.075)\end{array}$ \\
\hline Hierarchical Level 7 & $\begin{array}{r}-0.155 \\
(0.382)\end{array}$ & $\begin{array}{r}0.342 \\
(0.375)\end{array}$ & $\begin{array}{r}0.561 \\
(0.112)\end{array}$ \\
\hline Hierarchical Level 8 & $\begin{array}{r}0.577 \\
(0.504)\end{array}$ & $\begin{array}{r}0.928 \\
(0.415)\end{array}$ & $\begin{array}{r}0.528 \\
(0.140)\end{array}$ \\
\hline Evaluation: Unsatisfactory & $\begin{array}{r}-1.183 \\
(0.287)\end{array}$ & $\begin{array}{r}-1.124 \\
(0.429)\end{array}$ & $\begin{array}{r}0.130 \\
(0.088)\end{array}$ \\
\hline Evaluation: Very good & $\begin{array}{r}0.158 \\
(0.067)\end{array}$ & $\begin{array}{r}0.060 \\
(0.113)\end{array}$ & $\begin{array}{r}0.002 \\
(0.017)\end{array}$ \\
\hline Evaluation: Excellent & $\begin{array}{r}0.516 \\
(0.113)\end{array}$ & $\begin{array}{r}0.412 \\
(0.189)\end{array}$ & $\begin{array}{r}-0.003 \\
(0.029)\end{array}$ \\
\hline$-\sigma$ & & & $\begin{array}{r}-0.324 \\
(0.041)\end{array}$ \\
\hline $\begin{array}{l}\text { Observations } \\
\text { R-squared }\end{array}$ & 13500 & 1435 & $\begin{array}{r}1161 \\
0.66\end{array}$ \\
\hline
\end{tabular}

Notes: (1) is a parametric duration model with Weibull distribution. (2) is the Tobit regression of the number of offers, (3) is the wage regression of log monthly wages including the correction factor $-\sigma$. All regressions also include variables of Table 8.4, a constant and variables for age, tenure, and education level. Standard errors are given in parentheses below the coefficient estimates. The ratio of employed workers within layer is calculated separately for blue and white collar workers. 
Table 8.4: Regression Results - Local Variables

\begin{tabular}{lrrr}
\hline & $\begin{array}{r}(1) \\
\text { Time }\end{array}$ & $\begin{array}{r}(2) \\
\text { Offers }\end{array}$ & $\begin{array}{r}\text { Log Wage } \\
\text { Postcode 10-14 }\end{array}$ \\
& -0.531 & 0.149 & -0.086 \\
Postcode 15-20 & $(0.142)$ & $(0.243)$ & $(0.039)$ \\
& -0.365 & 0.109 & -0.076 \\
Postcode 21-24 & $(0.154)$ & $(0.261)$ & $(0.041)$ \\
& -0.328 & -0.237 & -0.086 \\
Postcode 25-27 & $(0.156)$ & $(0.273)$ & $(0.041)$ \\
& -0.472 & -0.510 & -0.037 \\
Postcode 32-33 & $(0.175)$ & $(0.297)$ & $(0.047)$ \\
& -0.306 & 0.148 & -0.076 \\
Postcode 34-39 & $(0.173)$ & $(0.287)$ & $(0.045)$ \\
& -0.684 & -0.070 & -0.116 \\
Postcode 40-41 & $(0.179)$ & $(0.311)$ & $(0.048)$ \\
Postcode 47-49 & 0.444 & -0.287 & 0.035 \\
\% Local Unemployed ${ }^{1}$ & $(1.015)$ & $(1.765)$ & $(0.249)$ \\
& -0.389 & 0.417 & -0.120 \\
Density of Firms in Region $[1-9]^{2}$ & $(0.190)$ & $(0.319)$ & $(0.050)$ \\
& -0.026 & -0.082 & -0.001 \\
& $(0.019)$ & $(0.033)$ & $(0.005)$ \\
Observations & 0.056 & 0.316 & -0.012 \\
R-squared & $(0.094)$ & $(0.158)$ & $(0.024)$ \\
\hline
\end{tabular}

Notes: (1) is a parametric duration model with Weibull distribution. (2) is the Tobit regression of the number of offers, (3) is the wage regression of log monthly wages including the correction factor $-\sigma$. All regressions also include the variables of Table 8.3, a constant and variables for age, tenure, and education level. Standard errors are given in parenthesis below the coefficient estimates.

${ }^{1}$ This is measured as a the percentage of the population between 25 and 64 who is not employed.

${ }^{2}$ The Density is on a scale from 1 to 9 , where 1 is the lowest density and 9 the highest. 
Figure 8.2: Development of Reservation versus First Accepted Wage

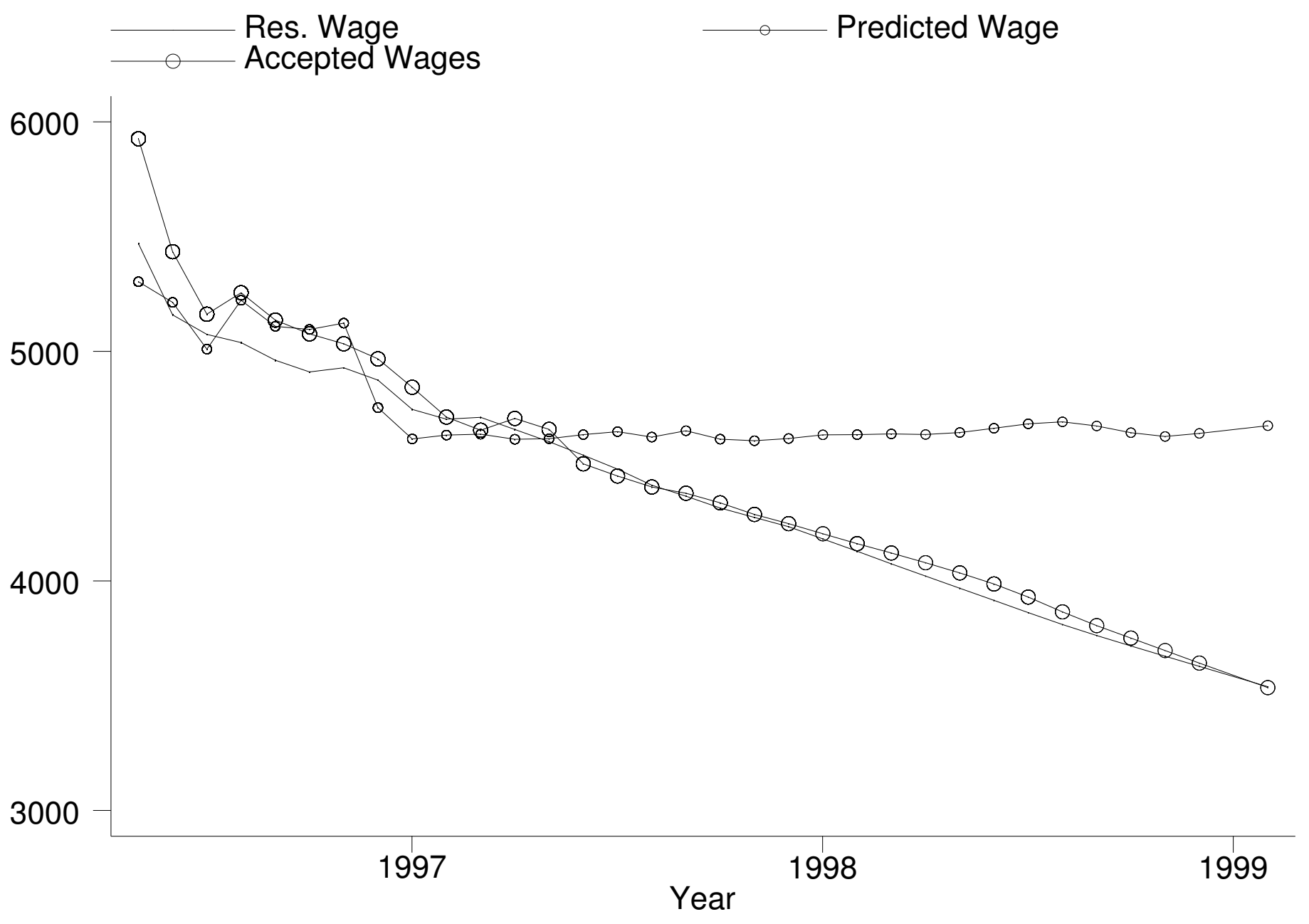

Notes: All wages are presented to reflect monthly gross wages in Dutch guilders. They are smoothed over all observations using a nearest neighbor density estimator. Predicted wages are wages predicted without correcting for job offers and job acceptance. Accepted wages are the observed wages accepted at different points in time. 
Figure 8.3: Reservation Wages for Selected Regions
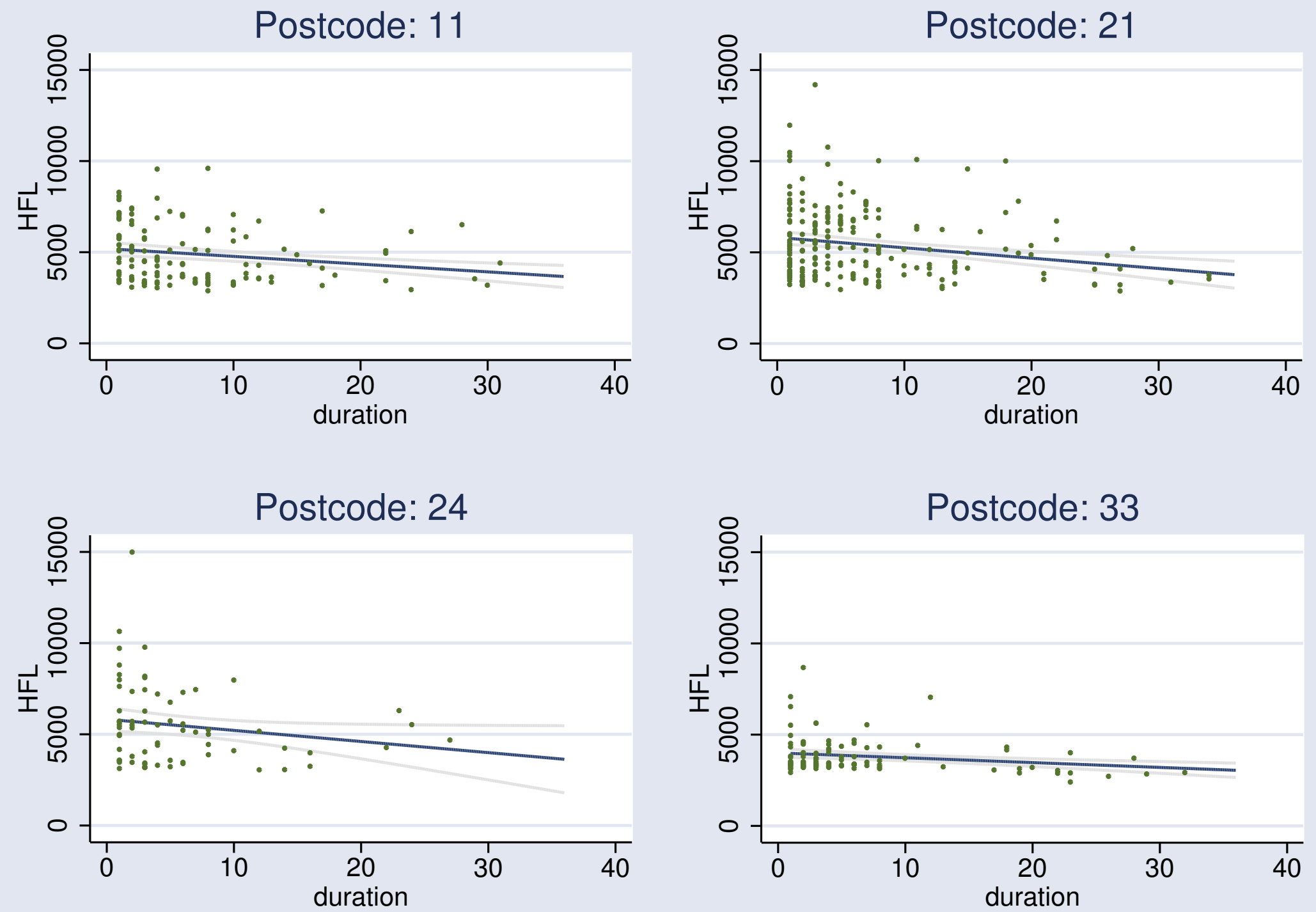

The graph gives the linear prediction as well as a scatter plot of the estimated reservation wages over the duration of job search. Bands give the 95 percent confidence intervals. All salaries are in Dutch Guilders (HFL) and reflect monthly wages, while the duration is in months. 
Figure 8.4: Accepted Wages for Selected Regions

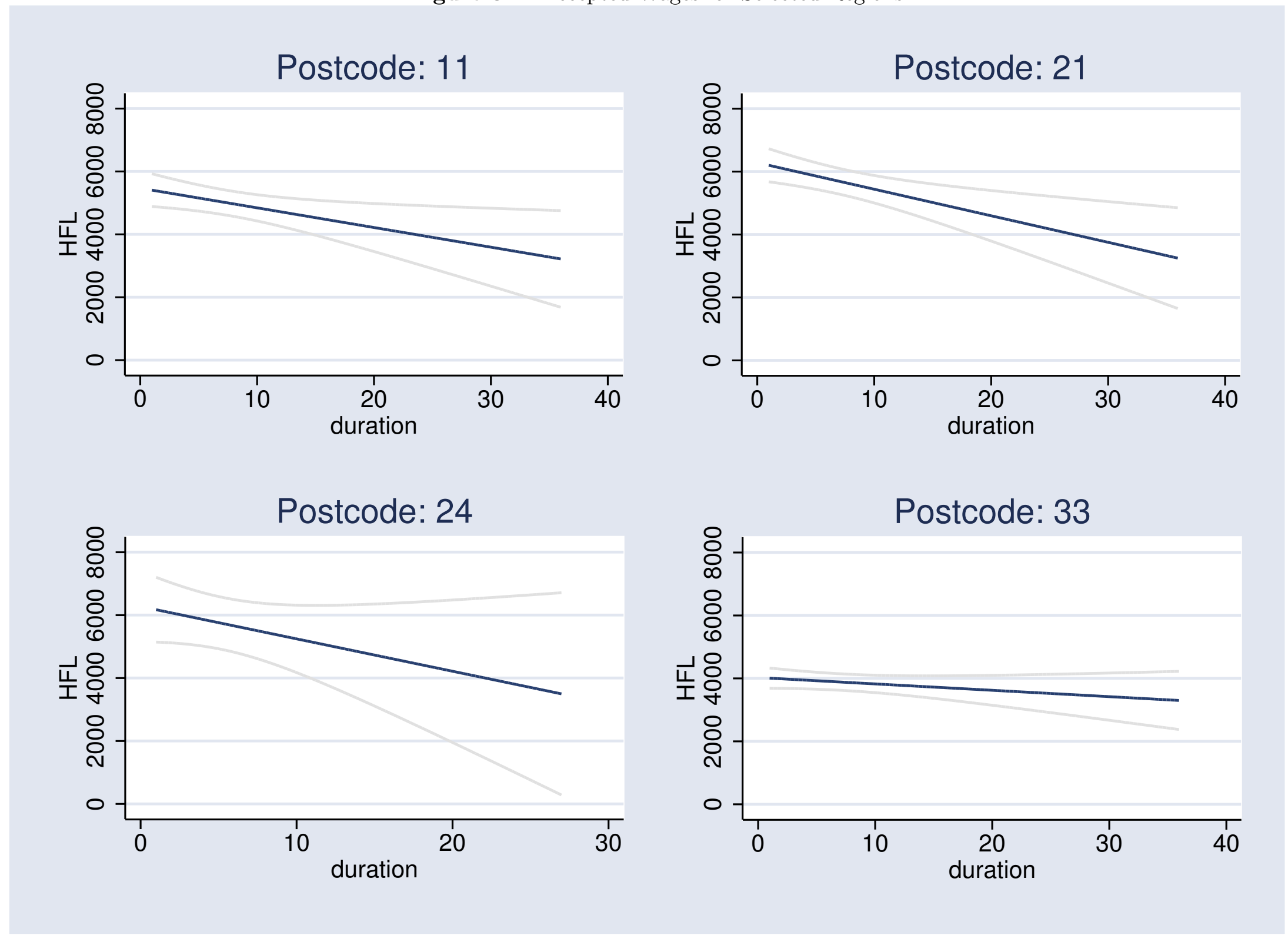

Notes: The graph gives the linear prediction of the accepted wages over the duration of job search. Bands give the 95 percent confidence intervals. All salaries are in Dutch Guilders (HFL) and reflect monthly wages, while the duration is in months. 
people outside of the firm and can hence lead to more job offers.

The evaluation also shows that compared to an average evaluation score, those that were below average also search much longer and have lower chances of receiving job offers. This can be both an effect of a worker's type, i.e. a worker that under-performs in their job also under-performs in job search. But he could also receive less job referrals from former colleagues, family, or friends, as those people are likely to know that the person performs below average. A worker that performs above average, on the other hand, has shorter search duration and more job offers. There is, however, no effect on the reservation wages of the evaluation score. We also included variables to correct for tenure, age, and education. As they turn out insignificant, we do not report the result in Table 8.3, nor do we discuss the results here.

We have proxied referral networks by the proportion of employed workers within the same hierarchical layer. Workers of the same layer are most likely to interact with each other, but also most likely to come across job openings suitable for their fellow workers of the same hierarchical level. While it is definitely not true that all workers of one hierarchical level are employed in similar jobs, or even know each other, it is true that the chance that they know each other is higher within the hierarchical level than across. The variable Ratio of employed workers within layer is updated over time, taking into account all changes that happened in the past. We can see that an increase in the ratio, i.e. an increase of employed workers, leads to shorter search time and more job offers being received.

Similar to the referral networks over hierarchical layers, one can also argue for information flows among workers that live close to each other. This local proximity is likely to lead to more information exchange and job referrals compared to workers that live far apart. However, in this context, job openings that are known and passed on are less likely to be suitable for a worker, as they are not necessarily similar — as was the case among workers in the same hierarchy. Local proximity will probably lead to more informal exchanges among workers than similar backgrounds (in terms of hierarchical level) would warrant. ${ }^{9}$ We have determined local proximity by the two digit postal code. The local ratio of employed workers among the entire (Fokker) population is also negatively related to the search time. However, different from the referral networks within hierarchical layers, the expected number of offers is not (significantly) increased with higher ratios of employed workers. This could be interpreted to conform with the earlier

\footnotetext{
${ }^{9}$ As we pointed out in the previous chapter, there was and still is (organized) interaction among former Fokker employees. This interaction within (social) clubs allows regular encounters and the exchange of information.
} 
suggestion, that while information is exchanged (even more frequently), relatively less referrals are taking place, as workers differ more.

For the same local regions that we used to calculate the ratio of employed persons among the Fokker population, we calculated a wage position of the worker. A worker is assumed to observe the wage realizations within the local neighborhood of his former co-workers. Further, by the new levels of employment realized he calculates his chance of reemployment. Together this forms the expected wage. This expected wage is then evaluated relative to the average wage paid to former co-workers in his neighborhood, yield the Local relative wage position. We can see in Table 8.3 that a higher position, i.e. higher expected wages, leads to shorter search times and to higher reservation wages.

Figure 8.2 summarizes the development of the reservation wage over time. The line with small circles gives the development of the predicted wages of workers if we had not corrected for the number of offers and the duration of search. The line with bigger circles gives development of the observed accepted wages. The normal line, finally, gives the predicted reservation wage. It can be clearly seen that the reservation wage is falling over time. This cannot be due to a composition effect of (observed characteristics of) the workers, as we would expect the predicted wage to fall as well. Further we can note that the initially accepted wages are much higher than the reservation wages, but that after a year of job search, reservation wages and accepted wages coincide. This can be explained by the fact that workers who accept jobs shortly after the bankruptcy got good job offers, i.e. at the higher end of the job offer distribution, but also that learning and information passing among the workers will lead them to accept wage offers on their reservation wage, even if this means that compared to their former Fokker salary, they encounter wage losses.

\subsubsection{Regional Differences}

The regression results of Table 8.4 show that almost all regions that have a larger group of former Fokker employees living there, have longer search times than those workers that happen to live farther away from the plants, and are not in a region with many former Fokker employees. We see also that the local economic condition has a significant impact on the number of job offers, but not on the wage or the search time. This implies that the acceptance ratio of job offers in regions with higher unemployment and fewer firms is higher. Workers seem to know that job offers are sparse and therefore will accept jobs more readily. Wages are lower in those regions that are close to the plants. Postcode 10-14, 21-24, and 34-39 are all around the three plants that were closing down. Note 
Table 8.5: Interquartile range of search time, accepted salary and reservation wage

\begin{tabular}{lc|rrr|rrr|rrr}
\hline Postal Code & Obs. & \multicolumn{3}{|c}{ Search Time } & \multicolumn{3}{c}{ Accept. Salary } & \multicolumn{3}{c}{ Reservation Wage } \\
(Two Digit) & & q25 & q50 & q75 & q25 & q50 & q75 & q25 & q50 & q75 \\
\hline $10-14$ & 380 & 2 & 5 & 14 & 3600 & 4700 & 6000 & 3490 & 4382 & 5914 \\
$15-20$ & 221 & 2 & 4 & 8 & 3500 & 4375 & 6000 & 3424 & 4348 & 5799 \\
$21-24$ & 411 & 2 & 5 & 11 & 3717 & 4950 & 6500 & 3571 & 4690 & 6445 \\
$25-27$ & 92 & 2 & 6 & 18 & 3550 & 4650 & 6750 & 3182 & 3792 & 5909 \\
$28-31$ & 73 & 2 & 3 & 8 & 3300 & 3800 & 4917 & 3312 & 3641 & 4148 \\
$32-33$ & 149 & 2 & 5 & 19 & 3200 & 3627 & 4350 & 3168 & 3424 & 4051 \\
$34-39$ & 99 & 1 & 4 & 9 & 3930 & 5500 & 7000 & 4009 & 5298 & 6853 \\
$40-42$ & 14 & 2 & 6 & 36 & 3700 & 5000 & 5600 & 2957 & 4428 & 6011 \\
$47-49$ & 64 & 2 & 4 & 11 & 3200 & 3525 & 4535 & 3156 & 3427 & 4048 \\
$43-46 \& \geq 50$ & 147 & 2 & 3 & 8 & 3618 & 5000 & 7350 & 3745 & 5139 & 6819 \\
\hline All & 1650 & 2 & 4 & 11 & 3500 & 4500 & 6200 & 3415 & 4236 & 5830 \\
\hline
\end{tabular}

Note: All postal codes with 20 or more observations are reported. Search time is in months. Wages are gross monthly wages in Dutch guilders for full time employment. The table gives the 25th, 50th, and 75 th percentile of the distribution, denoted by q25, q50, q75 respectively.

that all these coefficients are corrected for the hierarchical composition, education level, age tenure and evaluation scores.

\subsection{Conclusion}

This chapter investigated the interrelatedness of search, offers and (reservation) wages. We could show that reservation wages and accepted wages converge over time and offered an explanation based on learning and information passing. We use the fact that the Fokker Survey observes the number of offers a person receives. With this information, using the methodology developed by Blau and Robins (1986), we could identify and estimate the reservation wages of the workers. Information passing can be shown to take place both locally as well as among similar workers. We show specifically that workers within the same hierarchical level benefit from a higher proportion of workers being employed. We interpret this as being (partly) due to job referrals among similar workers. This is confirmed by a positive and significant effect of the ratio of employed workers on the number of offers received. The local ratio of employed workers - across all levels - is also negatively related to unemployment duration, but it does not affect the number of offers. Hence, the effect upon duration should be attributed to channels other than job referrals, e.g. information passing and learning. They could also reflect the general economic situation within the region, which would also yield a similar effect. 
A higher relative wage position leads to shorter search times. If we compare 'accepted wages observed' with the estimated reservation wages, we can see that over a short period of time accepted wages coincide with reservation wages predicted.

Also, the correction for search time turned out to be significant and essential. As we could illustrate graphically the estimation of expected wages, not correcting for offers and search time, overestimates the level of wages actually accepted.

As the information passing and learning was only investigated using proxy variables, we would suggest further research that collects data specifically geared towards examining the process of searching while interacting with former co-workers, neighbors and family. Also, the arrival and possible rejection of job offers seems to be important, yet is often neglected as the information is not easily obtainable. 
9 Conclusion 


\section{Conclusion}

At the end of this thesis it is time to take stock of what we have learned. The bankruptcy of Fokker and the survey among the displaced workers has allowed us investigate many issues in, or related to, the displacement literature that could not have been done in earlier work.

While the thesis has not been written in the same order that the chapters appear, their ordering amplify both the timing of the events faced by the displaced workers, but also the preparatory work necessary to do the displacement study of chapters seven and eight. This displacement study is novel in the sense that it includes firm and career specific variables as well as worker interaction post displacement. The career and firm variables are derived in chapter three, in which we describe and analyze the functioning of the internal labor market of the displacing firm. Chapter four describes and models the bankruptcy trustees' reorganization decision to select several workers into a leaner company. Chapter five and six are again preparatory as they describe the development, conduct and the results from the collection of post-displacement labor market information. The final chapters seven and eight were possible by combining the information from the early chapters on the firm and the information collected through the survey.

In Chapter 3 our analysis confirms the existence of an internal labor market and the importance of lateral and vertical job mobility therein. We add to the scant, but growing empirical literature by noting that wages are related to job level. This implies that transitions are material for workers' wage growth. Although immediate gains upon promotions are small — often job transitions and wage changes do not even coincide compared to the average difference in wages for adjacent job levels, promoted workers can look forward to a period of sustained wage growth as they move up in their new job level's wage distribution. The spread of these job-level wage distributions is substantial so that wages in job levels overlap. Therefore wages are not strictly tied to jobs as there remains considerable scope to reward workers individually. Within-level careers are another valuable possibility for workers to secure wage growth. Lateral job changes are a significant phenomenon, which can be explained by firm-specific capital requirements in particular jobs, involving more workers and more job changes than vertical job transitions.

For the firm, the staffing of positions from within is essential especially in jobs which require firm-specific knowledge. Such organizational or firm-specific capital seems crucial in a number of jobs. Workers hired from outside must make up for the lack of firm-specific capital by obtaining higher completed schooling degrees than workers pro- 
moted from within. Even though entry occurs at all levels, entry rates are substantially smaller in some career tracks for jobs further down the career path. We find that the firm's hierarchy of job levels is relatively stable throughout periods of expansion and contraction. Neither are levels added to the hierarchy during expansion, nor are job levels cut from the hierarchy during contraction. However, we can show that relative sizes of job levels change during downsizing when the firm becomes top-heavy. This is most likely the result of sizeable differences in adjustment costs for different workers, particularly when firm-specific capital is substantial in jobs further down a career path and future growth is expected, as was the case at our firm. Changes in firm size in general and changes in relative entry and exit rates have considerable impact on job transition rates. Promotion rates fall and demotion rates rise the more the net employment growth rates fall.

The role of a firm's organizational structure on the decision to restructure the firm's workforce was studied in Chapter 4. We modelled a hierarchical firm's optimal downsizing decision. Changes in the organizational structure can be described by a hierarchical menu costs model. If the firm's input of workers comprises different skill groups, and if the production of each of these skill group's is organized in ranks, then the ranks' contributions to the future value to the firm determines their size. During a reorganization rank-specific cut-off values determine changes in the firm's hierarchical structure. Factors that explain the cut-off values are rank-specific expected future profit growth, the uncertainty surrounding that growth, rent-sharing rules, as well as firing costs. The theoretical predictions of our model, that profit growth and firing costs lead to increases in higher ranks at the expense of lower ranks, and that increased uncertainty and worker rents broaden the bottom ranks of the hierarchical structure, are supported by the data from Fokker.

We find that reorganizations that modify the composition of ranks within skill groups can give rise to increased wage inequality between skill groups. Increased uncertainty about future profit growth increases the firm's propensity to hold a larger share of workers in ranks that contribute most to this uncertainty, because the firm is reluctant to lay off workers that may be needed in the near future. Finally, shocks that increase the workers' share of firm-specific rents, such as increased union power or aggregate positive demand shocks, will increase the negotiation power of workers and decrease profits flowing to the firm. If such shocks lead to reorganization of the workforce, the restructuring is such that it will lead to a decrease in wage inequality between low and high skilled workers. 


\section{Conclusion}

The combination of survey data from displaced workers and their personnel records allowed to investigate post-displacement differences in search time and earnings. We find that wage losses in the Netherlands are large and comparable to those found in the US. Since the workers in our data set are high tenured, relatively old, and probably worked for a high-wage firm, these results may not be inconsistent with other existing European studies that look at more representative sets of displacement.

Pre-displacement job-characteristics are found to be important predictors of both search time and earnings losses after displacement. Search time increases with age and tenure, whereas workers with a higher hierarchical position search significantly shorter than lower level workers. Although, the search-time seems to be largely unaffected by the specification of the job activity, it plays an important role in explaining displacement wage losses after displacement. The hierarchical level is inversely related to wage losses if employment is found within a year, while it has no effect afterwards. Pre-displacement lateral job movements reduce earnings losses by 3.2 percent per job rotation. The wagelosses of all workers together were estimated to amount to 11.9 percent. Staying within the same industry decreased the initial wage losses, but this effect was insignificant after three years.

We analyzed the displacement effects of tenure with the firm, within ranks, and jobs. None of these tenure variables are found to contribute to explaining observed wage losses. Other information on characteristics of old and new jobs and how they differ annihilated the role of the variables traditionally suggested to represent firm-specific and not transferable on-the-job investments in productive human capital. More research is needed that uses similar detailed information on pre- and post-displacement jobcharacteristics before we can draw further reaching conclusions. But for our data-set the explanation of firm-specific human capital to understand observed wage losses is not supported.

Our data refutes the Blanchard-Diamond (1994) ranking model. After a period of three years, workers who had multiple employers have lower wage losses. There is no 'badge of good behavior' to be earned after a bankruptcy, or at least none that has an effect after three years.

Idiosyncratic ability, measured as the residual wage growth during the last three years at the displacing firm, turned out to be an important and insightful variable. This is not because unobserved ability was found to be important to explain variation in postdisplacement search time and wage losses, but because it revealed that the distressed firm had a wage policy of paying 'risk' premiums during its final years of existence to 
entice workers not to abandon the distressed firm.

Allowing workers to learn from the labor market experience of their former co-workers and basing their search strategy on matching results observed of workers similar to themselves is found to be an important explanation of the simultaneous dynamics of reservation wages and observed unemployment durations. Similar workers who found high wage jobs increase the unemployed peer worker's reservation wage as well as the predicted search time. Workers from higher hierarchical positions find a new job faster than their lower ranked counterparts.

This last finding is extended in Chapter 8 , in which we investigate the interrelation of search, offers and (reservation) wages. We could show that reservation wages and accepted wages converge over time and offered an explanation based on learning and information passing. We used the fact that the Fokker Survey observes the number of offers a person receives. With this information, using the methodology developed by Blau and Robins (1986), we could identify and estimate the reservation wages of the workers. Information passing can be shown to take place both locally as well as among similar workers. We show specifically that workers within the same hierarchical level benefit from a higher proportion of workers being employed. We interpret this as being (partly) due to job referrals among similar workers. This is confirmed by a positive and significant effect of the ratio of employed workers on the number of offers received. The local ratio of employed workers - across all levels - is also negatively related to unemployment duration, but it does not affect the number of offers. Hence, the effect upon duration should be attributed to channels other than job referrals, e.g. information passing and learning. They could also reflect the general economic situation within the region, which would also yield a similar effect.

A higher relative wage position leads to shorter search times. If we compare 'accepted wages observed' with the estimated reservation wages, we can see that over a short period of time accepted wages coincide with predicted reservation wages. The estimation of expected wages not correcting for offers and search time, overestimates the level of wages actually accepted.

On a regional level the learning process and the adjustment of the reservation wages differ. Workers seem to have some notion of the economic environment in their region, and adjust their expectation accordingly. In regions that fared economically well, the learning process and the adjustments made are bigger than those in economically less developed regions. 


\subsection{Future Research}

Thanks to the detailed character of the data we could show many interesting aspects that determine the post displacement wage and search outcomes. This can be partly attributed to the decision to step away from the large data-sets and to also examine 'case studies' of displacement as have been done in the 1920s and 1950s, but now using the tools of modern economics and econometrics. This is an avenue that is promising. A replication with another case and other data, as only in such a way can the conclusion drawn here been validated for more general cases, therefore seems promising. More research is needed that uses similar detailed information on pre- and post-displacement job-characteristics before we can draw further reaching conclusions. But for our data-set the explanation of firm-specific human capital to understand observed wage losses is not supported.

Further research is needed in displacement and lay-offs in Europe in general. There are only a few studies, most of which in a recent book. However, these studies are by no means exhaustive and the depth of research compared to the U.S. studies can still be improved.

As the information passing and learning from co-workers was only investigated using proxy variables, we would suggest further research that collects data specifically geared towards examining the process of searching while interacting with former co-workers, neighbors and family. Integrating search time, the acceptance of wage losses and learning also seems to be important. Preferably with similar data, or even with more detail on the learning aspect of job searchers. Also, the arrival and possible rejection of job offers seems to be important, yet often neglected, as the information is not easily obtainable.

The use of personnel data - though difficult to obtain - contains a wealth of information. Careers with firms determine the wages paid to many workers. They can only be observed by using firm level data. Also, the empirical research into internal labor markets is still in its infancy. Every additional study allows generalizations of findings that are supported by all studies on firmer grounds, while contributing through differences found relative to other studies.

While the option model allowed us to give some theoretical insights into the reorganization process, by determining optimal cut-off values for a given hierarchical structure, it fell short of explaining the size within a rank and the number of ranks simultaneously. This is also research that calls for personnel data to test ideas and examine decision maker's choices. 


\section{Bibliography}

Abbring, J. H., van den Berg, G. J., Gautier, P. A., Gijsbert, A., van Lomwel, G. C., van Ours, J. C. and Ruhm, J. C.: 2002, Displaced Workers in the United States and the Netherlands, in P. J. Kuhn (ed.), Loosing Work Moving on: Worker Displacement in International Perspective, W.E. Upjohn Institute of Employment Research, Kalmazoo, Michigan.

Addison, J. T. and Portugal, P.: 1989, Unemployment Insurance and Unemployment Spells, Southern Economic Journal 56, 166-182.

Albæk, K., van Audenrode, M. and Browning, M.: 2002, Employment Protection and the Consequences for Displaced Workers: a Comparison of Belgium and Denmark, in P. J. Kuhn (ed.), Loosing Work Moving on: Worker Displacement in International Perspective, W.E. Upjohn Institute of Employment Research, Kalmazoo, Michigan.

Alchian, A. A. and Demsetz, H.: 1972, Production, Information Costs, and Economic Organization, American Economic Review 62(5), 777-795.

Altonji, J. G. and Pierret, C. R.: 2001, Employer Learning and Statistical Discrimination, Quarterly Journal of Economics 116, 313-350.

Ariga, K., Ohkusa, Y. and Brunello, G.: 1999, Fast Track: Is it in the Genes? The Promotion Policy of a Large Japanese Firm, Journal of Economic Behavior and Organization 38(4), 385-402.

Baker, E. F.: 1930, Unemployment and Technical Progress in Commercial Printing, American Economic Review 20(3), 442-466. 
Baker, E. F.: 1933, Displacement of Men by Machines, Columbia University Press, New York.

Baker, G., Gibbs, M. and Holmstrom, B.: 1994a, The Internal Economics of a Firm: Evidence from Personnel Data, Quarterly Journal of Economics 109(4), 881-920.

Baker, G., Gibbs, M. and Holmstrom, B.: 1994b, The Wage Policy of a Firm, Quarterly Journal of Economics 109(4), 921-955.

Bala, V. and Goyal, S.: 1998, Learning from neighbours, Review of Economic Studies 65(3), 595-622.

Bale, M. D.: 1977, United States Concessions In The Kennedy Round And Short-Run Labour Adjustment Costs, Journal of International Economics 7(2), 145-149.

Barnes, W. F.: 1975, Job Search Models, the Duration of Unemployment and the Asking Wage: Some Empirical Evidence, Journal of Human Resources 10, 230-240.

Becker, G. S.: 1962, Investment in Human Capital: A Theoretical Analysis, Journal of Political Economy 70(5), 9-49.

Bender, S., Dustmann, C., Margolis, D. and Meghir, C.: 2002, Worker Displacement in France and Germany, in P. J. Kuhn (ed.), Loosing Work Moving on: Worker Displacement in International Perspective, W.E. Upjohn Institute of Employment Research, Kalmazoo, Michigan.

Berry, S., Gottschalk, P. and Wissoker, D.: 1998, An Error Components Model of the Impact of Plant Closings on Earnings, Review of Economics and Statistics 70(4), 701-711.

Bethlehem, J. and Kersten, M.: 1986, Werken met Non-Response, PhD-Thesis, Universiteit van Amsterdam.

Bewley, T. F.: 1999, Why Wages Don't Fall During a Recession, Harvard University Press, Cambridge, MA.

Blanchard, O. J. and Diamond, P.: 1994, Ranking, Unemployment Duration and Wages, Review of Economic Studies 61, 417-434.

Blau, D. M.: 1991, Search for Nonwage Job Characteristics: A Test of the Reservation Wage Hypothesis, Journal of Labor Economics 9(2), 186-205. 
Blau, D. M. and Robins, P. K.: 1986, Job Search, Wage Offers, and Unemployment Insurance, Journal of Public Economics 29(2), 173-197.

Blau, F. and Kahn, L.: 1981, Causes and Consequences of Layoffs, Economic Inquiry 19, 270-296.

Blau, P. M.: 1964, Exchange and Power in Social Life, John Wiley \& Sons.

Bloemen, H. G. and Stancanelli, E. G. F.: 2001, Individual Wealth, Reservation Wages, and Transitions into Employment, Journal of Labor Economics 19(2), 400-439.

Böheim, R.: 2002, The Association Between Reported and Calculated Reservation Wages, ISOR-WP 2002-07.

Borland, J., Gregg, P., Knight, G. and Wadsworth, J.: 2002, They Get Knocked Down. Do They Get Up Again?, in P. J. Kuhn (ed.), Loosing Work Moving on: Worker Displacement in International Perspective, W.E. Upjohn Institute of Employment Research, Kalmazoo, Michigan.

Bound, J., Brown, C., Duncan, G. J. and Rodgers, W. L.: 1994, Evidence on the Validity of Cross-sectional and Longitudinal Labor Market Data, Journal of Labor Economics 12(3), 345-368.

Bradburn, N. M.: 1964, Inter-plant Transfer: the Sioux City Experience - A Study of Factors Related to Labor Mobility, National Opinion Research Center, Report No. 98.

Bradburn, N. M. and Sudman, S.: 1991, Current Status of Qeustionnaire Design, in Biemer, Groves, Lyberg and Sudman (eds), Measurement Errors in Surveys, John Wiley \& Sons, chapter 2.

Brown, C., Duncan, G. J. and Stafford, F. P.: 1996, Data Watch: The Panel Study of Income Dynamics, Journal of Economic Perspectives 10(2), 155-168.

Burda, M. and Mertens, A.: 1998, Estimating Wage Losses of Displaced Workers in Germany, Labour Economics 8(1), 15-41.

Caballero, R. J. and Engel, E. M.: 1999, Explaining Investment Dynamics in U.S. Manufacturing: A Generalized (S,s) Approach, Econometrica 67(4), 783-826. 
Calvó-Armengol, A. and Jackson, M. O.: 2001, Social Networks in Determining Employment and Wages: Patterns Dynamics and Inequality, Mimeo Caltech.

Calvo, G. A. and Wellisz, S.: 1979, Hierarchy, Ability, and Income Distribution, Journal of Political Economy 87(5), 991-1010.

Campion, Michael A., C. L. and Stevens, M. J.: 1994, Career-Related Antecedents and Outcomes of Job Rotation, Academy of Management Journal 37(6), 1518-1542.

Carrington, W. J.: 1993, Wage Losses for Displaced Workers. Is it Really the Firm that Matters?, Journal of Human Ressources 28(3), 435-462.

Carrington, W. J. and Zaman, A.: 1994, Interindustry Variation in the Cost of Displacement, Journal of Labor Economics 12(2), 243-275.

Carroll, G. R. and Hannan, M. T.: 2000, The Demography of Corporations and Industries, Princeton University Press.

Chan, S. and Stevens, A. H.: 1999, Employment and Retirement Following a Late-Career Job Loss, American Economic Review 89(2), 211-216.

Cochrane, W.: 1977, Sampling Techniques, 3rd edn, John Wiley \& Sons, New York.

Corson, W. and Nicholson, W.: 1981, Trade Adjustment Assistance for Workers, Research in Labor Economics 4, 417-469.

Couch, K. A.: 2001, Earnings Losses and Unemployment of Displaced Workers in Germany, Industrial and Labor Relations Review 54(3), 559-572. earnings losses and number of months unemployed using GSOEP 1991-1996.

De Vyver, F. T.: 1940, After the Shutdown: An Analysis of the Job-Hunting Experience of a Group of Durham Hosiery Workers, Journal of Political Economy 48(1), 105113.

Deterink, A., Knüppe, B., Leuftink, A. and Schimmelpenninck, R.: 1997, Onderzoek naar de Oorzaken van het Faillissement van Fokker, Kluwer, Deventer.

Dillman, D. A.: 2001, Mail and Internet Surveys: The Tailored Design Method, 2 edn, John Wiley \& Sons, New York.

Doeringer, P. B. and Piore, M. J.: 1971, Internal Labor Markets and Manpower Analysis, Heath Lexington Books, Lexington, MA. 
Dohmen, T. J. and Pfann, G. A.: 2000, Worker Separations in a Nonstationary Corporate Environment. IZA Discussion Paper No. 201.

Doiron, D. J.: 1995, Lay-offs as signals: The Canadian evidence, Canadian Journal of Economics 28(4), 899-913.

du Bois, M.: 1995, Aircraft Maker Fokker Faces a Bumpy Ride As Netherlands, DASA Begin Bailout Talks, Wall Street Journal Europe .

Dustmann, C. and Meghir, C.: 2001, Wages, Experience and Seniority, Institute for Fiscal Studies WP 01/01.

Eberly, J.: 1994, Adjustment of consumers' durables stocks: Evidence from automobile purchases, Journal of Political Economy 102(3), 403-436.

Ehrenberg, R. G. and Jakubson, G. H.: 1988, Advance Notice Provisions in Plant Closing Legislation, W.E. Upjohn Institute for Employment Research, Kalamazoo, Michigan.

Engberg, J.: 1991, Structural Job Search Models, PhD thesis, University of Wisconsin.

Eriksson, T. and Ortega, J.: December 2001, The Adoption of Job Rotation: Testing the Theories. Paper presented at Universidad Publica de Navarra (January 25, 2002).

Evans, D. S. and Leighton, L. S.: 1995, Retrospective bias in the displaced workers surveys, Journal of Human Resources 30(2), 386-397.

Fallick, B. C.: 1991, Unemployment insurance and the rate of re-employment of displaced workers, Review of Economics \& Statistics 73(2), 228-236.

Fallick, B. C.: 1996, A review of the recent empirical literature on displaced workers, Industrial \& Labor Relations Review 50(1), 5-15.

Farber, H. S.: 1997, The changing face of job loss in the United States: 1981-1995, Brookings Papers on Economic Activity: Microeconomics pp. 55-128.

Farber, H. S.: 1999a, Alternative and part-time employment arrangement as a response to job loss, Journal of Labor Economics 17(4), S142-S169.

Farber, H. S.: 1999b, Mobility and Stability: The Dynamics of Job Change in Labor Markets, in O. C. Ashenfelter and D. Card (eds), Handbook of Labor Economics, Vol. 3B, Elsevier Science, Amsterdam, The Netherlands, pp. 2439-2483. 
Farber, H. S. and Gibbons, R.: 1996, Learning and wage dynamics, Quarterly Journal of Economics 111(4), 1007-1047.

Flinn, C. and Heckman, J.: 1982, New methods for analyzing structural models of labor force dynamics, Journal of Econometrics 24, 115-168.

Forsyth, B. H. and Lessler, J.: 1991, Cognitive Laboratory Methods: A Taxonomy, in P. P. Biemer, R. Groves, L. Lysberg, N. Mathowetz and S. Sudman (eds), Measurement Errors in Surveys, Wiley, New York, pp. 393-418.

Franquinet, E.: 1946, Fokker - Een leven voor de luchtvaart, De Pelgrim, Eindhoven.

Garicano, L.: 2000, Hierarchies and the organization of knowledge in production, Journal of Political Economy 108(5), 874-904.

Geuzinge, L., van Rooijen, J. and Bakker, B. F.: 2000, The Use of Administrative Registers to Reduce Non-Response Bias in Household Surveys, Netherlands Official Statistics 15, 32-38.

Gibbons, R.: 1997, Incentives and Careers in Organizations, in D. Kreps and K. Wallis (eds), Advances in Economics and Econometrics: Theory and Applications, Vol. II, Cambridge University Press, Cambridge, pp. 1-37.

Gibbons, R. and Katz, L.: 1991, Layoffs and Lemons, Journal of Labor Economics 9(4), 351-380.

Gibbons, R. and Waldman, M.: 1999, A Theory of Wage and Promotion Dynamics Inside Firms, Quarterly Journal of Economics 114(4), 1321-1358.

Gibbons, R. and Waldman, M.: 1999b, Careers in Organizations: Theory and Evidence, in O. C. Ashenfelter and D. Card (eds), Handbook of Labor Economics, Vol. 3B, Elsevier Science, Amsterdam, The Netherlands, pp. 2373-2437.

Gibbs, M. and Hendricks, W.: 2001, Are Formal Salary Systems a Veil? Working Paper, University of Chicago.

Gitelman, H. M.: 1966, Occupational Mobility within the Firm, Industrial and Labor Relations Review 20(1), 50-65.

Granovetter, M.: 1974, Getting a Job: A Study of Contacts and Careers, Harvard University Press, Cambridge, MA. 
Gronau, R.: 1971, Information and Frictional Unemployment, American Economic Review 61(3), 290-301.

Groves, R. M. and Couper, M. P.: 1998, Nonresponse in Household Interview Surveys, Wiley, New York.

Grund, C.: 1999, Stigma Effects of Layoffs? Evidence from German Micro-Data, Economic Letters 64(2), 241-247.

Hall, R. E.: 1995, Lost Jobs, Brookings Papers on Economic Activity 1995(1), 221-256.

Hamermesh, D. S.: 1987, The Cost of Worker Displacement, Quarterly Journal of Economics 102(1), 51-76.

Hamermesh, D. S.: 1989a, Plant Closings and the Value of the Firm, Review of Economics and Statistics 70, 580-586.

Hamermesh, D. S.: 1989b, What Do We Know About Worker Displacement in the U.S.?, Industrial Relations 28(1), 51-60.

Hamilton, B. H.: 2000, Does Entrepreneurship Pay? An Empirical Analysis of the Returns to Self-Employment, Journal of Political Economy 108(3), 604-631.

Hansen, M. and Hurwitz, W.: 1958, The Problem of Nonresponse in Sample Surveys, The Journal of the American Statistical Association pp. 517-529.

Hansen, M., Hurwitz, W. and Madow, W.: 1953, Sample Survey Methods and Theory, Vol. II, John Wiley \& Sons, New York.

Heckman, J. J.: 1979, Sample Selection Bias as a Specification Error, Econometrica 47(1), 153-161.

Holt, D. and Elliot, D.: 1991, Methods of Weighting for Unit Non-Response, Statistician 40, 333-342.

Jacobson, L. S., LaLonde, R. J. and Sullivan, D. G.: 1990, Earnings Losses of Displaced Workers, W.E. Upjohn Institute of Employment Research, Kalmazoo, Michigan.

Jacobson, L. S., LaLonde, R. J. and Sullivan, D. G.: 1993, Earnings Losses of Displaced Workers, American Economic Review 84, 685-709. 
Jensen, P. and Westergård-Nielsen, N. C.: 1987, A Search Model Applied to the Transition from Education to Work, Review of Economic Studies 54, 461-472.

Jerome, H.: 1932, The Measurement of Productivity Changes and the Displacement of Labor, American Economic Review 22(1), 32-40. Supplement, Papers and Proceedings of the Forty-fourth Annual Meeting of the American Economic Association.

Käler, A.: 1933, Die Theorie der Arbeiterfreisetzung durch die Maschine, Julius Abel, Greifswald.

Kasper, H.: 1967, The Asking Price of Labor and the Duration of Unemployment, Review of Economics and Statistics 49(2), 165-172.

Kiefer, N. M. and Neuman, G.: 1979a, An Empirical Job Search Model with a Test of the Reservation-wage Hypothesis, Journal of Political Economy 87, 89-108.

Kiefer, N. M. and Neuman, G.: 1979b, Estimation of Wage Offer Distributions and Reservation Wages, in S. A. Lippman and J. J. McCall (eds), Studies in the Economics of Search, North-Holland, Amsterdam.

Kiefer, N. M. and Neuman, G.: 1981, Individual Effects in a Nonlinear Model: Explicit Treatment of Heterogeneity in the Empirical Job-search Model, Econometrica 49, 965-979.

Kish, L.: 1965, Survey Sampling, Wiley, New York.

Kletzer, L.: 1989, Returns to seniority after permanent job loss, American Economic Review 79, 536-543.

Kletzer, L.: 1998, Job Displacement, Journal of Economic Perspectives 12(1), 115-136.

Knight, F. H.: 1921, Risk, Uncertainty, and Profit, Hart, Schaffner \& Marx; Houghton Mifflin Company, Boston.

Krashinsky, H.: 2002, Evidence on Adverse Selection and Establishment Size in the Labor Market, Industrial and Labor Relations Review 56(1), 84-96.

Kruse, D.: 1988, International Trade and the Labor Market Experience of Displaced Workers, Industrial and Labor Relations Review 41(3), 402-417.

Kugler, A.: 2003, Employee Referrals and Efficiency Wages, 41(3). 
Kuhn, P. J.: 2002, Loosing Work Moving On: Worker Displacement in International Perspective, W.E. Upjohn Institute of Employment Research, Klaamazoo, Michigan.

Lancaster, T.: 1990, The Econometric Analysis of Transition Data, Cambridge University Press, Cambridge.

Lancaster, T. and Nickell, S.: 1980, The Analysis of Re-Employment Probabilities for the Unemployed, Journal of the Royal Statistical Society - Series A 143(2), 141-165.

Lazear, E. P.: 1979, Why is There Mandatory Retirement?, Journal of Political Economy 87(6), 1261-1284.

Lazear, E. P.: 1992, The Job as a Concept, in W. Bruns (ed.), Performance Evaluation and Incentives, Harvard Business School Press, Boston, pp. 183-215.

Lazear, E. P. and Rosen, S.: 1981, Rank-Order Tournaments as Optimum Labor Contracts, Journal of Political Economy 89(5), 841-864.

Lima, F.: 2000, Internal Labor Markets: A Case Study from an Institutional Survey. Working Paper, Universidada Nova Lisboa.

Lohr, S. L.: 1990, Survey Sampling, New York.

MacLeod, W. and Malcomson, J.: 1993, Investment, Holdups, and the Form of Market Contracts, American Economic Review 83(4), 811-837.

MacLeod, W. and Malcomson, J. M.: 1988, Reputation and Hierarchy in Dynamic Models of Employment, Journal of Political Economy 96(4), 832-854.

Madden, J. F.: 1987, Gender Differences in the Cost of Displacement: An Empirical Test of Discrimination in the Labor Market, American Economic Review 77(2), 246-252. Papers and Proceedings.

Magnani, E.: 2001, Risk of Labor Displacement and Cross-Industry Labor Mobility, Industrial and Labor Relations 54(3), 593-610.

Marschak, J. and Radner, R.: 1972, Economic Theory of Teams, number 22 in Cowles Foundation for Research in Economics Monograph, Yale University Press, New Haven. 
Marshall, A.: 1920, Principles of Economics, Macmillan and Co., Ltd., Philadelphia.

Martijn, C.: 1996, Vleugellam, F\&G Publishing, Bunnink.

Maxwell, N. L. and D'Amico, R.: 1986, Employment and wage effects of involuntary job separation: Male-female differences, American Economic Review 76(2), 373-377.

McCall, J. J.: 1970, Economics of Inormation and Job Search, Quarterly Journal of Economics 84(1), 113-126.

McCall, J. J.: 1997, Economics of Inormation and Job Search, Journal of Labor Economics 15(4), The Determinant of Full-time versus Part-time Employment following Job Displacement.

McFadden, D.: 1984, Econometric Analysis of Qualitative Response Models, Vol. II of Handbook of Econometrics, North-Holland, Amsterdam, pp. 1396-1457.

Medoff, J. L. and Abraham, K. G.: 1980, Experience, Performance, and Earnings, Quarterly Journal of Economics 95(4), 703-736.

Mesing, F.: 1988, Geschiedenis van de Mijnsluting in Limburg, Martinus Nijhoff, Leiden.

Meyer, B. D.: 1990, Unemployment Insurance and Unemployment Spells, Econometrica 58(4), 757-782.

Milgrom, P. and Roberts, J.: 1988, An Economic Approach to Influence Activities in Organizations, American Journal of Sociology 94(Supplement), S154-S179.

Mincer, J.: 1974, Schooling, Experience, and Earnings, NBER, New York.

Murphy, T.: 1996, A Piecewise-Constant Hazard-Rate Model for the Duration of Unemployement in Single-Interview Samples of the Stock of Employed, Economic Letters 51(2), 141-165.

Neal, D.: 1995, Industry-Specific Human Capital: Evidence from Displaced Workers, Journal of Labor Economics 13(4), 653-677.

Oh, H. and Scheuren, F.: 1983, Weighting Adjustment for Unit Non-Response, in Madow, Olkin and Rubin (eds), Incomplete Data in Sample Surveys, Vol. 2, Academia Press. 
Ortega, J.: 2001, Job Rotation as a Learning Mechanism, Management Science 47(10), 1361-1370.

Osterman, P.: 1979, Sex Discrimination in Professional Employment: A Case Study, Industrial and Labor Relations Review 32(4), 451-464.

Parsons, D. O.: 1972, Specific human capital: An application to quit rates and layoff rates, Journal of Political Economy 80, 1120-1143.

Pfann, G. A. and Palm, F. C.: 1993, Asymmetric Adjustment Costs in Nonlinear Labour Demand Models for the Manufacturing Sectors in the Netherlands and the UK, Review of Economic Studies 60, 397-412.

Podgursky, M. and Swaim, P.: 1987, Duration of Joblessness Following Displacement, Industrial Relations 26(3), 213-226.

Postel-Vinay, F. and Robin, J.-P.: 2002, Wage Dispersion with Worker and Employer Heterogeneity, Econometrica 70(6), 2295-2350.

Prendergast, C.: 1993a, The Role of Promotion in Inducing Specific Human Capital Acquisition, Quarterly Journal of Economics 108(2), 523-534.

Prendergast, C. and Topel, R.: 1996, Favoritism in Organizations, Journal of Political Economy 104(5), 958-978.

Prescott, E. C. and Visscher, M.: 1980, Organization Capital, Journal of Political Economy 88(3), 446-461.

Radner, R.: 1992, Hierarchy: The Economics of Management, Journal of Economic Literature 30(3), 1382-1415.

Rees, A.: 1966, Information Networks in Labor Markets, American Economic Review 56, 1007-1047.

Rosen, S.: 1982, Authority, Control, and the Distribution of Earnings, Bell Journal of Economics 13(2), 311-323.

Rosenbaum, J. E.: 1984, Career Mobility in a Corporate Hierarchy, Academic Press, London.

Ruhm, C.: 1991, Are Workers Permanently Scarred by Job Displacements?, American Economic Review 81(1), 319-324. 
Ruhm, C.: 1992, Advanced Notice and Postdisplacement Joblessness, Journal of Labor Economics 10(1), 1-32.

Ruhm, C.: 1994, Advanced Notice, Job Search, and Postdisplacement Earnings, Journal of Labor Economics 12(1), 1-28.

Say, J.-B.: 1802, A Treatise on Political Economy, english translation of the 4th-5th ed., 1855 edn, Grambo \& Co., Philadelphia.

Schoeni, R. F., Dalia, M., McCarthy, K. F. and Vernez, G.: 1996, Tracking California's Aerospace Workers, Technical Report RB-7510, Rand Institute.

Schwarz, N. and Hippler, H.-J.: 1991, Response Alternatives: The IMpact of their Choice and Presentation Order, in Biemer, Groves, Lyberg and Sudman (eds), Measurement Errors in Surveys, John Wiley \& Sons, chapter 3.

Seitchik, A.: 1991, Who Are Displaced Workers?, in J. T. Addison (ed.), Job Displacement, Wayne State University Press, Detroit, chapter 2.

Seltzer, A. and Merrett, D.: 2000, Personnel Policies at the Union Bank of Australia: Evidence form the 1888-1900 Entry Cohorts, Journal of Labor Economics 18(4), 573613.

Sen, A.: 1973, Behaviour and the Concept of Preference, Economica 15(159), 241-259.

Sennett, R.: 1998, The Corrosion of Character, W. W. Norton, New York.

Shapiro, D. and Sandell, S. H.: 1985, Age Discrimination in Wages and Displaced Older Men, Southern Economic Journal 52(1), 90-103.

Shultz, G. and Weber, A.: 1966, Strategies for the Displaced Worker: Confronting Economic Change, Harper and Row, New York.

Small, K. A.: 1987, A Discrete Choice Model for Ordered Alternatives, Econometrica 55(2), 409-424.

Smith, A.: 1776, An Inquiery into the Nature and Causes of the Wealth of Nations, glasgow edition edn, Clarendon Press, Oxford.

Steinberg, R. S. and Montfort, K.: 1987, Worker Displacement, Wayne State University Press, Detroit, chapter 6, pp. 136-161. 
Stern, S.: 1989, Estimating a Simultaneous Search Model, Jounral of Labor Economics $7(3), 348-369$.

Stevens, A. H.: 1997, Persisten effects of job displacement: The importance of muliple job losses, Journal of Labor Economics 15(1), 165-187.

Sudman, S. and Bradburn, N. M.: 1982, Asking Questions: A Practical Guide to Questionnaire Design, Jossey-Bass, London.

Swaim, P. L. and Podgursky, M. J.: 1991, Displacement and Unemployment, in J. T. Addison (ed.), Job Displacement: Consequences and Implications for Policy, Wayne State University Press, Detroit, chapter 6, pp. 136-161. cited in Abbringea1998.

Swaim, P. and Podgursky, M.: 1990, Advance Notice and Job Search, Journal of Human Resources 25(2), 147-179.

Teulings, C. and Hartog, J.: 1998, Corporatism or Competition?, Cambridge University Press, Cambridge.

Topel, R. H.: 1990, Specific capital and unemployment: Measuring the costs and consequences of job loss, Carnegie Rochester Conference Series in Public Policy 33, 181214.

Treble, J., Barmby, T., Bridges, S. and van Gameren, E.: 2001, The Internal Economics of The Firm: Further Evidence From Personnel Data, Labour Economics 8(5), 531552.

van Huijstee, J.: 1997, Vervlogen Jaren van Fokker, Van Soeren \& Co, Amsterdam.

Waldman, M.: 1984b, Job Assignments, Signalling, and Efficiency, Rand Journal of Economics 15(2), 255-267.

Williamson, O. E.: 1973, Organizational Forms and Internal Efficiency — Markets and Hierarchies: Some Elementary Considerations, American Economic Review 63(2), 316-325.

Williamson, O. E.: 1981, The Modern Corporation: Origins, Evolution,Attributes, Journal of Economic Literature XIX(4), 1537-1568.

Wolpin, K. I.: 1987, Estimating a Structural Search Model: The Transition from School to Work, Econometrica 55(4), 801-817. 


\section{Bibliography}

Wolpin, K. I.: 1995, Empirical Methods for the Study of Labor Force Dynamics, Vol. 60 of Fundamentals of Pure and Applied Economics Series, Harwood Academic Publishers, Luxembourg. 
Summary in Dutch 


\section{Nederlandse Samenvatting}

Het faillissement van Fokker in maart 1996 was het einde van een langdurige periode van zelfstandige vliegtuigbouw in Nederland. De faillissementsprocedure monde uit in een afsplitsing van enkele delen van het bedrijf, die niet verlieslijdend waren. Deze delen werden ondergebracht bij Stork N.V. en het faillissement van de rest van Fokker ging gepaard met een groot aantal gedwongen ontslagen. Doel van dit proefschrift was dan ook om inzichten te krijgen in de gevolgen van zo'n grootschalig faillissement voor de medewerkers.

In hoofdstuk twee wordt het kader van economisch onderzoek omtrent massa-ontslagen bij bedrijven geschetst. In de VS, waar het meeste onderzoek naar dit soort fenomenen werd gedaan, vindt men dat zulke ontslagen tot beduidende loonverliezen leiden. Ontslagen werknemers moeten gemiddeld genomen lagere lonen accepteren. Maar zowel in de duur van werkloosheid als ook in termen van loonverliezen staan zij er beter voor dan werknemers die ontslagen worden zonder dat het bedrijf reorganiseert of gesloten wordt.

Hoewel gemiddeld genomen duidelijke loonverliezen de gevolgen van zulke gedwongen ontslagen zijn, is er toch een duidelijke heterogeniteit onder werknemers vast te stellen. Een verklaring die hiervoor al gegeven is, is de partiële transfer van specifieke kennis binnen industrieën. Om de heterogeniteit van uitkomsten nader te verklaren, wordt in dit proefschrift gebruik gemaakt van de gedetailleerde informatie over de structuur van het sluitende bedrijf, de positie en het carrière-verloop van de werknemers voor ontslag, en hun banen na het faillissement.

Om dit te kunnen doen, hebben wij eerst de interne arbeidsmarkten binnen Fokker onderzocht gedurende de laatste tien jaar van het bestaan. Deze interne arbeidsmarkten worden in hoofdstuk drie beschreven. Wij onderzoeken de relatie van lonen en posities in het bedrijf, waarbij we ook analyses van andere, eerdere studies reproduceren en verifiëren. Deze verificatie is belangrijk omdat onze, nieuwe data van een ander bedrijf, uit een ander land en in een andere industrie afkomstig is dan de data in de bestaande literatuur. Maar het unieke karakter van de data laat een verdergaande analyse toe; de periode van groei, van eind jaren tachtig tot begin jaren negentig, en de daarop volgende krimp laten inzichten toe in de stabiliteit van interne arbeidsmarkten over deze fluctuaties.

Wij identificeren een hiërarchische ordening van posities door middel van transitities 
van werknemers. Werknemers beginnen meestal op het laagste niveau van de hiërarchie, hetzij binnen de productieafdeling, hetzij op hoger niveau onder het hoger personeel. Promoties binnen de organisaties zijn belangrijk voor het invullen van hogere posities. Hieruit kan geconcludeerd worden dat bedrijfsspecifieke kennis belangrijk is. De hiërarchische structuur is stabiel in tijden van groei - een feit dat ook andere studies al eerder hadden aangetoond. Nieuw daarentegen is dat in de periode van krimp de structuur weliswaar overeind blijft, maar dat er eerst aan de onderkant van de hiërarchische structuur gereorganiseerd wordt. Promotiekansen nemen in deze tijden af en het aantal degradaties neemt toe.

De loondistributie van een functie laat loongroei binnen een functie toe. Ook overlappen loondistributies van opeenvolgende hiërarchische posities elkaar. Toch is opwaartse mobiliteit cruciaal voor lang aanhoudende loongroei, omdat de loongroei binnen een functie beperkt is bij de bovengrens van de functiespecifieke loondistributie. Slechts een gedeelte van het gemiddelde verschil tussen de loondistributie van de initiële positie en de hogere nieuwe positie wordt bij de promotie vergoed. Werknemers promoveren van de hogere gedeeltes van een loondistributie naar een lager gedeelte in de nieuwe loondistributie. Laterale baanmobiliteit, "job rotation", is ook belangrijk binnen de onderneming; het bevordert promotiekansen, verhoogt de loongroei en verlaagt de kans op ontslag. Ook wordt in dit hoofdstuk aangetoond dat neerwaartse mobiliteit niet gepaard gaat met lagere nominale lonen. Toch voert een degradatie tot lagere verwachte loongroei. Reële loonsverandering wordt wel gevonden in tijden van krimp, doordat het nominale loon over meerdere jaren niet wordt aangepast.

Vervolgens onderzoeken wij de selectiebeslissing tijdens het faillissement. Voor de winstgevende gedeeltes van het bedrijf moest een deel van het personeel geselecteerd worden. Wij ontwikkelen in hoofdstuk vier een theoretisch model waarin de optimale grote van reorganisaties wordt bepaald. Baserend op bestaande modellen van aanpassingskosten, ontwikkelen wij een model van organisatieverandering, waarbij de hiërarchische structuur van het bedrijf met zijn onderlinge afhankelijkheid wordt meegenomen. Tijdens de reorganisatie worden drempelwaardes per niveau op basis van verwachte toekomstige groei in winst bepaald. Factoren die invloed hebben op deze drempelwaarde zijn niveauspecifieke toekomstige (verwachte) winstgroei, de onzekerheid omtrent deze winstgroei, de verdeling van winsten tussen werknemer en werkgever en ontslagkosten. De theoretische voorspelling van het model is dat winstgroei en hogere ontslagkosten leiden tot een vergroting van de hogere ten koste van de lagere hiërarchieën. 
Wij vinden empirisch dat reorganisaties die de composities van hiërarchieën binnen opleidingsniveau's veranderen tot meer loonsongelijkheid tussen opleidingsniveau's kan leiden. Grotere onzekerheid omtrent deze winstgroei vergroot het aandeel van werknemers op hiërarchische niveau's die het meeste bijdragen tot deze onzekerheid; het bedrijf wil geen werknemers ontslaan die het in de toekomst wellicht nodig zal hebben. Een verhoging van het werknemersaandeel aan de bedrijfsspecifieke winst zal leiden tot een versterking van de onderhandelingspositie van werknemers en tot een verlaging van de winsten van het bedrijf. Als een dergelijke verandering in een reorganisatie uitmondt, zal deze een vermindering van loononsgelijkheid met zich meebrengen tussen hoog en laag opgeleiden.

De interne personeelsdata van Fokker geven ons slechts een beeld van de situatie voor het faillissement. Om ook de situatie van de ontslagen werknemers na het faillissement te onderzoeken, hebben wij een schriftelijke enquête gehouden onder alle ontslagen werknemers gehouden. Deze 'Fokker-Enquête' werd in 1999 aan de werknemers verstuurd. Hoofdstuk vier beschrijft de ontwikkeling en de implementatie van deze enquête. Gezien het feit dat de kwaliteit van het onderzoek afhankelijk is van de kwaliteit van de data, hebben wij getracht de ontwikkeling van de enquête zo zorgvuldig mogelijk te doen. Verder hebben wij ook na afloop nog een onderzoek gedaan naar de gevolgen van nonresponse voor onze data. Gelukkig blijkt de nonresponse niet afhankelijk te zijn van variabelen die cruciaal zijn voor het onderzoek naar massa-ontslag.

Zo heeft een jaar na het faillissement slechts driekwart van de medewerkers nieuw werk gevonden. Tien procent van de medewerkers zegt nog op zoek te zijn naar werk. Daarmee ligt het werkloosheidscijfer van oud-Fokker medewerkers op dat moment duidelijk hoger dan het vergelijkbaar landelijk gemiddelde van 1996. Ook de categorie werknemers die zich teruggetrokken heeft uit de arbeidsmarkt is vier keer zo hoog als het vergelijkbaar landelijke gemiddelde van 1996. Het werkloosheidspercentage onder oud-Fokker medewerkers daalt in 1998 naar 6,2 procent, om in 1999 op 4,3 procent terecht te komen — dat is vergelijkbaar met het landelijk gemiddelde. Tweederde van de werkenden zijn na drie jaar nog bij de eerste werkgever. Eenderde van de werkenden had al meerdere nieuwe werkgevers nodig om de baan te vinden die zij drie jaar na het faillissement bekleden. Hoger opgeleiden veranderen minder vaak van werkgever en komen sneller terecht in een stabiele werkomgeving.

Veel werknemers die gedwongen werden ontslagen als gevolg van het faillissement moeten bij hun eerste nieuwe baan een positie op een lager niveau accepteren dan de 
positie die zij bij Fokker hadden. Echter, drie jaar naar faillissement geeft de helft van de respondenten aan dat zij inmiddels meer verantwoording hebben dan zij bij Fokker hadden.

In hoofdstuk zeven onderzoeken wij de loonverliezen en de duur van de werkloosheid van werknemers waarbij we gebruik maken van zowel de personeelsdata van Fokker als de data die door middel van de enquête verkregen werd. Wij vinden dat de loonverliezen groot zijn. Met een gemiddelde van 11.9 procent vinden wij waardes die ook in eerdere studies in de VS gevonden werden. Deze verliezen zijn wel hoger dan die de Europese studies tot nog toe gevonden hadden. De werkloosheidsduur is langer met een hogere leeftijd en met een langere staat van dienst binnen het bedrijf. De zoekduur is duidelijk korter naarmate werknemers hogere posities in de hiërarchie hadden. Ook al wordt de duur van werkloosheid niet significant beïnvloed door de job-activiteiten van de werknemer, toch spelen zij een grote rol bij het verklaren van loonverliezen.

Ook bij loonverliezen geldt dat hogere hiërarchische niveau's er relatief beter van af komen. Laterale veranderingen in posities - dus binnen een hiërarchisch niveau, maar over verschillende activiteitsgebieden van de onderneming - reduceren loonverliezen met ongeveer drie procent per beweging. Loonverliezen blijken - conform de bestaande literatuur - lager voor diegenen die binnen de luchtvaartsector blijven. Dit resultaat verdwijnt echter drie jaren na het faillissement.

Wij analyseren ook de invloed van 'tenure', dus de duur dat iemand bij het bedrijf werkzaam was, op de hoogte van de loonverliezen. Deze tenure wordt vaak als indicatie van de hoogte van het bedrijf- en industrie-specifiek menselijk kapitaal of opgebouwde kennis gezien. Gegeven het specifieke karakter van de data kunnen wij naar de tenure-effecten voor het gehele bedrijf, voor het hiërarchisch niveau en voor de functie kijken. Geen van deze variabelen kan de verschillen in loonverliezen verklaren indien voor alle overige variabelen gecontroleerd wordt. Wij moeten dus concluderen dat de tenure-variabelen door de specifieke informatie in de andere variabelen geen toegevoegde verklarende waarde hebben.

Onze data verwerpen ook het Blanchard-Diamond (1984) 'ranking' model. Na een periode van drie jaar hebben werknemers die in deze tijd bij meerdere werknemers hebben gewerkt, lagere loonverliezen.

Idiosyncratisch kunnen - gemeten als het residu van de loongroei van de laatste drie jaar — blijkt een belangrijke variabel te zijn. Deze variabel toonde aan dat het bedrijf aan het einde risico-premia betaalde. Dit om te voorkomen dat belangrijke medewerkers 
het bedrijf verlaten.

Werknemers leren van de arbeidsmarktervaring van hun voormalige collega's. In een model waarin wij een leerproces aan de hand van vergelijkbare werknemers die een baan gevonden hebben modelleren, kunnen wij de dynamiek van zoektijd en reservatieloon onderzoeken.

Dit model wordt uitgebreid en met een locale interactie in een context van zoektijd, baan-aanbiedingen en de dynamiek van reservatielonen over de tijd geplaatst. Gegeven dat wij het aantal aanbiedingen kennen, kunnen wij gebruik maken van een methode die door Blau en Robbins (1986) is ontwikkeld. Hierdoor kunnen wij loonsverdeling aan de hand van het aantal aanbiedingen en de zoektijd identificeren en zo het reservatieloon uitrekenen.

We kunnen aantonen dat informatie over de loonsverdeling, maar ook over open posities, lokaal wordt uitgewisseld. Ook tussen het hoger dan wel tussen het productiepersoneel wordt informatie doorgegeven. De ratio van werknemers van hetzelfde hiërarchisch niveau heeft een positieve invloed op het vinden van een baan. Ook passen werknemers hun reservatieloon over tijd aan. De ratio daarentegen heeft geen invloed op het aantal aanbiedingen dat een werknemer krijgt. Wij interpreteren deze effecten als het gevolg van een leerproces over de (lokale) arbeidsmarktsituatie.

Ook het vinden van nieuwe banen door middel van een bemiddeling van oud-collega's blijkt belangrijk te zijn. Het aandeel werknemers dat op hetzelfde niveau bezig was als de werkzoekende, heeft een positieve invloed op het krijgen van aanbiedingen.

Als wij de geaccepteerde lonen met de reservatielonen vergelijken is te zien dat zij in korte tijd redelijk dicht bij elkaar komen. Ook is een neerwaartse aanpassing van het reservatieloon over tijd te zien. 
Biography 


\section{Curriculum Vitae}

Ben Kriechel was born in Heinsberg (Germany) on March 23, 1973, where he started his secondary school education at the Kreisgymnasium Heinsberg in 1983. Before obtaining the Abitur in 1992, he spent one year at Linn-Mar High-School in Marion, Iowa (U.S.A.), where he obtained the high-school diploma in 1990.

After the compulsory military service, he studied economics — with a specialization in 'International Economic Studies' — at Maastricht University from 1993 until 1998. During this period, he worked as a research assistant. In the academic year 1996/97 he visited the Graduate School of International Economics and Finance of Brandeis University. There he followed the first year Ph.D. program in Economics. In 1998 he visited the National Opinion Research Center at the University of Chicago for a summer internship. In September 1998, he graduated cum laude from Maastricht University with a M.A. degree in economics.

Subsequently, he joined the Business Investment Research Center (BIRC) at Maastricht University as a Ph.D. researcher. In his doctoral studies, he specialized in labor economics. Since March 2000, he is a Research Affiliate at the 'Institute for the Study of Labor' (IZA) in Bonn, Germany. He received the diploma from the 'Network of Economics and Quantitative Economics' (NAKE) in 2000.

Since April 2003 he works as a researcher at the Research Centre for Education and the Labour Market (ROA). 
The Questionnaire 

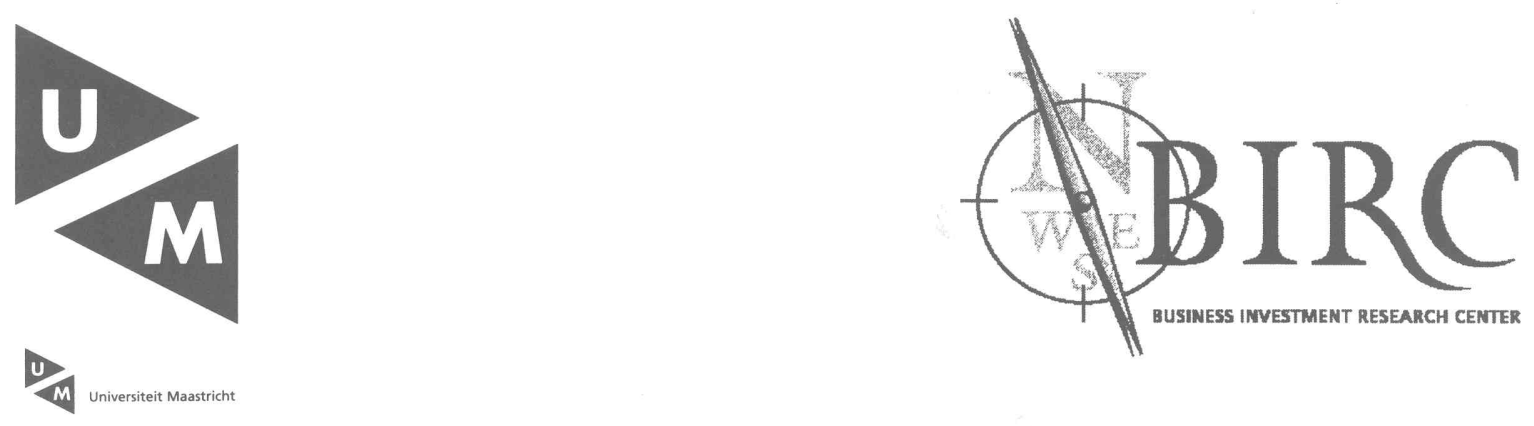

Geachte voormalig Fokker medewerker,

\section{Betreft:Fokker Enquête}

De Universiteit Maastricht heeft een enquête ontwikkeld om beter inzicht te krijgen in de problematiek en de kosten die voormalig Fokker medewerkers hebben ondervonden na het ontslag door faillissement. Deze enquête is tot stand gekomen met de ondersteuning van Mr.B.F.M. Knüppe, curator van Fokker, en de heer J. de Weerdt, oud-voorzitter OR Fokker Schiphol en bestuurslid Stichting Belangengroep Voormalig Fokker Medewerkers.

De enquête zal worden toegestuurd aan alle voormalig Fokker medewerkers die werkzaam waren bij Fokker Aircraft ten tijde van het faillissement. De resultaten van het onderzoek zullen worden gebruikt om een zo volledig mogelijk beeld te krijgen van de moeilijkheden en de kosten die medewerkers ondervonden hebben na het faillissement. Wij hopen met dit onderzoek een bijdrage te leveren om in de toekomst de belangen van medewerkers bij soortgelijke faillissementen zo goed mogelijk te kunnen behartigen. Uw medewerking is daarom van GROOT belang! Het invullen en terugsturen van de enquête levert een significante bijdrage aan het verkrijgen van een zo zorgvuldig en compleet mogelijk inzicht van de problematiek. 
Het invullen van de vragenlijst zal ongeveer 30 minuten in beslag nemen. Al Uw antwoorden zijn strikt vertrouwelijk en zullen anoniem worden verwerkt. $U$ kunt van de bijgesloten antwoord-enveloppe gebruik maken om het formulier aan ons te retourneren (een postzegel is niet nodig).

Indien $U$ vragen heeft, dan zijn wij uiteraard gaarne bereid deze te beantwoorden. U kunt daartoe tijdens kantooruren telefonisch contact opnemen met de project-leider, de heer Drs. B. Kriechel (043-3883642), of met de project-manager, mevrouw E. Nelissen (043-3883770).

In afwachting op Uw reactie, verblijven wij,

Hoogachtend,

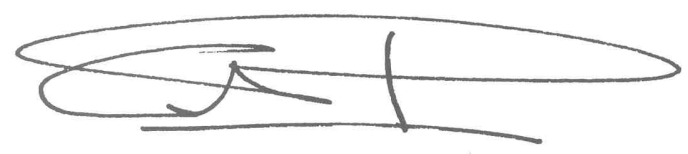

Prof.Dr.G.A.Pfann 

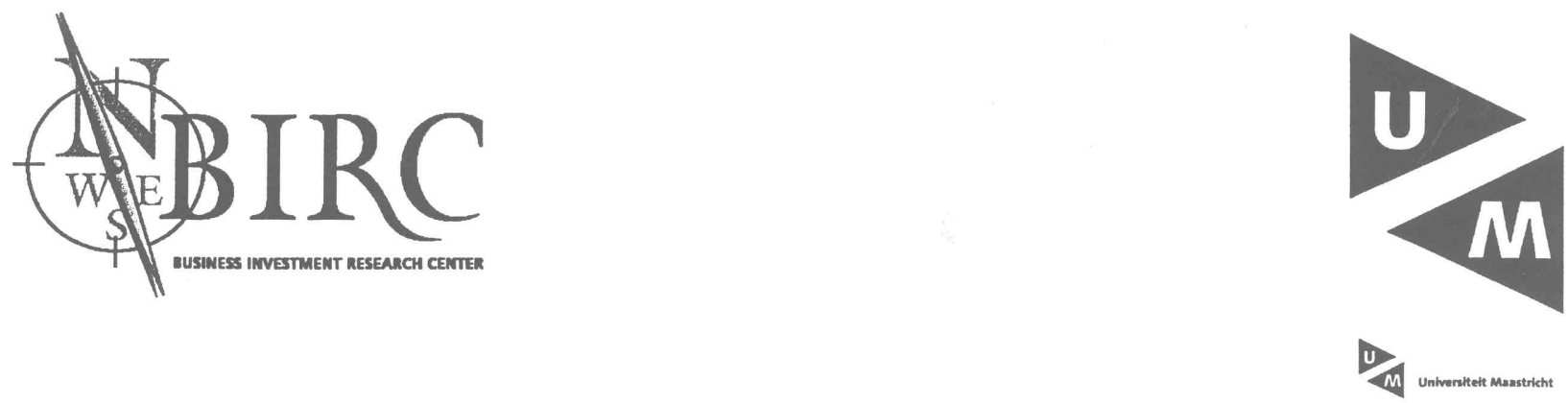

FOKKER ENQUÊTE (Tweede verzoek)

LET OP: Ook voor medewerkers van FOKKER AVIATION, STORK, FAIR, en de boedel

Geachte voormalig Fokker medewerker,

Enkele weken stuurden wij U de "Fokker-Enquête" van de Universiteit Maastricht. Tot nu toe is Uw enquête nog niet door ons ontvangen. Mogelijkerwijs bent U niet in de gelegenheid geweest om de vragenlijst in te vullen en terug te sturen. Wij willen $U$ vragen dat alsnog te doen.

Dit onderzoek wordt slechts één keer gehouden onder $\underline{\text { alle }}$ medewerkers die tot 16 maart 1996 werkzaam waren bij Fokker. Het doel is om inzicht te krijgen in de gevolgen van faillissementen in het algemeen, en voor het personeel van Fokker in het bijzonder. Uw hulp, het invullen van de vragenlijst, is daarvoor noodzakelijk! Al Uw antwoorden zullen strikt vertrouwelijk worden behandeld en anoniem worden verwerkt. Het invullen neemt ongeveer 30 minuten in beslag.

Wij zouden het zeer op prijs stellen om de enquête ingevuld van $U$ te mogen ontvangen. $U$ kunt hiervoor gebruik maken van de bijgevoegde antwoord-enveloppe (een postzegel is niet nodig).

Indien $U$ vragen heeft, dan zijn wij uiteraard gaarne bereid deze te beantwoorden. Tijdens kantooruren kunt $\mathrm{U}$ telefonisch contact opnemen met de projectleider, de heer Drs. B. Kriechel (043-3883642), of met onze projectmanager, mevrouw E. Nelissen (043-3883770).

Ik dank U hartelijk voor Uw medewerking.

Met vriendelijke groet,

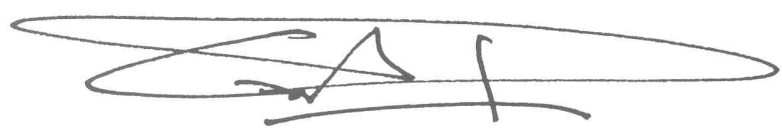

Prof.Dr.G.A.Pfann 


\section{Fokker Enquête Universiteit Maastricht}

\section{Periode rond het faillissement van Fokker}

1.1 Hoeveel jaren hebt u bij Fokker gewerkt? jaren

1.2 Hoeveel jaren werkervaring had u voordat u bij Fokker begon te werken? jaren

1.3 Wat was uw laatste functie bij Fokker?

(functieomschrijving)

1.3b Gaf $\mathrm{u}$ in uw functie leiding aan andere medewerkers?

$\square$ ja, ik gaf leiding aan personen

$\checkmark$ nee, ik gaf geen leiding aan anderen

1.4 Hoeveel verdiende u bruto per maand in deze functie? (excl. overwerk, vakantiegeld, 13e maand e.d.)

bruto gulden per periode van 4 weken.

1.5 Beschouwde u zichzelf voor het faillissement als kostwinner?

$$
\begin{aligned}
& \square \text { ja } \\
& \square \text { nee }
\end{aligned}
$$

1.6 Bent $\mathrm{u}$ voor het faillissement actief naar een andere baan gaan zoeken?

$$
\square \quad \text { ja, ca. }
$$
weken voor het faillissement

$\square \quad$ nee

1.7 $\mathrm{Na}$ faillissement van Fokker: na hoeveel weken begon u actief naar een nieuwe baan te zoeken? weken na het faillissement

1.8 Na het faillissement van Fokker: na hoeveel weken heeft $\mathrm{u}$ uw eerste sollicitatiebrief geschreven? weken na het faillissement

1.9 $\mathrm{Na}$ het faillissement van Fokker: hoeveel uren per week besteedde $\mathrm{u}$ aan zoeken naar een geschikte baan? uren per week

1.10 Na het faillissement van Fokker: hoeveel sollicitatiebrieven schreef u gemiddeld per vier weken gedurende deze periode? brieven per vier weken 


\section{Fokker Enquête Universiteit Maastricht}

1.11 Na faillissement van Fokker: heeft $\mathrm{u}$ banen aangeboden gekregen, die $\mathrm{u}$ niet heeft aangenomen?

$\square$ nee

$\square$ ja $\Rightarrow$ zo ja:

1.11.1 Hoe vaak heeft $\mathrm{u}$ een baan aangeboden gekregen?

keer

[indien u één of meerdere banen aangeboden kreeg, vul de volgende vragen in voor het beste aanbod]

1.11.2 Wat voor werk was dit?

(functieomschrijving)

1.11.3 Hoe hoog zou het bruto maandsalaris zijn?

HFL per maand.

1.11.4 Hoeveel werkuren zou u per week aangesteld worden? uren per week.

1.11.5 Over hoeveel mensen zou u leiding geven? mensen.

1.11.6 Wat is de belangrijkste reden dat $\mathrm{u}$ deze baan niet aangenomen heeft?
$\square$ te laag salaris
$\square$ tijdelijk dienstverband
$\square$ te weinig uren werktijd
$\square$ te grote reisafstand
$\square$ te laag functieniveau
$\checkmark$ andere reden, namelijk:

1.12 Hoe lang duurde het voordat u uw eerste nieuwe baan vond?

$\square$ direct een nieuwe baan gekregen in "doorstart":

\section{$\neg$ Fokker Aviation \\ $\square$ Boedel}

$\checkmark$ direct elders een nieuwe baan gevonden

$\square$ na ongeveer maanden

$\square$ met pensioen $\Rightarrow$ ga door naar pagina 12

$\checkmark$ niet meer gewerkt wegens arbeidsongeschiktheid

$\neg$ nog geen nieuw werk gevonden $\Rightarrow$ ga door naar pagina 3, vraag 1.15

1.13 Hoe heeft u uw eerste nieuwe baan na het faillissement gevonden?

$\square$ via het Arbeidsbureau

$\square$ via een uitzendbureau

$\checkmark$ via een commercieel bemiddelingsbureau

$\square$ via een open sollicitatie

$\square$ via een gerichte sollicitatie

$\square$ via een oud-collega van Fokker

$\square$ via contacten uit uw werk bij Fokker

$\square$ via familie

$\square$ via vrienden of kennissen 


\section{Fokker Enquête Universiteit Maastricht}

$\square$ anders, namelijk

1.14 Hoeveel bedroegen de sollicitatiekosten voor deze nieuwe baan? (dit zijn alle sollicitatiekosten vanaf het faillissement totdat u uw eerste baan gekregen hebt) HFL

De volgende vragen gaan over hulp die u gekregen heeft bij het vinden van een nieuwe baan na ontslag door Fokker.

1.15 Heeft $\mathrm{u}$ bij het vinden van een baan hulp ontvangen van een instelling?

$$
\begin{aligned}
& \square \mathrm{ja} \\
& \square \text { nee } \quad \Rightarrow \text { ga door naar pagina 4, "werk historie". }
\end{aligned}
$$

1.16 Heeft u hulp gekregen over hoe u zelf werk kunt vinden?
$\square \mathrm{ja}$
dit heeft..
$\square$ veel geholpen
$\neg$ geholpen
$\square$ nauwelijks geholpen

$\square$ nee

1.17 Heeft een instelling $\mathrm{u}$ in contact gebracht met potentiële werkgevers?
$\square$ ja
dit heeft...
$\square$ veel geholpen
$\square$ geholpen
$\square$ nauwelijks geholpen
$\square$ helemaal niet geholpen

$\square$ nee

1.18 Heeft $\mathrm{u}$ hulp gekregen met het schrijven van een $\mathrm{CV}$ of ter voorbereiding van sollicitatiegespreken?

$\begin{array}{ll}\square \text { ja } \quad \text { dit heeft... } & \square \text { veel geholpen } \\ & \square \text { geholpen } \\ & \square \text { nauwelijks geholpen } \\ & \square \text { helemaal niet geholpen } \\ \square \text { nee } & \end{array}$

1.19 Wie heeft voor deze hulp betaald:

$\square$ Fokker

$\square$ het Arbeidsbureau

$\square$ zelf betaald

$\square$ de vakbond

$\neg \mathrm{EU}$

$\square$ niet bekend

$\square$ anders, namelijk 


\section{Werk historie}

2.1 Geef in de onderstaande kalender voor iedere maand aan wat volgens $u$ op dat moment het best paste bij uw situatie. Zie het voorbeeld hiernaast. U mag per maand maar één cijfer omcirkelen.

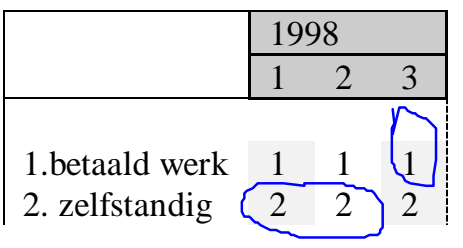

\begin{tabular}{|c|c|c|c|c|c|c|c|c|c|c|c|c|c|c|c|c|c|c|c|c|c|}
\hline & \multicolumn{9}{|c|}{1996} & \multicolumn{12}{|c|}{1997} \\
\hline & $\frac{\bar{c}}{4}$ & $\bar{e}^{\bar{e}}$ & 声 & $\bar{\Xi}$ & 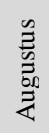 & 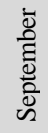 & 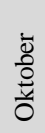 & 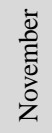 & 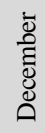 & 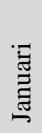 & 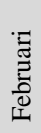 & $\stackrel{\overline{\tilde{m}}}{\mathrm{z}}$ & $\frac{\bar{c}}{4}$ & $\sum^{\bar{v}}$ & 志 & $\Xi$ & 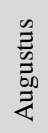 & 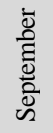 & $\begin{array}{l}\overline{\mathrm{d}} \\
\stackrel{0}{0} \\
\overline{0}\end{array}$ & $\begin{array}{l}\overline{\mathrm{o}} \\
\bar{z} \\
\overline{\mathrm{g}} \\
\mathrm{z}\end{array}$ & 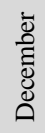 \\
\hline 1. betaald werk & 1 & 1 & 1 & 1 & 1 & 1 & 1 & 1 & 1 & 1 & 1 & 1 & 1 & 1 & 1 & 1 & 1 & 1 & 1 & 1 & 1 \\
\hline 2. zelfstandig & 2 & 2 & 2 & 2 & 2 & 2 & 2 & 2 & 2 & 2 & 2 & 2 & 2 & 2 & 2 & 2 & 2 & 2 & 2 & 2 & 2 \\
\hline 3. werkloos & 3 & 3 & 3 & 3 & 3 & 3 & 3 & 3 & 3 & 3 & 3 & 3 & 3 & 3 & 3 & 3 & 3 & 3 & 3 & 3 & 3 \\
\hline 4. onbetaald werk & 4 & 4 & 4 & 4 & 4 & 4 & 4 & 4 & 4 & 4 & 4 & 4 & 4 & 4 & 4 & 4 & 4 & 4 & 4 & 4 & 4 \\
\hline 5.cursus/opleiding & 5 & 5 & 5 & 5 & 5 & 5 & 5 & 5 & 5 & 5 & 5 & 5 & 5 & 5 & 5 & 5 & 5 & 5 & 5 & 5 & 5 \\
\hline 6. anders, nl.: & 6 & 6 & 6 & 6 & 6 & 6 & 6 & 6 & 6 & 6 & 6 & 6 & 6 & 6 & 6 & 6 & 6 & 6 & 6 & 6 & 6 \\
\hline
\end{tabular}

\begin{tabular}{|c|c|c|c|c|c|c|c|c|c|c|c|c|c|c|c|}
\hline & \multicolumn{12}{|c|}{1998} & \multicolumn{3}{|c|}{1999} \\
\hline & $\begin{array}{l}\bar{\Xi} \\
\bar{\Xi} \\
\text { 芯 }\end{array}$ & 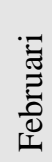 & ${ }_{\bar{Z}}^{\bar{J}}$ & $\overline{\bar{c}}$ & ${ }^{\circ}$ & 志 & $\bar{\Xi}$ & 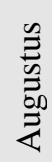 & $\begin{array}{l}\bar{\nabla} \\
\bar{E} \\
\overline{0} \\
\overline{0} \\
\tilde{\omega}\end{array}$ & $\begin{array}{l}\overline{0} \\
\overline{0} \\
\overline{0} \\
0\end{array}$ & $\begin{array}{l}\overline{\bar{\delta}} \\
\bar{\Xi} \\
\text { Dे } \\
z\end{array}$ & 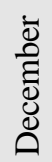 & 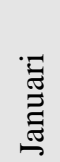 & 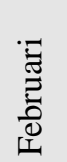 & $\begin{array}{l}\overline{\bar{J}} \\
\sum_{\Sigma}^{\mathbb{J}}\end{array}$ \\
\hline 1. betaald werk & 1 & 1 & 1 & 1 & 1 & 1 & 1 & 1 & 1 & 1 & 1 & 1 & 1 & 1 & 1 \\
\hline 2. zelfstandig & 2 & 2 & 2 & 2 & 2 & 2 & 2 & 2 & 2 & 2 & 2 & 2 & 2 & 2 & 2 \\
\hline 3. werkloos & 3 & 3 & 3 & 3 & 3 & 3 & 3 & 3 & 3 & 3 & 3 & 3 & 3 & 3 & 3 \\
\hline 4. onbetaald werk & 4 & 4 & 4 & 4 & 4 & 4 & 4 & 4 & 4 & 4 & 4 & 4 & 4 & 4 & 4 \\
\hline 5. cursus/ opleiding & 5 & 5 & 5 & 5 & 5 & 5 & 5 & 5 & 5 & 5 & 5 & 5 & 5 & 5 & 5 \\
\hline 6. anders, nl.: & 6 & 6 & 6 & 6 & 6 & 6 & 6 & 6 & 6 & 6 & 6 & 6 & 6 & 6 & 6 \\
\hline
\end{tabular}


2.2 Heeft u na faillissement van Fokker een baan gevonden?

$\square$ nee, maar ik heb wel zelfstandig / freelance gewerkt

$\Rightarrow$ ga door naar pagina 11, "Zelfstandig", vraag 2.40

$\square$ nee, ik heb na het faillissement niet meer gewerkt

$\Rightarrow$ ga door naar pagina 12, "Demografische Gegevens", vraag 3.1

$\square$ ja

zo ja: Is uw huidige baan uw eerste baan na het faillissement bij Fokker?

$\square$ ja, mijn huidige baan is de eerste baan na het faillissement $\Rightarrow$ ga door naar pagina 8 , "Huidige Werkgever", vraag 2.21

$\checkmark$ nee, mijn huidige baan is niet mijn eerste baan na het faillissement $\Rightarrow$ ga door naar vraag 2.3

De volgende vragen hebben betrekking op de eerste baan na u vertrek bij Fokker indien u nu niet meer in dienst bent bij deze eerste werkgever. Als eerste baan telt ook werk voor de boedel, de afbouw, Fokker Aviation, en dergelijk.

2.3 Wanneer bent $\mathrm{u}$ met deze eerste baan begonnen?

maand: jaar: 19

2.4a naam werkgever:

$2.4 \mathrm{~b}$ adres:

2.4c postcode / plaats

2.5 Wat was de officiële naam van uw eerste functie?

(functieomschrijving)

2.6 In wat voor richting is deze organisatie of het bedrijf werkzaam?

(richting)

(sector)

2.7 Hoeveel mensen werkten bij de organisatie of het bedrijf waar u werkzaam was?

$\square 1$ tot met 5

$\square 6$ tot met 20

$\square 21$ tot en met 50

$\square 50$ tot en met 100

$\square 101$ tot en met 500

$\square$ meer dan 500 


\section{Fokker Enquête Universiteit Maastricht}

2.8 In wat voor dienstverband werkte $\mathrm{u}$ ?

$\checkmark$ werk via een uitzendbureau, naam uitzendbureau:

$\checkmark$ in loondienst bij werkgever

$\square$ als oproepkracht

$\square$ gedetacheerd, naam detacheerend bedrijf:

$\square$ zelfstandig in eigen bedrijf of freelance

$\square$ anders, namelijk

2.9 Wat voor aanstelling had $\mathrm{u}$ ?

$\square$ oproepcontract

$\square$ tijdelijke aanstelling voor maanden, zonder uitzicht op vaste baan

$\square$ tijdelijke aanstelling voor maanden, met uitzicht op vaste baan

$\square$ proeftijd voor vaste baan.

$\square$ vaste aanstelling

2.10 Gaf $\mathrm{u}$ in uw functie leiding aan andere medewerkers?

$\square$ ja, ik gaf leiding aan personen

$\checkmark$ nee, ik gaf geen leiding aan anderen

2.11 Had u meer of minder verantwoordelijkheid dan bij Fokker?

$\square$ veel meer verantwoordelijkheid

$\square$ meer verantwoordelijkheid

$\square$ dezelfde verantwoordelijkheid

$\square$ minder verantwoordelijkheid

$\square$ veel minder verantwoordelijkheid

2.12 Was de ervaring die u bij Fokker opgedaan had noodzakelijk voor het krijgen van deze baan?

$\square$ ja, vooral mijn beroepservaring van Fokker

$\square$ ja, vooral mijn technische kennis van Fokker

$\square$ ja, zowel mijn technische kennis als ook mijn beroepservaring van Fokker

$\square$ nee, niet noodzakelijk maar wel een pre

$\square$ nee

2.13 Hoeveel scholing (of inwerktijd) zou iemand met een vergelijkbare opleiding nodig hebben om uw taken in dit bedrijf over te nemen? maand(en) scholing

en maand(en) inwerktijd

2.14 Hoe groot is de afstand woon-werkverkeer (enkele reis) die u dagelijks af moest leggen? $\mathrm{km}$ 


\section{Fokker Enquête Universiteit Maastricht

2.15 Hoeveel verdiende $\mathrm{u}$ aan het begin van uw dienstverband bruto per maand in deze functie? (excl. overwerk, vakantiegeld, 13e maand e.d.)

bruto gulden $\square$ per maand

$\checkmark$ per periode van vier weken

2.16 Op hoeveel werkuren per week was dit gebaseerd? uren per week

2.17 Aan het einde van het dienstverband: hoeveel verdiende u bij deze werkgever? (excl. overwerk, vakantiegeld, 13e maand e.d.)

bruto gulden $\square$ per maand

$\square$ per periode van vier weken

2.18 Op hoeveel werkuren per week was dit gebaseerd? uren per week

2.19 Wanneer bent u gestopt bij deze werkgever? $-19$

2.20 Wat was de redenen ervoor?

$\checkmark$ betere baan gevonden

$\checkmark$ afloop tijdelijk contract

$\checkmark$ zelf ontslag genomen

$\square$ ontslagen door werkgever

$\square$ arbeidsongeschiktheid

$\checkmark$ pensioen

$\square$ andere reden, namelijk 


\section{Fokker Enquête Universiteit Maastricht}

De volgende vragen hebben betrekking op uw huidige werkgever. Indien u op het ogenblik niet in loondienst werkt, vul dan dit gedeelte voor uw laatste werkgever na uw ontslag bij Fokker in.

\section{Huidige / Laatste Werkgever}

2.21 Hoe vaak bent $\mathrm{u}$ van werkgever veranderd sinds het faillissement van Fokker? verschillende werkgevers sinds faillissement

(vul in 1 indien dit uw eerste werkgever sinds het faillissement is).

2.22 Wanneer bent u bij uw huidige werkgever begonnen?

maand:

jaar: 19

2.23a naam werkgever:

$2.23 \mathrm{~b}$ adres:

$2.23 \mathrm{c}$ postcode / plaats

2.24 Hoe heeft u van deze baan vernomen?

$\square$ via het Arbeidsbureau

$\square$ via een uitzendbureau

$\square$ via een commercieel bemiddelingsbureau

$\checkmark$ via een gerichte sollicitatie

$\square$ via een open sollicitatie

$\square$ via een oud-collega van Fokker

$\square$ via contacten uit uw werk bij Fokker

$\square$ via familie

$\square$ via vrienden of kennissen

$\square$ anders, namelijk

2.25 Wat is de officiële naam van uw huidige functie?

(functieomschrijving)

2.26 Hoeveel mensen werken bij de organisatie of het bedrijf waar u werkzaam bent?

$\square 1$ tot met 5

$\square 6$ tot met 20

$\square 21$ tot en met 50

$\square 50$ tot en met 100

$\square 101$ tot en met 500

$\square$ meer dan 500 


\section{Fokker Enquête Universiteit Maastricht}

2.27 In wat voor richting is deze organisatie of het bedrijf werkzaam?

(richting)

(sector)

2.28 In wat voor dienstverband werkt $\mathrm{u}$ ?

$\checkmark$ werk via een uitzendbureau, naam uitzendbureau:

$\checkmark$ in loondienst bij werkgever

$\square$ als oproepkracht

$\checkmark$ gedetacheerd, naam detacheerend bedrijf:

$\checkmark$ zelfstandig in eigen bedrijf of freelance

$\square$ anders, namelijk

2.29 Wat voor aanstelling heeft $\mathrm{u}$ ?

$\square$ als oproepkracht

$\square$ tijdelijke aanstelling voor maanden, zonder uitzicht op vaste baan

$\square$ tijdelijke aanstelling voor maanden, met uitzicht op vaste baan

$\checkmark$ proeftijd voor vaste baan

$\square$ vaste aanstelling

2.30 Geeft $\mathrm{u}$ in uw functie leiding aan andere medewerkers?

$\square$ ja ik geef leiding aan personen

$\checkmark$ nee, ik geef geen leiding aan anderen

2.31 Heeft u meer of minder verantwoordelijkheid dan bij Fokker?

$\square$ veel meer verantwoordelijkheid

$\square$ meer verantwoordelijkheid

$\square$ dezelfde verantwoordelijkheid

$\square$ minder verantwoordelijkheid

$\square$ veel minder verantwoordelijkheid

2.32 Was uw ervaring die u bij Fokker opgedaan had noodzakelijk voor het krijgen van deze baan?

$\square$ ja, vooral mijn beroepservaring van Fokker

$\square$ ja, vooral mijn technische kennis van Fokker

$\square$ ja, zowel mijn technische kennis als ook mijn beroepservaring van Fokker

$\square$ nee, niet noodzakelijk maar wel een pre

$\square$ nee

2.33 Hoeveel scholing (of inwerktijd) zou iemand met een vergelijkbare opleiding nodig hebben om uw taken in dit bedrijf over te nemen? maand(en) scholing 
en maand(en) inwerktijd

2.34 Hoe groot is de afstand woon-werkverkeer (enkele reis) die u dagelijks terug moet leggen? $\mathrm{km}$

2.35 Hoeveel verdiende $\mathrm{u}$ bruto per maand aan het begin van uw dienstverband? (excl. overwerk, vakantiegeld, 13e maand e.d.) bruto gulden $\square$ per maand

$\square$ per periode van vier weken

2.36 Op hoeveel werkuren per week was dit gebaseerd? uren per week

2.37 Hoeveel verdient u nu bruto per maand? (excl. overwerk, vakantiegeld, 13e maand e.d.)

bruto gulden $\square$ per maand

$\square$ per periode van vier weken

2.38 Op hoeveel werkuren per week is dit gebaseerd? uren per week

2.39 Werkt u nog voor deze werkgever?

$\square$ ja $\quad \Rightarrow$ ga door naar "Zelfstandig" op de volgende pagina, vraag 2.40

$\square$ nee

$\Rightarrow$ zo nee:

2.39.1 Wanneer bent u gestopt bij deze werkgever?

$-19$

2.39.2 Wat was de redenen ervoor?

$\square$ afloop tijdelijk contract

$\square$ zelf ontslag genomen

$\square$ ontslagen door werkgever

$\square$ arbeidsongeschiktheid

$\square$ pensioen

$\square$ andere reden, namelijk 


\section{Fokker Enquête Universiteit Maastricht}

\section{Zelfstandig}

2.40 Heeft u inkomen uit uw eigen bedrijf of zelfstandig werk?

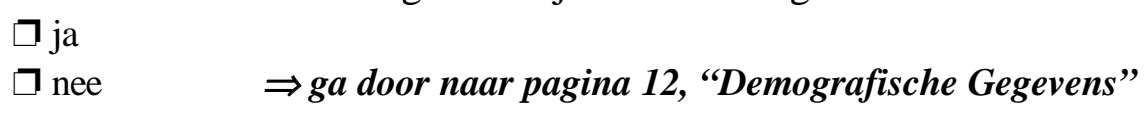

2.41 Sinds wanneer heeft u uw eigen bedrijf?

$-19$

(maand - jaar)

2.42 In wat voor richting is uw bedrijf werkzaam?

(richting)

(sector)

2.43 Voor ontslag bij Fokker: hoeveel uren heeft u gemiddeld per week voor uw eigen bedrijf gewerkt? uren per week

2.44 Na ontslag bij Fokker, heeft u meer tijd voor uw eigen bedrijf gewerkt?

$\square \quad$ ja $\Rightarrow$ zo ja: Hoeveel uren heeft u gemiddeld per week gewerkt: uren per week

$\square \quad$ nee

2.45 Is uw werk in het eigen bedrijf een belangrijke bron van inkomsten?

$\square$ ja $\Rightarrow$ zo ja:

2.45a Wat waren de gemiddelde jaarlijkse inkomsten (belastbaar inkomen) over de periode na ontslag bij Fokker? Guldens per jaar.

$\square$ nee

2.46 Bent u nog op zoek naar een betaalde baan?

$\square$ ja

$\square$ nee 


\section{Demografische gegevens}

\section{Opleiding}

3.1 Wat was de hoogste opleiding die u voltooid had toen u vertrok bij Fokker?

\begin{tabular}{ll}
$\square$ & Lagere school of basisonderwijs \\
$\square$ & MAVO of MULO of ULO \\
$\square$ & HAVO of MMS \\
$\square$ & VWO (incl. HBS) \\
$\square$ & LBO / LTS \\
$\square$ & MBO of KMBO \\
$\square$ & HBO \\
$\square$ & WO \\
$\square$ & TU \\
\hline
\end{tabular}

3.2 Wat is de naam van de studierichting of beroepsopleiding?

3.3 In welk jaar heeft u dit diploma gehaald:

19

3.4 Heeft u na het faillissement van Fokker nog een school- of beroepsopleiding afgesloten?

$\square$ nee

$\square$ ja, $\rightarrow$ zo ja:

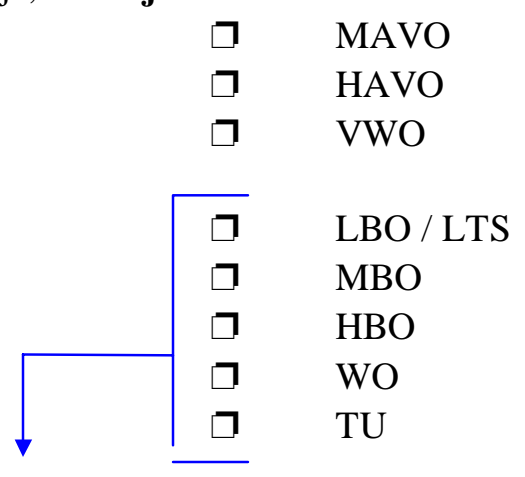

3.5 Wat is de naam van de studierichting of beroepsopleiding?

3.6 In welk jaar heeft u dit diploma gehaald:

19 


\section{Fokker Enquête Universiteit Maastricht}

\section{Omscholing / Bijscholing}

3.7 Heeft u na ontslag bij Fokker deelgenomen aan een omscholing of bijscholing?

$\neg$ ja, $\Rightarrow$ zo ja:

3.7.1 Aan hoeveel om- of bijscholingen hebt u deelgenomen?

3.7.2 Hoe lang duurde deze scholing(en) gemiddeld? weken

3.7.3 Hoeveel uren per week had u (gemiddeld) deze scholing(en)? uren per week

3.7.4 Wanneer heeft $\mathrm{u}$ de laatste omscholing of bijscholing afgesloten? $-19$

(maand / jaar)

3.7.5 Heeft de om- of bijscholing(en) geholpen bij het vinden van een nieuwe baan?

$$
\begin{aligned}
& \square \text { veel geholpen } \\
& \square \text { geholpen } \\
& \square \text { nauwelijks geholpen } \\
& \square \text { helemaal niet geholpen }
\end{aligned}
$$

$\square$ nee, $\Rightarrow$ zo nee:

3.7.6 Waarom heeft $\mathrm{u}$ niet aan een omscholing of bijscholing deelgenomen?

$\square$ had meteen een baan

$\square$ onvoldoende informatie om een goed programma te vinden

$\square$ extra scholing niet nodig voor een nieuwe baan

$\square$ scholing te duur

$\square$ te moeilijk

$\square$ anders, namelijk

3.7.7 Zou het achteraf gezien verstandig of beter zijn geweest om een bijscholing of omscholing te hebben gevolgd?

$\square$ ja, ik had aan een scholing deel moeten nemen

$\square$ nee

\section{Overige Informatie}

3.8 Hoeveel kinderen heeft $\mathrm{u}$ :

$\checkmark$ geen kinderen kind(eren) met een leeftijd tot en met 3 jaar kind(eren) met een leeftijd van 4 t.m. 16 jaar kind(eren) met een leeftijd van 17 t.m. 21 jaar kind(eren) met een leeftijd boven de 21 jaar 


\section{Fokker Enquête \\ Universiteit Maastricht}

3.9 Wat is uw geboortejaar?

19

\subsection{Burgerlijk staat}

$\square$ gehuwd

$\square$ samenwonend

$\square$ gescheiden

$\square$ weduwe / weduwnaar

$\square$ alleenstaand sinds:

sinds: 19 $-19$ (maand / jaar)

sinds: $-19$ (maand / jaar)

Indien u gehuwd bent of samenwoont:

3.10.1 Werkt uw partner in loondienst of zelfstandig?

$\square$ ja $\Rightarrow$ zo ja: (3.10.2) Wat is het jaarlijkse bruto inkomen van uw partner: HFL

$\square$ nee

3.11 Beschouwt u zichzelf nu als kostwinner?

$\square$ ja

$\square$ nee

$3.12 \mathrm{U}$ woont in een...

$\square$ koopwoning

$\square$ huurwoning

$\square$ anders, namelijk

\section{Overig}

Heeft u verder nog opmerkingen?

Hartelijk dank voor het invullen van deze enquête.

Wilt u een rapport over de resultaten van deze enquête ontvangen?

$$
\begin{aligned}
& \square \text { ja } \\
& \square \text { nee }
\end{aligned}
$$

\section{A.u.b. het ingevulde enquêteformulier in de bijgevoegde retourenvelop} terugsturen. 


\section{ROA Dissertation Series}

1. Lex Borghans (1993), Educational Choice and Labour Market Information, Maastricht: Research Centre for Educationa and the Labour Market (ROA).

2. Frank Cörvers (1999), The Impact of Human Capital on International Competitiveness and Trade Performance of Manufacturing Sectors, Maastricht: Research Centre for Education and the Labour Market (ROA).

3. Ben Kriechel (2003), Heterogeneity among Displaced Workers, Maastricht: Research Centre for Education and the Labour Market (ROA). 